Portland State University

PDXScholar

\title{
Measuring Community-Engaged Departments: A Study to Develop an Effective Self-Assessment Rubric for the Institutionalization of Community Engagement in Academic Departments
}

Kevin Kecskes

Portland State University

Follow this and additional works at: https://pdxscholar.library.pdx.edu/open_access_etds

Part of the Education Policy Commons, Public Administration Commons, and the Public Policy Commons

Let us know how access to this document benefits you.

\section{Recommended Citation}

Kecskes, Kevin, "Measuring Community-Engaged Departments: A Study to Develop an Effective SelfAssessment Rubric for the Institutionalization of Community Engagement in Academic Departments" (2008). Dissertations and Theses. Paper 2684.

https://doi.org/10.15760/etd.2680

This Dissertation is brought to you for free and open access. It has been accepted for inclusion in Dissertations and Theses by an authorized administrator of PDXScholar. Please contact us if we can make this document more accessible: pdxscholar@pdx.edu. 
MEASURING COMMUNITY-ENGAGED DEPARTMENTS:

A STUDY TO DEVELOP AN EFFECTIVE SELF-ASSESSMENT RUBRIC FOR THE INSTITUTIONALIZATION OF COMMUNITY ENGAGEMENT IN

ACADEMIC DEPARTMENTS

by

KEVIN JOHN KECSKES

A dissertation submitted in partial fulfillment of the requirements for the degree of

DOCTOR OF PHILOSOPHY

in

PUBLIC ADMINISTRATION AND POLICY

Portland State University

2008 


\section{DISSERTATION APPROVAL}

The abstract and dissertation of Kevin John Kecskes for the Doctor of Philosophy in Public Administration and Policy were presented October 28, 2008, and accepted by the dissertation committee and the doctoral program.

\section{COMMITTEE APPROVALS:}
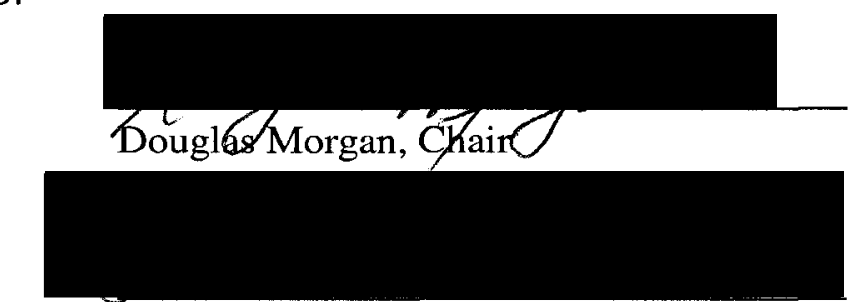

Peter Collier

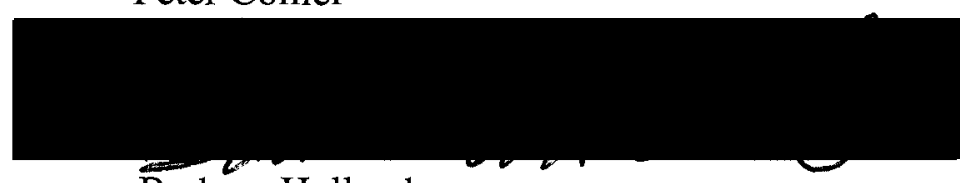

Barbara Holland

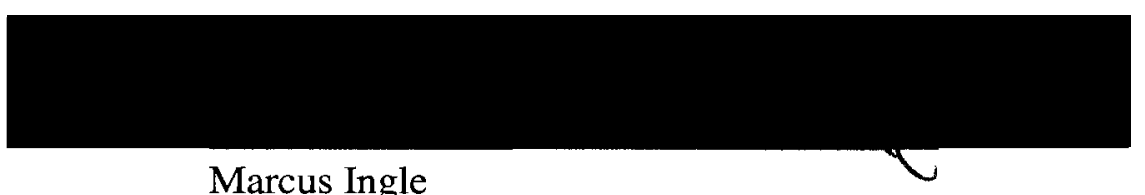

Marcus Ingle

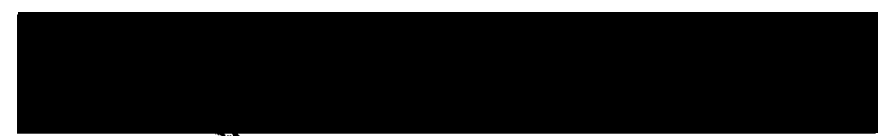

Craig Shinn

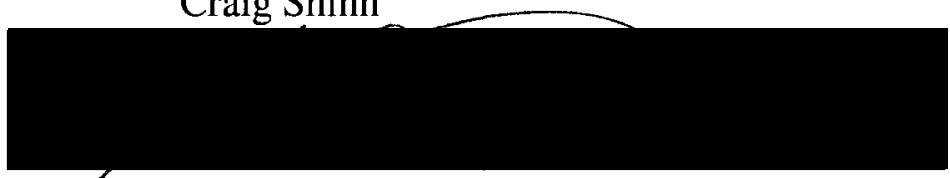

Sherwin Davidson

Representative of the Office of Graduate Studies

DOCTORAL PROGRAM APPROVAL:

Craig Shinn, Director

Public Administration and Policy Ph.D. Program 


\begin{abstract}
An abstract of the dissertation of Kevin John Kecskes for the Doctor of Philosophy in Public Administration and Policy presented October 28, 2008.
\end{abstract}

Title: Measuring Community-Engaged Departments: A Study to Develop an Effective Self-Assessment Rubric for the Institutionalization of Community Engagement in Academic Departments

Change in American higher education is occurring at a rapid pace. The increasing reemergence of civic or community engagement as a key component in the overall landscape of American higher is emblematic of that change. Academic departments play a critical role in higher education change, including institutionalizing community engagement on campuses. Yet, designing a way of measuring community engagement specifically at the level of the academic department has not been undertaken.

Based on advice from national expert/key informant interviews and the recognition of the importance of the role of academic departments in the overall institutionalization of community engagement in higher education, this study addresses a methodological gap in the literature concerning the measurement of community engagement. Several instruments have been developed primarily for institution-wide application, and some have been applied to academic units 
including colleges, schools, departments and programs. This study employs a grounded theory research strategy to develop and test a self-assessment rubric solely for use in academic departments.

To ascertain the utility and validity of the rubric, this study pilot tests the explanatory framework in twelve social science departments located in five, geographically-diverse American universities. A secondary purpose of the study is to initiate an exploration of the potential use of institutional theory to more completely understand the constitutive role of the academic unit in the institutional transformation process.

The research confirms the utility and validity of the departmental engagement self-assessment rubric. Additionally, the study categorizes and displays via histograms six overarching dimensions by level of support for community engagement for each of the twelve test departments. Finally, this research recommends instrumental as well as substantive areas for future research, including those that better connect institutional theory with efforts to embed civic engagement in the mission of traditional academic departments. 


\section{DEDICATION}

This dissertation study is dedicated to. my wonderful family, Beth, Sophia, and Nico Kecskes for their steadfast patience and support and for reminding me daily of the power of love. 


\section{ACKNOWLEDGEMENTS}

Heartfelt thanks go to all who have helped me along this journey of discovery. In particular, thanks go to the members of my dissertation committee (below), especially to Doug Morgan, my tireless and wise committee chair; to my family and friends; and to the Portland State University faculty, staff, and students who have supported and taught me much along the way. Special thanks go to PSU faculty member Sherril Gelmon for early and helpful comments on the assessment instrument; to David Smith-Ferri for friendship, encouragement and editing; and to Edward Zlotkowski for endless inspiration. Very important thanks go to my parents for never losing faith in me. And, final thanks go to my grandparents and to Doña Chepa, my hostess for two years of daily living in the Nicaraguan jungle, and to the hundreds of friends and colleagues in the "community" who have shown me that knowledge and wisdom emerges from many extraordinary sources.

Dissertation committee members:

Douglas Morgan, Ph.D., Committee Chair

Peter Collier, Ph.D.

Sherwin Davidson, Ph.D.

Barbara Holland, Ph.D.

Marcus Ingle, Ph.D.

Craig Shinn, Ph.D. 
TABLE OF CONTENTS:

\begin{tabular}{|c|c|c|}
\hline \multicolumn{2}{|l|}{ Content } & $\underline{\text { Page }}$ \\
\hline \multicolumn{2}{|c|}{ Acknowledgements } & ii \\
\hline \multicolumn{2}{|c|}{ List of Tables } & $\mathrm{V}$ \\
\hline \multicolumn{2}{|c|}{ List of Figures } & vii \\
\hline \multicolumn{2}{|c|}{ CHAPTER I: Introduction } & 1 \\
\hline I. & Overview & \\
\hline II. & Purpose of the Study & \\
\hline III. & Value and Importance of the Study & \\
\hline & Outline for the Dissertation & \\
\hline \multicolumn{2}{|c|}{ CHAPTER II: Relevant Literature } & 20 \\
\hline I. & The Civic Purposes of Higher Education & \\
\hline II. & The Role of Academic Departments in Academic Reform & \\
\hline III. & Developing a Self-Assessment Rubric to Measure & \\
\hline & Departmental Community Engagement & \\
\hline IV. & Summary of Research Objectives and Questions & \\
\hline \multicolumn{2}{|c|}{ CHAPTER III: Methods } & 51 \\
\hline I. & Research Strategy & \\
\hline II. & Phase One: Building a Conceptual Modal & \\
\hline III. & Phase Two: Testing the Utility of the Conceptual Model & \\
\hline IV. & Conclusions and Review of Central Research Questions & \\
\hline \multicolumn{2}{|c|}{ CHAPTER IV: Findings } & 97 \\
\hline I. & Test Departments & \\
\hline II. & Presentation of Rubric Responses - By Department & \\
\hline III. & $\begin{array}{l}\text { Summary Histograms Comparing each Department by Level } \\
\text { of Support }\end{array}$ & \\
\hline IV. & Findings from the Open Ended Survey Questions & \\
\hline V. & Conclusions - Summary of Findings & \\
\hline \multicolumn{2}{|c|}{$\begin{array}{l}\text { CHAPTER V: Discussion, Limitations, Areas for Future Research, } \\
\text { Implications and Concluding Thoughts }\end{array}$} & 149 \\
\hline I. & Discussion & \\
\hline II. & Limitations of the Study & \\
\hline III. & Areas for Future Research & \\
\hline IV. & Implications of this Study for Theory and Practice & \\
\hline V. & Concluding Thoughts - The Challenge of "Permeability" & \\
\hline \multicolumn{2}{|c|}{ REFERENCES } & 190 \\
\hline \multicolumn{2}{|c|}{ APPENDICES } & 200 \\
\hline \multirow{2}{*}{\multicolumn{2}{|c|}{$\begin{array}{l}\text { A. Holland, B. (1997) Levels of Commitment to Service, } \\
\text { Characterized by Key Organizational Factors Evidencing } \\
\text { Relevance to Institutional Mission } \\
\text { B. Furco, A. (2003) Self-Assessment Rubric for the }\end{array}$}} & 201 \\
\hline & & 203 \\
\hline
\end{tabular}




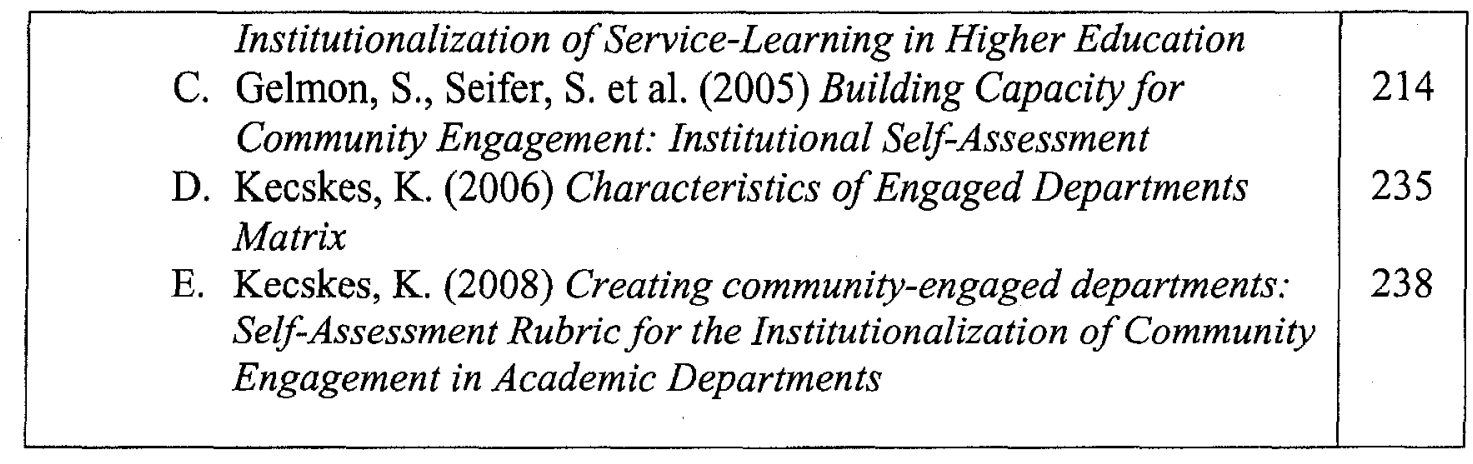


LIST OF TABLES

\begin{tabular}{|c|c|}
\hline TABLE TITLE & PAGE \\
\hline $\begin{array}{l}\text { Table 1: Dimensions and Components of the Furco Institutionalization } \\
\text { Rubric }\end{array}$ & 42 \\
\hline $\begin{array}{l}\text { Table 2: Dimensions and Components of the Engaged Departments } \\
\text { Matrix }\end{array}$ & 46 \\
\hline Table 3: Experts/Key Informants & 58 \\
\hline Table 4: Initial Codes from expert/key informant interviews & 61 \\
\hline Table 5: Focused codes from experts/key informants & 63 \\
\hline $\begin{array}{l}\text { Table 6: Theoretical Coding and Integration of Themes with Extant } \\
\text { Literature }\end{array}$ & 66 \\
\hline $\begin{array}{l}\text { Table 7: Dimensions and Components of the Explanatory Framework } \\
\text { (the Rubric) }\end{array}$ & 69 \\
\hline $\begin{array}{l}\text { Table 8: Dimensions and components of the departmental self- } \\
\text { assessment Rubric. }\end{array}$ & 74 \\
\hline $\begin{array}{r}\text { Table 9: Sections and Section Editors for Social Science from the } \\
\text { International Encyclopedia (Smelser and Baltes, 2001) }\end{array}$ & 85 \\
\hline Table 10: Open-ended questions concerning the Rubric & 88 \\
\hline Table 11: Categorization Decision Rules for Raw Data Responses & 92 \\
\hline $\begin{array}{l}\text { Table 12: (Example) Department 1: Self-assessments arranged by } \\
\text { dimensions }\end{array}$ & 92 \\
\hline $\begin{array}{l}\text { Table 13: (Repeat) Categorization Decision Rules for Raw Data } \\
\text { Responses }\end{array}$ & 98 \\
\hline Table 14: Display of test departments' disciplines & 99 \\
\hline Table 15: Department 1: Self-assessments arranged by dimensions & 101 \\
\hline Table 16: Department 2: Self-assessments arranged by dimensions & 103 \\
\hline Table 17: Department 3: Self-assessments arranged by dimensions & 106 \\
\hline Table 18: Department 4: Self-assessments arranged by dimensions & 109 \\
\hline Table 19: Department 5: Self-assessments arranged by dimensions & 112 \\
\hline Table 20: Department 6: Self-assessments arranged by dimensions & 115 \\
\hline Table 21: Department 7: Self-assessments arranged by dimensions & 118 \\
\hline Table 22: Department 8: Self-assessments arranged by dimensions & 121 \\
\hline Table 23: Department 9: Self-assessments arranged by dimensions & 125 \\
\hline Table 24: Department 10: Self-assessments arranged by dimensions & 127 \\
\hline Table 25: Department 11: Self-assessments arranged by dimensions & 131 \\
\hline Table 26: Department 12: Self-assessments arranged by dimensions & 133 \\
\hline $\begin{array}{l}\text { Table 27: Select Departmental Responses Regarding Self-Assessment } \\
\text { Processes }\end{array}$ & 139 \\
\hline $\begin{array}{l}\text { Table 28: Summary of Test Department Self-Assessment Response } \\
\text { Data }\end{array}$ & 141 \\
\hline $\begin{array}{l}\text { Table 29: Respondents' Verbatim Comments Regarding Utility of the } \\
\text { Rubric }\end{array}$ & 143 \\
\hline
\end{tabular}


LIST OF FIGURES

\begin{tabular}{|l|c|}
\hline \multicolumn{1}{|c|}{ FIGURE TITLE } & PAGE \\
\hline $\begin{array}{l}\text { Figure 1: (Example) Summary of Department 1: Departmental } \\
\text { Categorization }\end{array}$ & 91 \\
\hline Figure 2: Level of Departmental Engagement Displayed by Dimensions & 94 \\
\hline Figure 3: Summary of Department 1: Departmental Categorization & 100 \\
\hline Figure 4: Summary of Department 2: Departmental Categorization & 103 \\
\hline Figure 5: Summary of Department 3: Departmental Categorization & 106 \\
\hline Figure 6 Summary of Department 4: Departmental Categorization & 109 \\
\hline Figure 7: Summary of Department 5: Departmental Categorization & 112 \\
\hline Figure 8: Summary of Department 6: Departmental Categorization & 115 \\
\hline Figure 9: Summary of Department 7: Departmental Categorization & 118 \\
\hline Figure 10: Summary of Department 8: Departmental Categorization & 121 \\
\hline Figure 11: Summary of Department 9: Departmental Categorization & 124 \\
\hline Figure 12: Summary of Department 10: Departmental Categorization & 127 \\
\hline Figure 13: Summary of Department 11: Departmental Categorization & 130 \\
\hline Figure 14: Summary of Department 12: Departmental Categorization & 133 \\
\hline Figure 15: Summary histograms comparing each department by level of & 137 \\
\hline support categorization & \\
\hline Figure 16: Levels of Support for Departmental Community Engagement, \\
Displayed by Dimensions & 153 \\
\hline
\end{tabular}




\section{CHAPTER I: INTRODUCTION}

The $21^{\text {st }}$ century liberal arts curriculum must be anti-fractured and applied to real world problems.... We can no longer address these essential learning outcomes solely through the general education curriculum; we must address them in the majors, in the disciplines... The major plays the decisive role....We must be increasingly self-conscious and self-critical so to be regularly assured that we are focusing on these outcomes in the majors....

- Carol Geary Schneider, President, Association of American Colleges and Universities (Keynote speech delivered at Portland State University, Fall Faculty Symposium, September 20, 2007)

\section{Introduction}

Carol Geary Schneider, President of the Association of American Colleges and Universities, is only one of the latest in an increasingly long string of higher education leaders who, over the past quarter-century, have called for a more community centered focus that enlists university resources in support of community capacity building and in the cultivation of greater civic responsibility on the part of students. This civic agenda is not new. In fact, it is a call that urges academic institutions to return to their historical roots and re-commit to the social compact that informed their founding.

This effort to re-focus the institution of higher education away from silocentered departments to a larger civic mission has not been easy; the terrain is contested.

There is an important role for higher education in the global society, but the exact nature of that engagement is contested. Higher education's failure and best self can be found by engaging community partners in mutually transformative work that allows us to re-imagine, in ways both creative and practical, sustainable communities. Our choice of partners and our visions of what may be accomplished together create opportunities for us to become members of communities and of a world of which we would like to be part (Enos \& Morton, 2003, p. 40). 
Much is at stake for students, the community, and the academy in turning away from a half-century old agenda of increasing specialization and silo-like disciplinary focus and returning to the moral roots of American higher education that emphasize the building of partnerships with communities in the 'mutually transformative work' that Enos and Morton envision. For students, it provides an opportunity to explore and test their civic sensibilities and skills as they apply new learning and grow into effective leaders. For communities, there is the prospect of partnering with colleges and universities to teach, learn, and act cooperatively on important community-based projects and create informed research agendas that will make a palpable difference in people's lives. For the academy, there is the opportunity to respond positively and creatively to society's increasing call for relevance.

Indeed, the academy is responding to this long-term call to restore the civic role of universities. This dissertation supports this call and will investigate the history of community engagement in higher education as part of the literature review. This study will specifically explore the role of academic departments as a critical link in the long and increasingly successful struggle to increase the role of universities in promoting community engagement and responsibility.

The effort to link public service with higher education has gone through at least three distinct phases in the past half-century: community service initiatives, service-learning development and implementation, and a broader institutional focus on community engagement. Although their emphases differ, all three aspects of public 
service in higher education are present today and generally work in mutually supportive roles.

The first phase was mostly student-centered and student-organized. In the 1960s and 1970s, student movements inspired by a desire for greater social justice focused largely on community action and service. The second phase began roughly in the 1980s when part of the community service movement began to emphasize servicelearning, a more formal pedagogical initiative that links students (and sometimes faculty) with learning and action at community-based organizations. Service-learning implementation expanded quickly among faculty due in part to its proven positive impact on student learning (Astin \& Sax, 1998), an outcome to which most members of the higher education community pay attention. The third phase also emerged in the 1980s and is characterized by a shift away from an exclusive focus on the individual student and associated curriculum and pedagogical issues toward institution-centered capacity-building at the central university level. This study is interested particularly in the role of academic departments in this gradual shift in the unit of analysis away from individual students and instructors to the organizational and institutional role of academic institutions as a whole.

The institution centered work to revitalize the civic mission of higher education is captured in Frank Newman's 1985 book Higher Education and the American Resurgence, penned while working at the Carnegie Foundation for the Advancement of Teaching. As Saltmarsh \& Gelmon (2006) explain, Newman declared that "the most critical demand is to restore to higher education its original 
purpose of preparing graduates for a life of involved and committed citizenship....The advancement of civic learning, therefore, must become higher education's most central goal" (1985, xiv, 32, cited in Saltmarsh and Gelmon, 2006, p. 31). More recently, in the The Future of Higher Education, Newman wrote: "Higher education must work harder on encouraging the civic education of today's students to ensure the efficacy of tomorrow's democracy" (Newman, Couturier, \& Scurry, 2004, p. 129, cited in Saltmarsh and Gelmon, 2006, p. 31). Many others, including Ernest Boyer $(1990,1997)$ and former Harvard President Derek Bok in Universities in the Marketplace (2003), condemn the commercialization of higher education. They call for a renewed commitment to what Stanford's John Gardner often called the compact between freedom and service. Several higher education practitioners and theorists have attempted to establish a sense of institutional urgency, calling especially for a reexamination of "relevancy" of disciplines in society (Boyer, 1990; Bok, 1992; Christy and Williamson, 1992; Halliburton, 1997; Lynton, 1995; Lynton and Elman, 1987; Schön, 1995). Others have utilized organizational diagnostic tools to evaluate current institutional missions and cultures, and attempt to map emerging visions and strategies for change (Ansley and Gaventa, 1997; Adamany, 1994; Barr and Tagg, 1995; Bringle \& Hatcher, 2000; Boyer, 1994; Checkoway, 1991; Crosson, 1985; Ehrlich, 1995; Furco, 2003; Gelmon, Seifer et al., 2005; Greiner, 1994; Harkavy, 1993; Holland, 1997; Kecskes \& Muyllaert, 1997; Mathews, 1997; Rice, 1991; Rice and Richlin, 1993). The service-learning, and more recently the community engagement movement has spawned myriad studies to inform the literature of higher 
education institutional change. For example, Astin et al., $(1998,2000)$ have illuminated the positive social, intellectual and cultural affects of service on students and faculty.

In the past decade, the discourse within this higher education movement has intentionally broadened beyond a more limited focus on service-learning in the classroom toward an institutional approach for civic, political and/or community engagement (Colby et al., 2008). For example, over the past ten years over 1,000 college and university presidents have publicly vowed to take "community engagement"- - or, understood most broadly, a concern for the relevance of their institution to our communities-seriously by signing National Campus Compact's Presidents' Declaration on the Civic Responsibility of Higher Education (Presidents' Declaration, 1999). Adopting language and framing understanding beyond the earlier, stricter, course-focused approach of the service-learning movement has helped diversify the movement. For example, some faculty may favor community engagement as a means for creating good citizens. Others may favor it because, like a good book, it provides a rich context for engaging students in a liberal arts learning experience. Still others are attracted to the more applied or community-based research strategy associated with a community engagement approach. In short, community engagement is a way to expand notions of the purpose of education, and recover liberal arts education in addition to recovering an educational focus on the public good. 
Finally, and most recently, the Carnegie Foundation for the Advancement of Teaching has added considerable attention to an institutional focus for community engagement in higher education by creating and implementing the "Carnegie Elective Classification for Community Engagement" (http://www.carnegiefoundation.org/classifications/index.asp?key=1592). Since the Classification's inception in 2006 - the inaugural year in which the classification was available to institutions-interest from higher education institutions has increased considerably, as evidenced by the number of "letters of intent to apply" received by the Carnegie Foundation in 2008.

Much of this movement has been inspired and supported by Ernest Boyer's (1990) efforts to open up, or expand the definition of "what counts" as scholarly work within the academy (Ramaley, 2006). Toward the end of his life, Boyer's search for new ways to tie the academy and society more closely together led him to formulate his now classic description of the "scholarship of engagement" (1990): "At one level, the scholarship of engagement means connecting the rich resources of the university to our most pressing social, civic, and ethical problems....Campuses would be viewed by both students and professors not as isolated islands but as staging grounds for action....Increasingly, I'm convinced that ultimately, the scholarship of engagement also means creating a special climate in which the academic and civic cultures communicate more continuously and more creatively with each other....enriching the quality of life for all of us" (p. 19-20). Boyer also supported important work by Glassick et al. (1997) to guide documentation and evaluation for faculty scholarship. 
Additionally, Diamond and Adam (1993, 1995, 2000) worked for several years on related topics in the disciplines, including with 25 disciplinary associations on issues of faculty scholarship. They also argue in favor of increased flexibility and reward for directing faculty research toward social needs: "In the coming decades we expect to see important changes in faculty roles and expectations. We hope to see greater rewards for faculty who use their considerable expertise in our communities and in the world at large addressing social needs and concerns" (Diamond and Adam, 2000, p. 38).

However, the tradition-laden institution of higher education is slow to change. Edward Zlotkowski (2005) posits that national and regional disciplinary associations, working through individual academic departments, have "for many years now prioritized interests, values, and standards identified exclusively by their members over more public concerns" (p. 148). William Sullivan argues that "civic professionalism" has been sacrificed to "technical professionalism" in the disciplines and has established a disciplinary ethos in which "public service can only appear as an admirable but accidental feature" (Zlotkowski, 1995, p. 11) of the primary work of faculty.

Yet, despite resistance and inertia supported by tradition, Boyer's worknearly two decades later-is beginning to emerge in national disciplinary associations and in academic departments. Indeed, Holland (2000) reminds us that "higher education in fact is evolving, and that real progress has been made in articulating and enacting a new sense of purpose" (p. 52). In some notable cases, such as the work 
accomplished by the Campus Community Partnership for Health's (CCPH) 2004 national "Community Engaged Scholarship for Health Collaborative" (supported by national resources from the Fund for the Improvement for Post-Secondary Education FIPSE), important gains have been made in the area of engaged scholarship and the relation to the formal retention, promotion, and tenure process. Also, the American Association of Colleges of Nursing, Association of American Medical Colleges, American Medical Association, and the American Public Health Association in collaboration with the CCPH Association, as well as the American Political Science Association, National Communication Association, and the National Sociological Association, there is evidence that the scholarship of engagement is beginning to find a place in the national disciplinary journals and in more regular presentations at annual national conventions. In fact, in 2000, James Applegate, then-president of the National Communication Association (NCA), at the Association's national conference dubbed NCA “The Engaged Discipline.” Yet, despite Applegate's visionary proclamation regarding the discipline, and the continued increase in community engagement at the institutional and faculty levels, this work is just now beginning to emerge as a topic of primary importance to academic units in higher education. Zlotkowski and Saltmarsh (2006) summarize the critical importance of this topic.

The task of creating engaged departments is both one of the most important and one of the most challenging facing the service-learning movement. Like other academic initiatives before it, the future of service-learning will depend to a large extent on its ability to access and to win over the power at the heart of contemporary higher education: the academic department (p. 278). 
Astute students of higher education are now asking several questions: How to create that "special climate in which the academic and civic cultures communicate" through the scholarship of engagement (Boyer, 1990)? How to recover liberal arts education and by doing so recover a focus on the public good? How to infuse public service into professional education, thereby reclaiming a sense of "civic professionalism?" Most broadly, scholars are now asking about the public purpose of a college or university (Ehrlich et al., 2000, 2003; Kezar et al., 2005; Morgan, 2001). And, to narrow the question and put it in Zlotkowski's and Saltmarsh's most focused terms, this study invites departmental members to ask: How can $m y$ discipline contribute to the common good, and what does that look like in my department?

In order for faculty members in an academic unit to begin to respond to the questions above, they have to collaborate. Yet, as Battistoni et al. (2003) point out in the introduction to the Engaged Department Toolkit, "faculty culture is highly privatized; as a faculty member, my teaching, research, and service are my work" (p. 3). Placing individualistic academicians together in a privatized unit may inspire healthy debate and rigorous research; however, competition, rather than collaboration, generally describes their environment. Indeed, this aligns with the findings of departmental scholar Jon Wergin (2003) when he asks "Why is it that when you talk about departmental collaboration people treat it as an oxymoron? Why is it that, even though I wrote The Collaborative Department (Wergin, 1994)...ten years ago, I continue to be kidded by colleagues who say that it was the only book of pure fantasy ever published by AAHE [the American Association for Higher Education]?” (p. 42). 
The individualized nature of faculty work is not a new phenomenon. Over 40 years ago, the famed first president of the University of California system, Clark Kerr (1963), observed that the university had become more of a bureaucracy than a community - "a mechanism held together by administrative rules and powered by money... a series of individual faculty entrepreneurs held together by a common grievance over parking" (p. 20).

\section{Purpose of the Study}

Holland (2000) argues "that the academic department, the locus of curricular decisions, is the key organizational level where service-learning must be accepted and integrated if it is to be sustained. Thus, understanding the department role in organizational change is an area where further research is needed" (p. 54). Yet, to date, scholars have not developed a concise and powerful tool designed specifically for academic departments to measure what community engagement might look like in their home department. This measurement instrument for academic departments is missing from the field. Many scholars concur that one is needed and, if successfully created, will significantly assist academic departments and further the institutionalization process of deeply embedding community engagement into core higher education policies and practices. The overarching purpose of this dissertation is to create such an instrument, and in doing so, help us better understand and quantify academic community engagement at the level of the academic department. 
Lee Shulman, President of the Carnegie Foundation for the Advancement of Teaching, often reminds higher education leaders that people pay attention to that which is measured. It is for this reason (he told a small group at the Carnegie Foundation in 2004) that he decided to ask the Foundation to establish the elective classification for community engagement - to provide educational leaders an opportunity to pay more specific attention to this important topic. Therefore, this dissertation proposes to develop something at once bold and simple: a measurement instrument to assist academic departments to "pay attention" to community engagement. Thus, by building on existing literature and utilizing the expertise of key informants, through an iterative process, the primary purpose of this study is to fill in a methodological gap to develop and qualitatively test the utility of a self-assessment rubric for the institutionalization of community engagement in academic departments.

A secondary purpose of this study is to initiate an exploration of the potential use of institutional theory (DeMaggio \& Powell, 1991; Scott, 1987; Selznick, 1948, 1992; Shinn, 1996) to begin to more completely understand the constitutive or "regime forming" (Cook, 1996) role of the academic unit as an integral part of the higher education transformation process. The institutional school of analysis takes a sociological view of organizations (Perrow, 1986) which includes an analysis of the whole "that gives them meaning" (p. 158). It also goes beyond an exploration of the formal bureaucratic structures of organizations to include a focus on the "myriad subterranean processes of informal groups" (p. 159). While the large body of literature concerning institutional theory will not be reviewed as part of this study, 
salient parts of this theoretical perspective are introduced here and will be woven throughout this study. There are two reasons for doing so. First, the researcher has come to more fully appreciate in the process of undertaking this study the noticeable lack of theory in the service-learning and, more recently in the academic community engagement movement. Second, some of the response data generated in this study suggests "measures of success" that can not be adequately explained by an organizational theory perspective. For example, the role of group process in building and sustaining a community engagement agenda; the overriding role of culture and values in comparison to some of the conventional organizational dimensions that are a part of the Rubric; the relative importance of leadership by the departmental chair; and the weight and relative importance of each of the six departmental elements in relationship to one another. I will elaborate more fully on these two reasons in my concluding chapter. At this point I wish simply to introduce the reader to institutional theory and its relevance for this study.

Perrow (1986) argues that the "institutional school is preoccupied with values" (p. 160) and especially the way that values deepen or are weakened. Shinn (1996) argues that the institutional approach illuminates the inter-related and embedded meaning of human interaction. DiMaggio \& Powell (1991) argue in favor of a neoinstitutionalist view that suggests organizations are most successful and enduring when they become embedded in the community; in these cases, the organizations "go beyond their instrumental function to play a decisive constitutive role in shaping what the community is and means" (Banyan, 2003). Selznick (1992) outlines a three-stage 
continuum of movement from organization to institution in which the entity first assumes a rational approach that focuses primarily on short-term goals, then moves toward a longer-term strategic values focus and, finally, assumes a community orientation where organizational and larger community goals are indistinguishable. At the final stage, the entity becomes a moral agent for the community, plays an important role in constituting meaning for itself and the community, and exhibits a consistently interactive role with other organizations. Banyan (2003) suggests that the "institution-centered" view of organizations is contrasted with the "tool-centered" view that prevailed over the last half century. Tool-centered organizations emphasize formal and rational structures and processes and view the environment as instrumental. On the other hand, institution-centered organizations are seen to be deeply integrated into their environments - affecting and affected by it - while socially constructing meaning to promote the public interest. Sirianni \& Friedland (1995) argue that once an organization achieves institutional status it applies selfcriticism and reflects on it role and place in a participatory democracy.

This study joins with other scholars in arguing that academic departments need to play a key role if the community engagement reform agenda in higher education is to be successful. Institutional theory reminds us that these departments may be more than a mere set of organizational structures and processes that exist for the sole instrumental purpose of achieving the educational, research and service goals of the unit. They have the potential to become a community of shared values that play a constitutive role in shaping the meaning of the larger community within which they 
operate. This needs to be kept in mind when interpreting the findings of this study. This research invites departmental members to ask what it will take for departmental faculty to become more civically engaged in their academic roles. In answering this question, academic department scholar Jon Wergin (2003) argues that "members must address two matters they rarely address: the shared values upon which the work of the department rests, and the kind of evidence that will help them make the most useful judgments of quality" (p. 64). Institutional theorists can help us better understand both dimensions of the central question that is the focus of this study.

Much of the higher education reform over the past decade has focused its attention on the values side of the reform agenda (Boyer, 1990; Leslie and Fretwell, 1996; Plater, 1999; Ramaley, 2006; Rice \& Richlin, 1993; and Schön, 1995). Attention has been placed consistently on the civic roles of the institutional actors, asking questions of value both in traditional ways - concerning graduation rates, economic development impact, and so on-as well as by exploring more progressive or community-connective measures such as tangible community impact from research, student civic, democratic, and community-building skill development. On campus, departments play a critical role in arbitrating values and using evidence to measure success. Since traditional academic autonomy gives faculty the responsibility for developing curriculum and in hiring, retaining and promoting their fellow colleagues, the issue of values and evidence becomes critical. Several higher education scholars have attempted to establish a sense of educational urgency, calling especially for a reexamination of the "relevancy" of disciplines to society (Battistoni et al., 2003; Bok, 
1982, 2003; Halliburton, 1997; Lynton, 1995). Educational systems across the nation, and increasingly across the globe, have responded with a renewed commitment to public engagement, especially to the practices of service-learning, community-campus partnership building, and community-based research (Kezar, 2005).

In addition to making community engagement a central educational value of higher education institutions, reformers have also emphasized the importance of agreeing on what counts for evidence in measuring community engagement. This terrain is contested, as this study elucidates more fully in the next chapter. As argued above, institutional theorists point us in a different direction for collecting evidence than is the case for those who look at departments organizationally and bureaucratically. Near the heart of this matter are questions of motivations for evidence gathering (Holland, 2001). Is the evidence for improving quality of teaching and application of expertise in community-connected ways intended to transform the community or is the evidence intended to gain glory to set oneself or one's unit apart in a fiercely competitive environment? The former emphasizes the institutional theory framework for understanding the community engagement reform agenda, while the latter emphasizes the instrumental organizational goals it can serve.

The institutional theory framework may also be helpful in gaining a better understanding of the myriad institutional environments in which higher education organizations must act. For example, both values of community engagement and "what counts" for evidence in major urban centers might differ greatly from measures resonant in the rural Midwest. Or, measures of relevance might well differ in a large 
public institution versus smaller, faith-based, private liberal arts colleges. These are issues that go beyond the scope of this study.

This study is confined to a less complex and prior question of whether and how academic departments can play a role in the larger community engagement reform agenda. Some scholars like Zlotkowski and Saltmarsh (2006) are uncertain whether departments will become bureaucratic obstacles of change or institutional agents of the change agenda.

Will individual faculty interest [in community engagement] seeping up from below and administrative encouragement [for community engagement] trickling down from above finally reach each other at the level of departmental culture or will they instead encounter an impermeable membrane (p. 278)?

There is evidence to suggest that departments may be more open to change than they are obstacles. The intentional work of Portland State University's Center for Academic Excellence with twenty academic departments at PSU since 2001 demonstrates that many of the membranes are permeable. Moreover, the eleven departmental exemplars highlighted in Engaging Departments: Moving Faculty Culture from Private to Public, Individual to Collective Focus for the Common Good (Kecskes, 2006) reveal that the kinds of healthy collaborations that Wergin (1994) envisioned are alive. Despite the evidence suggesting that departments can be supportive of the larger community engagement reform agenda, we do yet have an answer to the following two leading questions: 1) what academic unit characteristics, or indicators, are critically important to look for in order to respond to Wergin's (2003) questions about evidence. And 2) how might those characteristics be measured? These two questions will be the focus of this research study. 


\section{Value and Importance of the Study}

The academic disciplines are at the heart of higher education; academic departments represent the most salient expression of the disciplines on college and university campuses today. Yet, as Richard Edwards (1999) confirms, there is little discussion about the role of academic departmental units in higher education reform:

The department is arguably the definitive locus of faculty culture, especially departments that gain their definition by being their campus's embodiment of distinguished and hallowed disciplines.... We could have expected that reformers would have placed departmental reform at the core of their agenda; yet just the opposite has occurred. There has been a noticeable lack of discussion of - or even new ideas about - departments' role in reform (p. 17).

The next chapter will explore in greater detail the measurement instruments developed over the past decade. They generally focus on the institutionalization of service-learning or community engagement at the central university/college level. This study will explore four specific measurement instruments and two frameworks/matrices germane to this topic. This detailed investigation of the extant tools will help to establish the importance of this study in filling a critically important gap in the literature regarding understanding and measurement of departmental reform, with specific focus on the institutionalization of community engagement in academic departments. The development of a self-assessment instrument designed specifically for academic departments will help address Edwards' (1999) concern for "a noticeable lack of discussion" about the role of departments in higher education reform. 
The researcher's professional experience in implementing community engagement at Portland State University and consulting with diverse departments across the country suggests that many faculty respond to a departmental engagement initiative in one of two ways. They either ignore it, or they claim that they (and by association, their respective department) are already doing $i t$. This study begins to bring into sharper focus what is meant by a community-engaged department. The instrument specifically adapted for this dissertation-Creating Community-Engaged Departments (hereafter referred to as the Rubric)-provides a mechanism for the selfassessment of departmental engagement along a continuum of key dimensions and components. In addition to creating a self-assessment instrument to track the development of collective, departmental engagement over time, the Rubric also can be used heuristically by department chairs and other faculty and administrative leaders to increase understanding about the community-focused agenda of the academic department (or, from an institutional theory perspective, to "make meaning") among its faculty, staff, students, and community partners. If Carnegie's Lee Shulman is correct, and scholars do "pay attention to what we measure," then the bottom-line value of this study is both instrumental and constitutive (or "regime forming").

Instrumentally, this study will provide academic departments concentrated in the social sciences in similar institutional contexts with a pilot-tested instrument for conducting (multiple) self-assessment(s) along a continuum of departmental community engagement. Constitutively, this study will: produce a pilot-tested instrument that can increase understanding and learning about community engagement 
with multiple constituents in the context of social science departments in similar institutional contexts; and provide members of those departments who have an interest in deepening their commitment to community engagement with a pilot-tested tool to be used as a basis for initiating and guiding discussion among themselves and with other interested parties such as students and community partners.

\section{Outline for this Dissertation}

Following this introductory chapter, chapter two briefly reviews the literature related to community engagement in higher education in general, the role of the department in academic reform, and the development of self-assessment rubrics and matrices for measuring community engagement. Chapter three describes the methodological approach used to conduct this research, including the presentation of select findings from the national key informant interviews, and discusses how they were integrated into the new departmental self-assessment Rubric. Chapter four presents the findings from research that involved pilot-test social science departments at five urban, engaged, public institutions of higher learning. Chapter five summarizes and analyzes the findings, presents conclusions, discusses limitations, suggests directions for future research, and explores implications of this study. 


\section{CHAPTER II: RELEVANT LITERATURE}

There are three main bodies of literature that are important for understanding the research goals of this dissertation. One body outlines a general re-awakening of awareness in American higher education regarding its historical roots and brings into particular focus the importance of the civic purposes of higher education today, and for the future. A second body of literature helps readers understand the role and importance of the disciplines and their campus expressions, the academic departments, in higher education reform efforts. Finally, a third body of literature is more narrowly focused on the scholarly work relating to the development of self-assessment rubrics or other types of measurement matrices or frameworks utilized for understanding and documenting the level of institutionalization of community engagement (including service-learning) in higher education in general, and in academic departments in particular. While this study will not review all of this literature, it is important to understand that the justification for the development of Creating Community-Engaged Departments: Self-Assessment Rubric for the Institutionalization of Community Engagement in Academic Departments is predicated on the following three assumptions: 1) the increasing salience of community engagement in higher education; 2) the pivotal role played by academic departments in higher education reform efforts; and 3) the importance of having a specialized and pilot-tested rubric for creating community-engaged departments, which now does not exist. 


\section{The Civic Purposes of Higher Education}

Before beginning to explore the assessment of community engagement at the academic department level - the primary topic of this dissertation - this study first begins by briefly looking at the role of civic engagement more broadly in higher education. There is a rapidly expanding body of literature regarding the civic or public purposes of higher education, but this literature connects to the past.

American higher education institutions have a rich history of service. For over 30 years, historians Lee Benson and Ira Harkavy of the University of Pennsylvania have been documenting the democratic history of American higher education. They remind us that in the 17th century, the colonial colleges (most of today's Ivy League schools) were founded on Christian values with service as a central aim (Benson et al., 2005). They connect this sense of service or engagement to education more broadly by demonstrating that in the mid- $18^{\text {th }}$ century, Benjamin Franklin described the purpose of the curriculum of the 'Academy of Philadelphia,' later named the University of Pennsylvania, in the following way:

The idea of what is true merit, should also be often presented to youth, explain'd and impress'd on their minds, as consisting in an Inclination join'd with an Ability to serve Mankind, one's Country, Friends and Family ... which Ability should be the great Aim and + End of all Learning (Best, 1962, p. 150-1, cited in Benson, at al, 2005, p. 192).

In general, Franklin and other Founders took a "noblesse oblige" view of the world. Those who are privileged have a moral obligation to give back to society by assisting those who are less fortunate (Barber, 1997). This "nobles oblige" view should be distinguished from the more contemporary and progressive expressions that emphasize 
the instrumental value of civic and political engagement to a healthy functioning democratic order (Putnam \& Feldstein, 2003; Colby et al., 2008). The more current view has "democratized" the notion of service, in part, through application as a pedagogical approach in the classroom and as an applied research approach in the field.

A century later, in 1862, the Morrill Act established America's land-grant institutions to spread education, advance democracy, and improve the mechanical, agricultural, and military sciences. This Act continued to anchor higher education to its original purpose of service to society. It is important to note how, among other things, public support of education was driven by the desire to have a prosperous economy.

Research institutions followed soon afterward. Benson, Harkavy and Hartley (2005) point out that America's first urban research university, Johns Hopkins, was founded with a sense of civic purpose. Daniel Gilman, Hopkins's first president, remarked in his inaugural address that universities should "make for less misery among the poor, less ignorance in the schools, less bigotry in the temple, less suffering in the hospitals, less fraud in business, less folly in politics" (Long, 1992, p. 119, cited in Benson et al., 2005, p. 193). Similarly, nine years later, in 1885, Leland Stanford and Jane Lathrop Stanford wrote in the Founding Grant to establish Stanford University's core principle of educating for the public good, specifically to "qualify its students for personal success, and direct usefulness in life; and its purposes, to promote the public welfare by exercising an influence on behalf of humanity and 
civilization..." (cited in Schmiede \& Ortolano, 2005, p. 223). Indeed, at the turn of the $20^{\text {th }}$ century higher education had an abiding belief in its social purposes (Harkavy, 2000). Charles W. Elliot, Harvard's president in 1908, spoke out of his institution's tradition when he said, "At bottom most of the American institutions are filled with the democratic spirit of serviceableness. Teachers and students alike are profoundly moved by the desire to serve the democratic community" (Veysey, 1965, p. 119, cited in Benson et al., 2005, p. 193). Again, here, it is important to distinguish between a) the more traditional, noblesse oblige-informed impulse evident in the Founders, b) the instrumental nation-building views reflected in the Morrill Act and adopted by research institutions a century ago, and c) the more constitutive, contemporary understanding of community engagement that focuses on recovering a sense of strong and effective citizenship through, in part, active political and other types of democratic participation (Battistoni, 2006; Boyte, 2004; Ramaley, 2006; Putnam \& Feldstein, 2003).

In the middle of the $20^{\text {th }}$ century and coinciding with the outset of the Cold War, a new trend emerges that runs counter to this long trend of "service" as a foundational attribute in higher education: the commodification of disciplines and degrees (Benson, Harkavy, \& Hartley, 2005). This market-driven trend in the Academy was not seriously challenged for four decades. Benson and Harkavy (2002) characterize this time in American history as the beginning of the big science, Cold War, entrepreneurial, commodified, American research university system. Benson, Et al (2005) write 
Perhaps the most important consequence of the commercialization of higher education is the devastating effect that it has on the values and ambitions of college students. When universities openly and increasingly pursue commercialization, it powerfully legitimizes and reinforces the pursuit of economic self-interest by students and contributes to the widespread sense among them that they are in college solely to gain career skills and credentials. It would only belabor the argument to comment further on how student idealism is even more sharply diminished, student disengagement is even more sharply increased, when students see their universities abandon academic values and scholarly pursuits to openly, enthusiastically function as entrepreneurial, ferociously competitive, profit-making corporations (p. 198).

When students witness universities acting in ways akin to competitive, profitmaking corporations, it can legitimize a career-only, credential-focused approach to education. An associated trend is a decrease in student engagement, youth voting, and so on. This concern is well founded, and these trends are well documented (Bok, 1992; Colby, Ehrlich et al., 2003, 2008; Ehrlich, 2000; Westheimer and Kahne, 2003).

Over the past two decades, many scholars have become increasingly more vocal in expressing their concern that higher education is out of step with communities and with societal issues (Bok, 1992; Edgarton, 1994; Rice, 2006, to cite just a few). Because the literature describing these concerns, as well as myriad institutional and faculty responses, is now well documented, for the purposes of this study, I will highlight only the most important markers.

Holland (2000, 2001) reminds us that Russell Edgerton, then President of the American Association of Higher Education (AAHE), brought the term "engagement" into the focus of higher education in 1994 when he explored the topic of "engaged institutions" at the AAHE Annual Meeting (Edgerton, 1994). In 1995, Ernest Lynton wrote "Making the Case for Professional Service," which helped establish the validity 
of the application of faculty expertise toward civic or public issues in ways that complement the larger institutional mission. Soon after, in 1999, Lynton and Amy Driscoll wrote Making Outreach Visible: A Guide to Documenting Professional Service and Outreach. This publication helped further distinguish more traditional concepts of "service" relating to the campus (e.g., committee work) from scholarly service (the application of scholarly expertise to societal issues). Also, in 1999, the Kellogg Commission on the Future of State and Land-Grant Universities published a report that established "engagement" as separate from and indeed beyond traditional concepts of "outreach and service." By arguing that engagement requires a "commitment to sharing and reciprocity" (1999, pp. vii, 11), Kellogg helped catalyze a major shift in the culture of higher education. The Commission helped to shift the focus from a one-way tradition of providing expertise to society, to a newer two-way model that emphasized community-university partnerships that connect colleges and universities much more directly with specific community issues (Holland, 2000).

Complementing this shift toward a two-way "partnership" instead of a oneway "service" approach is a concomitant movement to deepen the understanding of community engagement to explicitly include concepts of political engagement. Scholars supporting this effort regularly remind students that "political engagement" presupposes a decidedly non-partisan approach to politics and intentionally focuses on skill, knowledge, and attribute-building efforts similar to those explicated well in Boyte's (2004) "public work" model. In Civic Engagement Across the Curriculum (2002) political theorist Richard Battistoni worked with 13 national educational 
disciplinary associations to develop conceptual frameworks for civic engagement from distinct disciplinary perspectives. Battistoni's work has helped "translate" the concept of civic engagement into very specific frameworks that can resonate with faculty from the disciplines and associated academic departments that informed his study.

These two recent conceptual shifts in higher education impact the academy in two primary ways. First, the partnership model presupposes that members of the academy must recognize that knowledge and wisdom are located both inside the classroom as well as outside the walls of the academy - in the community (Gibbons, 1994). This has implications for how faculty organize the curriculum (including the curriculum of the major in the disciplines), the pedagogical approaches they choose to employ, how they conduct research, how they build infrastructure to support community connections, how budgets are allocated, the role of students, and so on. A second impact on the academy resulting from an emphasis on non-partisan political engagement is the importance of teaching political skills (e.g., community organizing strategies, communication skills, working effectively in diverse groups) much more explicitly (Colby et al., 2008). In short, to embrace these shifts and bring itself more "in step" (Bok, 1992) with communities, members of the academy must regularly and deeply engage with their respective communities. Moreover, the academy must provide students many more opportunities to learn why, when, and how to effectively engage with the community on multiple levels (Battistoni, 2006; Boyte, 2004; Putnam \& Feldstein, 2003; Ramaley, 2006; among many others). 
Significant evidence of the broad change that has occurred in the past decade can be found by examining the nature of discourse occurring at the national levels among several leading educational and some disciplinary associations. As mentioned in chapter one, in 1999 the National Campus Compact published the Presidents' Declaration on the Civic Responsibility of Higher Education (Presidents' Declaration, 1999), which was initially signed by over 600 college and university presidents. Several additional national higher education associations began to focus an increasing amount of attention on the topic of civic engagement. For example, in 2003, the Association of American State Colleges and Universities (AASCU) established the American Democracy Project (ADP). Under the leadership of AASCU Vice President for Academic Leadership and Change, George Mehaffey, the ADP has helped catalyze the attention of several hundred state colleges and universities, a cohort of institutions that, today, educates a majority of college students in the United States. Also, the American Association of Colleges and Universities (AAC\&U) has sponsored several initiatives and publications in direct support of higher education community engagement efforts (for example, see AAC\&U's multiple resources dedicated specifically to "civic engagement"(Retrieved November 14, 2008, from http://www.aacu.org/resources/civicengagement/index.cfm). Additionally, the National Association of State Universities and Land-Grant Colleges (NASULGC) - a long-term supporter of the traditional "outreach" agenda of the land-grant universities--established, in 2006, the W. K. Kellogg/C. Peter Magrath UniversityCommunity Engagement Award. Their website 
(http://www.nasulgc.org/NetCommunity/Page.aspx?pid=304\&srcid=183) states that the award "recognizes the outreach and engagement partnerships of four-year public universities. The award program seeks to identify colleges and universities that have redesigned their learning, discovery, and engagement functions to become even more sympathetically and productively involved with their communities." Finally, there has been increasing focus on the community engagement agenda in some national disciplinary associations, most notably the National Communication Association, which, in 2001 declared themselves the "engaged discipline."

In additional to W.K. Kellogg, other foundations have increased their strategic focus on facilitating the growth of the community engagement agenda of higher education. Most recently, in 2008, the Jimmy and Rosalynn Carter Foundation established the first-ever University-Community Partnerships award, see: http://www.pdx.edu/news/20547/.

Finally, over the past decade the federally-funded National Service-Learning Clearinghouse has served as the primary repository of information and guidance for practitioners and scholars associated with the service-learning and community engagement movement. Scholars at the Clearinghouse aptly summarize the current state of discourse at the national level in the History of Service-Learning in Higher Education (January, 2008):

The present moment of renewed attention to the civic mission of universities has been called the "fourth wave" of higher education civic engagement initiatives. This wave is a forward-looking vision at the future of highereducation itself. We are seeing a movement beyond efforts to bring civic engagement to individual classrooms. Instead, there is a push toward a fullyengaged university as a whole: active, vibrant partnerships of scholars, as well 
as students and citizens who have the support and resources to achieve phenomenal things in education and in transforming communities nationwide (http://www.servicelearning.org/what is servicelearning/history hesl/index.php).

In this section several examples of how the discourse is clearly changing in favor of much greater emphasis on engagement, understood broadly to include a twoway partnership approach that builds on and supplants a one-way "service" paradigm, and an explicit understanding that non-partisan political engagement skill and knowledge building strategies must be embedded in the curriculum has been discussed. Perhaps one of the most powerful markers of the change in focus for higher education came in 2006 when the Carnegie Foundation announced its new elective classification for community engagement. This new classification measures engagement at the institutional level and significantly advances Carnegie's strategy to influence higher education away from a one-way service approach toward a two-way social partnership model that embraces the goal of cultivating non-partisan political engagement. As discussed in chapter one, institutional interest in obtaining this classification has increased substantially in the past two years.

Finally, although descriptions of engagement in institutions outside of the United States fall well outside the purview of this study, this brief literature review would not be complete without noting the increase in interest in community engagement around the globe. In addition to interest and programmatic activity at individual institutions outside the United States ${ }^{1}$, Tufts University is providing

\footnotetext{
${ }^{1}$ For example, the University of Science, Ho Chi Minh City, Vietnam; America University of Cairo, Egypt; University of Kuwait, Kuwait; University of Bologna, Italy; University of Cape Town, South
} 
leadership and development of the Talloires Network, an international consortium of colleges and universities with interest in growing their community engagement profile (see: http://www.tufts.edu/talloiresnetwork/).

Former associate director of the National Communication Association (NCA), Sherwyn Morreale, and NCA past president James Applegate (2006) nicely summarize the state of community engagement in higher education today by pointing out that "[s]ociety appropriately is asking that we justify the huge investment made in both research and teaching institutions in higher education. Campuses configured in ivory towers are no longer acceptable. The academy is responding to this public mandate" (p. 264). In essence, a new era or "fourth wave" of higher education community engagement has emerged. From an institutional theory perspective, this new wave can be characterized as constitutive, regime forming work. The goal is a two-way partnership that ends up reconstituting the substantive meaning of the academy and the community it serves. While several higher education scholars and leaders are in favor of this transformative work, others consider it deeply misguided (Fish, 2004). There remain fundamental tensions between a more traditional, segregated, and instrumental view of the university and a more progressive, integrated, constitutive view of higher education institutions as embedded in and integral to the very fabric of the communities that comprise them. On the curricular level, these tensions surface in decisions about "what counts" for education in general, and how much specific disciplinary content needs to be "covered" by courses in the major in

Africa; as well as multiple universities and colleges in Canada, Japan, China, Australia, Latin America, Europe and the Middle East. 
particular. Recently, the Carnegie Foundation's (among others) focus on increasing non-partisan political education as part of the core curriculum of universities has called into question the role of the curriculum, conceptions of what counts most as critically important knowledge, and the role of the university in developing effective community-engaged citizens in the $21^{\text {st }}$ century.

\section{Academic Departments and Academic Reform}

Before discussing the key literature associated with the development of a selfassessment rubric for measuring community engagement, it is important to first elaborate more fully on chapter one's introductory discussion of why it is necessary to focus greater attention on the academic department as a unit of change.

Battistoni et al. (2003) argue that "[a]cademic work may be broken down into three levels: work of the individual faculty member, work of the department, and work of the school/institution. The work of the department is, rightly, at the center of this" (p. 22). But the authors point out that the community engagement reform efforts over the past several years have marginalized traditional academic units.

It is not uncommon for those seeking change to turn away from traditional units and structures. Until now, almost all engagement resources have been created to serve the needs of individual faculty members or whole institutions. Departments, like the disciplines they represent, are more often than not seen as part of the problem, not the solution. So minimal has been our awareness of and attention to the department as a factor in the scholarship of engagement that we rarely even encounter calls to address its absence.

Despite this gap, some of the most important issues facing higher education-and not just engaged work-can be effectively addressed only on a departmental level....Unless the department acts as a unit, failure is almost inevitable (p. 12). 
Edward Zlotkowski, an English literature scholar, has focused more attention over the past fifteen years than perhaps any other academic on the role of the disciplines in institutionalizing service-learning and community engagement in higher education. He is the editor of the 22 volume series "Service-Learning in the Disciplines," originally published by the now-defunct American Association of Higher Education (AAHE). Zlotkowski believes that only by working with the faculty in the disciplinary contexts of the home department will the engagement agenda be institutionalized.

Despite his Herculean efforts, he admits that "what we know at this point about service-learning's [community engagement's] discipline-specific efficacy is very limited" (Zlotkowski, 2000, p. 61). Notwithstanding this lack of knowledge, Zlotkowski continues to advocate for a disciplinary, or departmental approach for the engagement change agenda. His belief also draws on other well-known and respected higher education scholars, in this case, the former President of Stanford University, Donald Kennedy. Zlotkowski was one of the main drivers behind the several-year "Engaged Department" initiative implemented by National Campus Compact. In an influential article in 2000 he argued that

one of the field's top unanswered questions...must be a careful consideration of service-learning's relationship to individual disciplinary/interdisciplinary areas.

Indeed, the importance of such a focus would be hard to underestimate. The influence of the disciplines-through their organization into academic departments - has been repeatedly recognized in numerous studies of and statements on higher education reform. An observation by Donald Kennedy (1995), former president of Stanford University, is typical. Addressing the sometimes weak 
commitment of faculty to their home institutions, especially in the case of research universities, Kennedy asks:

Can the academic "center" - that is, administrative leadership-move us out of this vacuum [of commitment]? That will be difficult, because the action is all peripheral: it takes place at the level of departmental faculties....there is a powerful tradition of local control over most of the things that matter: disciplinary discretion, exercised through the choice of new faculty; curriculum; appointment and promotion criteria; and above all, the character of graduate study... Departments are the units in which the institution's strategy for academic development is formulated in practice. (p.12)

Granted, at many smaller and/or less exclusive institutions, institutional priorities and administrative leadership do exercise significant influence. Nonetheless, even in these cases, it is most often the department rather than the administration that determines how, if, and what policy decisions are implemented. Furthermore, on a personal level, the agenda of a faculty member's discipline continues to exercise significant influence regardless of the kind of institution with which he/she is involved. (p. 61)

Other higher education scholars confirm Zlotkowski's assessment of the importance of a disciplinary or departmental focus for institutionalizing community engagement in higher education. As pointed out earlier in chapter one by organizational change scholar Barbara Holland (2000), "the academic department, the locus of curricular decisions, is the key organizational level where service-learning must be accepted and integrated if it is to be sustained. Thus, understanding the department role in organizational change is an area where further research is needed" (p. 54). Holland (1999) also suggests that service-learning can gain legitimacy as a scholarly pursuit when it is genuinely valued within a discipline. Similarly, Furco (2001) notes that an increased focus on the role of the department has facilitated moving service-learning and community engagement toward the mainstream of faculty work. He argues that once community engagement is embedded in 
departments "faculty members will begin to perceive it [community engagement] as something that their peers value and consequently something of which they should be cognizant" (p. 76). Furco (2002) also calls for further study of the role of the academic department in legitimizing and sustaining engagement. "Given that the predominant association faculty members have is with their discipline, the departmental and discipline-based support for service-learning has the potential to raise the academic legitimacy of service-learning. As the issues of service-learning institutionalization are studied further, the role of the department should be more fully explored" (p. 55) ${ }^{2}$.

Harry Boyte (2004) captures perhaps some of the most important reasons why focusing on academic departments is essential to the success of the community engagement reform agenda. In his study of University of Minnesota faculty Boyte discovered a sense of loss as well as a yearning by faculty to connect more deeply to the public purposes of their discipline. From an institutional theory perspective, the faculty Boyte interviewed viewed their individual and departmental academic work largely in instrumental terms, as a "tool-centered" (Banyan, 2003, p. 16) work that serves individual faculty interests, begets "turf wars" and supports the "star system." This is disconcerting to these faculty; they experience "a strong and often painful

\footnotetext{
${ }^{2}$ In this section, the terms "service-learning" and "civic/community engagement" are used somewhat interchangeably despite the fact that this study distinguishes them as separate stages in the development of this movement. This is due, in part, to the fact that several of today's community engagement scholars grew out of the earlier service-learning movement. Also, the transition from the more strictly pedagogical focus of service-learning as a teaching and learning methodology into the broader understanding of the role of the curriculum as a whole and that of the academic department and university as community actors is still in a relatively nascent stage. Thus, some of the field's key journals still carry the term "service-learning" in their titles, and the literature within is still expected to connect to the rhetoric of service-learning. However, as is evident in the citations in this section, the field has indeed begun to conceptually move toward a broader civic engagement agenda, while the language and terminology of the field lags behind.
} 
sense of loss of public purposes." Further, in their statement of yearning, faculty can be seen to be calling for a more "institution-centered" (Banyan, 2003, p. 16) view of their work and organization. Boyte and Fogelman seemed to find that there is a great desire to build meaning and connect the tool-like organization of the department in a much more institution-like manner to larger public issues-indeed, to embed core academic work into the public work of communities. Here is an excerpt from their study.

Edwin Fogelman, chair of the Political Science Department, and I conducted dozens of interviews with faculty across the university, using a political approach that focused especially on faculty members' deeper self interests. This gave us a way to see the potential of civic engagement to address issues of professional work identity, tied to self-interest, prestige, institutional incentive structures, professional cultures and the like.

We interviewed people who were widely respected in different departments and colleges, who were seen to embody the ethos or culture of their disciplines and the university, and who were knowledgeable about its history and operations. Far more than we expected, the interviews surfaced a strong and often painful sense of loss of public purposes in individual jobs, professions and disciplines, and the whole institution. There was widespread alarm at turf wars and the "star system." Faculty voiced desire for public engagement to be constitutive of professional work. Interest in the public relevance of teaching and research was not simply an individual desire but was also framed in disciplinary terms. "Our whole department feels too cloistered," said one department chair in the College of Liberal Arts. She expressed the widespread department desire to engage more deeply the urban scene and the public world. (p. 4-5)

Consider the statement by the chair cited at the end of the passage who "expressed a widespread department desire to engage more deeply the urban scene and the public world." Interpreting this through an institutional theory lens could suggest that the chair is calling for the current instrumental orientation of her department to be 
transformed toward an institutional, constitutive orientation that helps build deep meaning for the professional work of the organization.

To summarize this second section of Chapter 2, there are three reasons why it is important to focus additional attention on the academic department as a unit of change. First, Battistoni et al. (2003), Furco (2001, 2002) Holland (2000), Kennedy (1995) and Zlotkowski (2000), among others, all confirm the pressing need to focus on the disciplines and academic departments to create sustainable change in higher education. Specifically, these scholars recognize academic units as the "key organizational levers" (Holland, 2000, p. 54) to help community engagement gain legitimacy as a scholarly pursuit. They recognize departments as the organizational unit where policy decisions are made and implemented regarding curriculum, promotion and tenure policies, and approaches to research. Second, Holland (2000), Furco (2002), and Zlotkowski (2000), among others, argue that further study is needed into the role that academic departments play in legitimizing and sustaining community engagement. Finally, Boyte (2004) argues that faculty yearn to connect more deeply to the public purposes of their discipline.

In the following section, the body of literature that discusses both why and how to measure engagement as a precursor to building a self-assessment rubric for specific use in academic departments will be reviewed. 


\section{Developing a Self-Assessment Rubric to Measure Departmental Engagement}

In this section, the literature dealing with the measurement of community engagement in higher education and in academic departments in particular will be reviewed. Measurement becomes more difficult when there is a lack of agreement on the definition of community engagement and the motivations for measuring it. Both problems plague the literature on community engagement.

Since community engagement is still quite a new concept in higher education at the national level, it should not be surprising to realize that while there are many definitions available in the national literature there is not a strong national consensus about what is specifically meant by community engagement. Nor is there a clear set of motivations for assessing engagement activities. While it is not the purpose of this study to explore these motivations, it is important to be cognizant of the fact that they are diverse. Holland (2001) has provided us with the following useful summary of the range of motivations that inform and guide the assessment of community engagement.

1) Academic legitimacy - this motivation includes concerns for impacts on student learning and personal development, faculty research and scholarship, and community impact, among others.

2) Image and reputation - Holland (2001) asks critically important questions regarding the role of assessment (and "rankings") to further a potentially harmful, competitive environment in higher education: "Do we envision a descriptive or comparative system that makes engagement a tool for identifying superior institutions or for conferring the aura of prestige? If yes, how does that meld with the view that 
engagement is about the vital citizenship role of education in a democratic society, more than a tool for recognition" (p. 4)?

3) Accountability - as discussed earlier in Chapter 1, diverse constituents are beginning to require colleges and universities to demonstrate their public purpose.

4) Different civic missions - this motivational factor recognizes the centrality of the role of mission in higher education while respecting the diversity of institutional types and nuanced expressions of community engagement (e.g., more of a teaching focus on service-learning versus more of a public scholarship focus with communitybased research; faith-based institutions versus secular; large public research universities versus small liberal arts colleges).

5) Quality - fundamental questions arise when considering the motivation of assessing engagement for indicators of quality. Is the primary purpose to increase internal understanding and practices or to compare one institution to another?

6) Matching measures to purposes and audiences - this motivation suggests that attention be paid to the purpose of measuring engagement, and for whom the information is intended, including internal and external funders.

Given the nascent arrival of community engagement on the national stage, and the flexibility and innovation necessary to implement new programs and pedagogical and research strategies on campuses, one could easily feel overwhelmed when thinking about assessment. Indeed, the complexity of the mix of potential motivations inherent in any attempt to measure community engagement might lead one to surmise that the endeavor is pointless. However, Holland (2001) and others (Driscoll et al., 
1996; Driscoll, 2008; Gelmon et al., 2001) suggest otherwise. Indeed, Holland (2001) writes, "this kind of flexibility, experimentation and openness to innovation is essential during exploratory phases of change, if we are to ensure the sustainability of engagement as a component of academic work. This does not mean measurement or description is futile at this point. To the contrary, it is an essential and timely activity" (p. 24). Thus, in the next section, key measurement or descriptive instruments and frameworks developed by scholars as a precursor to developing an instrument suitable for use in academic departments will be explored.

\section{A. Building a Rubric - Dimensions and Constructs (Component Parts)}

While not exhaustive, this study will briefly examine six frameworks that have been developed over the past dozen or so years to assess service-learning and/or community engagement in higher education. What is of particular interest for the purposes of building a self-assessment rubric especially designed for departmental use is the relevance of these studies for constructing dimensions and/or categories that can be used for measurement at the departmental level. The paragraphs that follow provide the reader with a chronological summary of the concept-building steps that have been taken by various scholars to create instruments for measuring community engagement. .

Holland (1997) was one of the first scholars to develop a robust matrix to ascertain "institutional commitment to service" that was based on more than a single, or very few institutional case studies. She identified "four potential levels of 
commitment and seven organizational factors that characterize institutional choice and behaviors regarding service" (p. 33). Holland (1997) is clear to remind readers that her Matrix is not prescriptive. Rather, it portrays patterns of current trends and choices relating to institutional commitment to service. This non-prescriptive strategy has been maintained in all of the other measurement instruments investigated in this study. Further, the following seven original organizational factors Holland identified have also been largely carried forward in subsequent instrumentation: Mission; Promotion, Tenure, Hiring; Organization Structure; Student Involvement; Faculty Involvement; Community Involvement; and Campus Publications. Over the past decade, the Holland matrix (1997) has clearly influenced the development of all of the measurement and descriptive instruments that are germane to this study. Holland (1997) argues that "the matrix is meant to be a useful diagnostic tool to describe and interpret the dimensions, approaches, and levels of institutional commitment to community service and service-learning and, there to facilitate institutional planning, decision-making and evaluation" (p. 33). This diagnostic tool, similar to the Kecskes and Muyllaert (1997) benchmark, the Furco (2000, 2003) rubric, and the Bringle and Hatcher CAPSL matrix (2000), was designed for application at the institutional level. In 1997, Kecskes and Muyllaert developed a Benchmark Worksheet that was used repeatedly by 43 West Coast and Hawaiian college and university sub-grantees over a three-year period as part of the Western Region Campus Compact Consortium's Continuums of Service grant program. In the development of the Worksheet the authors maintained the concept of "levels of engagement" but reduced 
the number from four to three, which they called: Critical Mass Building (one); Quality Building (two); and Sustained Institutionalization (three). Also, they reduced the number of organizational factors, which they called "indicators," from seven to four: Faculty; Students; Institutional; and Evaluation.

In 2000, Andrew Furco, evaluator for the Western Region Campus Compact Consortium's Continuum of Service program, developed and published through National Campus Compact the Self-Assessment Rubric for the Institutionalization of Service-Learning in Higher Education. Furco (2002) observes that he utilized the rich data from the semi-annual Benchmark Worksheet responses of the 43 institutions involved in the Western Region Campus Compact Consortium program to create his rubric. The Furco rubric builds on the predecessors in two key ways: 1) it divides the organizational factors into broad "dimensions," and delineates associated "components" within those dimensions; and 2) it populates the cells of the rubric with short descriptions for each of the levels. Similar to Holland (1997) and Kecskes \& Muyllaert (1997), Furco also emphasizes that his rubric is not meant to be prescriptive. The Furco rubric also maintains the three-level approach and wording used by Kecskes \& Muyllaert (1997): Critical Mass Building (level one); Quality Building (level two); and Sustained Institutionalization (level three). Today, the Furco rubric has been used by over 200 higher education institutions globally and has been repeatedly adapted and translated into multiple languages. Table 1 delineates the "dimensions" and "components" of the original Furco rubric. 
Table 1: Dimensions and Components of the Furco Institutionalization Rubric

\begin{tabular}{|l|l|}
\hline \multicolumn{1}{|c|}{ Dimensions } & \multicolumn{1}{c|}{ Components } \\
\hline Mission and Philosophy & Definition of Service-Learning \\
\hline Faculty Support for and Involvement & Faculty Involvement \\
in Service-Learning & Faculty Support \\
& Faculty Leadership \\
& Faculty Incentives and Rewards \\
\hline Institutional Support for Service- & Coordinating Agent \\
Learning & Policy-Making Entity \\
& Staffing \\
& Reporting Lines \\
& Funding \\
& Administrative Support \\
\hline Student Support for and Involvement & Evaluation \\
\hline in Service-Learning & Student Awareness \\
& Student Incentives and Rewards \\
& Student Voice \\
\hline Community Participation and & Student Opportunities \\
Partnerships & Community Awareness \\
& Community Incentives and Rewards \\
& Community Agency Voice \\
& Community Status \\
& Mutual Understanding \\
\hline
\end{tabular}

Furco (2002) concluded that

Overall, more comprehensive study is needed to gain a deeper understanding of the dimensions that contribute most to the institutionalization of servicelearning in higher education. Although faculty and institutional issues appear to be primary in the institutionalizing of service-learning in higher education, the full range of factors must be considered. At the very least, new investigations should consider at least five interdependent dimensions that appear to be part of all campuses' institutionalization efforts (p. 62).

In 2003, Andrew Furco published a revised version of the original rubric published in 2000. Under the heading "Revisions to the Rubric," he notes that "the 2003 version maintains the rubric's original five dimension structure. The new version includes a new 'departmental support' component. This component was added to the rubric to 
reflect new insights regarding the important role departments play in the advancement of service-learning in higher education (Holland, 2000)." The 2003 revised version of Furco's rubric appears in Appendix B.

In 2000, Bringle and Hatcher developed and tested what is known as the Comprehensive Action Plan for Service-Learning (CAPSL) Matrix. The CAPSL model identifies four constituencies as being critical stakeholders in service learning (i.e., institution, faculty, students, community) and describes ten activities for each stakeholder: Planning; Awareness; Prototype; Resources; Expansion; Recognition; Monitoring; Evaluation; Research; and Institutionalization. This model is the most prescriptive in the literature. The authors suggest that the activities be accomplished in sequential order, although the authors do recognize that the diverse climate and cultures of multiple campuses make ordering somewhat tenuous. The structure of the CAPSL Matrix deviates significantly from the other five instruments that are explored as part of this literature review.

The four instruments discussed thus far (Holland, 1997; Kecskes \& Muyllaert, 1997; Furco 2000, 2003; and Bringle \& Hatcher, 2000) have all been developed to understand and/or assess service-learning at the institutional level. As mentioned, the 2003 revision of Furco's institution-wide rubric provided, for the first time in the literature, a venue for assessing "departmental support" as one of the components in the "institutional support" dimension.

In 2005, Gelmon, Seifer et al. developed and published Building Capacity for Community Engagement: Institutional Self-Assessment. This self-assessment is the 
most comprehensive of all of the instruments to be discussed. Broadly speaking, and with the exception of the Bringle \& Hatcher (2000) tool, this instrument is similar to the predecessors in the following ways: 1) it suggests a developmental approach as evidenced by the use of "levels"; 2) it maintains the overall structure of the Furco rubric in the use of broad "dimensions" and embedded "components," which are called "elements" in the self-assessment instrument; and 3) notwithstanding nuanced language differences, the first five dimensions largely mirror those of the Furco rubric. The Gelmon, Seifer et al. (2005) self-assessment builds on and differs from the Furco rubric and the others in the following major ways: 1) it increases the number of "levels" from three to four, mirroring Holland's (1997) original matrix; 2) it adds a completely new, sixth dimension called "Community-Engaged Scholarship"; 3) the self-assessment is explicitly intended to be used for building capacity for "community engagement," which reflects a clear shift away from a more narrow concern for service-learning only toward a widening understanding of the community engagement movement; and 4) the term "Institutional" used in the title of the instrument is defined as a generic term for the level of organization on which the assessment is focused (e.g., a department, college, school, or university). This represents the first time in the literature that scholars have created an instrument that is intended for use at different levels of organization within the academy instead of solely at the institutional level. The following six dimensions are included in the Gelmon, Seifer et al. (2005) selfassessment (see Appendix $\mathrm{C}$ for the complete Building Capacity for Community Engagement: Institutional Self-Assessment). 
I. Definition of Vision and Community Engagement (8 elements);

II. Faculty Support for and Involvement in Community Engagement (6 elements);

III. Student Support for and Involvement in Community Engagement (3 elements);

IV. Community Support for and Involvement in Community Engagement (6 elements);

V. Institutional Leadership and Support for Community Engagement (9 elements);

VI. Community-Engaged Scholarship (12 elements).

In the introduction to the instrument the authors note that the instrument is designed for use at multiple levels of organization in higher education (a department, college, school, university). This dissertation study differs in that its focus is to adapt a complimentary instrument for specific use at the department level. This approach is informed by the importance of the role of the academic department in the overall higher education community engagement reform agenda.

The most recent addition to the list of community engagement measurement instruments was published by Kecskes in 2006 (Characteristics of Engaged Departments Matrix). This matrix is descriptive in nature and was designed largely as a heuristic tool to increase understanding about the community-focused agenda of the academic department among its faculty, staff, students, and associated community partners. It was developed solely for academic departments interested in building community engagement. It follows the "dimension" and "component" format of most of the predecessors, yet does not provide a graduated scale for different stages of 
implementation. Rather, this framework provides only a brief description of an advanced level of implementation for each of the components and, thus, while useful for departments, constitutes a limitation for its broad utility and application. Indeed, in the creation of this matrix the author became aware of the need for a more robust and focused rubric that explores and explicates key dimensions and components of community-engaged departments and displays them along a self-ässessment continuum. That realization has provided the motivating inspiration for this dissertation study. The complete Characteristics of Engaged Departments Matrix is located in Appendix D of this study. The dimensions and components of the framework are summarized below in Table 2.

Table 2: Dimensions and Components of the Engaged Departments Matrix

\begin{tabular}{|l|l|}
\hline \multicolumn{1}{|c|}{ Dimensions } & \multicolumn{1}{|c|}{ Components } \\
\hline Unit dimension & Mission \\
& Visibility \\
& Leadership \\
& Collaboration \\
& Resource development \\
& Inventory \\
& Assessment \\
\hline Faculty dimension & Common understanding \\
& Rewards \\
& Research \\
& Articulation to students/community \\
& partners \\
\hline Student dimension & Common understanding \\
& Clarity of purpose \\
& Inclusion \\
& Leadership \\
\hline Community dimension & Common understanding \\
& Clear expectations \\
& Interaction \\
& Connection \\
\hline
\end{tabular}


The value of and need for the development of a department-focused instrument is further supported by literature concerning ecological correlations. William Robinson's (1950) landmark work with ecological correlations cautions against ecological fallacy, or interpreting data collected in an ecological study to make inferences about the nature of individuals based solely upon aggregate statistics collected for the group to which those individuals belong. This fallacy assumes that all members of a group exhibit characteristics of the group at large. Using census data from the 1930s, Robinson (1950) determined "that the thing described is the population of a state, and not a single individual. The variables are percentages, descriptive properties of groups, and not descriptive properties of individuals" ( $p$. 351). Robinson (1950) concluded his study with the following pragmatic reminder: "From a practical standpoint, therefore, the only reasonable assumption is that an ecological correlation is almost certainly not equal to its corresponding individual correlation" (p. 357). Taking Robinson's advice to heart in this study, one should avoid making the assumption that testing for the institutionalization of servicelearning or community engagement at the institution-wide level will provide sufficient data to draw conclusions at the individual (faculty) level, or by extension, about subgroups of the institution, such as academic departments. In short, the "unit of analysis" is critically important in the development of assessment instruments.

As Robinson (1950) argued more than a half century ago, ecological correlations do not provide us sufficient data and analysis regarding individuals and/or 
sub-groups within the population. Thus, given the importance of the academic department in the higher education reform agenda, the lack of specific attention to the development of diagnostic tools regarding the expressions of community engagement in academic departments constitutes a gap in the literature. As the review of the previous literature regarding the development of measurement instruments demonstrates, this gap still exists.

\section{Summary of Research Objectives and Questions}

The literature review undertaken in this chapter has briefly explored three areas: 1) a focused sub-set of the research and writing related to community engagement in higher education; 2) the role of academic departments in academic reform efforts; and, 3) the development of measurement instruments designed to assess or institutionalize service-learning and/or community engagement in higher education.

As discussed, there exists no concise tool designed specifically for members of academic departments to measure what community engagement might look like in their home department. Therefore, the overarching purpose of this dissertation is to help address this gap in the literature and, in doing so, increase our ability to better understand and quantify academic community engagement at the departmental level.

The strategy employed in this dissertation study is to build on the existing literature and utilize the active expertise of key informants, through an iterative 
process, to develop and qualitatively test the utility of a self-assessment rubric for the institutionalization of community engagement in academic departments.

The author's experience in the field of civic engagement and the literature raise the following central research questions:

1. Can a self-assessment rubric for the institutionalization of community engagement be specifically designed for academic departments?

2. If so, what are the broad dimensions of community engagement that need to be included at the departmental level? And, within those dimensions, what key constructs, or components must be present and sufficiently explicated?

3. Finally, can the utility and validity of the new instrument be confirmed by using qualitative methods (Charmaz, 2006) to evaluate the responses from pilot-test social science departments located at five urban, geographically-diverse, Carnegie-classified community engaged, public higher education institutions?

In the pursuit of responses to these questions, this study makes certain assumptions and treats others as problematic. First, it assumes that community engagement in higher education is increasingly re-emerging as a key component in the overall landscape of American higher education. It assumes that the academic disciplines and, on campuses, academic departments play a critical role in institutionalizing community engagement on campuses. It also assumes that the various self-assessments, frameworks, matrices and other types of extant instruments 
serve their intended purposes well at the institutional level, and perhaps at other organizational levels as well. Finally, it assumes that the development of a selfassessment rubric specifically designed for application in academic departments will add significantly to the literature as well as provide academic units with both a heuristic and assessment instrument to support reform efforts toward increased community engagement in the unit.

The study treats as problematic the elements of departmental community engagement and the development of a useful self-assessment instrument that can assist in the development and measurement of that engagement. These problems will be explicated more fully in the next chapter, which sets forth the research methodology used for this study. 


\section{CHAPTER III: METHODS}

This chapter elaborates more fully on the methodology used in this study, including the two-phase (or two-pronged) research strategy. The first section of the chapter discusses the decision to use a qualitative research approach and the accompanying issues of validity and transferability that arise when using qualitative research. The next section of the chapter discusses the development of the conceptual framework for the study. This will be followed by a specific discussion of the key elements in phase-two of the research project, including the design, setting, subjects, measures, method of data collection, and analysis. The chapter concludes by reviewing the central research questions and explicitly links these questions to the responses to them in the data collected in phases one and two.

\section{Research Strategy}

The overarching purpose of this dissertation is to help scholars' and practitioners' better understand and quantify community engagement at the organizational level of the academic department. In order to accomplish this task the study utilizes a two-phase qualitative, grounded theory (Charmaz, 2006) research strategy.

The purpose of phase one is to build a conceptual model or explanatory framework (the Rubric) by using an inductive, iterative process involving the expertise of key informants (Wagner \& Sternberg, 1985) and existing literature germane to this topic. The iterative process employed in phase-one includes three steps: 
identification, integration, and confirmation. In step one (identification), a grounded theory approach (Charmaz, 2006) is used to evaluate interviews with experts/key informants in order to determine major themes, dimensions and components for the Rubric. In step two (integration) the themes established in step one are integrated with the categories, dimensions and themes from the existing literature. Finally, in step three (confirmation) the experts/key informants is again utilized, but this time to refine and confirm the organization of the Rubric. Phase-one of the research strategy directly addresses central research questions one and two of this dissertation study.

Phase-two of the research strategy directly addresses the third and final central research question of this study by utilizing a deductive, qualitative approach to empirically test the utility and validity of the conceptual model. In this phase of the research a grounded theory approach is used to elicit and evaluate the responses from twelve social science departments located in five urban, public, Carnegie-classified engaged higher education institutions from diverse geographic areas in the United States.

\section{Qualitative Research}

Strauss and Corbin (1998) describe qualitative research as a "type of research that produces findings not arrived at by statistical procedures or other means of quantification. It can refer to research about persons' lives, lived experiences, behaviors...as well as about organizational functioning, social movements... and interactions" (p. 10-11). Strauss and Corbin (1998) explain that there are many 
reasons for doing qualitative research, including "attempt[ing] to understand the meaning or nature of persons...to explore substantive areas about which little is known or about which much is known to gain novel understanding...to obtain the intricate details about phenomena...that are difficult to extract or learn about through more conventional research methods" (p. 11). Grounded theory is a specific type of qualitative research.

As Charmaz (2006) explains, grounded theory methods emerged from sociologists Barney G. Glaser and Anselm L. Strauss's (1967) successful collaboration during their studies of dying in hospitals. Grounded theory countered the predominant methodological assumptions based on mid-twentieth century positivist conceptions of scientific method that stressed objectivity, replication of research and falsification of competing hypotheses and theories. For Glaser and Strauss (1967; Glaser, 1978; Strauss, 1987) the defining components of grounded theory include simultaneous involvement in data collection and analysis, constructing analytic categories from data, and using constant comparative methods to make comparisons at each stage of analysis. Charmaz (2006) extends Glaser and Strauss's work by assuming an interactionist theoretical perspective. Charmaz "assume[s] that neither data nor theories are discovered. Rather, we are part of the world we study and the data we collect. We construct our grounded theories through our past and present involvements and interactions with people, perspectives, and research practices" (p. 10). For this reason, among others, a grounded theory is especially appropriate for use by experienced practitioners who rely on their personal experience to shape the 
categories of analysis and the interpretation of the data that is collected. As Charmaz (2006) notes in using grounded theory, it is important for the researcher to gain familiarity with subjects or subject-related material. In this way, over a series of years of close and repeated experience with ill patients, Charmaz was able to write her landmark work on individuals with chronic diseases, Good Days, Bad Days: The Self in Chronic Illness and Time (1991). In similar fashion, the familiarity of the author of this study with the subject of community engagement in higher education settings enhances the construction of the categories of analysis and the interpretation of study findings.

In contrast to traditional scientific theory, which describes and explains events in abstract, generalized terms, grounded theory aims to provide a set of principles that enable actors to understand real situations and make decisions about how to act in the face of complexity (Craig \& Tracy, 1995). Finally, Strauss and Corbin (1998) argue that "theory derived from data is more likely to resemble the 'reality'... and grounded theories, because they are drawn from data, are likely to offer insight, enhance understanding, and provide a meaningful guide to action" (p. 12, italics added).

\section{Issues of validity and transferability in qualitative research}

Johnson (1997) argues that "when qualitative researchers speak of research validity, they are usually referring to qualitative research that is plausible, credible, trustworthy, and, therefore, defensible" (p. 160). The three-step iterative process in phase-one of this study was intentionally designed to create an explanatory framework 
that is plausible, credible, trustworthy, and defensible, thereby establishing support for all three main types of validity in qualitative research: descriptive, interpretative, and theoretical validity (Johnson, 1997).

This study follows Wagner \& Sternberg's (1985) strategy of utilizing experts/key informants to both generate initial data and later refine and confirm the construct validity of the explanatory framework their expertise help generate. Maxwell (2005) refers to this strategy as "respondent validation" (p. 111) and suggests that this process helps counter the two main threats to validity in qualitative research: researcher bias and reactivity. Johnson (1997) discusses three type of validity in qualitative research: descriptive, interpretative, and theoretical validity. Descriptive validity refers to the factual accuracy of the account. Interpretive validity is obtained to the degree that the participants' viewpoints are accurately understood and reported. Theoretical validity is obtained to the degree that a theoretical explanation fits that data and is therefore credible and defensible.

This study employs several strategies to increase the validity of the research, including: 1) respondent validation, or what Johnson (1997) terms "participant feedback" (p. 161); 2) the use of rich data (Maxwell, 2005) or low-inference descriptors (Johnson, 1997) which are descriptions phrased very close to participants' accounts; 3) reflexivity or critical self-reflection of the researcher to "minimize the influence of the interviewer and the interview situation" (Maxwell, 2005, p. 109); and 4) triangulation, or use of multiple sources of information to corroborate findings 
(Charmaz, 2005; Johnson, 1997; Lincoln and Guba, 1985; Maxwell, 2005; Miles and Huberman, 1993).

The transparent process of beginning with and sticking close to the data, developing and refining codes and raising them to the theoretical level of relationships validates qualitative research and generates "generalizable theoretical statements" (Charmaz, 2006, p. 46), or, as Maxwell (2005) argues, creates "face generalizability" (p. 115). Lincoln and Guba (1985) prefer to use the term "transferability" when discussing the application of findings to other cases or contexts. They argue that qualitative researchers "cannot specify the external validity of an inquiry; [they] can provide only the thick description necessary to enable someone interested in making a transfer to reach a conclusion about whether transfer can be contemplated as a possibility" (p. 316). Further, they suggest that the researcher "can only set out working hypotheses together with a description of the time and context in which they were found to hold. Whether they hold in some other context, or even in the same context at some other time, is an empirical issue, the resolution of which depends upon the degree of similarity between sending and receiving (or earlier or later) contexts" (p. 316).

At the most fundamental level, this dissertation study is intended to create one of the "meaningful guides to action" (p. 12) referenced by Strauss and Corbin (1998). As discussed in the previous chapter, a guiding supposition driving this study is that focusing assessment and development efforts for community engagement at the organizational level of the academic department is critically important for continuing 
to bring about durable, positive change in higher education. Thus, it follows that creating, empirically testing, and eventually disseminating an effective self-assessment rubric for developing community-engaged departments is an important next step for scholars and practitioners working in the field of community engagement in higher education. The process of creating the effective self-assessment rubric is the focus of phase-one of this research.

\section{Phase One: Building a Conceptual Model}

As discussed in the literature review chapter, extant assessment instruments associated with community engagement at the institutional level feature many common themes, dimensions and/or components. Yet, while none of these efforts focuses specifically on assessing community engagement at the organizational level of the academic department, it is logical to assume that some of the common themes might be applicable to the development of a self-assessment rubric for use at the departmental level. However, how can it be determined which of the existing themes, dimensions, and components, if any, are applicable?

To respond to this question, the three-step process in phase-one of the study follows Charmaz' (2006) suggestion to:

- Step One: begin with data collection and analysis;

- Step Two: check initial category development based on the raw data with categorical schemes from the present literature; and finally, 
- Step Three: confirm the dependability and validity of the conceptual model (Lincoln and Guba, 1985). This phase of the study used participant feedback to examine "the researcher's interpretations and conclusions ...for verification and insight" (Johnson, 1997, p. 161). Charmaz (2006) describes this as a process of "abductive inference...to pursue the most plausible explanation" (p. 104).

Step One: Collection and Analysis of Initial Data

Following Wagner \& Sternberg's (1985) and Sternberg et al. (2000) argument for the use of experts/key informants in the development, refinement and confirmation of criterion measures of performance, this study identified nine experts from whom to gather data, feedback and confirmation concerning measurement criteria for departmental engagement. A list of the nine experts selected for this study, the date of interview, and a brief accounting of the connection of their particular area of expertise to this study and justification for their inclusion appears in Table 3.

Table 3: Experts/Key Informants

\begin{tabular}{|l|l|}
\hline $\begin{array}{l}\text { Expert/Key Informant } \\
\text { and Interview Date (in } \\
\text { parenthesis) }\end{array}$ & $\begin{array}{l}\text { Area of expertise/Brief justification for } \\
\text { inclusion }\end{array}$ \\
\hline $\begin{array}{l}\text { Richard Battistoni, } \\
\text { Providence Collage } \\
(3 / 05 / 07)\end{array}$ & - $\begin{array}{l}\text { Nationally recognized expert on service- } \\
\text { learning, community engagement, and } \\
\text { political engagement. } \\
\text { Co-author: The Engaged Department } \\
\text { Toolkit (2003) }\end{array}$ \\
\hline $\begin{array}{l}\text { Amy Driscoll, } \\
\text { Consulting Scholar, } \\
\text { Carnegie Foundation for }\end{array}$ & $\begin{array}{l}\text { Nationally recognized expert on service- } \\
\text { learning, community engagement, and } \\
\text { assessment. }\end{array}$ \\
\hline
\end{tabular}




\begin{tabular}{|c|c|}
\hline $\begin{array}{l}\text { the Advancement of } \\
\text { Teaching } \\
(3 / 06 / 07)\end{array}$ & $\begin{array}{l}\text { Author: Carnegie Community Engagement } \\
\text { Classification Framework (2006) }\end{array}$ \\
\hline $\begin{array}{l}\text { Andrew Furco, } \\
\text { University of Minnesota } \\
(2 / 19 / 07)\end{array}$ & $\begin{array}{l}\text { - Nationally recognized expert on service- } \\
\text { learning, community engagement, and } \\
\text { institutional engagement. } \\
\text { Author: Self-Assessment Rubric for the } \\
\text { Institutionalization of Service-Learning in } \\
\text { Higher Education (2003) }\end{array}$ \\
\hline $\begin{array}{l}\text { Sherril Gelmon, } \\
\text { Portland State } \\
\text { University } \\
(2 / 19 / 07)\end{array}$ & $\begin{array}{l}\text { Nationally recognized expert on service- } \\
\text { learning, community engagement, } \\
\text { institutional engagement and assessment. } \\
\text { - Co-author: The Engaged Department } \\
\text { Toolkit (2003) } \\
\text { - Lead author on CCPH assessment }\end{array}$ \\
\hline $\begin{array}{l}\text { Barbara Holland, } \\
\text { National Service- } \\
\text { Learning Clearinghouse } \\
(2 / 26 / 07)\end{array}$ & $\begin{array}{l}\text { - Nationally recognized expert on service- } \\
\text { learning, community engagement, and } \\
\text { assessment. } \\
\text { - Author: “Analyzing Institutional } \\
\text { Commitment to Service: A Model of Key } \\
\text { Organizational Factors." (1997) } \\
\text { Member of author's dissertation } \\
\text { committee. }\end{array}$ \\
\hline $\begin{array}{l}\text { Steve Jones, Indiana } \\
\text { University-Purdue } \\
\text { University Indianapolis } \\
(2 / 20 / 07)\end{array}$ & $\begin{array}{l}\text { Nationally recognized expert on service- } \\
\text { learning and community engagement. } \\
\text { Co-Author: Quick Hits for Educating } \\
\text { Citizens (2006) }\end{array}$ \\
\hline $\begin{array}{l}\text { John Saltmarsh, New } \\
\text { England Resource } \\
\text { Center for Higher } \\
\text { Education, University of } \\
\text { Massachusetts, Boston } \\
(1 / 18 / 07)\end{array}$ & $\begin{array}{l}\text { - Nationally recognized expert on service- } \\
\text { learning and community engagement. } \\
\text { Co-author: The Engaged Department } \\
\text { Toolkit (2003) }\end{array}$ \\
\hline $\begin{array}{l}\text { Jon Wergin, Antioch } \\
\text { University } \\
(2 / 19 / 07)\end{array}$ & $\begin{array}{l}\text { - Nationally recognized expert on academic } \\
\text { departments. } \\
\text { - Co-author: The Engaged Department } \\
\text { Toolkit (2003) }\end{array}$ \\
\hline $\begin{array}{l}\text { Edward Zlotkowski, } \\
\text { National Campus } \\
\text { Compact, Bentley } \\
\text { College } \\
(1 / 16 / 07) \\
\end{array}$ & $\begin{array}{l}\text { Nationally recognized expert on service- } \\
\text { learning and community engagement. } \\
\text { - Co-author: The Engaged Department } \\
\text { Toolkit (2003) }\end{array}$ \\
\hline
\end{tabular}




\section{Initial Data Collection}

Between January 16 and March 6, 2007, interviews were conducted: two faceto-face interviews, one with Dr. Sherril Gelmon and the other with Dr. John Saltmarsh, and phone interviews with each of the other key informants for this study. Each interviewee was asked two open-ended questions. 1) If you were assessing or evaluating an academic department and wanted to determine if it was a communityengaged department what indicators would you look for? 2) If you were asked to determine if an effort toward departmental engagement were going to be sustained what particular indicators (e.g., structures, skills, knowledge, attitudes, activities, etc.) would you look for in order to make an assessment? Copious, detailed, hand-written notes were taken during each interview; these notes were then transferred shortly after the interview to an electronic word processing file. The amount of time involved in conducting the interviews ranged between approximately 20 and 100 minutes, and most interviews were completed in approximately 45 to 50 minutes.

\section{Coding the Data}

The data were then coded following a grounded theory approach. According to Charmaz (2006), coding in qualitative research is "the process of defining what the data are all about'" (p. 43). Coding is a systematic process that allows the researcher to "make an interpretative rendering that...illuminates studied life" (p. 43). Coding is a critical step in theory building. Charmaz (2006) argues that the "codes take form together as elements of a nascent theory that explains these data....By careful attention 
to coding, [the researcher] begin[s] weaving two major threads in the fabric of grounded theory: generalizable theoretical statements that transcend specific times and places and contextual analyses of actions and events" (p. 46). This study uses these two fundamental processes to build a theoretical model, or explanatory framework for departmental engagement. Charmaz (2006) observes that "grounded theory consists of at least two main phases: 1) an initial phase involving naming...followed by 2) a focused, selective phase that uses the most significant or frequent initial codes to sort, synthesize, integrate, and organize large amounts of data" (p. 46). Finally, building on Glaser (1992), Charmaz (2006) suggests that once the focused codes have been developed, the researcher uses theoretical coding to "specify possible relationships between categories [that have been] developed during focused coding" (p. 63).

\section{Analysis of the initial data}

Table 4 outlines and summarizes the initial codes that were generated by a line-by-line (initial) coding process (Charmaz, 2006) of the nine expert/key informant interviews. It is important to display this information transparently so the reader can follow the process from the initial stages of coding through to the end product of theoretical code and ultimately Rubric development.

\section{Table 4 - Initial Codes from expert/key informant interviews}

- Consensus on importance of community engagement

- Critical mass of departmental members

- Accountable definition

- Partnerships (reciprocal) at the individual and collective (departmental) levels

- Intentional curricular integration strategy (developmental curriculum)

- Community-based research ("transdisciplinary research") 
- Faculty roles and rewards (RPT) - at institutional and departmental levels

- Leadership (of departmental faculty) in the larger university

- Internal "democratic practices" (at the departmental level)

- Student voice and leadership opportunities

- Documents and documentation of civic engagement available

- Consistency of alignment between word and action

- Departmental mission

- Programming to support civic engagement

- Budget and fiscal support

- Hiring practices (advertisement and interview protocols that mention community engagement)

- Marketing materials

- Reciprocal partnerships

- Assessment strategies in place (including alumni activity tracking)

- "Climate and Culture" - reflective practices within the department

- Organizational culture and behavior (healthy communication strategies)

- Intentionality

- Empowering culture in department

- Faculty leadership at national level - influencing of the discipline at the national level

- Sense of collective responsibility

- Scholarship of engagement

- Coherent departmental agenda (departmental goals)

- Sense of safety for trying new pedagogies, research strategies

- Awareness of "the mosaic" of community engagement activities

- Tolerance among members of the department

- Curricular learning goals articulation

- Multiple, diverse faculty interest in the unit

- Consensus decision making strategies at the unit level

- Collective self-awareness ('Does the department know itself?')

- Student activity in the community that is connected to the unit - curricular and co-curricular (programming)

- Expanded sense of epistemology to include community partners (and students) as valid knowledge sources

- Discourse on community engagement evident on regular departmental agendas

- New faculty recruitment

- Community partners seen as resources to the department

- Student-faculty connections in meaningful community projects

- Evidence of impacts

The next step of the grounded theory analytic process is to engage in focused

coding (Charmaz, 2005). This study employed a specific, three-step strategy to create 
the focused codes. First, similar initial codes were grouped together via a standard analytic grouping strategy. Second, broad categories were identified that best characterized the themes of the groupings established in step one discussed above. Finally, the power of each initial and focused code, and thereby the power of each of the associated groupings, was established by ascertaining and noting the number of times a particular theme or response/theme category was mentioned by the experts/key informants. The numerical values below in the table of focused codes represent the number of experts/key informants that identified this theme (e.g., a " 6 " means that 6 of the 9 interviewees mentioned this theme). The themes and focused codes are listed in priority order of strength, as determined by amount of times the themes or codes were identified by the interviewees. Table 5 represents the focused codes that emerged from this inductive process; and * and bolding of the code indicates a theme that has not been previously addressed in existing instruments.

\section{Table 5: Focused codes from experts/key informants}

6- Roles and Rewards (Promotion \& Tenure)

At the departmental level (vs. at institutional level)

Active support of a unit as a whole for the "scholarship of engagement"

(willingness to "go to bat" for faculty involved in community-based activities)

Engagement is expected for faculty evaluation purposes

6- Commitment - Mission - Collective Responsibility

\section{5- Curriculum}

* 4- Intentional and developmental approach Curricular coherence

First- to senior-year integration (including, for example, "capstones") Multiple courses

5- Community-based research (community-engaged research) Includes: "transdisciplinary research, and view of community partners as valid knowledge sources

5- Faculty recruitment and hiring practices, including:

Orientation to engagement expectations for new faculty hires 
Engagement evident in advertising, interview protocols, letters of offer, etc 5- Budgetary allocation for community engagement, at departmental level

4- Partnerships

Recognition of inherent risks

Recognition of extra time requirements

Individual faculty level

Structured integration into core department roles (e.g., on hiring committees)

Visibility of partnerships (marketing, committee participation, etc.)

Long-range goals that intentionally affect community issues

3- Valued as having role in (co-educators) students' learning

* 3- (Core) Department-level community partnerships

* 4- Marketing (Articulation of community engagement in brochures, web sites, etc)

* 4- Reflective practices/self awareness (reflections/adjustment) within the department

3- Faculty count - empirical count of faculty involved in community engaged activities

3- Definition of community engagement (shared understanding)

3- Articulation: community learning outcomes are clearly defined

* 3- Climate and culture (organizational culture), including: collaborative spirit, open communication, civic discourse, acceptance of "difference," collective responsibility

Leadership

* 3- faculty demonstrate leadership on national disciplinary association in support of community engagement (on committees, as disciplinary publication editors, special interest group leadership, conference planning committees, etc)

2- campus-level leadership (e.g., pushes scholarship of engagement integration into promotion and tenure policies while serving on university committees

Students

* 2- multiple opportunities for "public work"

* 2- (in)formal roles in departmental structures (voice- in curriculum, projects, etc.)

* 3- Value "students as colleagues" in co-teaching and research roles

2- Course count - empirical measure of number of community-based learning courses offered in the department

2- Departmental meetings (engagement is regularly evident as agenda item)

2- Strategic planning for engagement at the departmental level

2- Leadership from chair (to ensure open discourse, planning, promotion \& tenure integration, budgetary considerations, etc.)

2- Assessment mechanisms/evidence, including:

On-going and coordinated in linked courses

Exit interviews of students in the majors

Student learning outcomes 
Alumni interviews -5 years out

Public forums (convening function, multiple audience including students and public)

1- Visible documents of partnership work displayed

2- Disciplinary history and disciplinary bias awareness

1-Accountability - designated point person for community engagement in department

1- Skills: values civic as much as traditional disciplinary skill set

1- Internal democratic practices, including for professional staff and students

1 - Senior faculty role (including chair)

Step Two - Integrating emergent themes/focused codes with extant literature

Charmaz (2006) suggests that grounded theory researchers turn to the literature only after focused codes have been established. Further, she argues that the constructs from the literature must earn their way into the researcher's grounded theory. Thus, as discussed in the previous chapter, this study examined the major engagement assessment instruments and outlined in detail their major (consistent) themes, dimensions, and categories present. The next step, therefore, for the development of the explanatory framework associated with this study (the Rubric) was to determine the extent to which themes, dimensions, and categories present in the existing literature map to the focused codes that emerged from the expert/key informant interviews via theoretical coding. Charmaz (2006) suggests that once the focused codes have been developed, the researcher uses theoretical coding to "specify possible relationships between categories [that have been] developed during focused coding" (p. 63). The information in Table 6 below summarizes the possible relationships and demonstrates the initial integration associated with this theoretical coding step. It is important to note at this point that this study assumed a standard practice in survey research, which suggests that the survey developer keep intact as much of the original 
instrumentation as is reasonable and efficient. Therefore, whenever possible, the major "dimensions" identified below (bolded in Table 6) are intentionally drawn from the extant literature. In keeping with this principle of building on accepted categories and rubrics, the author intentionally chose much of the specific language in the cells of the Rubric because of its widespread use and acceptance by community engagement scholars. This reliance wherever possible on the work of others presents the researcher with a creative tension between a grounded theory approach to ensure that the codes emerge from the raw data on the one hand, and a pragmatic step by the researcher to follow standard survey instrument development protocols on the other. The researcher has sought to capture this tension in Table 6 by identifying the major themes from the literature in bold, and organizing the original codes that emerged from the raw data into clustered subthemes within the broader major themes found in the literature.

Clearly, relationships among and within the focused codes and themes/dimensions from the literature become evident at this step.

\section{Table 6: Theoretical Coding and Integration of Themes with Extant Literature}

\section{- Mission, Climate and Culture}

6- Commitment - Mission - Collective Responsibility

4- Reflective Practices/Self Awareness (reflections/adjustment)

3- Definition (shared understanding)

3- Climate and Culture (organizational culture), including: collaborative spirit, open communication, civic discourse, acceptance of "difference," collective responsibility Leadership

2- Disciplinary history and disciplinary bias Awareness

1- Internal democratic practices, including for professional staff and students

- Faculty Support for (commitment to) Community Engagement

3- Faculty count - \#

2- Course count - \#

\section{Community-Engaged Research}


6- Roles and Rewards (P \& T)

At the departmental level (vs. at institutional level)

Active support of department as a whole for scholarship of engagement

(willingness to "go to bat" for community-engaged faculty)

Engagement is expected for evaluation purposes

5- Community-based research (includes: "transdisciplinary research, and community partners as valid knowledge sources

Curricular Integration for Community Engagement

5- Curriculum

4- Intentional and developmental approach

Curricular coherence

First- to senior-year integration (capstones)

Multiple courses

1- Skills: values civic as much as traditional disciplinary skill set

3- Civic learning outcomes are clearly articulated

- (Community) Partner and Partnership Support for Community Engagement

4- Partnerships

Recognition of inherent risks

Recognition of extra time requirements

Faculty level, individual

3- (Core) Department-level community partnerships

Visibility of partnerships

Long-range goals that affect community issues

3- Community partners valued as having role in (co-educators) students'

learning

4- Structured integration into core department roles (e.g., on hiring

committees)

1- Senior faculty role (including the role of the chair)

- Student Support for Community Engagement

Students

3- Value "students as colleagues" in co-teaching and research roles

2- Multiple opportunities for "public work"

2- (In)formal roles in departmental structures (voice- in curriculum, projects, etc.)

- Programmatic Support (and evidence?) for Community Engagement (budget, assessment, marketing.

5- Hiring practices, including:

Orientation to engagement for new faculty hires

Engagement evident in advertising, interview protocols, letters of offer, etc. 
5- Budgetary allocations at departmental level in support of community engagement

4- Marketing (articulation in brochures, web sites, etc)

2- Departmental meetings (engagement regularly is evident as agenda item)

2- Strategic planning for engagement at the departmental level

Evidence

2- Public forums (convening function, multiple audience including students and public)

1- visible documents of partnership work displayed

Assessment mechanisms, including:

On-going and coordinated in linked courses

Exit interviews of students in the majors

Student learning outcomes

Alumni interviews -5 years out

1-Accountability - point person

- Leadership

2- (Internal department level) Leadership from chair (to ensure open discourse, planning, promotion and tenure integration, budgetary allocations, etc)

2- (Campus-level leadership) Advocates for scholarship of engagement recognition and integration on university committees

3- (National level) Demonstrates national disciplinary association leadership (on committees, publication editors, special interest group leadership, conference planning committees, etc.)

The final step in this theoretical coding phase is to determine the main dimensions and embedded component parts for the explanatory framework and then fill in the individual cells with descriptions of each stage of development. Table 7 below outlines the six dimensions and a set of components that characterizes each dimension. Components specific to departmental engagement are underlined; components closely associated with departmental engagement are italicized. 
Table 7: Dimensions and Components of the Explanatory Framework (the Rubric)

\begin{tabular}{|c|c|}
\hline DIMENSIONS & COMPONENTS \\
\hline $\begin{array}{l}\text { I. Mission and Culture Supporting } \\
\text { Community Engagement }\end{array}$ & $\begin{array}{l}\text { - } \text { Mission } \\
\text { - Teachinition of Community Engage } \\
\text { - Definition of Community Engage } \\
\text { - } \text { Desearch } \\
\text { Definition of Community Engage } \\
\text { - Climate and Culture } \\
\text { - Collective Self-Awareness } \\
\end{array}$ \\
\hline $\begin{array}{l}\text { II. Faculty Support and Community } \\
\text { Engagement }\end{array}$ & 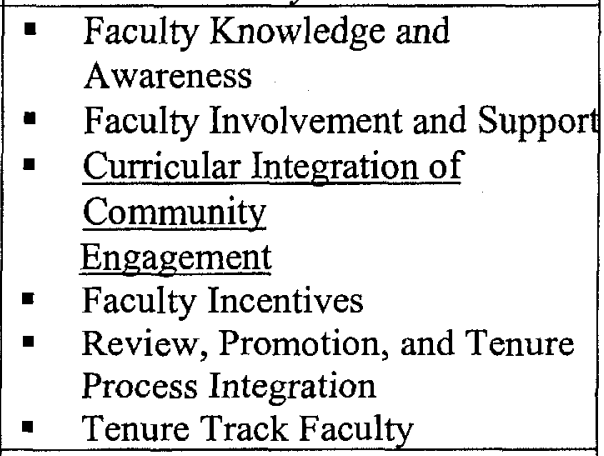 \\
\hline $\begin{array}{l}\text { III. Community Partner and Partnership } \\
\text { Support and Community Engagement }\end{array}$ & 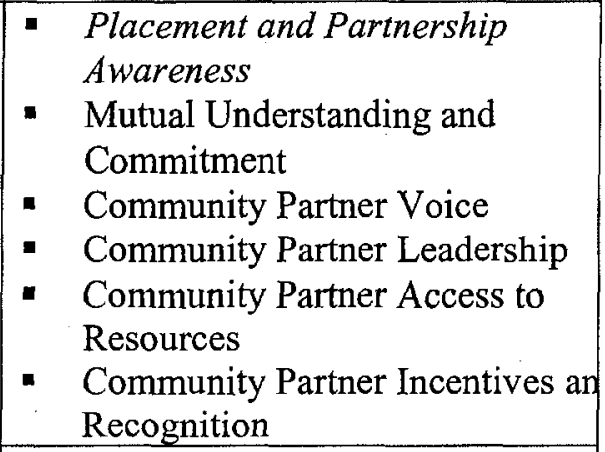 \\
\hline $\begin{array}{l}\text { IV. Student Support and Community } \\
\text { Engagement }\end{array}$ & 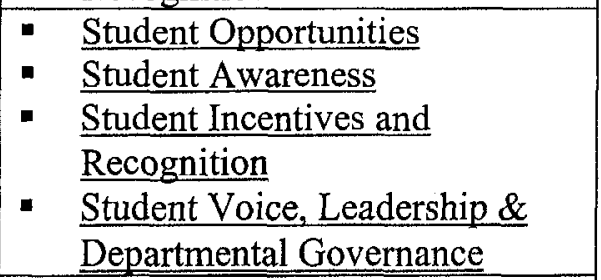 \\
\hline $\begin{array}{l}\text { V. Organizational Support for Communit } \\
\text { Engagement }\end{array}$ & $\begin{array}{ll}\text { - } & \text { Administrative Support } \\
\text { - } & \text { Evalitating Entity } \\
\text { - } & \text { Departmental Planning } \\
\text { - } & \text { Faculty Recruitment and } \\
\text { - } & \text { Markentation } \\
\text { - } & \text { Dissemination of Community }\end{array}$ \\
\hline
\end{tabular}




\begin{tabular}{|l|l|}
\hline & $\begin{array}{l}\text { Engagement } \\
\text { Results } \\
\end{array}$ \\
\hline $\begin{array}{c}\text { VI. Leadership Support for Community } \\
\text { Engagement }\end{array}$ & $-\frac{\text { Department Level Leadership }}{\text { Campus Level Leadership from }}$ \\
\hline & $-\frac{\text { Departmental Faculty }}{\text { National Level Leadership from }}$ \\
\hline
\end{tabular}

Finally, based largely on the literature, the researcher decided that each component needed to be divided into four cells representing four stages of development. The first is an "awareness building" stage; the second is a "critical mass building" stage; the third is a "quality building" stage; and finally, the fourth is an "institutionalization" stage. The four "phases" are based on the scholarly literature on best practices with respect to commitment to community engagement (Furco, 2000, 2003; Gelmon \& Seifer et al., 2005; Holland, 1997; Kecskes \& Muyllaert, 1997).

As noted previously, there was a tension between allowing the language of the data to direct the creation of the specific components and language in the cells of the Rubric versus directly using or adapting the language that is present in other rubrics in the existing literature. Where the theoretical codes from the data largely matched the themes and categories from the literature, the existing language from the categories/cells was intentionally utilized. When this was not practical or possible, new language was developed and incorporated to elucidate the meaning and progressive stages of the new components. In the following section the reader will see that the original source data for the specific components, and language in the cells associated with those components has been identified and documented. This detailed scholarly work to specifically cite the source of each component was undertaken at the 
recommendation of one of the key informants. A more thorough discussion of this process as well as a presentation of the overall feedback from all of the key informants is presented in the next section. Once the overall new explanatory framework was formatted with new or adapted components and language in the cells of the components, the first complete draft of the Rubric was ready for participant feedback from the experts/key informants.

Step Three - Using Participant Feedback to Revise and Confirm the Conceptual Model (Rubric)

As noted earlier in this chapter, this study employs an intentional strategy of participant feedback (Johnson, 1997) to increase "trustworthiness" (Lincoln \& Gupa, 1985), dependability, and credibility of the research. In qualitative research, this strategy increases the content validity of the instrument (Charmaz, 2006; Maxwell, 2005).

In the spring, 2008, the draft explanatory framework was sent to the experts/key informants with the request for verification, recommendations, clarifications, articulation of concerns, etc. Responses were received in the form of within-text edits, written summary observations, phone conversations or a combination of the above. There were three major types of responses from the experts/key informants:

1) Distinction between cells: Some concerns were expressed about the meaning of language with accompanying recommendations regarding specific distinctions 
between stages of some of the components. For example, a common response was that the use of language to differentiate between two or more particular stages of a component was not sufficiently different to enable the end user to substantively distinguish between cells (stages).

2) Ordering of components: It was suggested that the ordering of the components within the "organizational support for community engagement" dimension did not follows a logical progression. Therefore, the following order was established based on key informant feedback:

- Administrative Support

- Facilitating Entity

- Evaluation and Assessment

- Departmental Planning

- Faculty Recruitment and Orientation

- Marketing

- Dissemination of Community Engagement

- Results

- Budgetary Allocation

The rationale for this ordering follows the logic that for community engagement to be implemented at the departmental level, the first step requires "infrastructural support and facilitation." This includes the administrative support, facilitating entity and evaluation and assessment. Next, it was suggested that planning was a critical "hinge activity." The final stage of departmental implementation is "broadcasting." This stage is characterized by faculty recruitment (announcing to faculty), marketing (announcing broadly to external entities), dissemination of community engagement results (the representation of the commitment), and budgetary allocation. 
3) Crediting prior scholarly work: It was suggested that the explanatory framework be footnoted in a way that clearly elucidates the various primary sources of intellectual content that influenced the development of the Rubric. Thus, the final version of the explanatory framework features four primary, footnoted sources. A footnote at the bottom of each one of the six dimension pages reads: “Adapted by Kevin Kecskes, Portland State University, 2008. Components based on the (1) Gelmon, Seifer et al., Building Capacity for Community Engagement: Institutional Self-Assessment, 2005;(2) the Furco Service-Learning Institutionalization Rubric, 2003;(3) the Kecskes Characteristics of Engaged Departments Matrix, 2006; (4) and key informant interviews, 2008." This particular section of the self-assessment Rubric follows in Table 8. The complete version of the Rubric (which, in addition the section below, includes an introduction, references, and the six survey questions) is included in Appendix E. 


\section{Phase Two: Testing the Utility of the Conceptual Model}

Phase-two of this research involves testing the utility and validity of the conceptual model by means of a deductive approach using a purposeful sampling strategy. Using the Rubric, twelve social science departments are categorized based on self-evaluations of their respective department's relative levels of institutionalization of community engagement. In addition, participants' feedback from each department on the usefulness of this instrument for capturing institutionalization of community engagement in their academic unit is presented.

The next section will briefly discuss the study design, setting, subjects, measures, data collection, and analysis of phase-two of this research.

\section{Research Design}

The design of the second phase of the research strategy is a one-shot case study typically used in educational research (Campbell \& Stanley, 1963). This approach allows the researcher to test the applicability of the instrument at a single point in time with a discrete group of subjects. According to Campbell \& Stanley $(1963$, p. 8), in the typical educational research study a design that does not include a control group can be criticized for not addressing threats to internal validity (history, maturation, selection, and subject mortality) or to external validity (interaction of subject selection and treatment). However since the present study does not involve either an explicit or implicit assumption of some kind of treatment effect, this basic case study design is adequate for the requirements of this research. 
Setting and Subjects

As a point of clarification, in this study "setting" refers to a specific higher education institution and "subject" refers to a specific academic department. To determine the settings and subjects for this phase-two of this study a purposeful sampling strategy was developed. Based on discussions with key informants, professional colleagues, and research associates, a set of inclusion factors was developed in order to limit the number of possible confounding factors. This strategy also limits the transferability of these research findings. This topic will be revisited in the discussion on limitations of the study in chapter five.

The following criteria were used in determining the universities that would be targeted to participate in his study:
a) from geographically diverse sections of the United States,
b) urban,
c) public,
d) comprehensive, and
e) Carnegie classified for community engagement.

While insuring diversity in responses, this strategy also eliminates a number of potentially confounding factors associated with widely divergent institutional contexts (e.g., private, faith-based institutions vs. public institutions, or two-year colleges vs. four-year doctoral-granting institutions, and so on). A brief discussion of each of the specific inclusion factors follows. 
The first inclusion factor was that participating universities needed to be located in different parts of the country. Thus, the five higher education institutions included in this study were intentionally selected to represent diverse geographic areas of the United States, including the South, the North, the Midwest and the Pacific Northwest. This strategy was employed to increase the potential transferability of the findings to departments located in a similar range of geographical locations.

Next, only public institutions were selected. The rationale for this choice is that public institutions arguably have a sense of public mission and implicit in those missions is a sense of responsibility to the public. While some private institutions also likely share this sense of public responsibility, it may not be as regularly stated or implicitly understood.

Also, only universities located in urban areas, versus suburban and rural areas of the country, were included in the study group. While suburban and rural settings are home to a variety of social concerns, one can plausibly argue that urban settings are the most saturated with complex social issues and in these settings community engagement can be put to a robust test by faculty, students and staff associated with a particular academic unit.

Finally, only comprehensive universities that had chosen to apply and subsequently received the elective Carnegie classification for community engagement were included. The rationale for this choice is that, since all institutions in this study have received the Carnegie engagement classification, we can assume that all of the academic departments share a common set of factors. They all are housed at 
institutions that explicitly mention engagement in their institutional mission. All test departments for this study are located at institutions that have a coordinating entity to facilitate community interaction between faculty/staff/students and community partners. They all work on a campus that shares a common definition of servicelearning and/or community engagement. They all recognize the value of communitybased research, and so on. It was relatively easy to identify the comprehensive institutions selected to participate in this study, since 76 schools received the Carnegie classification in 2006.

Another important consideration was the fact that the Carnegie Foundation Community Engagement Framework (2006) is now widely recognized as a validated instrument that is in broad use among higher education institutions. Prior to 2006, there was no common understanding about what community engagement meant on higher education campuses and, therefore, it was significantly more challenging to control for even the most basic institutional factors. Now that there is a common framework and a shared understanding that all of the Carnegie classified institutions must comply with a defined sub-set of criteria, researchers can make substantive comparisons among institutions-or sub-organizational levels of institutions (i.e., academic departments) - that have received the classification. For this reason, this study intentionally utilizes the definition for community engagement from the Carnegie Elective Classification for Community Engagement:

Community Engagement describes the collaboration between institutions of higher education and their larger communities (local, regional/state, national, global) for the mutually beneficial exchange of knowledge and resources in a 
context of partnership and reciprocity.

(http://www.carnegiefoundation.org/dynamic/downloads/file_1 614.pdf.)

This definition also appears in the introductory pages of the Rubric.

The subjects for this study were limited to social science departments because these disciplines generally assume an active definition of community engagement, one that includes and accounts for the "application of knowledge to discrete problems...[and] captures some of the major concerns of civilization" (Smelser \& Baltes, 2001). Still an issue exists in that there is not consensus as to which disciplines should be considered social science departments. While the Social Science Research Council (SSRC) does not provide a listing of current fields they consider to be social sciences, they do offer what is called a consolidated list of SSRC Council Committees which gives an indication of the breadth of fields they consider to be social sciences (http://www.ssrc.org/inside/about/consolidated_list_of_committees_1924-1997/). A second neutral source is The International Encyclopedia of the Social and Behavioral Sciences (Smelser and Baltes, 2001). The introduction to the tome includes a detailed discussion of the process undertaken by the authors to determine which disciplines qualify for inclusion. The following Table 8 lists the broad disciplinary categories included in Smelser and Baltes' (2001) International Encyclopedia. The social science departments included in this study fall into at least one of these two groupings, the former more extensive list from the SSRC or the more specific list from the Encyclopedia. 
Table 9: Sections and Section Editors for Social Science from the International Encyclopedia (Smelser and Baltes, 2001)

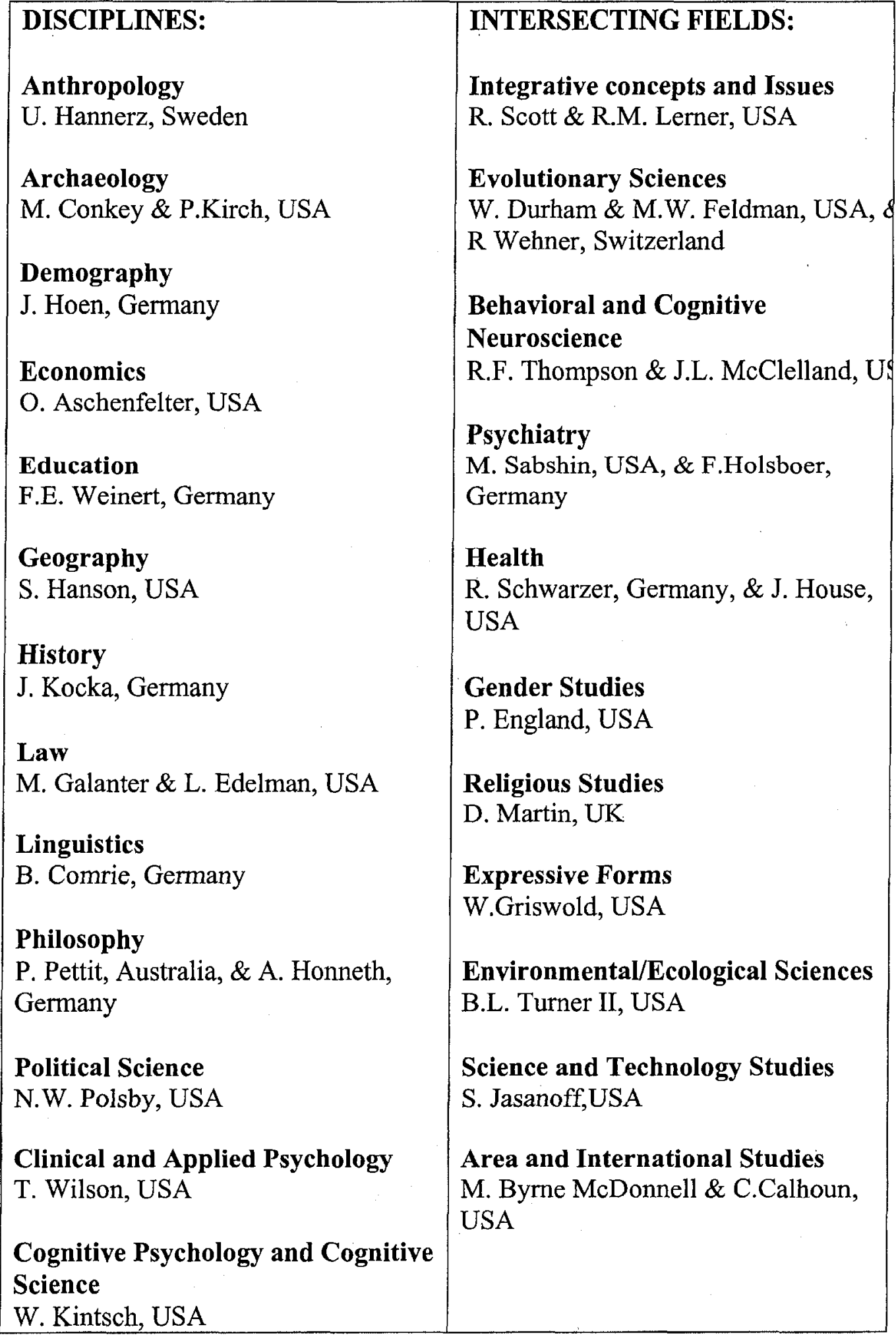


Developmental, Social, Personality, a Motivational Psychology

N. Eisenberg, USA

\section{Sociology}

R.Boudon, France

OVERARCHING TOPICS:

Institutions and Infrastructure

D.L. Featherman, USA

APPLICATIONS:

Organizational and Management

Studies

Martinelli, Italy

History of the Social and Behavioral

Sciences

P. Wagner, Italy

Media Studies and Commercial

Applications

M. Schudson, USA

Ethics of Research and Applications

R.McC.Adams, USA, \& J. Mittelstrass,

Germany

Urban Studies and Planning

E. Birch, USA

Biographies

K.U. Mayer, Germany

Public Policy

K. Prewitt \& I.Katznelson, USA

Statistics

S. Fienberg \& J.B. Kadane, USA

Modern Cultural Concerns (Essays)

R.A. Shweder, USA

Logic of Inquiry and Research Desig

T. Cook \& Ragin, USA

The community engagement director at each of the participating schools was contacted to determine which specific social science departments on the campus would be most appropriate for and amenable to study inclusion. In all cases, these individuals are professional colleagues. Charmaz (2006) argues that taking into account the "situational demands" and recognizing "interactional reciprocities" are key to "gain[ing] ready access to information" (p. 110). Charmaz (2006) justifies a personalized approach, and indeed suggests that qualitative researchers run the risk of 
"dehumanizing research participants - and [our]selves" (p. 110) if there is no assumption of a personal relationship at some level: "we gain access through the trust that emerges through establishing on-going relationships and reciprocities. Ignoring such reciprocities weakens [y] our chances of obtaining telling data..." (p. 110).

The purpose, parameters, and potential outcomes of the study were explained to each of the campus directors. They were then asked to suggest potential departments from their institution for possible consideration based on the following two, broad factors:

1) Willingness to Participate: which department or departmental representatives would be most likely to complete the questionnaire and selfassessment in a timely fashion, and

2) Variance: departments that reflected variance with respect to their implementation of a community engagement agenda (i.e., those that were just beginning the process compared to those at an advanced stage of development).

Campus directors were reminded that the results of the self-assessment would remain confidential and that the overarching purpose of the study was to test the utility of, and validation for, the Rubric. They were reminded of the importance of obtaining willing subjects that represented a range of stages in implementing a community engagement agenda. They were further assured that, given the confidential design of the study, there was no way for anyone to gain institutional or departmental notoriety based on their responses. This encouraged campus directors to assist the researcher in 
gaining access to the widest possible range of departments in terms of their understanding and institutionalization of community engagement in the unit.

\section{Measures}

The development of the instrument utilized in this study - the Rubric-was discussed earlier in this chapter. The Rubric contains two measures: 1) a selfassessment instrument; and 2) a survey consisting of six open-ended questions.

Measure One is a self-assessment instrument that departments utilized to rate their relative level of institutionalization of community engagement. The measure contains six dimensions, each with embedded constructs/component parts (the selfassessment instrument - the Rubric-is located in Appendix E).

Measure Two is a survey consisting of the following six open-ended questions. The questions are used to obtain qualitative feedback on the utility of the instrument. The questions are displayed in Table 10 .

\section{Table 10: Open-ended questions concerning the $R$ ubric}

1) Process: Please describe the process by which the self-assessment team was selected and organized. In particular, describe the specific process by which the departmental self-assessment was accomplished.

\section{2) Involvement:}

a. Was the chair or academic department head informed about this process? ( $\mathrm{y} / \mathrm{n})$ Involved in the process? $(\mathrm{y} / \mathrm{n})$

b. Was the Rubric primarily completed by only one individual? If so, what is the title of that individual?

c. Was the Rubric primarily completed by a group or team, or in some way completed through a consultative process? If so, please 
include the titles of the individuals involved and specifically describe the collective aspects of the activity.

3) Confusion: Were any parts of the Engaged Department Rubric unclear or confusing? If so, please briefly explain.

4) Missing: Is there any information that was not requested that you consider significant evidence of your department's overall community engagement efforts? If so, please explain.

5) Usefulness: What dimension(s) and/or component(s) did you find most useful in assessing your department's community engagement? Least useful? Was there one particular component in each of the dimensions that you found most useful? Least useful?

6) Suggestions: Please provide any suggestions or comments you may have regarding the process and/or content of the Engaged Department Rubric.

\section{Data Collection}

Data were collected over a two-month period during summer, 2008, a time of reduced activity on university campuses. Typically, many faculty disengage from campus during the summer break. Some campus directors voiced concerns about their ability to realistically obtain robust (i.e. multiple participants from the same department) responses from multiple academic departments. Therefore, after thanking them in advance for that effort, campus directors were instructed to do the best they could to obtain appropriate departmental responses. In at least one case, this resulted in the department self-assessment and survey questions being answered by only one departmental representative. In other cases, the self-assessment was taken by multiple members of the department and final decisions were made by consensus. This issue will be revisited in the section in Chapter $\mathrm{V}$ on limitations of the study. Finally, while 
all test departments were provided with both hard-copy and electronic copy versions of the Rubric (including the survey questions), all but one department chose to respond to the self-assessment instrument and survey questions electronically.

\section{Methods of Analysis}

As discussed previously, the Rubric contains two measures: 1) a selfassessment instrument, and 2) a survey consisting of six open-ended questions. Therefore, the analysis in phase-two parallels these two sets of activities: one summarizing and displaying the self-assessment instrument response data and the other focusing on the responses to the open-ended survey questions.

The researcher chose to use histograms and tables to present and summarize the self-assessment instrument response data. The responses are grouped by departments and presented in numerical order for ease and clarity. First, the department's responses for each of the six dimensions are categorized and presented in summary format in a histogram as "low," "medium-low," "medium-high," or "high" level of support for community engagement for each dimension (see histogram below for an example). 
Figure 1: (Example) Summary of Department 1: Departmental Categorization

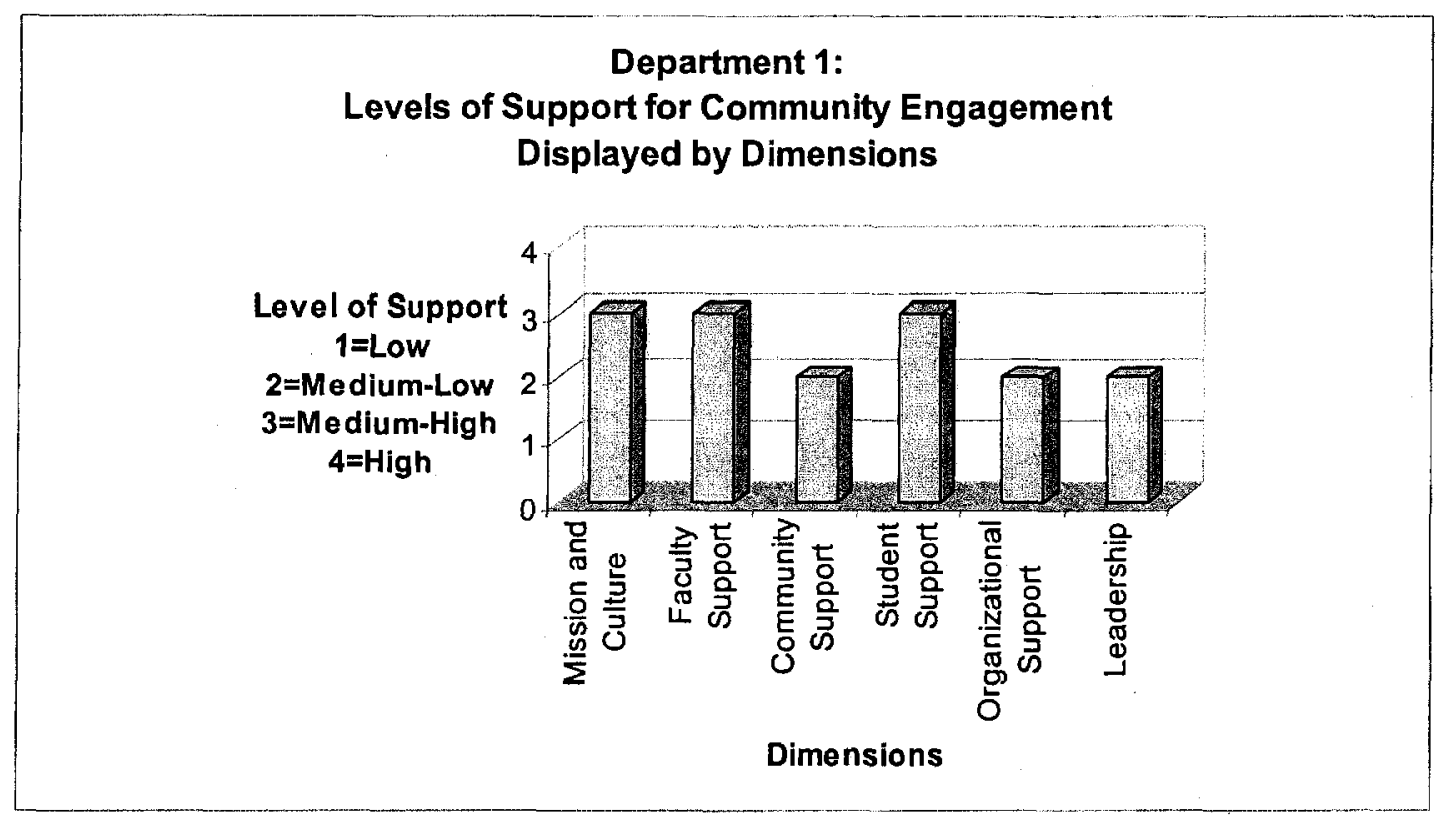

This study categorizes responses for each of the dimensions as "low,"

"medium-low," "medium-high," or "high" level of support for community engagement using the decision rules displayed in Table 11. The values that form the basis for these calculations originate from the departmental responses to the Rubric. For example, if a department determined that it was currently at "stage two" for a particular component, and signaled that determination as requested in the instructions for the Rubric by placing a circle around "stage two", then the designation would be converted into the numerical value of " 2 ," as displayed in Table 12 below. 
Table 11: Categorization Decision Rules for Raw Data Responses

\begin{tabular}{|l|l|}
\hline $\begin{array}{c}\text { Level of Support for } \\
\text { Community } \\
\text { Engagement }\end{array}$ & \multicolumn{1}{c|}{ Categorization Decisions Rules } \\
\hline Low & The mean number of all of the responses is $<2.0$ \\
\hline Medium-Low & $\begin{array}{l}\text { The mean number of all of the responses is between } 2.0 \\
-2.5\end{array}$ \\
\hline Medium-High & $\begin{array}{l}\text { The mean number of all of the responses is between } 2.6 \\
-3.0\end{array}$ \\
\hline High & The mean number of all of the responses is $>3.0$ \\
\hline
\end{tabular}

Using this technique, the responses to the Rubric can be viewed easily in table format. Table 12 below provides an example of how the raw data for Department One's responses to the components of each of the six dimensions are presented. Using this presentation strategy, the response scores are then easily totaled, the mean score calculated and presented, and the decision rule applied to determine the categorization level of support for community engagement for each dimension. It is this categorization level of support that is displayed, in an associated manner for all six dimensions of the Rubric, in the example summary histogram (Figure 1, above).

Table 12: (Example) Department 1: Self-assessments arranged by dimensions

Dimension I: Mission and Culture Supporting Community Engagement

\begin{tabular}{lc} 
Component & Self-assessment \\
Mission & 4 \\
Definition: Teaching & 3 \\
Definition: Research & 2 \\
Definition: Service & 2 \\
Climate \& Culture & 4 \\
Collective Self-Awareness & 2 \\
\hline TOTAL & 17 \\
Mean score & 2.8 \\
Categorization for Dimension & Medium-high
\end{tabular}


The example above, then, would be categorized as having a "medium-high" level of support for community engagement designation in for Dimension I (Mission and Culture Supporting Community Engagement) since the mean number for the responses to the six components of that dimension is 2.8 and the decision rule shows that a mean score between $2.5-3.0$ equates to a "medium-high" designation. That designation would then be displayed with a "3" which, according to the descriptor along the $\mathrm{Y}$ axis in the example histogram above is associated with a "medium-high" level of support.

Although the Rubric does not use an equal interval scale, Borgatta (1968) argues that "for correlation and regression analysis, assumptions of normality and continuous distributions are not necessary" (p. 29). Therefore, by analogy, this study assumes that for calculating means-a less rigorous form of analysis than correlation or regression analysis—continuous distributions are also not necessary.

Finally, after the summary categorization histograms and raw data tables are displayed in numerical order for all 12 departments, one final set of multi-shaded histograms relating to all the departments' categorizations is aggregated and displayed (see example for departments 1-6 below). This data display format allows the researcher to view patterns in responses, and to be able to differentiate and group the test departments relative to each other based on whether they demonstrate a "low," "medium-low," "medium-high," or "high" level of support for community engagement. This differentiation facilitates within-case and across-case analysis. 
Figure 2: Levels of Departmental Engagement Displayed by Dimensions

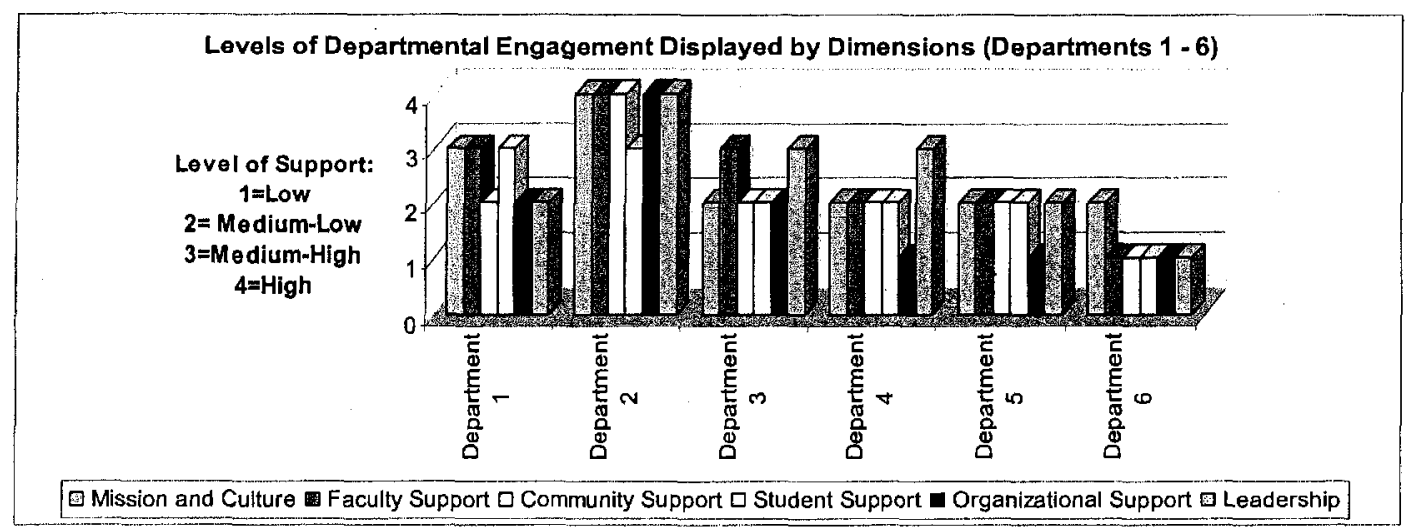

To analyze participants' responses to the open-ended survey questions a threepart strategy was employed. Part one consists of a summary of the various strategies used by departments as they reported those strategies in the first two questions of the open-ended survey regarding "process." Part two involves locating and selecting key verbatim statements, or "low inference descriptors" (Johnson, 1997), that respondents made in which they commented directly or otherwise provided an opinion regarding the utility of the explanatory framework (the Rubric). This strategy was used to provide direct evidence, in the form of verbatim quotations, in response to question three of this study regarding utility of the instrument. Part three focuses on recommendations for improvements and general comments regarding use of the Rubric. In this final section, the study employs a thematic analysis strategy (Charmaz, 2006), in order to make additional "analytic sense of the material" (p. 54) for the purpose of grouping respondents' comments and recommendations regarding possible future improvements to the instrument as well as general comments about the Rubric and departmental engagement. While modifying the instrument is beyond the scope of 
this study, there is potential future utility in aggregating the responses for future application. Once the responses have been analyzed, it is possible to selectively test within-case and across-cased relationships between the written responses to the openended questions and the actual responses to the self-assessment instrument.

\section{Conclusion and Review of Central Research Questions}

In this chapter, the two-phase qualitative, grounded theory research strategy developed in order to answer the three central research questions of this dissertation was presented. Phase-one of this research strategy utilized experts/key informants and extant literature germane to this topic through a three-step process of identification, integration, and modification/confirmation to build an explanatory framework (the Rubric) to directly address research questions one and two:

1. Can a self-assessment rubric for the institutionalization of community engagement be specifically designed for academic departments?

2. If so, what are the broad dimensions of community engagement that need to be included at the departmental level? And, within those dimensions, what key constructs, or components must be present and sufficiently explicated?

Further, the deductive, qualitative approach and specifically the design, setting, subjects, measures, method of data collection, and analysis of phase-two of the research strategy were discussed. This phase was developed to directly address the third research question of this dissertation: 
3. Can the utility and validity of the new instrument be confirmed by using qualitative methods (Charmaz, 2006) to evaluate the responses from pilottest social science departments located at four urban, geographicallydiverse, Carnegie-classified community engaged, public higher education institutions?

The following Chapter 4 will present the findings from both parts of phase-two of this dissertation study: 1) the summary and display of the twelve test departments' self-assessment instrument response data; and, 2) pertinent aspects of the departmental responses to the six open-ended survey questions. 


\section{CHAPTER IV: FINDINGS}

This chapter presents the findings from phase-two of the overall research strategy that has been outlined in detail in the previous chapter ${ }^{3}$. The goal of phasetwo-testing the Rubric with select social science departments from across the country - was to ascertain the utility and validity of the new instrument that was deliberatively "designed to assess the capacity of a higher education academic department for community engagement" (from the Rubric Introduction) The objective of this chapter is to 1) provide sufficient background information on the test departments, and 2) display the findings from both parts of this test study in order to make reasonable determinations about the utility and validity of the Rubric. These determinations-including the discussions and conclusions concerning limitations of the study and further areas of research regarding this study-are the topic of the $5^{\text {th }}$ and final chapter. This $4^{\text {th }}$ chapter, which summarizes the findings, is organized as follows:

- Listing of the test departments, identified by discipline

- Presentation of the departmental data, which is divided by department and presented in numerical order. Each departmental data presentation is divided into two sections:

- First, the reader is provided a summary histogram displaying categorizations ("low," "medium-low," "medium-high," or "high" level

\footnotetext{
${ }^{3}$ Phase-one of this research strategy culminated in the development of the self-assessment Rubric. Salient parts of the Rubric were presented in the previous Chapter 3 . The complete Rubric is located in Appendix $\mathrm{E}$ of this dissertation study.
} 
of support for community engagement) for each dimension in the Rubric;

- Second, in table format, raw departmental response data are presented, including component-level scores, total score, mean calculation, and categorization determination in accordance with the decision rules first outlined in chapter three, and repeated here for convenience:

Table 13: (Repeat) Categorization Decision Rules for Raw Data Responses

\begin{tabular}{|l|l|}
\hline $\begin{array}{c}\text { Level of Support for } \\
\text { Community } \\
\text { Engagement }\end{array}$ & \multicolumn{1}{|c|}{ Categorization Decisions Rules } \\
\hline Low & The mean number of all of the responses is $<2.0$ \\
\hline Medium-Low & $\begin{array}{l}\text { The mean number of all of the responses is between } \\
2.0-2.5\end{array}$ \\
\hline Medium-High & $\begin{array}{l}\text { The mean number of all of the responses is between } \\
2.6-3.0\end{array}$ \\
\hline High & The mean number of all of the responses is $>3.0$ \\
\hline
\end{tabular}

- There is a summary presentation of responses to the open-ended questionnaire

- The chapter ends with a section titled, "Conclusion - Summary of Findings".

\section{$\underline{\text { I. Test Departments }}$}

The following Table 14 displays the social science disciplines of the twelve academic departments that participated in this study. Each department is embedded in one of five universities located in the South, North, Midwest, or Northwest of the United States of America. Each university is public, urban, comprehensive and Carnegie-classified for community engagement. In this study only one discipline is represented by two departments: history. Also, there is an uneven spread of 
departments from each institution. For example, only one department from institutions $\mathrm{D}$ and $\mathrm{E}$ responded, while 4 responded from institution $\mathrm{C}$ and three each responded from institutions $\mathrm{A}$ and $\mathrm{B}$.

Table 14: Display of test departments' institution and discipline

\begin{tabular}{|c|c|l|}
\hline $\begin{array}{c}\text { Department } \\
\text { Number }\end{array}$ & Institution & Disciplinary focus of department \\
\hline 1 & A & Speech, Language and Hearing \\
\hline 2 & A & Family Social Science \\
\hline 3 & A & Sociology \\
\hline 4 & B & Agriculture Resources and Economics \\
\hline 5 & B & Adult and Higher Education \\
\hline 6 & B & History \\
\hline 7 & C & History \\
\hline 8 & C & Political Science \\
\hline 9 & D & Social Work \\
\hline 10 & C & Environmental Science and Resources \\
\hline 11 & C & Applied Linguistics \\
\hline 12 & E & Psychology \\
\hline
\end{tabular}

\section{$\underline{\text { II. Presentation of Rubric responses - by department }}$}

This section provides a summary of the departmental data, which is divided by department and presented in numerical order. For each department, there is first a summary histogram displaying categorizations ("low," "medium-low," "mediumhigh," or "high" level of support for community engagement) for each of the dimensions in to the Rubric. If viewed electronically, this histogram has a light blue background and has darker blue bars; if viewed in print format, the histogram features shaded bars. Following the histogram that summarizes the categorizations of the department's self-assessment is a series of tables that display the raw departmental 
response data. These tables display data at the level of component scores, as well as provide the total score, mean calculation, and categorization determination in accordance with the decision rules outlined in chapter three, and repeated above.

\section{Department 1 - Speech, Language and Hearing}

Figure 3: Summary of Department 1: Departmental Categorization

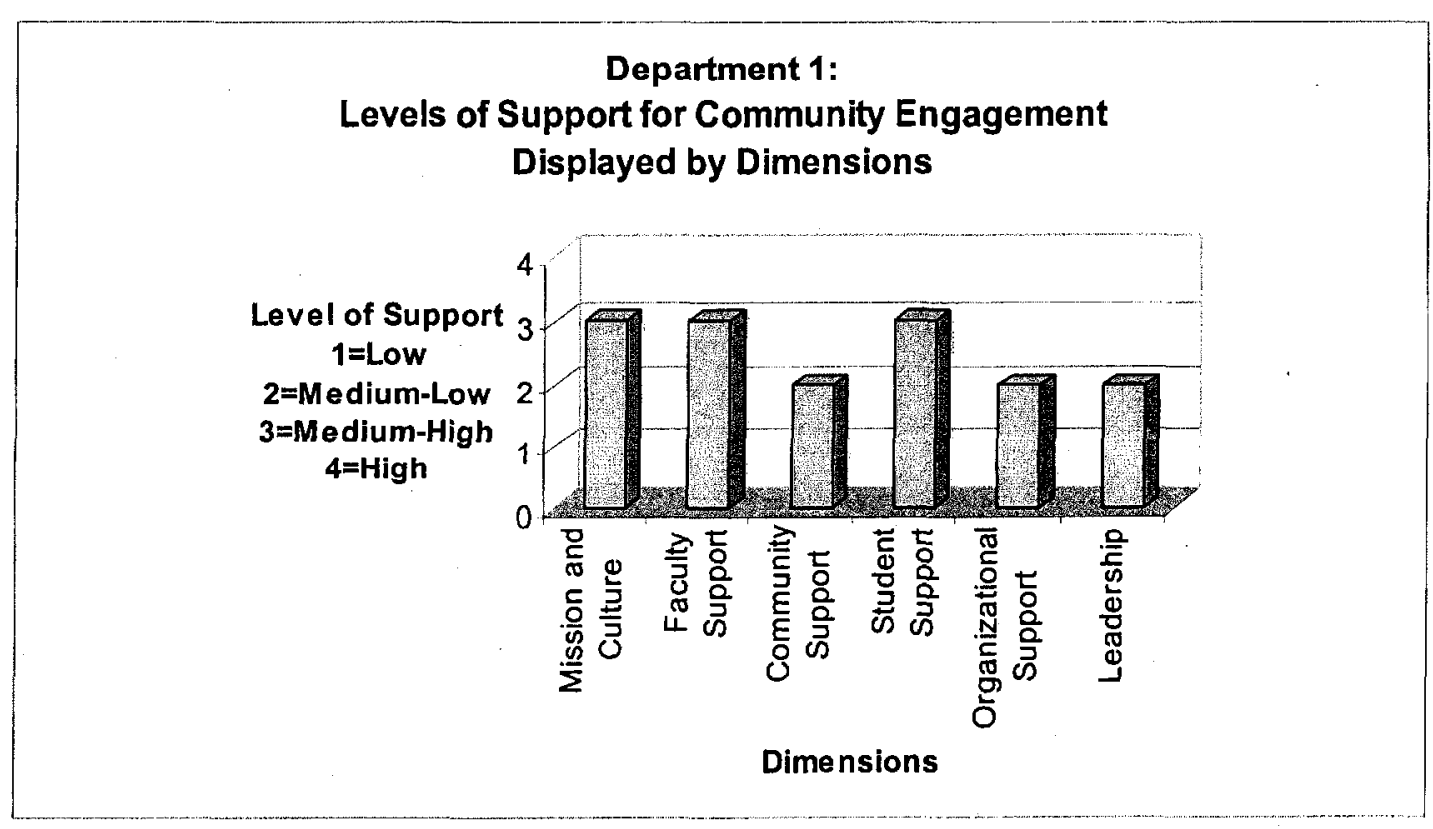

The self-assessment from Department 1 indicates that the department categorizes itself as having a medium-high level of support for community engagement for three dimensions and a medium-low level of support for community engagement for three dimensions. 
Table 15: Department 1: Self-assessments arranged by dimensions

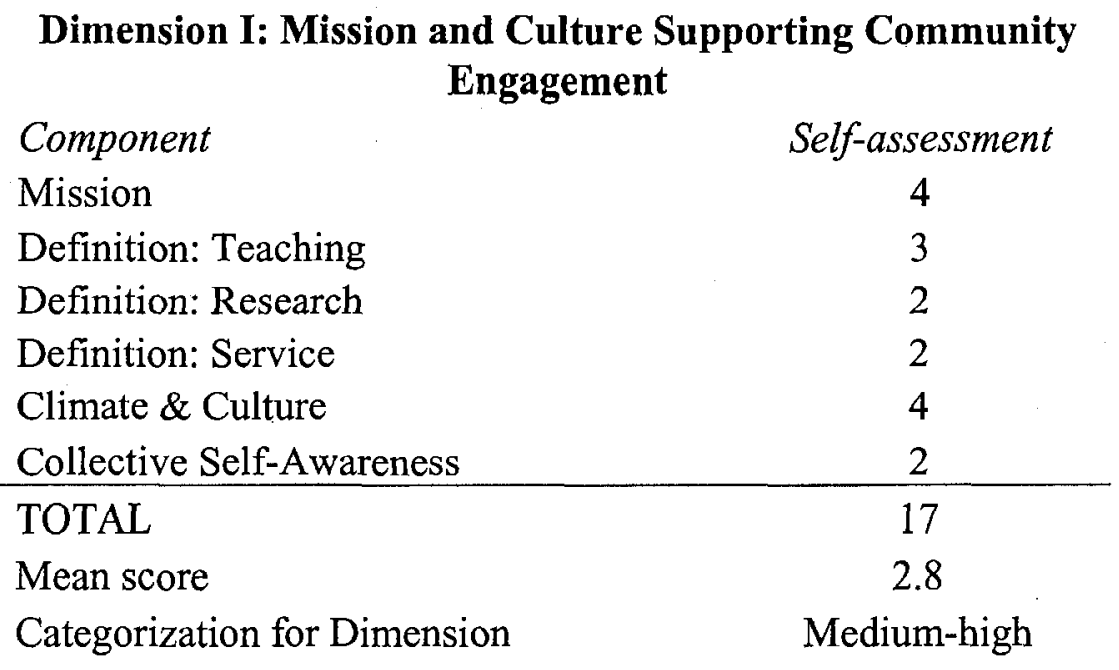

\section{Dimension II: Faculty Support and Community Engagement}

\section{Component}

Knowledge/Awareness

Self-assessment

Involvement/Support

3

Curricular Integration

3

Faculty Incentives

2

Review, Promotion \& Tenure

2

Tenure Track Faculty

TOTAL

Mean score

2.5

Categorization for Dimension

Medium-low

\section{Dimension III: Community Partner and Partnership Support and Community Engagement}

\section{Component}

Partnership Awareness

Understanding \& Commitment

Partner Voice

Partner Leadership

Access to Resources

Partner Incentives/Recognition
Self-assessment

3

2

3

2

3

2

15 
Mean score

2.5

Categorization for Dimension

Medium-low

\section{Dimension IV: Student Support and Community \\ Engagement}

Component

Student Opportunities

Self-assessment

Student Awareness

3

Student Incentives \& Recognition

Student Voice, Leadership \& Governance

TOTAL

Mean score

3.0

Categorization for Dimension

Medium-high

\section{Dimension V: Organizational Support for Community \\ Engagement}

Component

Administrative Support

Self-assessment

Facilitating Entity

3

Evaluation \& Assessment

2

Departmental Planning

1

Faculty Recruitment and Orientation 2

Marketing 4

Dissemination of Results $\quad 3$

Budgetary Allocation $\quad 2$

TOTAL 20

Mean score

2.5

Categorization for Dimension Medium-low

\section{Dimension VI: Leadership Support for Community Engagement}

Component

Student Opportunities

Self-assessment

Student Awareness

2

Student Incentives \& Recognition

2

TOTAL

3

Mean score

2.3 


\section{Department 2 - Family Social Science}

Department 2 was one of the two departments in this study that had the highest self-assessment scores.

Figure 4: Summary of Department 2: Departmental Categorization

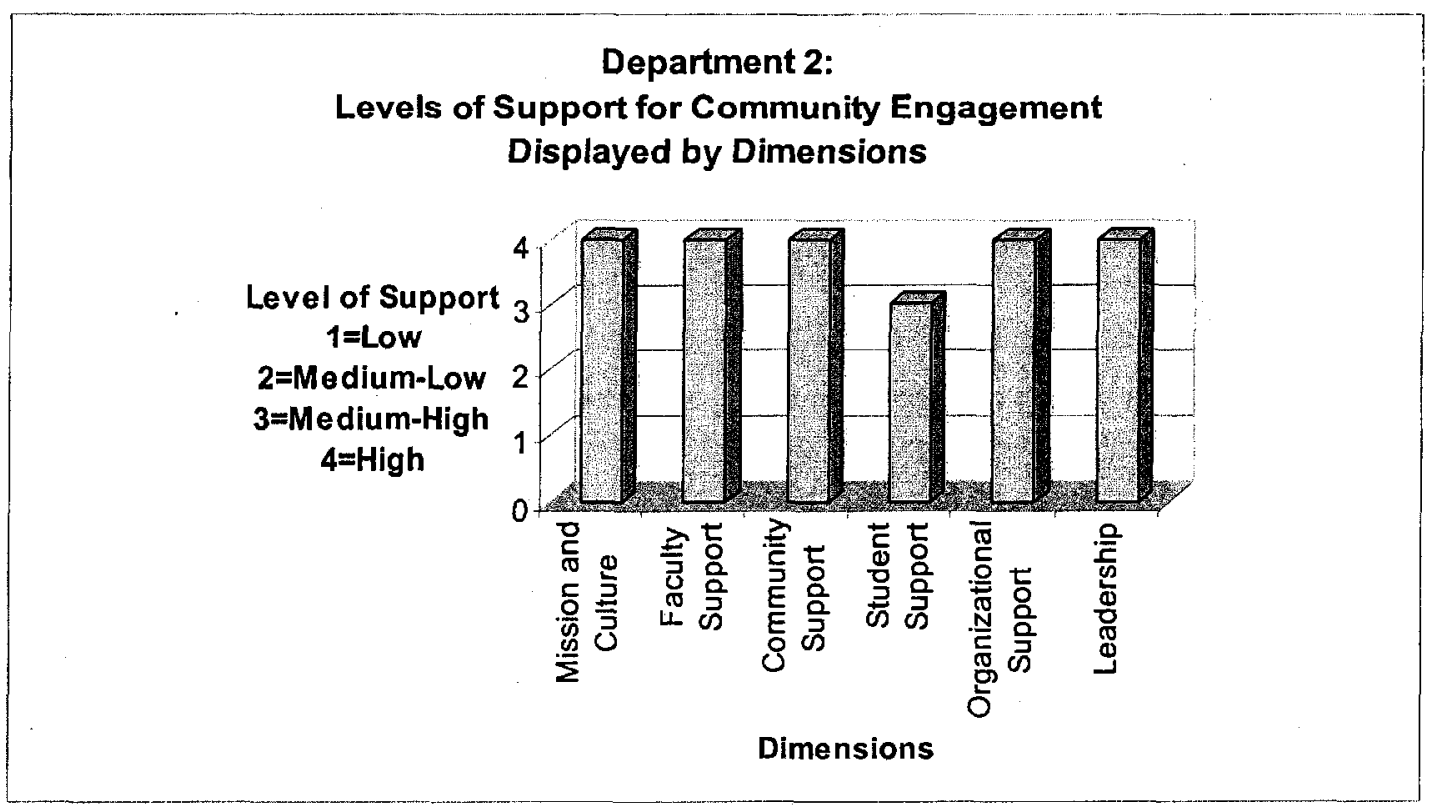

The self-assessment from Department 2 indicates that the department categorizes itself as having a high level of support for community engagement for five dimensions and a medium-high level of support for community engagement for one dimension.

Table 16: Department 2: Self-assessments arranged by dimensions

\section{Dimension I: Mission and Culture Supporting Community Engagement}

Component

Mission

Definition: Teaching

\section{Self-assessment}

4

2 
Definition: Research 4

Definition: Service 4

Climate \& Culture $\quad 4$

Collective Self-Awareness $\quad 4$

TOTAL 22

Mean score $\quad 3.7$

Categorization for Dimension High

Dimension II: Faculty Support and Community Engagement

Component

Knowledge/Awareness

Involvement/Support

Curricular Integration

Faculty Incentives

Review, Promotion \& Tenure

Tenure Track Faculty

TOTAL

Mean score

Categorization for Dimension
Self-assessment

4

3

3

4

4

4

22

3.7

High

\section{Dimension III: Community Partner and Partnership} Support and Community Engagement

Component

Partnership Awareness

Understanding \& Commitment

Partner Voice

Partner Leadership

Access to Resources

Partner Incentives/Recognition

TOTAL

Mean score

Categorization for Dimension
Self-assessment

4

3

3

3

4

2

19

3.2

High

\section{Dimension IV: Student Support and Community Engagement \\ Component \\ Self-assessment}


Student Opportunities $\quad 3$

Student Awareness 4

Student Incentives \& Recognition 3

Student Voice, Leadership \& Governance 3

TOTAL 13

Mean score $\quad 3.3$

Categorization for Dimension High

Dimension V: Organizational Support for Community Engagement

Component

Administrative Support

Facilitating Entity

Evaluation \& Assessment

Departmental Planning

Faculty Recruitment and Orientation

Marketing

Dissemination of Results

Budgetary Allocation

TOTAL

Mean score

Categorization for Dimension
Self-assessment

4

4

3

4

4

3

4

3

29

3.6

High

\section{Dimension VI: Leadership Support for Community Engagement}

Component

Student Opportunities

Student Awareness

Student Incentives \& Recognition

TOTAL

Mean score

Categorization for Dimension
Self-assessment

4

4

4

12

4.0

High 
Figure 5: Summary of Department 3: Departmental Categorization

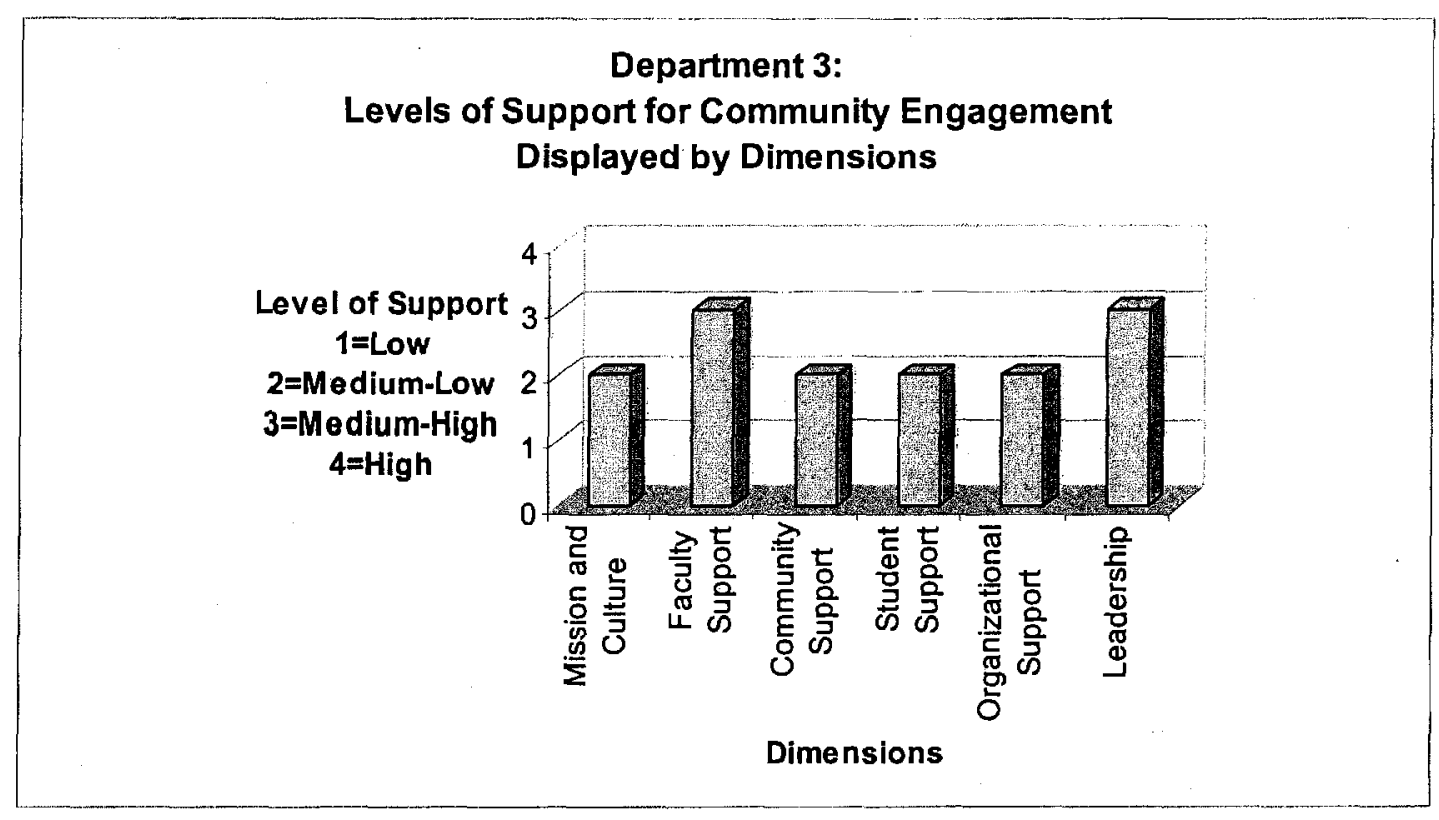

The self-assessment from Department 3 indicates that the department categorizes itself as having a medium-high level of support for community engagement for two dimensions and a medium-low level of support for community engagement for four dimensions.

Table 17: Department 3: Self-assessments arranged by dimensions

Dimension I: Mission and Culture Supporting Community Engagement

Component

Mission

Definition: Teaching

Definition: Research

Definition: Service

Climate \& Culture

Collective Self-Awareness
Self-assessment

3

3

2

2

3

2 
TOTAL

Mean score

Categorization for Dimension

Medium-low

\section{Dimension II: Faculty Support and Community Engagement}

\section{Component}

Knowledge/Awareness

Self-assessment

Involvement/Support

3

Curricular Integration

Faculty Incentives

2

Review, Promotion \& Tenure

3

Tenure Track Faculty

TOTAL

Mean score

Categorization for Dimension

3

17

2.8

Medium-high

Dimension III: Community Partner and Partnership Support and Community Engagement

Component

Partnership Awareness

Understanding \& Commitment

Partner Voice

Partner Leadership

Access to Resources

Partner Incentives/Recognition

TOTAL

Mean score

Categorization for Dimension
Self-assessment

$$
3
$$

2

3

2

2

2

14

2.3

Medium-low

\section{Dimension IV: Student Support and Community Engagement}

Component

Student Opportunities

Student Awareness

Student Incentives \& Recognition

3

Student Voice, Leadership \& Governance

2

2 
TOTAL

Mean score

2.5

Categorization for Dimension

Medium-low

\section{Dimension V: Organizational Support for Community}

Engagement.

Component

Administrative Support

Self-assessment

Facilitating Entity

3

Evaluation \& Assessment

3

Departmental Planning

1

Faculty Recruitment and Orientation

2

Marketing

3

Dissemination of Results

Budgetary Allocation

TOTAL

Mean score

2.5

Categorization for Dimension

Medium-low

\section{Dimension VI: Leadership Support for Community Engagement}

Component

Student Opportunities

Student Awareness

Student Incentives \& Recognition

TOTAL

Mean score

Categorization for Dimension
Self-assessment

3

2

3

8

2.7

Medium-high 


\section{Department 4 - Agriculture Resources and Economics}

Figure 6: Summary of Department 4: Departmental Categorization

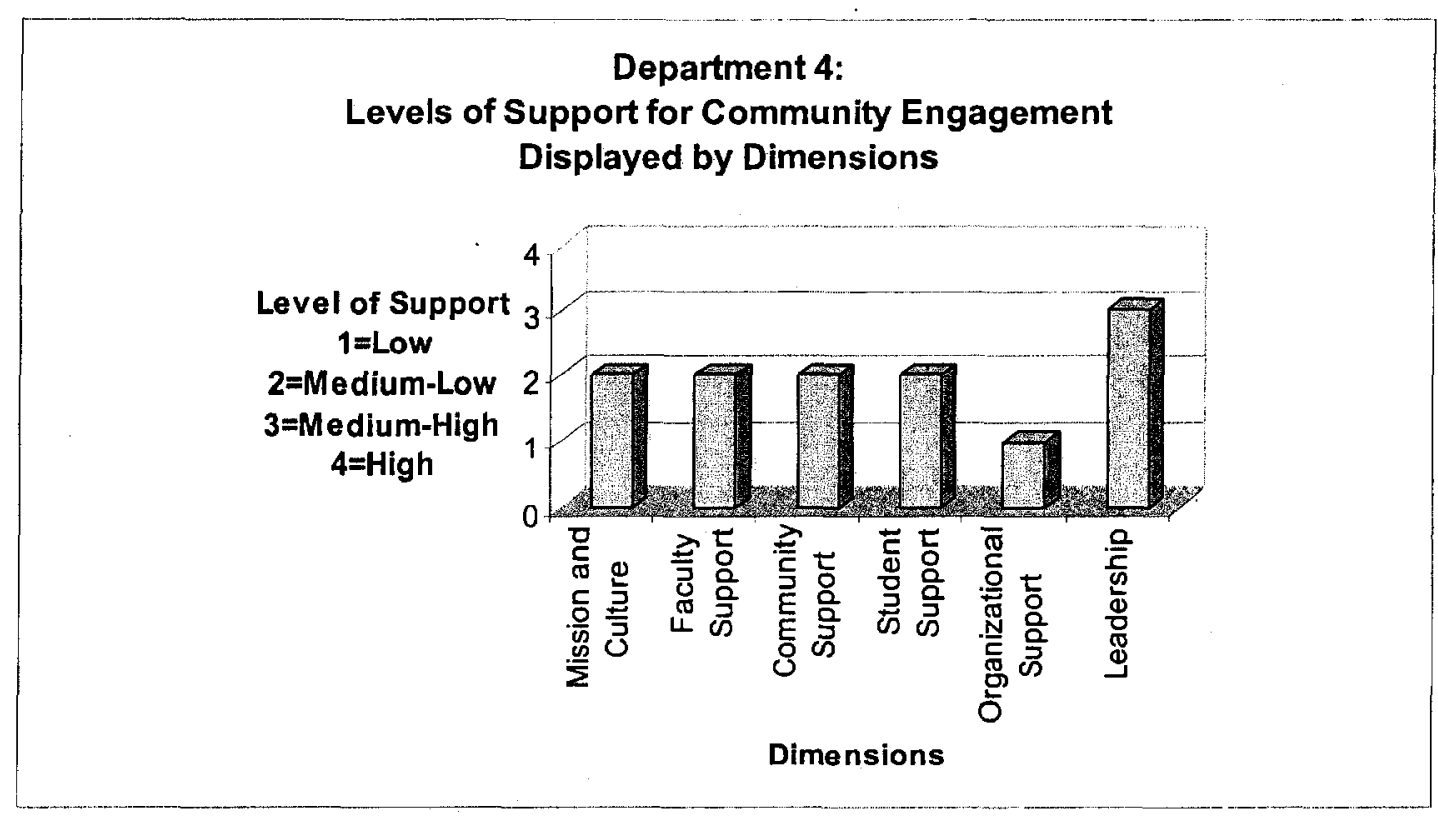

The self-assessment from Department 4 indicates that the department categorizes itself as having a medium-high level of support for community engagement for one dimension, a medium-low level of support for community engagement for four dimensions, and a low level of support for community engagement for one dimension.

Table 18: Department 4: Self-assessments arranged by dimensions

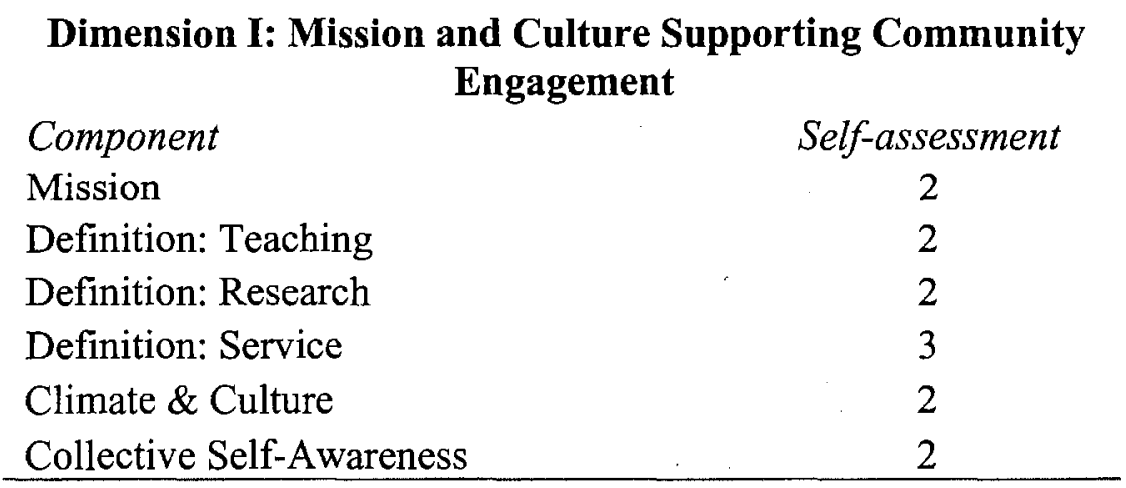


Mean score

Categorization for Dimension

Medium-low

\section{Dimension II: Faculty Support and Community Engagement}

Component

Knowledge/Awareness

Involvement/Support

Curricular Integration

Faculty Incentives

Review, Promotion \& Tenure

Tenure Track Faculty

TOTAL

Mean score

Categorization for Dimension
Self-assessment

2

3

1

3

3

2

14

Medium-low

\section{Dimension III: Community Partner and Partnership} Support and Community Engagement

Component

Partnership Awareness

Understanding \& Commitment

Partner Voice

Partner Leadership

Access to Resources

Partner Incentives/Recognition

TOTAL

Mean score

Categorization for Dimension
Self-assessment

2

2

2

2

3

2

13

Medium-low

\section{Dimension IV: Student Support and Community Engagement}

Component

Student Opportunities

Student Awareness

Student Incentives \& Recognition

Student Voice, Leadership \& Governance
Self-assessment

2

2

2 
TOTAL

Mean score

2.0

Categorization for Dimension

Medium-low

\section{Dimension IV: Student Support and Community Engagement}

Component

Student Opportunities

Self-assessment

Student Awareness

2

Student Incentives \& Recognition 2

Student Voice, Leadership \& Governance

TOTAL

Mean score

2

2

2

Categorization for Dimension

2.0

Medium-low

\section{Dimension V: Organizational Support for Community Engagement}

Component

Administrative Support

Self-assessment

Facilitating Entity

3

Evaluation \& Assessment

3

Departmental Planning

Faculty Recruitment and Orientation

Marketing

Dissemination of Results

3

Budgetary Allocation

TOTAL

Mean score

1.9

Categorization for Dimension

Low

\section{Dimension VI: Leadership Support for Community Engagement}

Component

Student Opportunities

Student Awareness

Student Incentives \& Recognition

TOTAL
Self-assessment

3

3

3

9 
Mean score

Categorization for Dimension
3.0

Medium-high

\section{Department 5 - Adult and Higher Education}

Figure 7: Summary of Department 5: Departmental Categorization

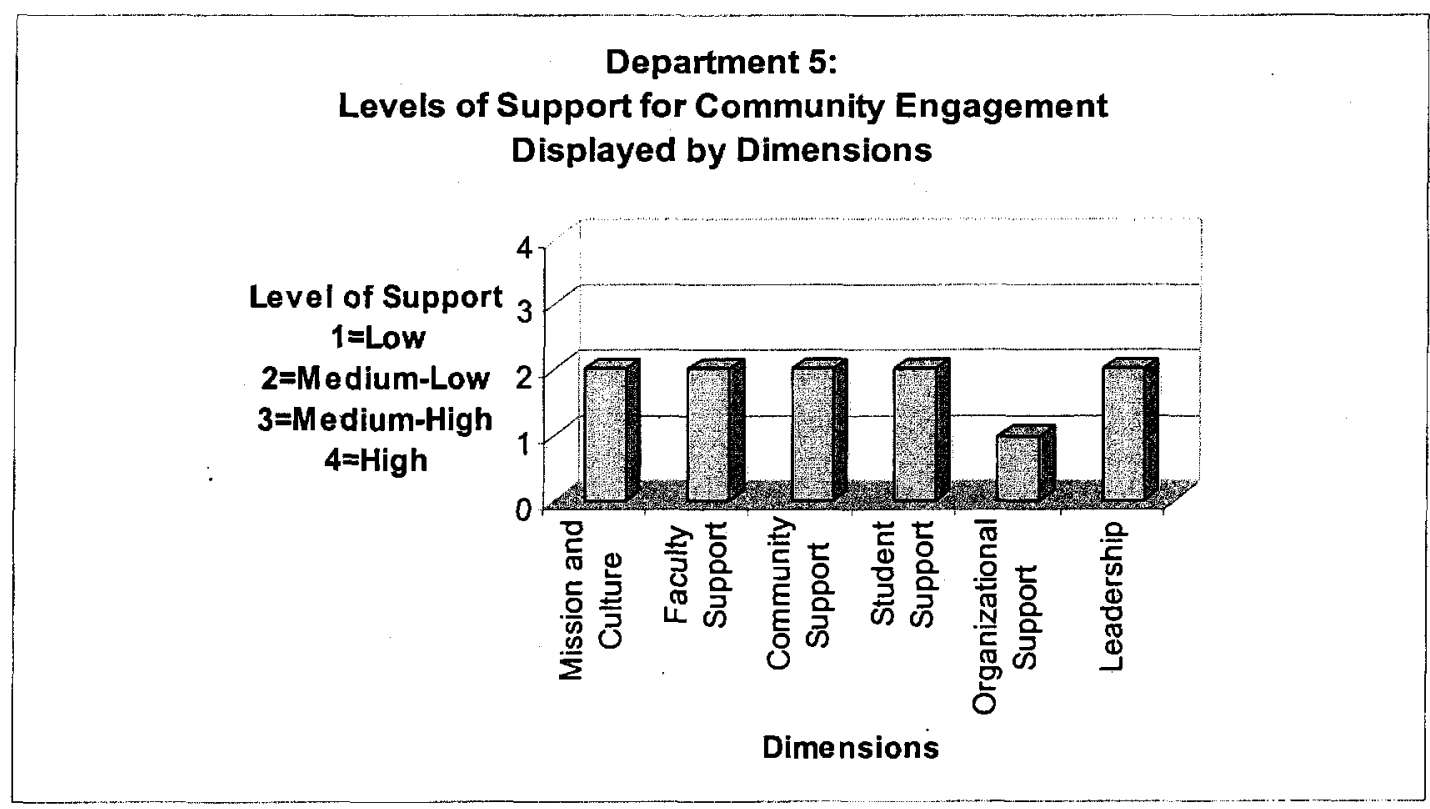

The self-assessment from Department 5 indicates that the department categorizes itself as having a medium-low level of support for community engagement for five dimensions and a low level of support for community engagement for one dimension.

Table 19: Department 5: Self-assessments arranged by dimensions

\section{Dimension I: Mission and Culture Supporting Community Engagement}

Component

Mission

Definition: Teaching

Definition: Research

Definition: Service
Self-assessment

2

2

2

2 
Climate \& Culture 3

Collective Self-Awareness 1

TOTAL

12

Mean score

2.0

Categorization for Dimension

Low

Dimension II: Faculty Support and Community Engagement

Component

Knowledge/Awareness

Self-assessment

Involvement/Support

3

Curricular Integration

3

Faculty Incentives

3

Review, Promotion \& Tenure

2

Tenure Track Faculty

TOTAL

Mean score

15

Categorization for Dimension

Medium-low

Dimension III: Community Partner and Partnership Support and Community Engagement

Component

Partnership Awareness

Self-assessment

Understanding \& Commitment

3

Partner Voice

2

Partner Leadership

3

Access to Resources

2

Partner Incentives/Recognition

TOTAL

Mean score

Categorization for Dimension

Medium-low

\section{Dimension IV: Student Support and Community} Engagement

Component

Student Opportunities

Self-assessment

Student Awareness

3

2 


\begin{tabular}{lc} 
Student Incentives \& Recognition & 1 \\
Student Voice, Leadership \& Governance & 2 \\
\hline TOTAL & 8 \\
Mean score & 2.0 \\
Categorization for Dimension & Medium-low
\end{tabular}

\section{Dimension V: Organizational Support for Community} Engagement

\begin{tabular}{lc} 
Component & Self-assessment \\
Administrative Support & 3 \\
Facilitating Entity & 2 \\
Evaluation \& Assessment & 1 \\
Departmental Planning & 1 \\
Faculty Recruitment and Orientation & 2 \\
Marketing & 2 \\
Dissemination of Results & 1 \\
Budgetary Allocation & 2 \\
\hline TOTAL & 14 \\
Mean score & 1.8 \\
Categorization for Dimension & Low
\end{tabular}

\section{Dimension VI: Leadership Support for Community} Engagement

Component

Student Opportunities

Self-assessment

Student Awareness

2

Student Incentives \& Recognition

TOTAL

Mean score

2

Categorization for Dimension

3

7

2.3

Medium-low 


\section{Department 6 - History}

Figure 8: Summary of Department 6: Departmental Categorization

Department 6 was one of the two departments in this study that had the lowest self-assessment scores.

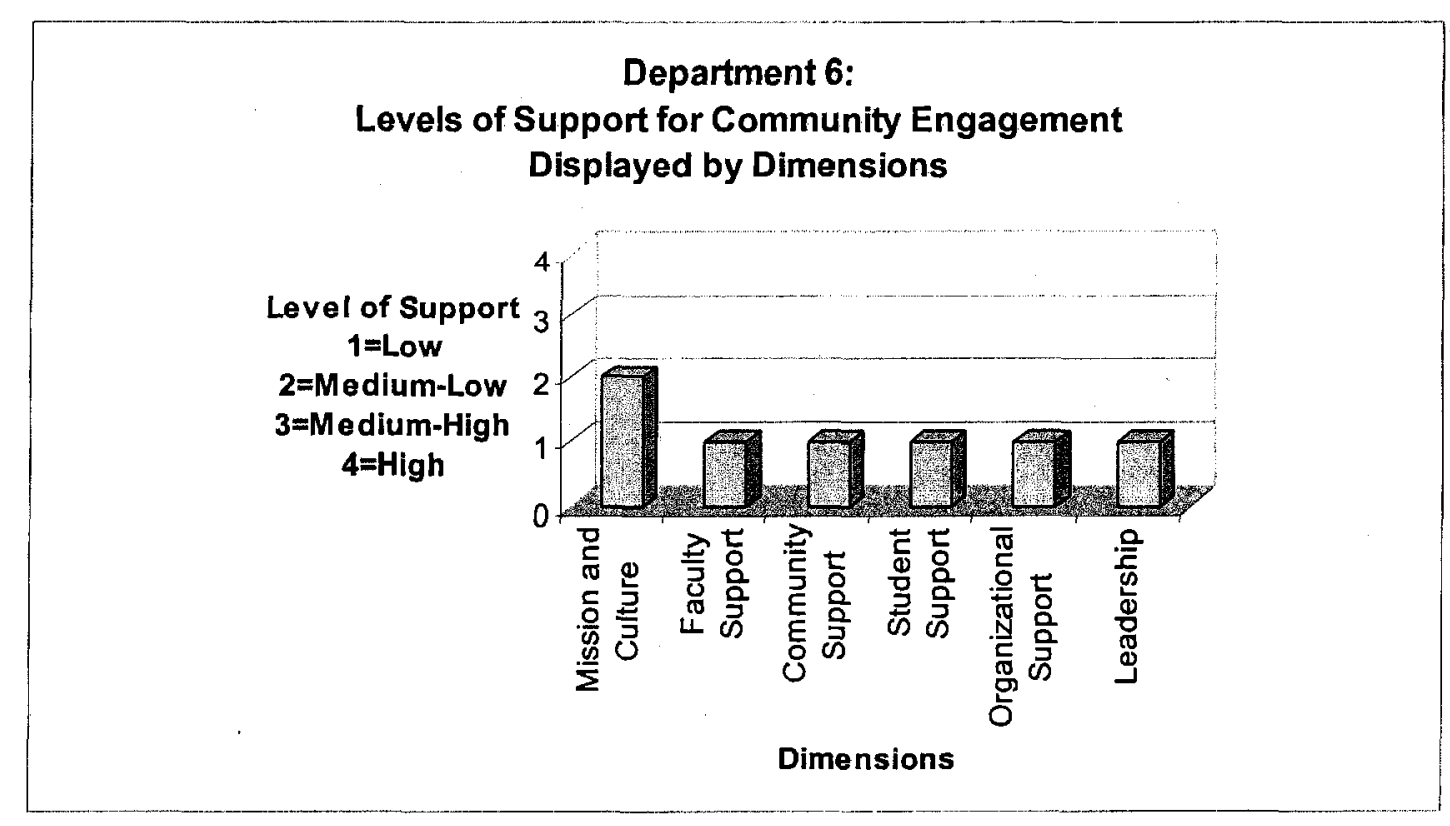

The self-assessment from Department 6 indicates that the department categorizes itself as having a medium-low level of support for community engagement for one dimension and a low level of support for community engagement for five dimensions.

Table 20: Department 6: Self-assessments arranged by dimensions

\section{Dimension I: Mission and Culture Supporting Community Engagement}

Component

Mission

Definition: Teaching

Definition: Research

Definition: Service

Climate \& Culture
Self-assessment

2

1

1

4

3 


\begin{tabular}{lc} 
Collective Self-Awareness & 2 \\
\hline TOTAL & 13 \\
Mean score & 2.2 \\
Categorization for Dimension & Medium-low
\end{tabular}

\section{Dimension II: Faculty Support and Community Engagement}

Component

Knowledge/Awareness Self-assessment

Involvement/Support

2

Curricular Integration

2

Faculty Incentives

Review, Promotion \& Tenure

2

Tenure Track Faculty

2

TOTAL

11

Mean score

1.8

Categorization for Dimension

Low

\section{Dimension III: Community Partner and Partnership} Support and Community Engagement

\section{Component}

Partnership Awareness

Understanding \& Commitment

Partner Voice

Partner Leadership

Access to Resources

Partner Incentives/Recognition

TOTAL

Mean score

Categorization for Dimension
Self-assessment

2

2

2

1

2

. 1

10

1.7

Low

\section{Dimension IV: Student Support and Community Engagement}

Component

Student Opportunities

Student Awareness

Student Incentives \& Recognition
Self-assessment

2

2

1 
Student Voice, Leadership \& Governance

TOTAL

1

Mean score

1.5

Categorization for Dimension

Low

Dimension V: Organizational Support for Community

Engagement

Component

Administrative Support

Self-assessment

Facilitating Entity

2

Evaluation \& Assessment

2

Departmental Planning

Faculty Recruitment and Orientation

2

Marketing

1

Dissemination of Results

1

Budgetary Allocation

TOTAL

12

Mean score

1.5

Categorization for Dimension

Low

\section{Dimension VI: Leadership Support for Community Engagement}

Component

Student Opportunities

Self-assessment

Student Awareness

2

Student Incentives \& Recognition

TOTAL

2

Mean score

1.7

Categorization for Dimension

Low 
Department 7-History

Figure 9: Summary of Department 7: Departmental Categorization

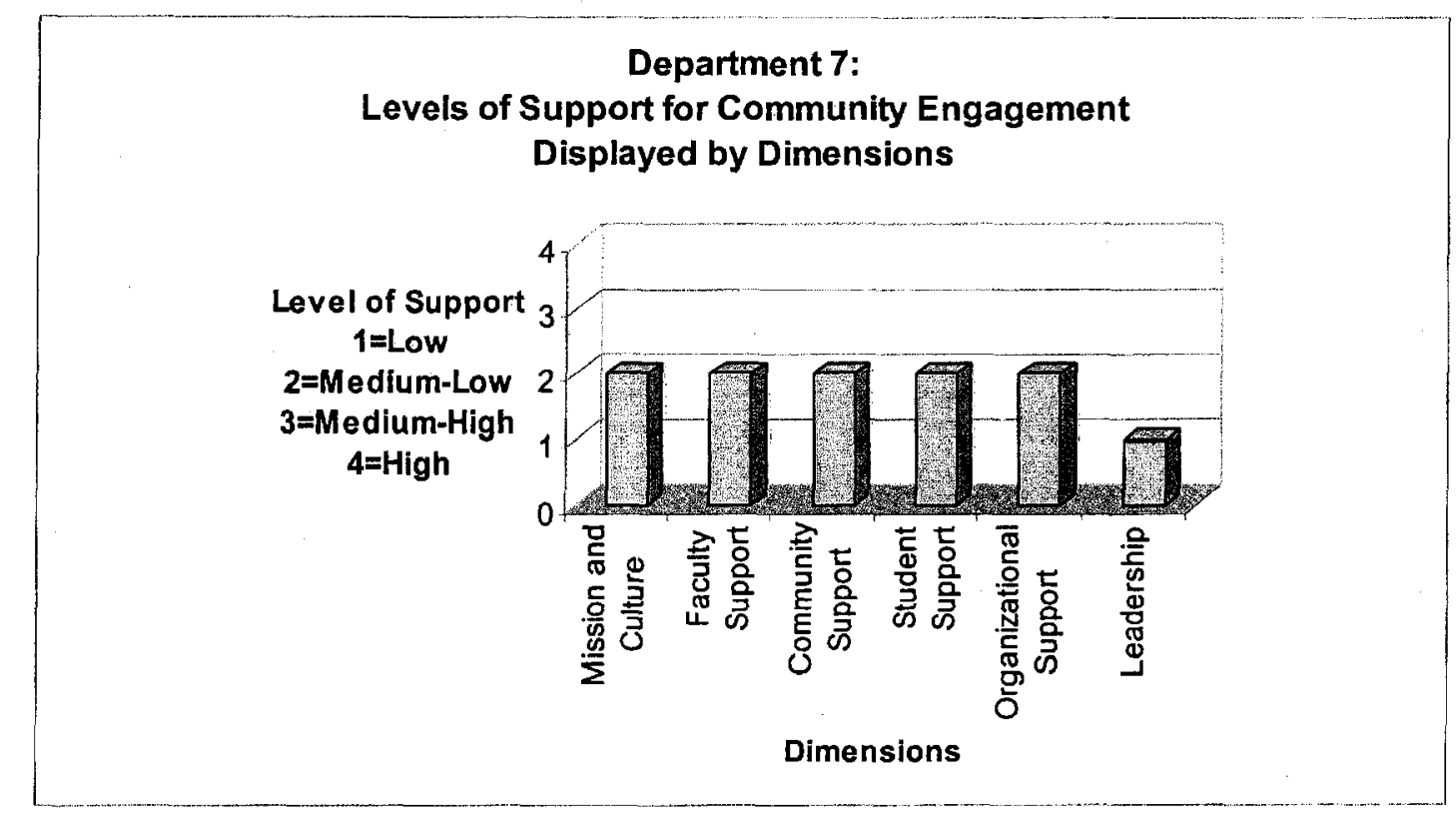

The self-assessment from Department 7 indicates that the department categorizes itself as having a medium-low level of support for community engagement for five dimensions and a low level of support for community engagement for one dimension.

Table 21: Department 7: Self-assessments arranged by dimensions

\begin{tabular}{lc}
$\begin{array}{l}\text { Dimension I: Mission and Culture Supporting Community } \\
\text { Engagement }\end{array}$ \\
Component & Self-assessment \\
Mission & 3 \\
Definition: Teaching & 2 \\
Definition: Research & 2 \\
Definition: Service & 2 \\
Climate \& Culture & 2 \\
Collective Self-Awareness & 1 \\
\hline TOTAL & 12 \\
Mean score & 2.0
\end{tabular}




\section{Dimension II: Faculty Support and Community} Engagement

Component

Knowledge/Awareness

Involvement/Support

Curricular Integration

Faculty Incentives

Review, Promotion \& Tenure

Tenure Track Faculty

TOTAL

Mean score

Categorization for Dimension
Self-assessment

3

3

1

1

3

3

14

2.3

Medium-low

\section{Dimension III: Community Partner and Partnership} Support and Community Engagement

\section{Component}

Partnership Awareness

Understanding \& Commitment

Partner Voice

Partner Leadership

Access to Resources

Partner Incentives/Recognition

TOTAL

Mean score

Categorization for Dimension
Self-assessment 2

2

1

4

1

12

Medium-low

\section{Dimension IV: Student Support and Community Engagement}

\section{Component}

Student Opportunities

Student Awareness

Student Incentives \& Recognition

Student Voice, Leadership \& Governance

TOTAL

Mean score
Self-assessment

2

2

2

3

9

2.3 
Categorization for Dimension

Medium-low

\section{Dimension V: Organizational Support for Community Engagement}

\begin{tabular}{lc} 
Component & Self-assessment \\
Administrative Support & 3 \\
Facilitating Entity & 2 \\
Evaluation \& Assessment & 1 \\
Departmental Planning & 1 \\
Faculty Recruitment and Orientation & 2 \\
Marketing & 2 \\
Dissemination of Results & 3 \\
Budgetary Allocation & 2 \\
\hline TOTAL & 16 \\
Mean score & 2.0 \\
Categorization for Dimension & Medium-low
\end{tabular}

\section{Dimension VI: Leadership Support for Community Engagement}

Component

Self-assessment

Student Opportunities

2

Student Awareness

1

Student Incentives \& Recognition

1

TOTAL 4

Mean score

1.3

Categorization for Dimension

Low 
Department 8 - Political Science

Figure 10: Summary of Department 8: Departmental Categorization

Department 8 was one of the two departments in this study that had the lowest self-assessment scores.

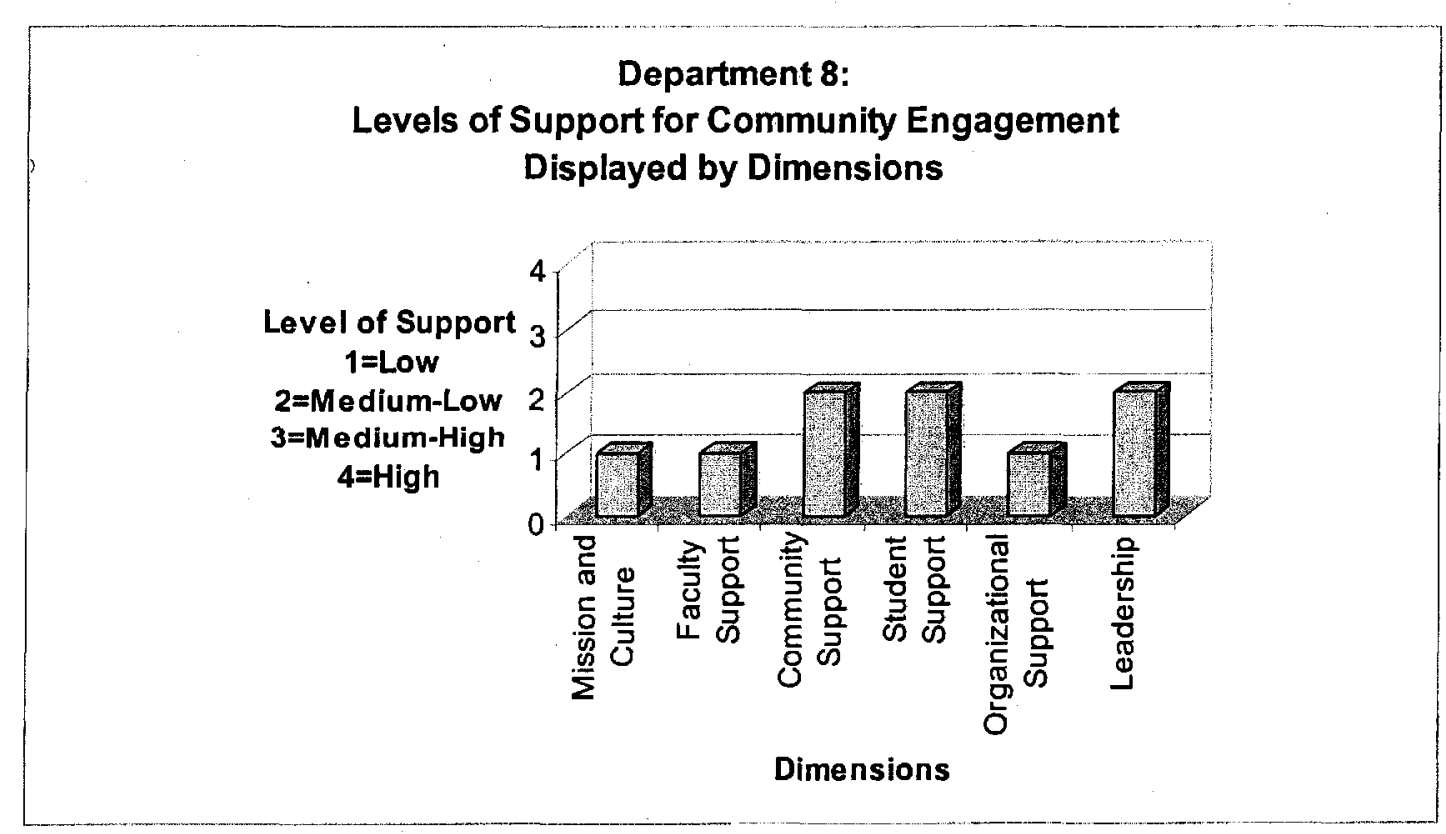

The self-assessment from Department 8 indicates that the department categorizes itself as having a medium-low level of support for community engagement for three dimensions and a low level of support for community engagement for three dimensions.

Table 22: Department 8: Self-assessments arranged by dimensions

\section{Dimension I: Mission and Culture Supporting Community Engagement}

Component

Mission
Self-assessment

3 
Definition: Teaching 1

Definition: Research · 1

Definition: Service $\quad 1$

Climate \& Culture 2

Collective Self-Awareness 1

TOTAL 9

Mean score $\quad 1.5$

Categorization for Dimension Low

Dimension II: Faculty Support and Community

Engagement

\begin{tabular}{lc} 
Component & Self-assessment \\
Knowledge/Awareness & 2 \\
Involvement/Support & 2 \\
Curricular Integration & 1 \\
Faculty Incentives & 1 \\
Review, Promotion \& Tenure & 1 \\
Tenure Track Faculty & 2 \\
\hline TOTAL & 9 \\
Mean score & 1.5 \\
Categorization for Dimension & Low
\end{tabular}

Dimension III: Community Partner and Partnership Support and Community Engagement

Component

Partnership Awareness

Understanding \& Commitment

Partner Voice

Partner Leadership

Access to Resources

Partner Incentives/Recognition

TOTAL

Mean score

Categorization for Dimension
Self-assessment

4

2

2

2

3

2

15

2.5

Medium-low

Dimension IV: Student Support and Community

Engagement 
Component

Student Opportunities

Self-assessment

Student Awareness

2

Student Incentives \& Recognition

Student Voice, Leadership \& Governance

TOTAL

Mean score

9

Categorization for Dimension

Medium-low

Note: for the following Dimension $\mathrm{V}$ for this test department, the component “Administrative Support" was left blank; therefore, there is no designation for this component in the following table. Thus, when calculating the mean score of all responses to determine the overall "level of support" for this dimension, the missing component was intentionally skipped. In other words, instead of summing eight scores and dividing by eight as was done in all of the other test cases, in this case, the seven scores that were provided were totaled, and then divided by seven.

\section{Dimension V: Organizational Support for Community Engagement}

\begin{tabular}{lc} 
Component & Self-assessment \\
Administrative Support & \\
Facilitating Entity & 2 \\
Evaluation \& Assessment & 1 \\
Departmental Planning & 2 \\
Faculty Recruitment and Orientation & 1 \\
Marketing & 3 \\
Dissemination of Results & 2 \\
Budgetary Allocation & 2 \\
\hline TOTAL & 13 \\
Mean score & 1.9 \\
Categorization for Dimension & Low
\end{tabular}

\section{Dimension VI: Leadership Support for Community Engagement}


Component

Student Opportunities

Student Awareness

Student Incentives \& Recognition

TOTAL

Mean score

Categorization for Dimension

\section{Self-assessment}

2

1

3

6

2.0

Medium-low

\section{Department 9 -Social Work}

\section{Figure 11: Summary of Department 9: Departmental Categorization}

Department 9 was one of the two departments in this study that had the highest self-assessment scores.

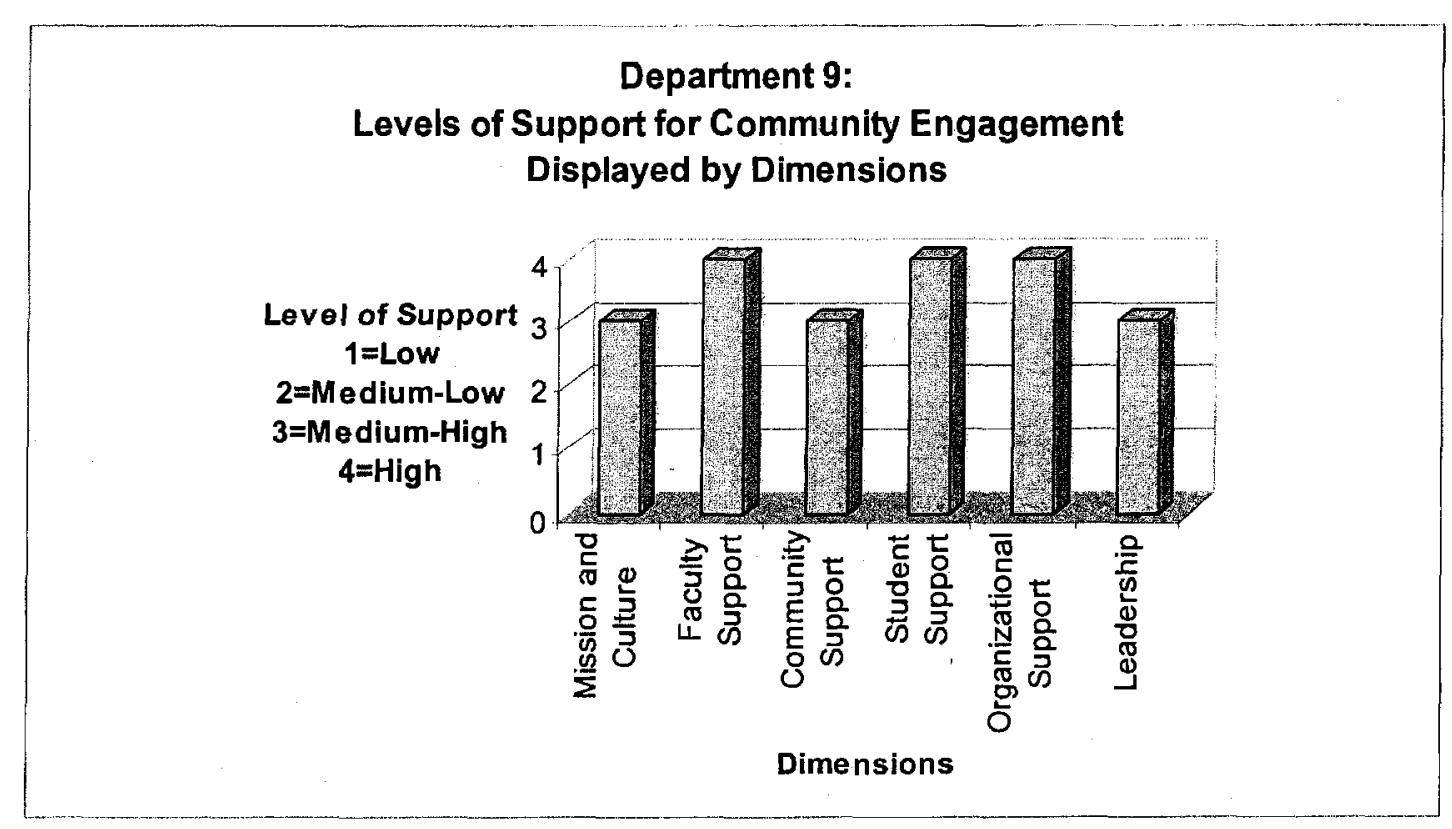

The self-assessment from Department 9 indicates that the department categorizes itself as having a high level of support for community engagement for three dimensions and a medium-high level of support for community engagement for three dimensions. 
Table 23: Department 9: Self-assessments arranged by dimensions

\section{Dimension I: Mission and Culture Supporting Community Engagement}

\begin{tabular}{lc} 
Component & Self-assessment \\
Mission & 3 \\
Definition: Teaching & 3 \\
Definition: Research & 3 \\
Definition: Service & 3 \\
Climate \& Culture & 3 \\
Collective Self-Awareness & 3 \\
\hline TOTAL & 18 \\
Mean score & 3.0 \\
Categorization for Dimension & Medium-high
\end{tabular}

\section{Dimension II: Faculty Support and Community Engagement}

Component

Knowledge/Awareness

Self-assessment

Involvement/Support

4

4

Curricular Integration 3

Faculty Incentives 3

Review, Promotion \& Tenure 4

Tenure Track Faculty 4

TOTAL 22

Mean score $\quad 3.7$

Categorization for Dimension High

\section{Dimension III: Community Partner and Partnership} Support and Community Engagement

\section{Component}

Partnership Awareness

Understanding \& Commitment

Partner Voice

Partner Leadership

Access to Resources

Partner Incentives/Recognition

TOTAL
Self-assessment

3

2

3

3

4

3 
Mean score

Categorization for Dimension

Medium-high

\section{Dimension IV: Student Support and Community Engagement}

\begin{tabular}{lc} 
Component & Self-assessment \\
Student Opportunities & 4 \\
Student Awareness & 3 \\
Student Incentives \& Recognition & 3 \\
Student Voice, Leadership \& Governance & 3 \\
\hline TOTAL & 13 \\
Mean score & 3.3 \\
Categorization for Dimension & High
\end{tabular}

\section{Dimension V: Organizational Support for Community Engagement}

Component

Administrative Support

Self-assessment

Facilitating Entity

4

Evaluation \& Assessment

3

Departmental Planning

3

Faculty Recruitment and Orientation 3

Marketing

3

Dissemination of Results 3

Budgetary Allocation $\quad 3$

TOTAL

25

Mean score

3.1

Categorization for Dimension

High

\section{Dimension VI: Leadership Support for Community Engagement}

Component

Student Opportunities Self-assessment

Student Awareness

Student Incentives \& Recognition

3

TOTAL 3

Mean score 


\section{Department 10 - Environmental Science and Resources}

Figure 12: Summary of Department 10: Departmental Categorization

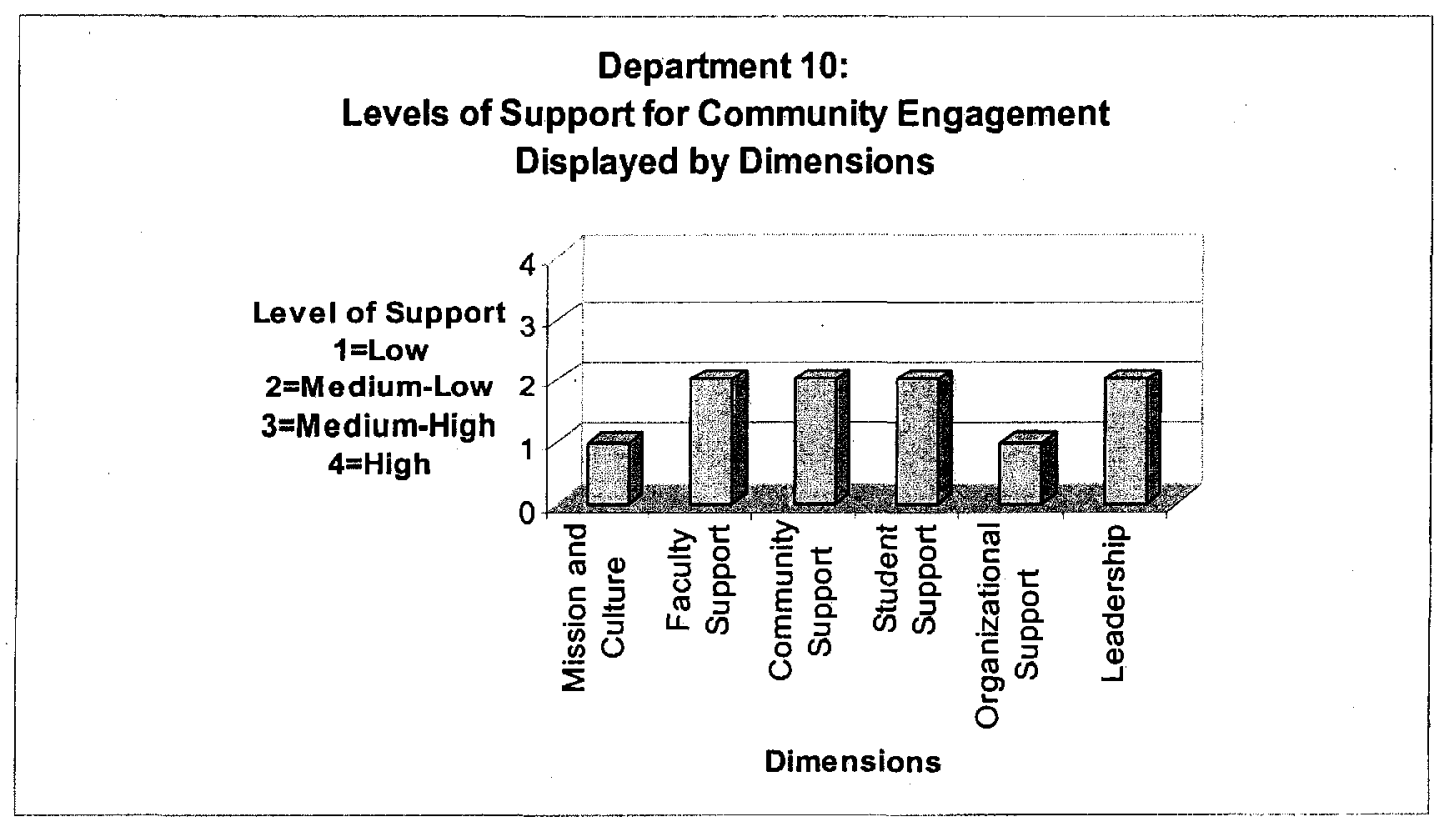

The self-assessment from Department 10 indicates that the department categorizes itself as having a medium-low level of support for community engagement for four dimensions and a low level of support for community engagement for two dimensions.

Table 24: Department 10: Self-assessments arranged by dimensions

\section{Dimension I: Mission and Culture Supporting Community}

\section{Engagement}

Component

Mission

Definition: Teaching

Definition: Research

Definition: Service

Climate \& Culture
Self-assessment

2

2

2

1

3 


\begin{tabular}{lc} 
Collective Self-Awareness & 1 \\
\hline TOTAL & 11 \\
Mean score & 1.8 \\
Categorization for Dimension & Low
\end{tabular}

\section{Dimension II: Faculty Support and Community Engagement}

\begin{tabular}{lc} 
Component & Self-assessment \\
Knowledge/Awareness & 3 \\
Involvement/Support & 3 \\
Curricular Integration & 1 \\
Faculty Incentives & 2 \\
Review, Promotion \& Tenure & 2 \\
Tenure Track Faculty & 3 \\
\hline TOTAL & 14 \\
Mean score & 2.3 \\
Categorization for Dimension & Medium-low
\end{tabular}

Dimension III: Community Partner and Partnership Support and Community Engagement

Component

Partnership Awareness

Understanding \& Commitment

Partner Voice

Partner Leadership

Access to Resources

Partner Incentives/Recognition TOTAL

Mean score

Categorization for Dimension
Self-assessment 2

2

2

2

3

2

13

2.2

Medium-low

\section{Dimension IV: Student Support and Community Engagement}

Component

Student Opportunities

Student Awareness

Student Incentives \& Recognition
Self-assessment

2

3

2 
Student Voice, Leadership \& Governance

TOTAL

Mean score

Categorization for Dimension
2 9

2.3

Medium-low

\section{Dimension V: Organizational Support for Community}

\section{Engagement}

Component

Administrative Support

Self-assessment

Facilitating Entity

3

Evaluation \& Assessment

2

Departmental Planning

2

Faculty Recruitment and Orientation

Marketing

Dissemination of Results

Budgetary Allocation

TOTAL

Mean score 15

Categorization for Dimension 1.9

Low

\section{Dimension VI: Leadership Support for Community}

\section{Engagement}

Component

Student Opportunities

Student Awareness

Student Incentives \& Recognition

TOTAL

Mean score

Categorization for Dimension
Self-assessment

3

2

1

2.0

Medium-low 
Figure 13: Summary of Department 11: Departmental Categorization

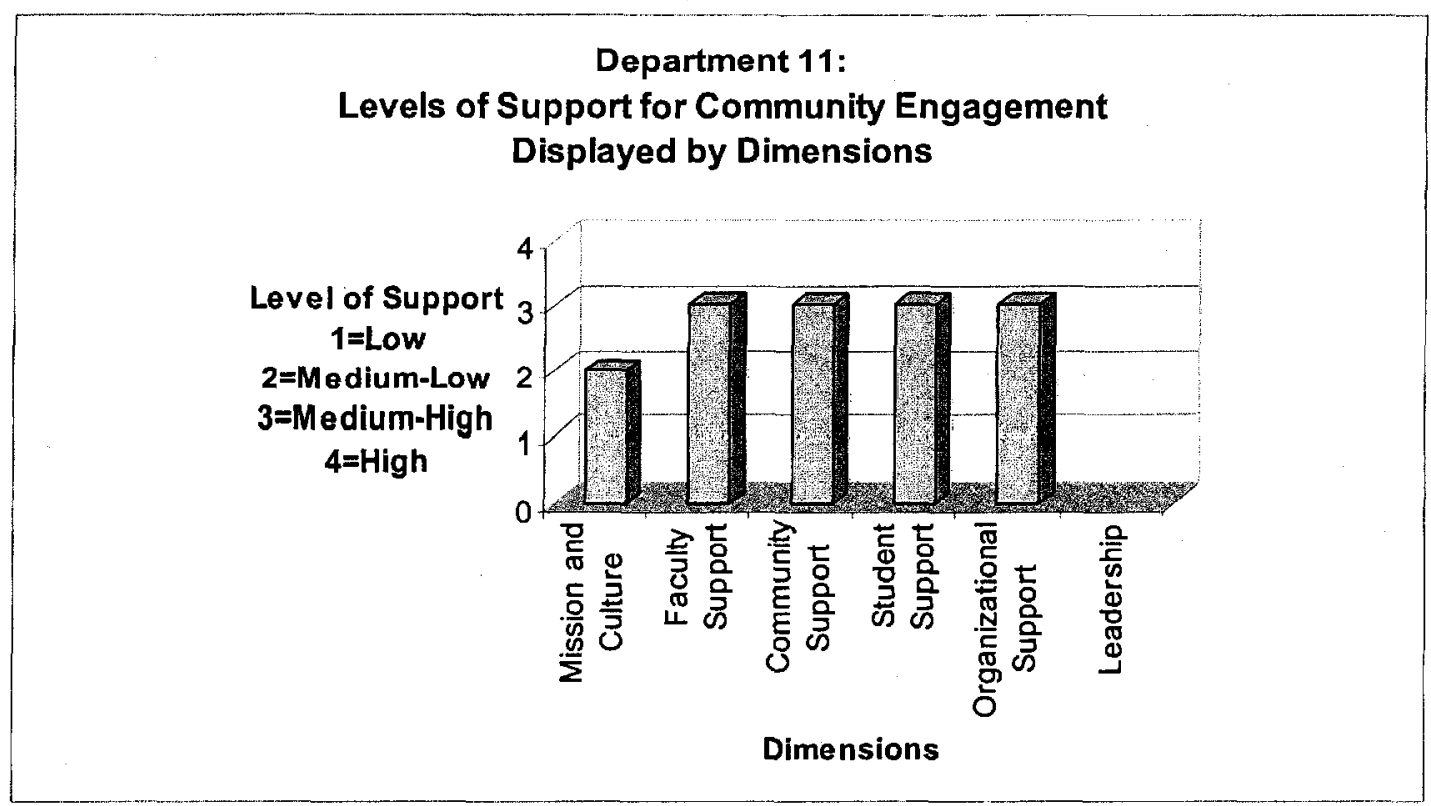

The self-assessment from Department $11^{4}$ indicates that the department categorizes itself as having a medium-high level of support for community

${ }^{4}$ Participants from Department 11 left two of the three components of Dimension VI blank - "Campus Level Leadership from Departmental Faculty" and "National Level Leadership from Departmental Faculty." Therefore, there is no designation for these components in the associated table below. This occurrence made calculating the mean score of all responses to determine the overall "level of support" for this dimension impossible since two of the overall three scores were missing. Thus, there is no designation for Dimension VI ("Leadership Support for Community Engagement") in the "Summary of Department 11: Departmental Categorization" histogram above. Also, for Dimension II from Department 11 (below), the component "Review, Promotion, and Tenure Process Integration" was left blank; therefore, there is no designation for this component in the following table. Thus, when calculating the mean score of all responses to determine the overall "level of support" for this dimension, the missing component was intentionally skipped. In other words, instead of summing six scores and dividing by six as was done with the other test cases, in this case, the five scores that were provided were summed, and then divided by five. 
engagement for four dimensions and a medium-low level of support for community engagement for one dimension.

Table 25: Department 11: Self-assessments arranged by dimensions

\begin{tabular}{lc}
$\begin{array}{l}\text { Dimension I: Mission and Culture Supporting Community } \\
\text { Engagement }\end{array}$ \\
Component & Self-assessment \\
Mission & 3 \\
Definition: Teaching & 2 \\
Definition: Research & 2 \\
Definition: Service & 2 \\
Climate \& Culture & 4 \\
Collective Self-Awareness & 2 \\
\hline TOTAL & 15 \\
Mean score & 2.5 \\
Categorization for Dimension & Medium-low
\end{tabular}

\section{Dimension II: Faculty Support and Community Engagement}

Component

Knowledge/Awareness

Self-assessment

Involvement/Support

3

Curricular Integration

3

Faculty Incentives

Review, Promotion \& Tenure

Tenure Track Faculty

TOTAL

2

Mean score

2.6

Categorization for Dimension

Medium-low

Dimension III: Community Partner and Partnership

Support and Community Engagement

Component

Partnership Awareness

Understanding \& Commitment
Self-assessment

3

3 
Partner Voice 3

Partner Leadership 2

Access to Resources 4

Partner Incentives/Recognition $\quad 3$

TOTAL 18

Mean score $\quad 3.0$

Categorization for Dimension Medium-high

\section{Dimension IV: Student Support and Community}

\section{Engagement}

Component

Student Opportunities

Self-assessment

Student Awareness

4

Student Incentives \& Recognition

Student Voice, Leadership \& Governance $\quad 2$

TOTAL

Mean score

3.0

Categorization for Dimension

Medium-high

\section{Dimension V: Organizational Support for Community} Engagement

Component

Self-assessment

Administrative Support

4

Facilitating Entity

3

Evaluation \& Assessment

3

Departmental Planning

2

Faculty Recruitment and Orientation

3

Marketing

3

Dissemination of Results

2

Budgetary Allocation

TOTAL

23

Mean score

2.9

Categorization for Dimension

Medium-high

\section{Dimension VI: Leadership Support for Community Engagement}

Component

Self-assessment 
Student Opportunities

Student Awareness

Student Incentives \& Recognition

\begin{tabular}{ll}
\hline TOTAL & na \\
Mean score & na \\
Categorization for Dimension & na
\end{tabular}

Department 12 - Psychology

Figure 14: Summary of Department 12: Departmental Categorization

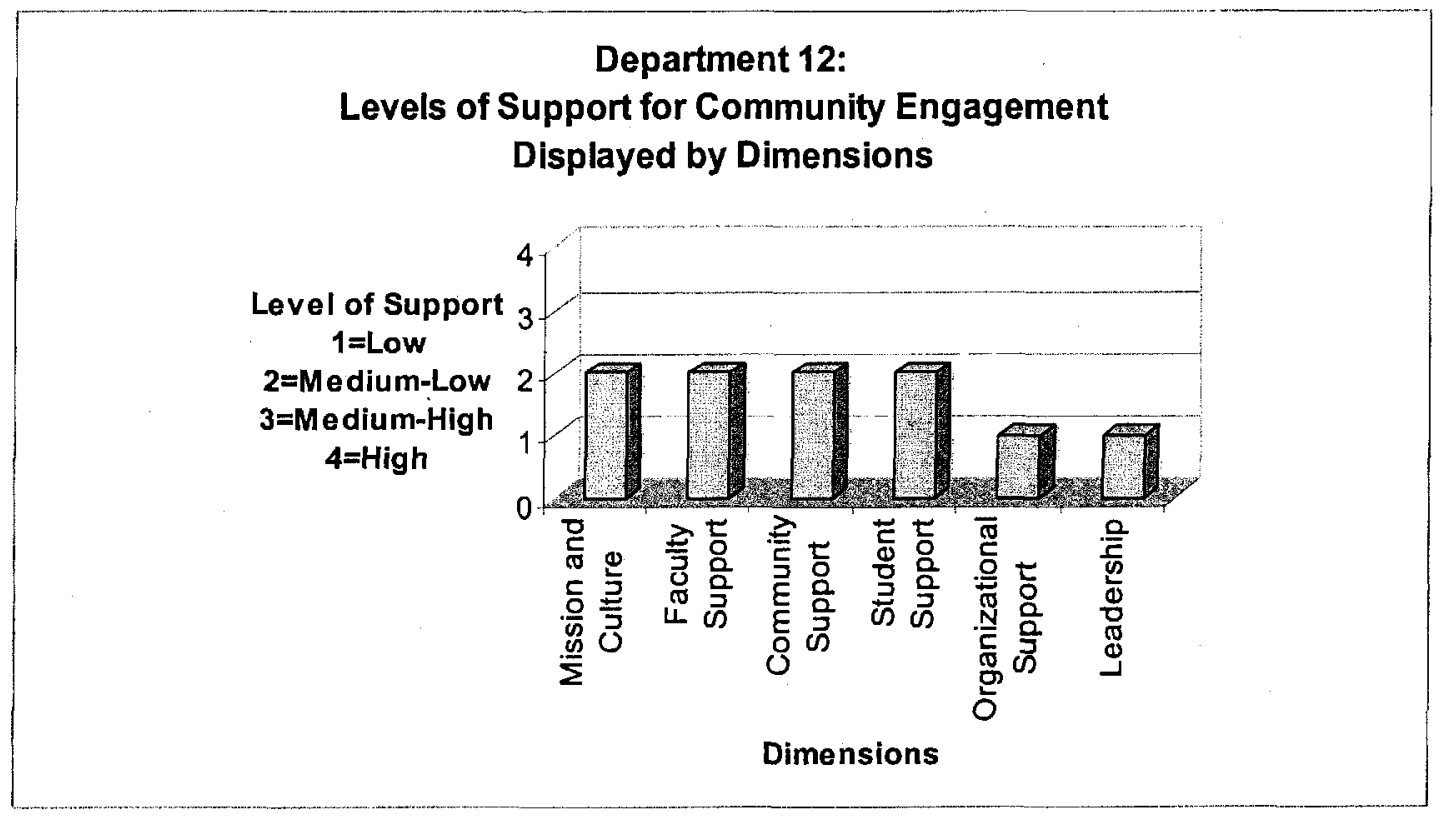

The self-assessment from Department 12 indicates that the department categorizes itself as having a medium-low level of support for community engagement for four dimensions and a low level of support for community engagement for two dimensions.

Table 26: Department 12: Self-assessments arranged by dimensions

Dimension I: Mission and Culture Supporting Community Engagement
Component
Self-assessment 
Mission 2

Definition: Teaching 2

Definition: Research 1

Definition: Service 2

Climate \& Culture 3

Collective Self-Awareness $\quad 2$

TOTAL 12

Mean score $\quad 2.0$

Categorization for Dimension Medium-low

\section{Dimension II: Faculty Support and Community} Engagement

Component

Knowledge/Awareness

Involvement/Support

Curricular Integration

Faculty Incentives

Review, Promotion \& Tenure

Tenure Track Faculty

TOTAL

Mean score

Categorization for Dimension
Self-assessment

3

2

2

1

4

3

15

2.5

Medium-low

Dimension III: Community Partner and Partnership Support and Community Engagement

Component

Partnership Awareness

Understanding \& Commitment

Partner Voice

Partner Leadership

Access to Resources

Partner Incentives/Recognition

TOTAL

Mean score

Categorization for Dimension
Self-assessment

3

2

2

2

3

3

2.5

Medium-low 


\section{Dimension IV: Student Support and Community Engagement}

Component

\begin{tabular}{c} 
Self- \\
assessment \\
3 \\
3 \\
2 \\
2 \\
\hline 10 \\
2.5 \\
Medium-low
\end{tabular}

Student Opportunities

Dimension V: Organizational Support for Community Engagement

Component

Administrative Support Self-

Facilitating Entity assessment

Evaluation \& Assessment

Departmental Planning

Faculty Recruitment and Orientation

Marketing 2

Dissemination of Results

Budgetary Allocation 3

TOTAL 15

Mean score 1.9

Categorization for Dimension

Low

\section{Dimension VI: Leadership Support for Community Engagement}

Component

Student Opportunities Self-assessment

Student Awareness

2

Student Incentives \& Recognition

TOTAL

2

Mean score 2.0

Categorization for Dimension Low 
This section featured the presentation of departmental data, divided by department and presented in numerical order. First, for each department the reader was provided with a summary histogram displaying categorizations ("low," "mediumlow," "medium-high," or "high" level of support for community engagement) for each of the dimensions in the Rubric. Following the histogram that summarizes the categorizations of the department's self-assessment the reader was presented with a series of tables that feature the raw departmental response data. These tables display data at the level of component scores, as well as provide the total score, mean calculation, and categorization determination in accordance with the decision rules outlined in chapter three. Any missing scores were highlighted and briefly discussed.

\section{Summary histograms comparing each department by level of support}

\section{categorization}

The two histograms that follow (Figure 15 - first, test departments 1-6; then, test departments 7-12) display the categorizations ("low," "medium-low," "mediumhigh," and "high" level of support for community engagement) of each of the test departments organized by dimension. For ease of viewing, this data display has been divided into two histograms.

Displaying the data in this fashion enables researchers to quickly review the data; within case and across case analysis is facilitated. Departments 2 (Family Social Science) and 9 (Social Work) scored the highest self-assessment ratings. Conversely, Departments 6 (History) and 9 (Political Science) scored the lowest self-assessment 
ratings. Also, as will be discussed in greater detail in the following chapter 5, only one department (Department 5) had more than one "level of support" differentiation between dimensions. All other departments displayed strong consistency in mean score self-assessment. In other words, departments that self-assessed highest along the scale had all mean scores of "medium-high" or "high." Conversely, departments that self-assessed lowest along the scale had all mean scores of "medium-low" or "low." Some of these findings, and others, will be discussed in the next chapter.

Figure 15: Summary histograms comparing each department by level of support categorization
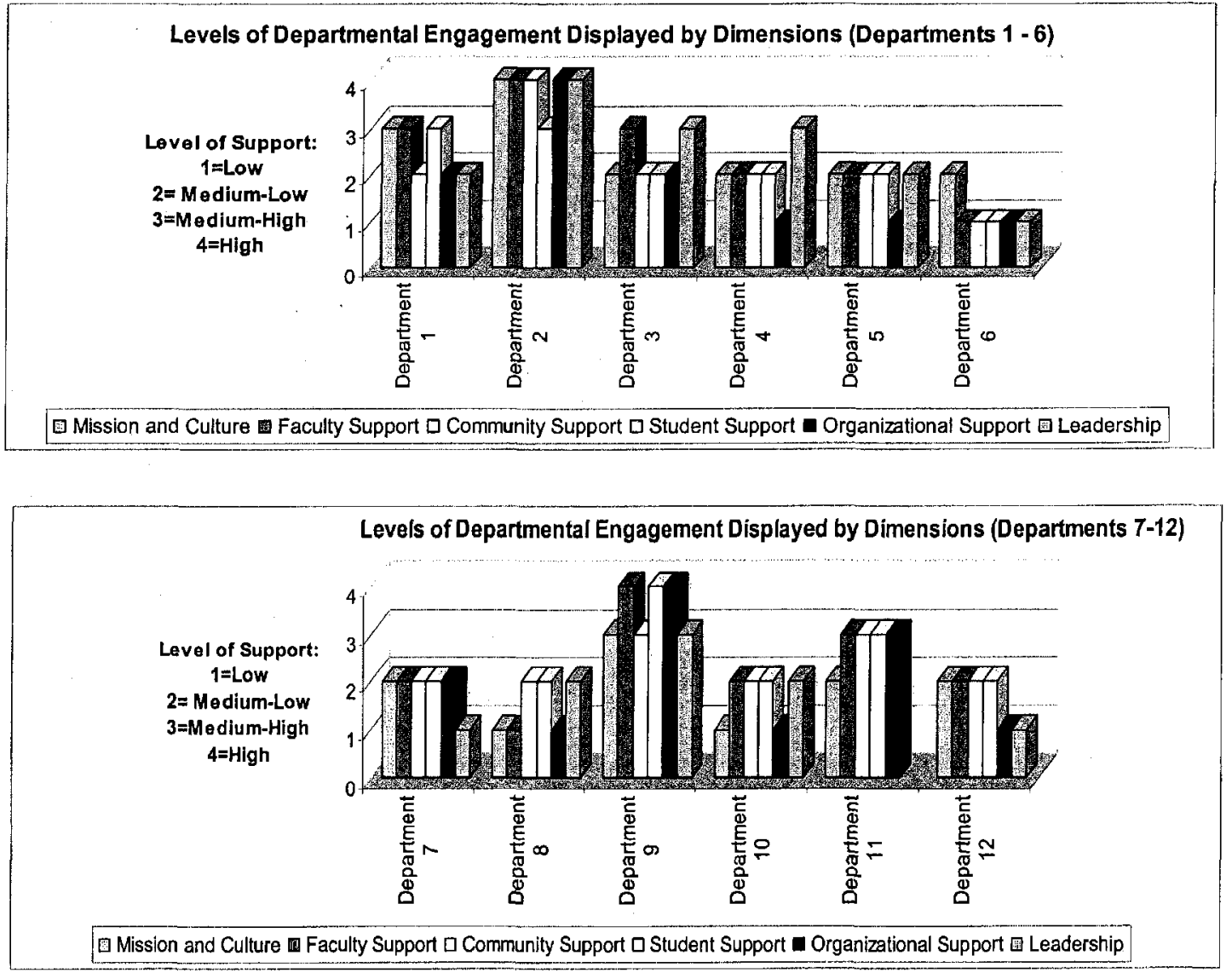


\section{Finding from the open-ended survey questions}

To analyze participants' responses to the open-ended survey questions, a threepart strategy was employed. Part one features a summary table of the various strategies used by departments as they reported those strategies in the first two questions of the open-ended survey regarding "process." A macro-analysis of responses is also provided in descriptive and table format. Part two focuses on locating and selecting key verbatim statements, or "low inference descriptors" (Johnson, 1997), that respondents made in which they commented directly or otherwise provided an opinion regarding the utility of the explanatory framework (the Rubric). This strategy was used to provide direct evidence, in the form of verbatim quotations, in response to question three of this study regarding the utility of the instrument. The data regarding utility are included from eleven of the twelve test departments associated with this study are displayed in Table 29. Part three focuses on recommendations for improvements and general comments regarding use of the Rubric. In this final section, the researcher employed a thematic analysis strategy (Charmaz, 2006) to make additional "analytic sense of the material" (p. 54) for the purpose of grouping respondents' comments and recommendations regarding possible future improvements to the instrument as well as general comments about the Rubric and departmental engagement. 
Part One-Summary of strategies used by departments to take the self-assessment

Table 27 below displays select verbatim statements regarding departments'

comments about the process of working with the self-assessment Rubric. Second, a

brief discussion and summary (Table 28) will be provided in which key macro-

analytic observations are displayed.

Table 27 - Select Departmental Responses Regarding Self-Assessment Processes

- Institution A (Department 1) "Department was approached by representative from community engagement office. Department chair contacted faculty member who engages in service-learning. A faculty member and chair completed the assessment together, and discussed responses through collaborative processes until consensus was reached."

- Institution A (Department 1) "We were reminded that we should initiate and seek more community partners when revisiting departmental goals, mission statements and strategic goals."

- Institution A (Department 2) "The department chair and the communitycampus health liaison (faculty member) each completed the form independently. We then consulted about items for which our responses were more than one category apart. We consulted with the director of undergraduate studies on the curricular integration questions, as well as one other faculty member."

- Institution A (Department 2) "It would have been more useful if we had more time to consult with the faculty as a whole."

- Institution B (Department 4) "Wrestling with the decision as to which stage to place our department. And the placement being what we desire it to be, what it is, or what it should be (based on the respondent's perspective)."

- Institution B (Department 4) "Provide a response field for the information about departmental support as well as from other levels of the institution... [and] for the respondent to describe any particularly unique interpretation or perspective, or approach to community engagement that influenced the respondent's answers in the Rubric"

- Institution B (Department 5) "I [department head] sent out an email to all my department colleagues informing them of the opportunity and seeking their 
input on the self-assessment. Given that it is the middle of the summer, only 4 out of 15 indicated that they were available to meet.... We each shared our individual responses and then collectively completed the assessment on behalf of the department."

- Institution C (Department 11) "Because the request for doing the rubric came at the end of the term no attempt was made to put a self-assessment team together specifically for this project.... [Recently] faculty volunteered to be members of various departmental committees, one of which is a departmental self-assessment committee. I think the rubric will be very useful to us when we do meet in the fall."

- Institution C (Department 11) "I definitely see why having a team of people think about and discuss it would be very useful. One could imagine, with incentives, having the community partner in on the process as well."

- Institution E (Department 12) "The Psychology Department Executive Committee members completed the scale as individuals and then they convened and established a group consensus on the rating." [Group included 6 individuals: Chair, undergraduate director, Heads of the three graduate programs, senior lecturer]

The overarching purpose of Table 27 is to provide the reader with summary verbatim comments regarding the various processes that the different departments undertook to complete the self-assessment. There was a range of response strategies which included responses from a single individual to responses from a six-person team. The data suggest that department members see value in a team approach to completing the self-assessment. This issue will be revisited in Chapter 5 in the limitations of the study section.

The overarching purpose of the following Table 28 is to provide the reader with macro-analytic observations in order to begin to view key components of the departmental responses in table format. Items displayed include the disciplinary identification, the highest and lowest overall self-categorizations, chair involvement 
and self-assessment process with focus on whether a group process was used by the department to complete the self-assessment.

Table 28: Summary of Test Department Self-Assessment Response Data

\begin{tabular}{|c|c|c|c|c|c|}
\hline $\begin{array}{c}\text { Dept } \\
\#\end{array}$ & $\begin{array}{l}\text { Disciplinary } \\
\text { Focus of } \\
\text { Department }\end{array}$ & $\begin{array}{l}\text { Highest } \\
\text { Categor- } \\
\text { izations }\end{array}$ & $\begin{array}{l}\text { Lowest } \\
\text { Categor- } \\
\text { izations }\end{array}$ & $\begin{array}{l}\text { Dept. } \\
\text { Chair } \\
\text { Involved }\end{array}$ & $\begin{array}{l}\text { Rubric } \\
\text { Completed by } \\
\text { Group Decision }\end{array}$ \\
\hline 1 & $\begin{array}{l}\text { Speech, } \\
\text { Language and } \\
\text { Hearing }\end{array}$ & $\sqrt{ }$ & & $\sqrt{ }$ & $\sqrt{ }$ \\
\hline 2 & $\begin{array}{l}\text { Family Social } \\
\text { Science }\end{array}$ & $\sqrt{+}$ & & $\sqrt{ }$ & $\sqrt{ }$ \\
\hline 3 & Sociology & $\sqrt{ }$ & & $\sqrt{ }$ & $\sqrt{ }$ \\
\hline 4 & $\begin{array}{l}\text { Agriculture } \\
\text { Resources and } \\
\text { Economics }\end{array}$ & & & & \\
\hline 5 & $\begin{array}{l}\text { Adult and } \\
\text { Higher } \\
\text { Education }\end{array}$ & & & $\sqrt{ }$ & $\sqrt{ }$ \\
\hline 6 & History & & $\sqrt{ }$ & & \\
\hline 7 & History & & & & \\
\hline 8 & $\begin{array}{l}\text { Political } \\
\text { Science }\end{array}$ & & $\sqrt{ }$ & $\sqrt{ }$ & \\
\hline 9 & Social Work & $\sqrt{t}$ & & $\sqrt{ }$ & $\sqrt{ }$ \\
\hline 10 & $\begin{array}{l}\text { Environmental } \\
\text { Science and } \\
\text { Resources } \\
\end{array}$ & & $\sqrt{ }$ & $\sqrt{ }$ & \\
\hline 11 & $\begin{array}{l}\text { Applied } \\
\text { Linguistics }\end{array}$ & $\sqrt{ }$ & & & \\
\hline 12 & Psychology & & & $\sqrt{ }$ & $\sqrt{ }$ \\
\hline
\end{tabular}

Summary comments regarding the data displayed in Table 28 include: 1) In all twelve cases the department chair was informed about departmental participation in this study. 2) In eight of the twelve cases the department chair was directly involved in the self-assessment. Further, 3) in six of the eight cases that the chair was involved, 
other departmental representatives were also involved in a group decision-making process to complete the self-assessment.

Other observations that emerge from macro-analysis of the data in Table 28 revolve around the groupings of highest and lowest scores. In four of the five cases of highest self-assessment scores, the Rubric was completed by a consultative group process, most often by a consensus decision-making model. Conversely, in all three of the lowest self-assessment score cases the Rubric was completed by a single individual. While these relationships are too weak, and this study was not designed to make substantive co-relational claims, the data do suggest that probing in this area in future research might be useful. For example, for an engaged or highly engaged academic unit it might seem out of step to take a departmental self-assessment without involving others from the department in the process. On the other hand from an institutional theory perspective, if everyone in the department shares the same values about the role of community engagement and what counts for evidence, the involvement of others may be less problematic. The data in this small study support the need to study this issue further. For example, even in the one case of a department that scored high on the self-assessment (Deparment 11) and did not involve the chair or complete the Rubric by group process, the researcher was told directly by the chair and the individual who filled out the Rubric that they were disappointed that the full group could not participate more fully due to the summer recess. Probing further the consequences of the group process for the lowest scoring departments could also be useful. 


\section{Part Two - Verbatim quotations from respondents}

The following excerpts located in Table 29 are verbatim statements made by respondents regarding the utility of the explanatory framework (the Rubric). This strategy follows the recommendation of Maxwell (2005) to provide "rich data" display and Johnson (1997) to transparently report "low inference descriptors," or where possible verbatim statements from respondents.

\section{Table 29: Respondents' Verbatim Comments Regarding Utility of the Rubric}

- "Evaluating community engagement is something that we have not formalized....Formal measurement could be very useful and is something that we will seriously consider implementing" (Department 1).

- "We were reminded that we should initiate and seek more community partners when revisiting departmental goals, mission statements and strategic plans" (Department 1).

- "It [the process of completing the Rubric] would have been even more useful if we could have had more time to consult with the faculty as a whole" (Department 2).

- The process of completing the Rubric made us "more sensitive to evaluation and assessment - no plans in place" (Department 3).

- "I found the Rubric to be well organized and a useful thought process to go through in terms of thinking about the intensity of community engagement supported by and done by the department" (Department 4).

- "I found al1 [dimensions and components] to be useful" (Department 4).

- "Dimensions III and IV [were most useful] - how our department interfaces with community partners - in approaches and [how we] involve them, recognize them, and communicate with them" (Department 4).

- "...we did think the conversations about community engagement was valuable and helpful to our future strategic planning" (Department 5).

- "No significant difference in usefulness of various components" (Department 6). - Note: this department mentioned that nothing was unclear and nothing was missing in other sections of the open-ended survey, suggesting that a reasonable interpretation of the verbatim statement is that all components were equally useful. 
- "The Rubric was very lucid and sane" (Department 7).

- "The Rubric is very thorough...it asks what pieces are either there or not there from an institutional standpoint (perfectly reasonable and helpful things to think about to be sure!)" (Department 7).

- 'I can't help but try to imagine what an historians' custom 'wish list' for supporting engagement would look like" (Department 7).

- "The specific anchors and examples were helpful" (Department 9).

- "Dissemination of results is something we are working on, the question reinforces that our approach is the right one" (Department 10).

- "Our department has a self-assessment team that will be getting together during the 2008-2009 academic year. That team was formed during a recently scheduled department meeting in which faculty volunteered to be members of various departmental committees, one of which is a department selfassessment committee. I think the Rubric will be very useful to us when we do meet in the fall" (Department 11).

- "I can't think of any missing information. The Rubric is very educational in itself, providing ideas for where to move forward in civic engagement. GREAT TOOL!!!" (Department 11).

- "The entire Rubric is VERY useful. It is quite educational!! It's easy to get locked into your own department and you own work. It was very enlightening and useful to see on a continuum regarding how far we've come and where we might go. The Rubric will be an excellent resource when our assessment committee meets. THANKS!" (Department 11).

- "When descriptions of the components included concrete examples of how engagement might be expressed, that was most helpful" (Department 11).

- "The Rubric was useful for me in my own community engagement work. I definitely see why having a team of people think about and discuss it would be very useful. One could imagine, with incentives, having the community partner in on the process as well" (Department 11).

- "[There are] plenty of points for discussion, but no confusion" (Department 12).

- "As a reflective exercise, the task was very useful to the department and has been referenced to in subsequent discussion in the department" (Department 12).

Table 29 contains verbatim statements from eleven of the twelve departments that took the self-assessment. Without exception, the statements clearly suggest that the test departments found the Rubric to be useful. There were no comments that 
contradicted this claim about utility of the Rubric from any of the test departments.

This topic will be revisited in Chapter 5 in greater detail.

Part Three - Additional Responses to the Rubric

Generally, additional participant responses to the Rubric fall into two

categories: 1) specific, instrumental recommendations aimed to clarify or enhance the instrument, and 2) broad comments about community engagement in higher education seen through the lens of the interaction with the Rubric. A thematic summary of these comments follow in Table 30 ; first with recommendations, followed by general comments.

Table 30: Recommendations for Rubric Enhancement and General Comments

$\underline{\text { Recommendations }}$

- Add a "response field" to allow participants to clarify and expand their responses.

- Clarification recommendations:

- Address concern about a double-barreled question in one of the components ("Administrative Support" cells)

- Address a consistency in language issue ("Faculty Support" cells; "National Level Leadership" cells).

\section{General Comments}

Promotion and tenure concerns

- "With regards to promotion and tenure it's not the presence of community engagement that gives one's research particular value, it's the quality of the research that is highly valued" (Department 1 ).

- “A key legitimizing source for historians...is other practicing disciplinary historians. Insofar as our work with engagement has currency with other scholars, my sense is that it advances. When it does not, it stalls or is actively resisted" (Department 7). 


\section{Community partners and partnership challenges}

- 'One major challenge is that history is 'global' but community partnerships tend to be physically local (though potentially global in reach). With limited resources, we run the risk of being asked to look around nearby when it might be a good thing to look far, far beyond immediate, physical, geographical "community"' (Department 7).

" "Is the community partner always right?" (Department 5).

- "It is possible...to imagine a scenario in which deeper institutionalization would actually create resistance, particularly in the rubric cells which seem to validate 'incentives' and 'leadership' for community partners within the work of the department. In an academic setting where regular faculty struggle to get just rewards and exercise leadership over the curriculum, this will likely be a very tough sell" (Department 7).

Regarding the suggestion to add a "response field," members of Department 4 wrote, "Providing an answer box (field) for the respondent to describe any particularly unique interpretation or perspective, or approach to community engagement that influenced the respondent's answers in the Rubric. For example, how our department's unique 'core' thread of economics impacts how we approach many areas of community engagement from policy makers, to elected community leaders, to community members with a special interest in the topic or issue" (bolded in the original comments). Members of Department 5 wrote, "perhaps adding an 'other' category in the stages section for respondents to add qualitative comments. This would have been helpful given the uniqueness of our department."

Regarding the issue of the double-barreled question, members of Department 8 argue, "Row one in Dimension 5 ("Administrative Support") asks two questions at once: whether the chair understands community engagement AND whether the issue 
appears on unit agendas. There is not an option to report that the chair understands community engagement deeply AND does not place the issue on unit agendas, which would be my answer to this question."

Finally, with respect to clarifying the language in two specific rows of cells, members of Department 11 wrote, "Under 'Faculty Incentives' stages 2, 3, and 4 do you mean 'within the unit, faculty member are...' because it appears in stage 1, but not the others. I wasn't sure if that was intentional" (italics in original). Also, later in the survey members of Department 11 comment on a lack of clarity in the "Leadership Support” cells: “'National Level Leadership from Departmental Faculty' talks about 'national disciplinary association leadership'. Does this refer to leadership in one's field, or leadership in community engagement?"

The summary general comments cluster around two main themes-promotion and tenure concerns and partnership and community partner challenges-and point to additional areas of thought and/or concern on the part of the participants. They will be briefly discussed in the final chapter.

\section{Conclusion - Summary of Findings}

The purpose of this chapter was to present findings from phase-two of this dissertation research-responses of test departments to the explanatory framework (the Rubric). The chapter was organized in two sections: Section One, which lists the test departments, identified by discipline; and Section Two, which presents the findings, separated by departments, in the following order: 
- presentation, via a summary histogram, of the categorizations of each dimension of the departmental responses to the Rubric;

- presentation, via the use of a series of tables, of the component-level raw data from the departmental responses to the Rubric followed by the total of all scores, mean score, and categorizations ("low," "medium-low," "mediumhigh," or "high" level of support for community engagement) of each dimension in accord with the decision rules outlined in chapter three;

- presentation, via two summary histograms, comparing each department by level of support categorization; and

- summary presentation of responses to the open-ended questionnaire. This final section was organized into three parts: 1) outline of various processes enacted by departments; 2) low inference descriptors regarding utility of the explanatory framework; and 3) recommendations for enhancement to the framework and general comments regarding community engagement. The next and final chapter discusses the data presented in chapter four. It also provides a discussion of the limitations of the study and areas for future research. Finally, the chapter will conclude with an exploration of some of the theoretical and practical implications of this research. 


\section{Chapter V: Discussion, Limttations, AREAS For Future Research, IMPLICATIONS AND CONCLUDING THOUGHTS}

This chapter will begin with a discussion of the data resulting from phase-two of the overall research strategy of this dissertation - the testing of the explanatory framework. Since this phase of the research was developed to directly address the third research question of this dissertation, the discussion will focus specifically on responding to the following central research question:

3. Can the utility and validity of the new instrument be confirmed by using qualitative methods (Charmaz, 2006) to evaluate the responses from pilot-test social science departments located at five urban, geographically-diverse, Carnegie-classified community engaged, public, higher education institutions? After addressing this research question in the light of the data collected for this study, the chapter will discuss some of the limitations of this study. This will be followed by a discussion of areas for future research. Then, the major theoretical and practical implications of the study will be explored, with special focus on the relevance of an institutional theory perspective for the study of civic engagement at the level of academic departments. Finally, the chapter will present some overarching conclusions.

\section{$\underline{\text { I. Discussion }}$}

Proposition: There was clear agreement that the Rubric was useful.

Rationale: At a most basic, indirect level, this study confirms this claim because all twelve departments took the time to fill out the Rubric completely and send their responses to the researcher. Much more directly and powerfully, eleven of the 
twelve departments provided concrete, positive responses regarding the utility of the instrument. In the previous chapter, a focused set of 21 positive, verbatim quotations from departmental respondents regarding the direct utility of the instrument were provided. Departmental respondents did not make any comments to suggest that the Rubric was not useful. It is therefore reasonable to confirm from the following list of potent, low inference descriptors (with no descriptors to the contrary) that respondents found the explanatory framework to have significant utility:

- "The Rubric was very lucid and sane" (Department 7).

- "The entire Rubric is VERY useful. It is quite educational!! It's easy to get locked into your own department and you own work. It was very enlightening and useful to see on a continuum regarding how far we've come and where we might go. The Rubric will be an excellent resource when our assessment committee meets. THANKS!" (Department 11).

- "I found the Rubric to be well organized and a useful thought process to go through in terms of thinking about the intensity of community engagement supported by and done by the department" (Department 4).

- "...we did think the conversations about community engagement were valuable and helpful to our future strategic planning" (Department 5).

- "The specific anchors and examples were helpful" (Department 9).

- "Dissemination of results is something we are working on, the question reinforces that our approach is the right one" (Department 10). 
- "We were reminded that we should initiate and seek more community partners when revisiting departmental goals, mission statements, and strategic plans" (Department 1).

- "As a reflective exercise, the task was very useful to the department and has been referenced to in subsequent discussion in the department" (Department 12).

Proposition: The Rubric meets the test of being a valid self-assessment instrument for the pilot-test social science departments located at the five higher education institutions associated with this qualitative study.

Rationale: There are two major processes as well as a transparent data set that substantiate this validity proposition.

During the first major process — the building of the explanatory frameworkcare was taken to follow standard qualitative, grounded theory research protocols. As outlined in chapter three, Johnson (1997) argues that "when qualitative researchers speak of research validity, they are usually referring to qualitative research that is plausible, credible, trustworthy, and, therefore, defensible" (p. 160). In phase-one of this study, a three-step iterative process was intentionally designed that utilized experts/key informants (Wagner \& Sternberg, 1985) to generate initial data and later refine and confirm the content validity of the explanatory framework through a process of "respondent validation" (Maxwell, 2005, p. 111). As discussed previously, this three-step process of theory building based on expert/key informant interviews, 
integration with extant literature, and respondent validation established support for all three main types of validity in qualitative research: descriptive, interpretive, and theoretical validity (Johnson, 1997).

During the second major process of this dissertation-phase-two in which data were collected from twelve test departments that took the departmental selfassessment-the descriptive validity (or, the factual accuracy of the account) is supported by the dimension-by-dimension data reporting strategy of using six rawdata display tables for each test department. Interpretive validity (or, the degree to which participants' viewpoints are accurately understood and reported) is supported by the use of low inference descriptors (Johnson, 1997) or verbatim, "rich data displays" (Maxwell, 2005, p. 110). Transparently, displaying raw data responses from subjects increases trustworthiness, dependability, and credibility in the qualitative research process (Lincoln \& Gupa, 1985). Theoretical validity (or, the degree to which the theoretical explanation fits that data) is supported by the delineation of and rigorous adherence to the decision rules that determine the dimension-by-dimension support categorizations of "low," "medium-low," "medium-high," and "high" level of support for community engagement for each dimension of community engagement. Face validity, or "the extent to which the items appear to measure the intended constructs" (John \& Benet-Martinez, 2000, p. 352), is supported by the consistent lack of substantive responses to the open-ended survey questions regarding "confusion" and "items missing," (questions 3 and 4 on the open-ended survey) and consistent and positive participant responses to queries regarding the instrument's usefulness 
(question 5 on the open-ended survey). Finally, the proposition that the explanatory framework exhibits construct validity, or "whether the measure accurately reflects the construct intended to measure" (John \& Benet-Martinez, 2000, p. 352), is supported by the strong consistency in the within-case responses. For example, an analysis of Figure 16 below indicates that in all cases except one (Department 4) none of the "levels of support" responses are separated by more than one level. This suggests that there is strong internal consistency among participants' ratings of the six dimensions. In other words, if departmental participants rated themselves "low" for any one dimension, and there was strong consistency of self-rating across the six dimensions of the measure (i.e., construct validity), then it could be expected that the self-ratings for the remaining five dimensions would either be "low" or "medium-low." Indeed, as indicated in Figure 15 below, eleven of the twelve test departments confirm this pattern of consistency in response.

Figure 16: Levels of Support for Departmental Engagement, Displayed by

\section{Dimensions}

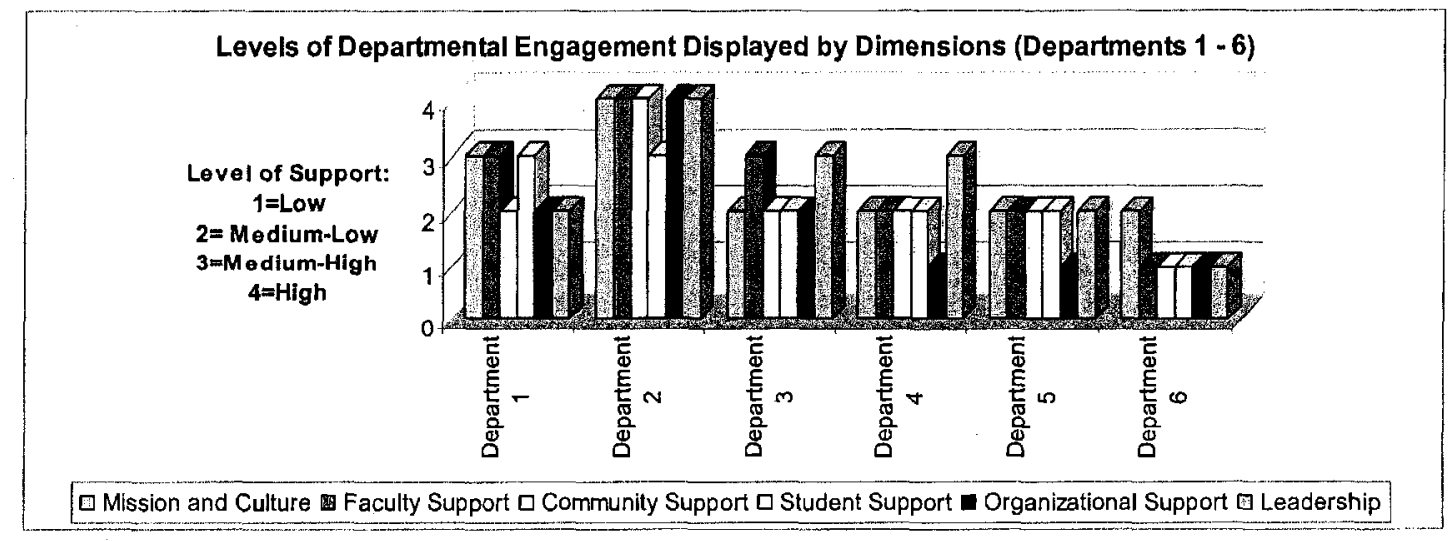




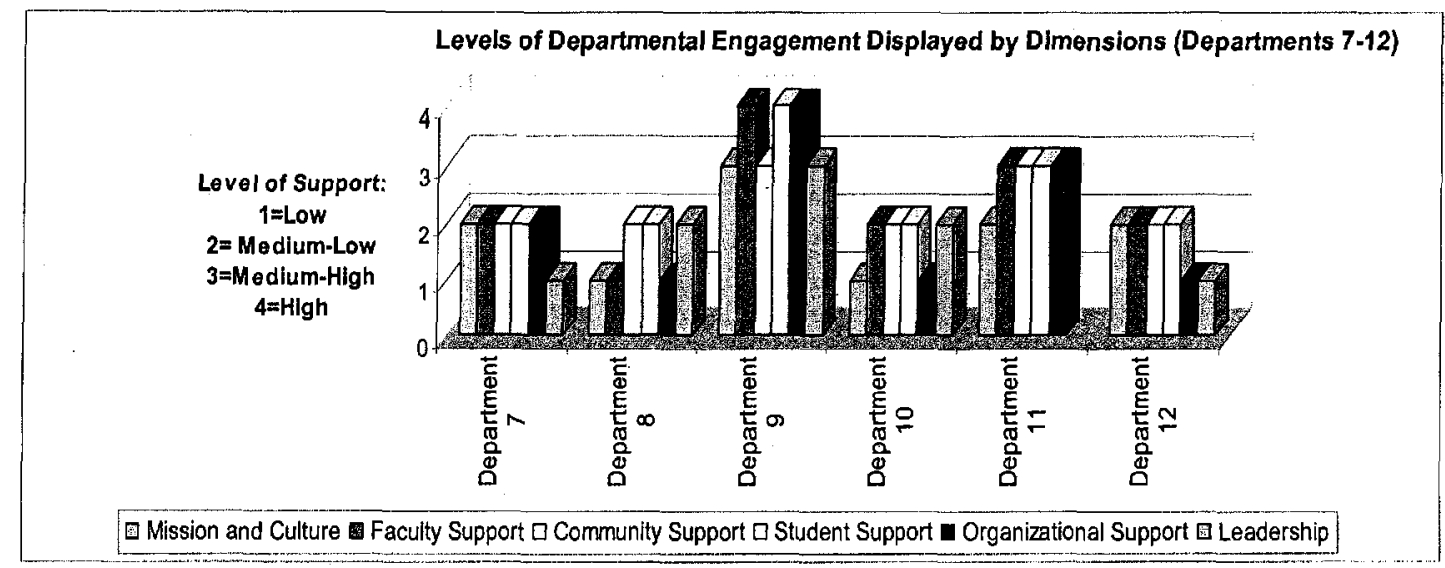

In summary, notwithstanding the limitations to this study discussed in the next section, the findings indicate an affirmative response to the $3^{\text {rd }}$ central research question of this study. The utility and validity of the new instrument has been confirmed by using qualitative methods to evaluate the responses from pilot-test social science departments located at five urban, geographically-diverse, Carnegie-classified community engaged, public, higher education institutions. There was clear agreement that the test departments found the self-assessment Rubric to be useful. The transparent display of departments' raw-data responses increases trustworthiness and dependability in the qualitative research process and outcomes (Lincoln and Guba, 1985). And, within the defined limits of this study the explanatory framework is valid in accord with the broad understanding and definitions of descriptive, interpretive, theoretical, content, face, and construct validity claims in qualitative research. 


\section{$\underline{\text { Recommendations }}$}

In this section, responses to study participants' summary recommendations and general thoughts will be provided. It is noted that further modification and testing of the Rubric is beyond the scope of this dissertation study. However, briefly discussing participants' summary recommendations is not inappropriate.

The first major recommendation was for the addition of some type of additional, qualitative "response field" (Department 4). This suggestion is entirely appropriate and should be incorporated into the next iteration of the Rubric. Providing participants with multiple avenues to interact with the self-assessment will increase researchers' abilities to triangulate data responses. During the development of the Rubric, an intentional choice was made to remove the "other" column that is featured in both the Furco (2003) and Gelmon, Seifer et al. (2005) instruments. While this study acknowledged that the "other" column might have provided sufficient permission for respondents to add some qualitative clarification, the size of the cell seemed too small to allow for more than a few words or bulleted phrases to be included. This was an intentional measurement design choice. Also, with respect to this dissertation study, the researcher was aware that respondents would be invited to respond to the six-question, open-ended survey, thus ensuring sufficient opportunity for participants to provide substantive nuanced, qualitative responses. Based on respondents' feedback, it is now clear that reincorporating the "other" column similar to that originally included in the Furco $(2000,2003)$ and Gelmon, Seifer et al. (2005) instruments is desirable. 
Providing a balanced option of response venues would be best. If the Rubric were designed to elicit only qualitative responses, departmental teams might possibly become too mired in the specific, contextual explanations. Also, the time commitment necessary to write a substantive qualitative response to each of the existing series of questions regarding community engagement at the departmental level would be quite large, thus decreasing the motivation to complete the assessment. This burden becomes even greater if departments are asked to use the Rubric to re-assess repeatedly over time in order to determine or measure movement along any of the salient components or dimensions. By contrast, the categorization strategy and easyto-view tables and graphic depiction (histograms) and analysis of the data consisting of "low," "medium-low," "medium-high," and "high" level of support for community engagement provides interested parties a mechanism to view a snapshot of departmental engagement at any one point in time, or over time. Indeed, the next iteration of the explanatory framework should include an optional, additional, qualitative response field.

The recommendation for removal of "double-barreled" questions (e.g., "Administrative Support" cells) is excellent and appropriate. Also, the confusion around language for the "Faculty Incentives" cells and the "National Level Leadership" cells is also appropriate and very useful feedback. Indeed, the qualifying term "within the unit" should have been consistent throughout all four stages in the "Faculty Incentives" component, rather than only appearing in the first stage cell. Similarly, the "National Level Leadership from Departmental Faculty" component 
discusses "national disciplinary association leadership" but it is not clear if that leadership is more general in nature, applied to one's field, or more specifically meant to measure national level leadership for community engagement in one's field. The intent was to measure the latter. It is advised that each one of these recommendations be implemented in the development of the next iteration of the Rubric.

Summary of participants' general comments (below) do not signal technical, instrumental issues with the explanatory framework. Rather, they are more constitutive in nature; they point toward on-going issues in the academy such as the role and understanding of the promotion and tenure process and the role and relation of community partners to the academic enterprise. In both cases, the low inference descriptors below-first, regarding promotion and tenure, and next regarding community partnerships - are emblematic of traditional tensions within and among departmental disciplines.

- "With regards to promotion and tenure it's not the presence of community engagement that gives one's research particular value, it's the quality of the research that is highly valued" (Department 1 ).

- "A key legitimizing source for historians...is other practicing disciplinary historians. In so far as our work with engagement has currency with other scholars, my sense is that it advances. When it does not, it stalls or is actively resisted" (Department 7).

It is not difficult to agree with both of these statements. However, both statements use traditional lenses that often are used to determine the value of a 
particular scholarly activity. In the first case, the "quality" of research is what is valued - indeed, as it should be. However, if quality is the lone indicator of value and that value is determined by the leading scholars in ones field, then application (or use) of new knowledge may be viewed as having less importance or no importance at all. This study argues in accord with emerging transdisciplinary research paradigms (Gibbons, 1994; Gibson, 2006) that application and use of new knowledge needs to be valued as highly as quality of research as measured by the conventional practice of used by "refereed" journals in ones disciplinary field.

Regarding comments about community partners and partnership challenges one might applaud the thoughtfulness of the following responses.

- 'One major challenge is that history is 'global' but community partnerships tend to be physically local (though potentially global in reach). With limited resources, we run the risk of being asked to look around nearby when it might be a good thing to look far, far beyond immediate, physical, geographical 'community"' (Department 7).

- "Is the community partner always right?" (Department 5).

- "It is possible...to imagine a scenario in which deeper institutionalization would actually create resistance, particularly in the rubric cells which seem to validate 'incentives' and 'leadership' for community partners within the work of the department. In an academic setting where regular faculty struggle to get just rewards and exercise leadership over the curriculum, this will likely be a very tough sell" (Department 7). 
Many of these comments, however, suggest a subtle penchant to see the academic enterprise through a "zero-sum" lens. For example, in the first quotation, one might wonder what stops the faculty member or department from looking and acting both locally and globally. A reasonable assumption is that the faculty member perceives him/herself as an actor in a resource scarce environment. There are many questions that might be asked about the second quotation, such as "Is the faculty member always right?" Or, "What does 'right' mean?" Again, this statement seems to suggest there is only "one right way," indicating a zero-sum, rational approach tó teaching, learning, research and knowledge production. Finally, the last quotation suggests the presence of a competitive departmental environment; one in which the "limited resources" are divided up in smaller and smaller bits among "struggling" faculty. Working within that mental framework, or within a departmental climate and culture that does not question a zero-sum view of the work and organization, community partners might indeed encounter resistance from disgruntled (and competitive) faculty, especially if incentives are not offered to them for their participation.

An explanatory framework like the one developed for this dissertation study does indeed challenge some of the most fundamental, traditional concepts that were, until recently, held sacrosanct in the "hallowed halls" of higher education. To a large extent, the subjects of this study are positively disposed to the emerging "community partnership" model of teaching and research. This is no surprise since the participating departments were intentionally selected by community engagement 
directors on their campuses because of their leadership role in this emerging new model. One might wonder, then, what kind of response would be expected if the Rubric were tested more broadly, especially in settings less positively predisposed toward community-connected teaching, learning and knowledge creation.

\section{Limitation of this Study}

There are several limitations to this study, which will be discussed in the following four major categories: 1) rubric development; 2) study population; 3) data collection and analysis; and 4) meta-level questions.

\section{Rubric Development}

As previously discussed, the expert/key informant interviews were conducted over a seven-week period in early 2007 . Although extensive, hand-written notes were taken during the interview process, and then soon afterward these notes were typed by the researcher into electronic format in order to expand on and clarify key points while the information was still fresh, this study did not employ a recording and transcription strategy. Charmaz (2006) suggests that recording and transcription is the preferred data gathering strategy for using a grounded theory approach. Therefore, it is possible that the researcher missed some nuanced points from the expert/key informants. These points may have led to a deeper understanding of one or more components or dimensions, and possibly even led to the addition of more or different components or dimensions to the explanatory framework. 
Also, seven of the nine expert/key informant interviews were conducted by phone conversation. Although this process is admittedly not uniform, the researcher was familiar with each of the experts/key informants and made the determination that the setting of the interview was less (or not) important compared to other issues, such as ensuring that there was sufficient time to conduct the interview. The researcher consistently asked the same two questions to each of the interviewees and conducted the interviews in an informal, conversational style in order to take advantage of (in most cases) a long-term personal relationship with each of the experts.

\section{Study population}

As discussed in chapter 3, this dissertation intentionally limited the study setting and subjects to members of social science departments located within public, urban, Carnegie-classified for community engaged, 4-year higher education institutions in order to attempt to limit the confounding factors of this research. Conversely, the study did select institutional settings that were geographically diverse and fairly representative of the United States, including one or more institutions each from the South, North, Midwest and Northwest. These strict setting and subject choices make generalization of the findings problematic. However, in qualitative research, the term "transferable" (Lincoln and Guba, 1985) is preferred over the more traditional term "generalizable." Lincoln and Guba (1985) argue that qualitative researchers "can provide only the thick description necessary to enable someone interested in making a transfer to reach a conclusion about whether transfer can be 
contemplated as a possibility" (p. 316). Further, they argue that the researcher "can only set out working hypotheses together with a description of the time and context in which they were found to hold. Whether they hold in some other context, or even in the same context at some other time, is an empirical issue, the resolution of which depends upon the degree of similarity between sending and receiving (or earlier or later) contexts" (p. 316). The validity claims associated with this study are made in light of Lincoln and Guba's comments cited above regarding qualitative research, thus limiting the research claims of this study to the pilot-test institutional and departmental contexts outlined in this study.

The fact that neither students nor community partners were invited to participate in this initial study is another limitation to this research. For future research, ideally, one might imagine a study setting in which all or most of the department personnel are present along with several students and key community partners. Organizing and facilitating a departmental self-assessment with such a diverse group would require additional time and commitment that was beyond the scope of this present study. Implementing the self-assessment in this manner, however, presents the possibility of using the instrument heuristically to increase the understanding of multiple, diverse constituents regarding the role and public purposes of the academic unit. Applying, and perhaps eventually requiring this type of expanded and more inclusive self-assessment process, if tested more fully, has the potential to add to the body of literature on institutional theory with regard to deep meaning making as part of a transformational process. Indeed, Zuiches (2008) argues, 
when discussing the experience of North Carolina State University while undergoing the study for inclusion in the Carnegie Classification that "pursuing this elective classification stimulated intense discussions across the campus about NC State's commitment to community engagement, and the process generated a new energy for greater investment by the colleges and units" (p. 45).

Also, while the researcher selected the setting (individual universities that conformed to study inclusion factors) the actual subjects (test departments) were chosen by the local community engagement director. Although written instructions were provided in two places in the Rubric, the researcher never spoke directly with most of the subjects and so was unable to ensure that each test department received the same process instructions for completing the self-assessment. This led to significant deviation in the localized processes for undertaking the self-assessment. Indeed, as outlined in chapter 4 , some departments involved the chair, while others did not; some completed the self-assessment by using a group decision-making strategy, while in some departments the self-assessment was undertaken by one individual only.

Additionally, having the local community engagement director select the subjects for inclusion reduced the control of the principal researcher over the selection process and thus could legitimately be seen as a limitation. However, working with and through the local program directors can also be viewed in a positive light since they are the ones who know their subjects best and were able to most effectively motivate and support the departments during the process. Also, the local directors were specifically asked to select social science departments that were diverse in terms 
of their familiarity with and commitment to departmental community engagement. This strategy was followed so to ensure overall variance in response. Again, working with local directors facilitated this selection and was an efficient use of time and resources.

Finally, due to timing constraints, the self-assessment was administered over the summer months. This is largely interpreted as a limitation of the study since many departmental faculty and staff were likely away from campus during the summer months, thus making it more challenging for any department to engage with the selfassessment by using a fully inclusive process. It would have increased the probability of having more departmental faculty participate in this study if the survey instrument had been administered during the regular academic year. Yet, notwithstanding the summer deployment of the study, six of the twelve test departments undertook the self-assessment by using a consultative group process, in some cases utilizing a consensus decision-making model.

\section{Data Collection and Analysis}

As discussed above, the data for phase-two of this study were generally derived from individual departmental representatives or small groups of departmental personnel. This is a limitation of the study since departments, in most cases, were not able to have a full departmental discussion concerning engagement or the selfassessment. Also, only two sources of data were collected for this study: 1) responses to the self-assessment Rubric, and 2) responses to the six question open-ended survey. 
While this data collection strategy was appropriate for the size and scope of this pilot study, it is limiting. The study, as designed and implemented, relies heavily on individual and/or group perception and not on original source material. From an institutional theory perspective, perceptions of what is going on are not the heart of the matter; rather, the goal for an institutionalist is to create a capacity that adds up to a durable difference that counts for the organization and the community that comprises it. This surfaces a creative tension between the use of the Rubric and the implementation of a departmental change strategy. On the one hand, the utility of simply having academic unit members participate in the self-assessment instrumentally can be accomplished relatively quickly, can have significant value for the department, but that value could be limited. Yet, if the Rubric is utilized more constitutively as a heuristic tool by the chair or other facilitative leaders associated with the unit, then there is greater opportunity for unit members-and those associated with the unit, i.e., students and key community partners - to deepen understanding and socially construct new meaning regarding the role of teaching and research through community engagement. But the time commitment necessary to implement this kind of engagement will be significantly increased. Whether one is interested in the Rubric as a measurement instrument or a developmental opportunity for the department and its larger community, it would be useful in the future to collect salient documents as evidence for departmental engagement, such as past department meeting agendas in which community engagement appears as an item, budget documents, assessment 
documents, marketing materials, examples of curricular materials from the required courses in the major, and so on.

Finally, a limitation in qualitative research studies is researcher bias, or the effects of the researcher on the data gathering and analysis. This study attempted to intentionally mitigate this issue by employing the strategy of responder verification (Maxwell, 2005) during the development of explanatory framework. Further, the researcher kept and regularly consulted a reflective log to document process decisions as well as regularly consulted one or more dissertation committee members, other faculty, and other research associates throughout the process in an effort to minimize researcher bias, increase efficiencies, reduce confusion, and so on. However, one limitation of this study is the fact that the results of the departmental support categorizations and the summary of the low inference descriptor statements were not sent back to the test department personnel for responder verification. Although study participants would surely find this information interesting, especially to see how their department fared compared to others in the study, given the scope of this study this limitation has minimal impact.

\section{Meta-level questions}

In its current state, the Rubric does not provide respondents with sufficient open-ended discussion or writing prompts to guide department-level considerations of larger questions of purpose and value. Notwithstanding the issue of the tensions associated with time considerations for departments taking the self-assessment, a 
limitation of this study is that open-ended writing and/or discussion questions or prompts such as those that follow were not integrated into the Rubric. 1) Why does your department engage with community? 2) How does your department engage with community? 3) What difference does it make? To whom? How do you know? And, 4) Has a departmental focus on community engagement changed any internal or external departmental processes? Within the departmental faculty? For students? For community partners? Within the College, or university-wide? From an institutional theory perspective, asking these questions and evaluating the responses could eventually lead to deeper insights regarding how members of departmental units create collective meaning for themselves, their professional colleagues, their students, and their community partners.

\section{Conclusion - Summary of Limitations}

This section has discussed the numerous limitations to this study with a focus on four major categories of limitations: 1) Rubric development; 2) Study population; 3) Data collection and analysis; and 4) meta-questions. The next section of this chapter will discuss areas for future research that have emerged in the course of completing this study 


\section{Areas for Future Research}

Several areas for future research are suggested by this study. These areas can be organized around the following four central themes: 1) transferability; 2) use and utility; 3) correlations; and 4) the potential of connecting self-assessment research and development efforts to institutional theory.

\section{Transferability}

Given the limitations of this study summarized in the previous section, some of the most immediate areas for future research cluster around application of the instrument (or one that has been further modified to accommodate the recommendations surfaced in this study) in diverse departmental and institutional settings. The questions that follow align with this clustered area of future research.

- To what extent might the Rubric be effectively utilized in additional social science-related academic units located in similar institutional settings? In dissimilar institutional settings?

- To what extent might the Rubric be effectively utilized in humanities, arts, and/or natural science academic departments in similar institutional settings? In dissimilar institutional settings?

- Might the Rubric need to be modified specifically to accommodate difference in disciplinary and/or institutional settings. For example, should different descriptors, components and/or dimensions be developed for use with natural 
science disciplines? With disciplines in the humanities? With disciplines located in non-urban areas? Or, in non Carnegie-classified institutions?

- To what extent might the Rubric be effectively utilized in international institutional settings, including in social science-related academic units or in the arts, humanities, or natural sciences-related departments?

- Are there specific dimensions and/or components that might be especially effective for the self-assessment of predominantly undergraduate programs? Graduate programs? How might the Rubric be modified to accommodate these differences in curricular level?

\section{Utility and Use}

Areas for future research in this sub-section are divided into two groupings. Group one features questions that are predominantly instrumental in nature; group two suggests areas that are more substantive in nature and thus relate to the possible use of institutional theory to help us better understand the transformative process that is involved in obtaining ownership of the community engagement agenda at the academic department level.

Group One: Instrumental Areas for Future Research

The suggestions for future research in this section focus on improvements in research methodology and the instruments used to collect and display the findings.

- Is the histogram method of displaying summary data helpful? If so, how so? 
- Might the use of the histograms and relatively short and easy-to-use Rubric add to departmental willingness to engage with the self-assessment repeatedly over time? If so, what difference might that make? To whom? Toward what end?

- Might the overall outcome of the self-assessment be enhanced by simultaneously collecting extant departmental documents and evaluating them for evidence of commitment to community engagement, such as marketing materials, course descriptions and syllabi, department meeting agendas, budget documents, and so on? If so, how so?

\section{Group Two: Substantive Areas for Future Research}

The areas for further research identified in this section focus on substantive changes that may inhibit or advance the ability of academic departments to develop ownership of the community engagement agenda and incorporate this ownership into multiple dimensions of the departmental community.

- To what extent might departments use the Rubric for planning purposes?

Might department-level interactions with the Rubric, over time, deepen understanding and help socially construct new meaning around various topics, including community engagement, community building, participatory democracy, the role of education in society, refocusing research agendas to make them more community-engaged, applied or user-inspired, and so on? 
- Might the development and dissemination of a companion planning guide and/or user's guide be helpful to departments? If so, how so? What elements would be useful to include in a companion planning or user's guide? For example, would a series of definitions be useful? Would URLs to specific resources that are linked to particular dimensions and components be useful?

- To what extent could a case study approach focusing on academic units that have successfully undergone a process of transformation toward deeper community connectedness be useful? To whom? For what?

- Might the eleven case studies of successful "engaged departments" described in Engaging Departments (Kecskes, 2006) be analyzed for major themes that might further inform the development of a departmental, self-assessment

\section{Rubric?}

\section{Correlations}

- In this dissertation study, 80 percent of the departments that self-rated in the highest categories ("medium-high," or "high" level of support for community engagement) had direct chair participation in the self-assessment, and engaged with the self-assessment by using deliberation and group decision-making approach. To what extent might those correlations hold in similar departments/institutional settings? In dissimilar departments/institutional settings? 
- Might self-assessment ratings on the Rubric correlate with an emerging list of barriers to, and facilitators for, departmental engagement (Kecskes, Gelmon, and Spring, 2006)? Do any specific barriers or facilitators tend to correlate with any specific dimensions or components from the Rubric? Might researchers develop and test specific applications of facilitators in order to expedite increased departmental engagement and/or mitigate departmental barriers to deeper commitment and sustained action?

- Do Rubric self-assessment ratings correlate with levels of community-based, interdisciplinary, transdisciplinary or other types of applied or "user-inspired" research outputs?

- To what extent, if any, might correlations exist between Rubric self-assessment ratings and

- Student success (as defined by student satisfaction? Graduation rates? Etc.)

$\circ$ Alumni giving

- Alumni career choices 1 years, 3 years, 5 years, 10 years after graduation

- Alumni (and student) political and/or other civic engagement rates, over time

- Alumni (and student) volunteerism rates, over time

- Employee satisfaction ratings regarding graduates from the department, over time 


\section{Connections to Institutional Theory}

As mentioned in Chapter One, institutional theory provides researchers with a frame of reference that focuses on the processes for arbitrating competing values that result in community agreement, a working consensus and the ability to hold disagreements in the face of differences. It also focuses on the processes of change that enable organizations to accommodate changes in the external environment in ways that ensure their central and on-going relevance as institutions within the larger civic community. Both of these dimensions of institutional theory suggest important areas for further research that grow out of the findings of this study.

- What is the role of group process in building and sustaining a community engagement agenda? How might the utility and power of the Rubric change depending on the number of departmental representatives that engage with the self-assessment? For example, is there a qualitative and/or quantitative difference if one person from the department takes the self-assessment compared to more than one? Compared to the full departmental group? What current or newly-created research methodology could be applied to effectively measure this type of transformational change?

- What is the overriding role of culture and values in comparison to some of the more conventional organizational dimensions that are part of the Rubric? In particular, how might the following set of questions or prompts add to 
substantive discussions of culture, value and purpose internally within the academic department, as well as with external constituents?

- Why does your department engage with community?

- How does your department engage with community?

What difference does it make? To whom?

- How does one know? Has a departmental focus on community engagement changed any internal or external departmental processes?

Within the departmental faculty? For students? For community partners? Within the College, or university-wide?

- How might both the process and outcome of the self-assessment change if community partners are invited to participate? If students are invited to participate? If both students and community partners are invited to participate? How might this be measured? To what ends might these research results be applied?

- What is the relative importance of leadership by the department chair?

- What is the weight and relative importance of each of the six departmental elements in relationship to one another?

- What are some different interpretations as to why the departmental responses to the various dimensions of the Rubric tended to have small amounts of variability?

- What are some of the best practices that maximize the heuristic value of the Rubric to increase understanding of and commitment to community 
engagement? That maximize the assessment value as well as the meaningmaking value of the Rubric, especially repeatedly over time?

- To what extent might departmental engagement with the Rubric, and/or discussions regarding engaging departments affect a dialogue at the level of the host campus and/or the level of national disciplinary associations regarding the role of community engagement in specific disciplinary contexts?

- How might research associated with departmental engagement and the Rubric inform institutional theory?

Clearly, there are many areas for future research that could connect to and extend the findings from this dissertation study. Only a few areas and potential research questions have been suggested here. They have been presented in clusters that aggregate around four themes: 1) transferability, 2) utility and use- - both instrumentally and constitutively, 3) correlations, and 4) the potential of connecting self-assessment research and development efforts to institutional theory. The final section of this chapter will consider the potential implications of this research and end with some concluding thoughts.

\section{Implications of this Research for Theory and Practice}

This dissertation has general theoretical and practical implications, which are organized for discussion purposes into the following three broad categories: 
implications for students, communities, and the academy. Within each category, both theoretical and practical implications will be briefly explored.

As mentioned in chapter one, over the past quarter-century there has been relatively little theory building in the service-learning or educational community engagement movement. In 2006, I had an opportunity to use cultural theory as an analytic approach in understanding the process of building community-university partnerships (Kecskes, 2006). After decades of program development and implementation, I found this theory-building work intellectually stimulating.

Yet, a few years ago, when I was deliberating about possible dissertation topics, I intentionally chose to focus on producing something that would have immediate, palpable use for practitioners in the field. Based on feedback from diverse faculty members in twelve academic departments located at five different higher education institutions around the U. S., I have achieved this primary goal, with all of the qualifiers and limitations inherent in this study. I am left wondering, however, about additional applications of this work to the theory-building domain. While it has not been the focus of this study, I have become increasingly aware that an institutional theory perspective undergirds much of my own approach to this work of increasing community-university engagement.

For me, there are layers of goals, ranging from instrumental to institutional. By instrumental I simply mean all of the bureaucratic mechanisms available to academic institutions and their respective units to undertake organizational change. These include the classic instruments of organizational control: budgets, personnel, 
curriculum, etc. While these instrumental devices and organizational layers are certainly critically important, perhaps most immediately obvious, easiest to measure, and often requested in important studies such as those associated with accreditation, they are not always the most interesting to me personally. The Rubric acknowledges the importance of and measures several of these instrumental components of organizations (e.g., faculty incentives, definitions, budgetary allocations, the presence of facilitating entities, amount of community-engaged activity, etc).

It is the "second layer" of goals that are of greater interest to me and are the focus of attention of institutional theorists. As mentioned in an earlier section of this chapter, institutional theorists are interested in the processes for arbitrating competing values that result in community agreement, a working consensus and the ability to hold disagreements in the face of differences. They are interested in the processes of change that enable organizations to accommodate changes in the external environment in ways that ensure their central and on-going relevance as institutions within the larger civic community. Institutional theorists have developed categories of analysis and research methods that I believe can be useful to those of us who are morally committed to the importance of the community engagement reform agenda and the need to create ownership of this agenda at the academic department level (Banyan, 2003; Cook, 1996; DeMaggio \& Powell, 1991; Perrow, 1986; Scott, 1987; Selznick, 1948, 1992; Shinn, 1996; Sirianni \& Friedland, 1995).

The body of research by institutional theorists has helped me realize that questions of values and how they relate to knowledge production and strategies to 
institutionalize community engagement approaches in education and community settings deeply informs much of my professional work. In 1995, Zlokowski wrote about the need for a complete "transformation of a set of elitist, self-referential academic assumptions" (p. 130) arising from the academy. The deepest and most challenging work then, as now, is about increasing connectivity, at many levels for the common good. I am interested in studying, facilitating, and supporting processes in academic institutions that can lead to the social construction of new and socially relevant meaning and action. In as much as the Rubric associated with this study helps that, I have succeeded in this second set of goals. If, however, the Rubric is used by faculty to simply reify an organizational control approach to their work, I will have unwittingly failed. The study sample in this dissertation is too limited to fully test for a response to these latter questions, however, they remain a strong motivating force for future study.

An institutionalist would not stop until the work of community engagement became a "way of life" that could stand outside of the vicissitudes of the personalities and people that populate particular academic departments, or the universities that comprise them. An institutionalist would want a community engagement orientation to be both the beginning and end point of how departments and universities think and work.

My daily work in this field, indeed my overall pragmatic approach to "getting things done" oriented me initially to fill a methodological void with this dissertation study. Thus, what I have produced is a highly descriptive study that has the possibility 
of having reasonable and positive impact on the field of community engagement in higher education at some point in the future. This is important. However, I am reminded of the general lack of theory in this field, and so, it is from an institutional theory perspective that I approach a brief discussion of the potential theoretical and practical implications for the field in the section that follows. In the end, my overarching supposition is that it cannot be possible to do the real work of transformation associated with community engagement unless key higher education actors (including students and eventually community partners as well) enter regularly into substantive, meaning-making conversations about every aspect of the academic enterprise. These conversations must be transparent, and they must include increasingly diverse constituencies, ideally including students and community partners. This is an untested supposition. Further, these transformative conversations need to continue to occur in the national disciplinary associations as well. Today, faculty care deeply about three core items: control over curriculum, control over personnel, and control over research. In short, these three items define the bulk of what is meant by "academic freedom." However, maintaining such a tight rein on these items may only lead to a partial "ventilation of the professions" that William Sullivan described, and is not likely to lead to the kind of "complete transformation" away from elitist assumptions that Zlotkowski envisioned. Today, the Art Department at Portland State University invites community partners to sit on and have full voting rights on faculty hiring committees. When I tell this story outside of Oregon, some faculty gasp. At Portland State University students can propose and teach senior 
capstones. This can be tricky because often they do not have what most academics would consider the requisite academic background and/or life experience to instruct such a class. There are trade-offs associated with decisions such as these.

There are signs in multiple places that both the academy and the community are ready for such a transformation. For example, in this study one interpretation of the repeated comments from subjects requesting an additional "response field" in the Rubric is to assume a desire on the part of participants to share how the department approaches the work of community engagement; how they "make meaning" of this work. Or, as is evident in the following passage, the yearnings for deep connection from the University of Minnesota faculty chair interviewed by Boyte (2004) could be interpreted as a desire for more comprehensive institutional transformation:

Far more than we expected, the interviews surfaced a strong and often painful sense of loss of public purposes in individual jobs, professions and disciplines, and the whole institution. There was widespread alarm at turf wars and the "star system." Faculty voiced desire for public engagement to be constitutive of professional work. Interest in the public relevance of teaching and research was not simply an individual desire but was also framed in disciplinary terms. "Our whole department feels too cloistered" (p. 4-5).

An institutional theory approach may hold promise in the community engagement field today. While the tool-like activities of the organization of the academic department are critically important to securing the success of the community engagement agenda, the institution-like activities of the academic department are the ones that may hold the most promise to promote and sustain deeper community connectivity and transformation. The Rubric associated with this study provides members of academic departments an opportunity to self-assess both instrumental and 
constitutive activities. In the following section I will briefly discuss some of the theoretical and practical implications of this study for students, community partners and the academy as a whole.

\section{Students}

Theory: This dissertation joins with others in arguing that the role of academic departments needs to reach beyond the development of students' intellectual knowledge and embrace a commitment to the cultivation of community engagement. This study indicates that academic departments are willing and able to play a more central role in developing students' civic skills and sensibilities in addition to increasing content area knowledge. This finding counters some of the literature which argues that students pursue higher education largely for economic reasons (Hallgren, 2004). Through the use of a self-assessment instrument to measure the importance of community engagement at a departmental level, academic units have the ability to design a curriculum that is more balanced. In moving in this direction, it is important to view students as co-educators and co-learners in increasingly innovative, community-connected, intellectually stimulating, practical, democratic, and collaborative learning environments. Engaging with students along these lines has the potential to apply and extend Mezirow's (2000) learning theories concerning transformational education.

Practice: This study provides a self-assessment $R u b r i c$ that when further tested in multiple institutional and departmental settings may help departments begin to 
ascertain the level of commitment within their units to intentionally tie students' civic skill development to increasingly democratic decision-making structures, departmental goals, and actions that directly invite and include student participation.

\section{Communities}

Theory: An assumptions undergirding this study is that the relationship of community partners to universities needs to continue to be transformed from one of supplicant to one of true partnership. In the Carnegie classification framework for community engagement (2006) the word "reciprocity" is used repeatedly. However, Driscoll (2008) writes

Most institutions could only describe in vague generalities how they achieved genuine reciprocity with their communities. Community partnerships require new understandings, new skills, and even a different way of conceptualizing community. There are generally significant barriers left over from both internal and external perceptions of higher education as an "ivory tower" and those barriers must be addressed for authentic community partnerships to develop (http://www.carnegiefoundation.org/dynamic/downloads/file_1 614.pdf.).

Roper \& Hirth, (2005) argue that since the late $20^{\text {th }}$ century, the mission of higher education has been transformed from one-directional service to a bi-directional engagement which emphasizes relationships and interactions between higher education and society. Plater (2004) argues that when these bi-directional partnerships are based on principles of reciprocity and resource sharing, they build trust and can initiate conversations which bridge cultural differences and provide platforms for deep, cumulative learning, and research built on common interests. 
The partnership model for community engagement transformation has received increasingly serious attention. For example, the report of the Community Partner Summit (Community-Campus Partnerships for Health, 2008, p. 13) identified three essential components for authentic community-higher education partnerships:

1. Quality processes-relationship-focused, characterized by integrity; trust-building; acknowledgement of history, commitment to learning and sharing credit; 2. Meaningful outcomes-specific and significant to all partners;

3. Transformation - at individual, institutional and organizational, and societal levels. Kecskes (2006) uses a cultural theory lens to argue that the "partnership model" between higher education and the larger community has been largely accomplished by co-opting the language of egalitarianism to temper the predominantly individualistic and hierarchic mechanisms inherent to the university setting.

Practice: This study provides a practical instrument that could be used as a heuristic tool to initiate or inform conversations regarding the role of the academic department in its connection to communities. For this connection to be fully realized, community partners' self-image must continue to evolve so they may confidently assume increasingly important roles as co-educators of university students, partners in community-based research initiatives, and co-creators of a transformational process that will lead to ever deepening organizational and institutional connections and commitments. 


\section{The Academy}

Theory: This study confirms and helps to further operationalize most of Holland's (1997) seven organizational factors that characterize institutional choice and behaviors regarding service from her groundbreaking research on institutional commitment to service. In similar manner, this study helps further validate the specific measurement or heuristic instruments designed for service-learning or community engagement that specifically informed the Rubric associated with this study (in particular, Gelmon, Seifer et al., Building Capacity for Community Engagement: Institutional Self-Assessment (2005); Furco, Self-Assessment Rubric for the Institutionalization of Service-Learning in Higher Education (2000, 2003); and Kecskes (2006), Characteristics of Engaged Departments Matrix).

Practice: The use of the Rubric in additional academic departments has the potential to increases unit-level practitioners' opportunities to envision and perhaps enact change in favor of departmental engagement. The explanatory framework associated with this dissertation study has the potential to provide departments a useful measurement instrument to evaluate their level of collective, unit-level engagement as well as chart a path forward toward increased commitment to community engagement strategies and practices.

Theory and Practice: This study helps set the stage for potential institutional theory building with a focus on the process of transformation-from organization to institution-of academic departments as they become increasingly engaged with the community. Ramaley (2006) argues that what "counts" for excellence-and 
specifically for promotion and tenure considerations-locally, and at the level of the national disciplinary associations, must continue to change. This study supports Ramaley's position and additionally posits that if education is to be transformed and transformative for students, then they should have an increasing number of opportunities to be included in the most important decisions of their academic home unit. Similarly, if academic departments are to become the "moral agents" envisioned by the institutionalists, they must regularly, deeply and reciprocally engage with multiple communities so that their goals and community goals are indistinguishable. Units must go beyond their instrumental function to play a decisive constitutive role in shaping what the community is and means (Banyan, 2003). This is unlikely to be accomplished without regular self-reflection, ideally implemented in coordination with key constituents such as students in the major and key community partners.

From an institutional theory perspective, researchers could ask about the interactive role the academic department plays with the community. To what extent does the department display a more "tool-centered" view that prevailed over the last half century? For example, is the department most concerned about largely instrumental issues like student credit hours and regional accreditation? Or, is there regular space created in the structure of the department for "institution-centered" questions and activities, such as deep discussions about the values served by the curriculum, concerns about educating students for effective lives in a healthy participatory democracy, and an increasing awareness of how the department affects and is affected by the environment? Does the department exhibit a consistently 
interactive role with other community organizations? An institutionalist might ask: to what extent does this occur? How can this activity be captured and measured at the level of the academic department and disseminated? Of course, as briefly discussed in the chapter two literature review, it is clear that some excellent attempts have been made to respond to some of these questions. Yet, this study suggests that there is still much room to grow, and to build out a particular aspect of institutional theory relevant to academic departments.

This study posits that interacting with the Rubric, over time, may be able to help practitioners arrive at deeper levels of common understandings of departmental engagement. But to be transformative, this understanding must include students and community partners in conversations about the meaning of teaching, learning and research practices in the academy.

This study acknowledges that critics of a departmental approach might suggest that turning extra attention toward the academic department at this time is counterproductive to much needed interdisciplinary initiatives. Indeed, there is a creative tension between disciplinary and interdisciplinary approaches. However, institutional theory largely addresses this tension with a bedrock concern for values-based interaction among organizations as well as a constant focus on socially constructing broader, community-wide meaning. An institutionalist might argue that as academic departments truly "ventilate" their practices through reflection, innovation, risk-taking, and community connection, two things may naturally occur: 1) departments might become keenly aware of their own areas of strength and challenge which eventually 
could lead them to 2) a natural movement toward greater connectivity - both on campus through interdisciplinary activities as well as externally through communitybased teaching, research and service activities.

In this section, theoretical and practical implications of this dissertation study were briefly explored through the lenses of students, community and the academy, with a particular focus on the relevance of institutional theory.

\section{Concluding Thoughts - The Challenge of "Permeability"}

This dissertation has used an iterative, inductive and deductive grounded theory methodology to build, test, and validate an explanatory framework to measure community engagement at the organizational level of the academic department. If Ernest Boyer's (1990) vision to create that "special climate in which the academic and civic cultures communicate more continuously and more creatively with each other" (p. 19-20) is to be realized, then the broad process of institutionalizing community engagement in higher education must now focus on sustained change at the organizational level of the academic department.

The nation's, and increasingly the world's, senior contemporary scholars are asking hard questions today about the institution of higher education: How to recover liberal arts education and by doing so recover a focus on the public good? How to ventilate professional education to reclaim a sense of "civic professionalism?" Up to this point the community engagement reform agenda has been primarily driven from the top down by administrators working outside traditional academic units. This 
research assumes, along with other scholars in the field (Applegate \& Morreale, 2001;

Battistoni et al., 2003), that lasting reform needs to be carried by the traditional disciplines that are characteristically organized into academic departments. This dissertation study documents the existing success of this bottom-up strategy and considerable hope for the future. But the question still remains as to the proper balance between a department-centered strategy from below and a reform initiative carried by central administrative units in the university. As Zlotkowski and Saltmarsh's (2006) work reminds us, the outcome is still in question.

Will individual faculty interest [in community engagement] seeping up from below and administrative encouragement [for community engagement] trickling down from above finally reach each other at the level of departmental culture or will they instead encounter an impermeable membrane (p. 278)?

Will the disciplines rise above the narrow provincialism that has at times defined them and look toward greater connectivity between themselves, and with communities for the good of all, or will they retrench and redouble their resistance to change?

In 1995, in the Chronicle of Higher Education Alexander Astin, educational researcher from UCLA, asked university presidents a big question.

We [higher education] educate a large proportion of the citizens who bother to vote, not to mention most of the politicians, journalists, and news commentators. We also educate all the school administrators and teachers, who in turn educate everyone at the pre-college level. And we do much to shape the pre-college curriculum through what we require of our college applicants. In short, not only have we helped to create the problems that plague American democracy, but we also are in a position to begin doing something about them. If higher education doesn't start giving citizenship and democracy much greater priority, who will? (p. B2) 
Astin, although he did not use the word "moral," is talking about morality. A sense of urgency permeates higher education today, and a period of rapid transition has arrived. Community-engaged departments represent part of the vanguard of 21 st century durable change in higher education. They keep asking and responding to the big picture questions about recovering liberal arts education and refocusing on the public good. Community-engaged departments continue to ensure that the "membranes" separating their collective units - from individual faculty engagement and institutional inspiration-remain "permeable." To rephrase Astin, if academic departments and the disciplinary associations that guide them don't start giving community engagement, public problem solving, and democracy much greater priority, who will? 


\section{REFERENCES}

Agre-Kippenhan, S. and Charman, E. (2006). Engagement in the arts: Commitment to an urban experience. In K. Kecskes (Ed.), Engaging departments: Moving faculty culture from private to public, individual to collective focus for the common good (pp. 89-107). Boston: Anker Publishing Company, Inc.

Applegate, J. \& Morreale, S. (2001). Creating engaged disciplines. The AAHE 16 (pp. 7-9). Washington, DC: American Association for Higher Education.

Astin, A. (1995). The causes of citizenship. The Chronicle of Higher Education, 42(6), B1-B2.

Banyan, M. (2003) Civic infrastructure, organizational civic capacity and service learning: A community capacity-building model (Unpublished doctoral dissertation, Portland State University).

Barber, B. R. (2000). Passion for democracy: American essays. Princeton, NJ: Princeton University Press.

Battistoni, R. M. (2002). Civic engagement across the curriculum: A resource book for service-learning faculty in all disciplines. Providence, RI: Campus Compact.

Battistoni, R. M. , Gelmon, S. B., Saltmarsh, J. A., Wergin, J. F. , \& Zlotkowski, E. (2003). The Engaged Department Toolkit. Providence, RI. Campus Compact.

Battistoni, R. M. (2006). Civic engagement: A broad perspective. In K. Kecskes (Ed.), Engaging departments: Moving faculty culture from private to public, individual to collective focus for the common good (pp. 89-107). Boston: Anker Publishing Company, Inc.

Bell, R., Furco, A., Ammon, M.S., Muller, P., \& Sorgen, V. (2000). Institutionalizing Service-Learning in Higher Education: Findings from a Study of the Western Region Campus Compact Consortium. Western Region Campus Compact Consortium. Bellingham WA: Western Washington University.

Benson, L. and I. Harkavy. 2002. Saving the Soul of the University: What is to be Done? In The Virtual University: Information, Markets, and Management, ed. K. Robins and F. Webster (pp. 169-209). Oxford: Oxford Univ. Press.

Benson, L., I. Harkavy and M. Hartley. (2005). Higher Education for the Public Good: Integrating a Commitment to the Public Good into the Institutional Fabric. In A. Kezar, T. Chambers, and J. Burkhardt. (Eds.), Higher Education for the 
Public Good: Emerging Voices from a National Movement. San Francisco: Jossey-Bass.

Bok, D. (1982). Beyond the ivory tower: Social responsibility of the modern university. Cambridge, MA: Harvard University Press.

Bok, D. (1992). Reclaiming the public trust. Change, 24 (3).

Borgatta, E. (1968). My student the purist: A lament. The Sociological Quarterly, 9, 29-34.

Boyer, E. (1990). Scholarship reconsidered: Priorities of professoriate. San Francisco: The Carnegie Foundation for the Advancement of Teaching.

Boyer, E. L. (1997). The scholarship of engagement. Journal of Public Service and Outreach, 1(1), 11-20.

Boyte. (2004). Everyday Politics and Civic Engagement. Retrieved June 20, 2008 from

http://www.aascu.org/programs/adp/toolkit0104/Reflections/Everyday_Politics Boyte.pdf

Boyte, Harry C. (2004). Everyday politics: Reconnecting citizens and public life. Philadelphia, PN: University of Pennsylvania Press.

Bringle R.G., Malloy E.A., \& Games R. (Eds.). (1999). Colleges and universities as citizens. Needham Heights, MA: Allyn and Bacon.

Community-Campus Partnerships for Health. (2008). Achieving the promise of authentic community-higher education partnerships: Community partners speak out. Racine, WI: Wingspread Conference Center. Retrieved on October 7, 2008 from http://depts.washington.edu/ccph/pdf files/CPS-Casestories.pdf

Campus Compact. (2003). The Indicators of Engagement. Retrieved March 2, 2008, from http://www.compact.org/indicators/detail.php?id=14.

Carnegie Foundation Elective Classification: Community Engagement. (2007).

Retrieved March 2, 2008, from http://www.carnegiefoundation.org/dynamic/downloads/file_1_614.pdf.

Charmaz, K. (2001). Grounded Theory. Contemporary field research (pp. 335-352). Prospect Heights, IL: Waveland Press. 
Charmaz, K. (2006). Constructing Grounded Theory: A practical guide through qualitative analysis. London: Sage.

Colby, A., Ehrlich, T., Beaumont, E., \& Stevens, J. (2003). Educating citizens: Preparing America's undergraduates for lives of moral and civic responsibility. Indianapolis, IN: Jossey-Bass Publishers.

Colby, A., Beaumont, E., Corngold, J., Ehrlich, T. (2007). Education for democracy: Preparing undergraduates for responsible political engagement. San Francisco: Jossey-Bass.

Commission on Community Engaged Scholarship in the Health Professions. (2005). Retrieved March 2, 2008, from http://depts.washington.edu/ccph/pdf files/Commission\%20Report $\% 20 \mathrm{FINAL}$ pdf

Cook, B. J. (1996). Bureaucracy and self-government: Reconsidering the role of public administration in American politics. Baltimore: MD: Johns Hopkins University Press.

Craig, R. \& Tracy, K. (1995). Grounded practical theory: The case of intellectual discussion. Communication Theory, 5, 248-272.

Creswell, J. W. (2003). Research design: Qualitative, quantitative and mixed method approaches. $\left(2^{\text {nd }}\right.$ ed.). Thousand Oaks, CA: Sage Publications, Inc.

Damrosch, D. (1995). We scholars: changing the culture of the university. Cambridge, MA: Harvard University Press.

DiMaggio, P. J., \& Powell, W. W. (1991). Introduction. In W. W. Powell \& P. J. DiMaggio (Eds.), The new institutionalism in organizational analysis. Chicago: University of Chicago Press.

Campbell, D. T. and Stanley, J. C.. (1963). Experimetnal and Quasi-experimental design for Research. Chicago, IL. Rand McNally \& Company.

Driscoll, A., Holland, B., Gelmon, S., \& Kerrigan, S. (1996). An assessment model for service-learning: comprehensive case studies of impact on faculty, students, community and institution. Michigan Journal of Community Service Learning, 3: 66-71.

Driscoll, A. (2008). Carnegie's community-engagement classification: Intention and insights. Change, January/February, 39-41. 
Edgerton, R. (1994) The engaged campus: organizing to serve society's needs. $A A H E$ Bulletin, 47(1): 2-3.

Edwards, R. (1999). The academic department: How does it fit into the university reform agenda? Change, September/October, 17-27.

Ehrlich, T. \& Hollander, E. (1999). Presidents' Declaration on the Civic Responsibility of Higher Education. Retrieved February 4, 2006, from www.compact.org/resources.

Ehrlich, T. (Ed.). (2000). Civic responsibility and higher education. Phoenix: Oryx Press.

Fish, S. (2004). 'Intellectual Diversity': the Trojan Horse of a Dark Design. Retrieved on October 7, 2008 from http://chronicle.com/free/v50/i23/23b01301.htm Chronicle of Higher Education, February 13, 2004

Furco, A., Muller, P., and Ammon, M.S. (1998). Institutionalizing service-learning in higher education: findings from a study of the western region campus compact consortium. University of California, Berkeley.

Furco, A. \& Shumer, R. (2000). Developing a self-assessment instrument for higher education. In Kecskes, K (Ed.), $4^{\text {th }}$ Annual "Continuums of Service" Conference Proceedings. Retrieved June 30, 2006, from http://www.acadweb.wwu.edu/campcomp/pdf/4thCOSAnnualProceedings.pdf

Furco, A. (2001). Advancing service-learning in research universities. In M. Canada and B. Speck (Eds.), Developing and Implementing Service-Learning Programs (pp. 67-78). San Francisco: Jossey-Bass.

Furco, A. (2002). Institutionalizing service-learning in higher education. Journal of Public Affairs, 6, 39-67.

Furco, A. (2003). Self-assessment rubric for the institutionalization of service-learning in higher education. Providence, RI: Campus Compact.

Gelmon, S. B., Holland, B. A., Driscoll, A., Spring, A., \& Kerrigan, S. (2001). Assessing Service-Learning and Civic Engagement: Principles and Techniques. Providence, RI: Campus Compact.

Gelmon, S. B., Seifer, S. D., Kauper-Brown, J., \& Mikkelsen, M. (2005). CommunityEngaged Scholarship for Health Collaborative: Institutional Self-Assessment. Seattle, WA: Community-Campus Partnerships for Health. 
Gelmon, S. B., Seifer, S. D., Kauper-Brown, J. \& Mikkelsen, M. (2005). Building capacity for community engagement: Institutional self-assessment. Seattle, WA: Community-Campus Partnerships for Health. Retrieved June 18, 2008, from http://depts.washington.edu/ccph/pdf_files/self-assessment-copyright.pdf.

Gibbons, M., Limoges, C., Nowotny, H., Schwartzman, S., Scott, P., Trow, M. (1994). The new production of knowledge: The Dynamics of science and research in contemporary societies. London: SAGE Publications Ltd.

Gibson, C. M. (Ed.). (2006). Proceedings from research universities and civic engagement conference: New times demand new scholarship: A leadership agenda. Medford, MA: Tufts University \& Campus Contact.

Glaser, B., \& Strauss, A. (1967). The discovery of grounded theory. Chicago: Aldine.

Glaser, B. (1992). Basics of grounded theory analysis. Mill Valley, CA: Sociology Press.

Hallgren, M. (2004). College grads earn more money. The Arkansas Traveler. Retrieved November 16, 2008, from http:/www.thetraveleronline.com/

Halliburton, D. (1997). John Dewey: A voice that still speaks to us. Change, 29(1), 24-29.

Harkavy, I. (2000). Service-learning, academically based community serice, and the historic mission of the America urban research university." In I. Harkavy \& B. M. Donovan (Eds.), Connecting past and present: Concepts and models for service-learning in history (pp. 27-41). Washington, DC: American Association for Higher Education.

Holland, B. A. (1997). Analyzing Institutional Commitment to Service: A Model of Key Organizational Factors. Michigan Journal of Community Service Learning, Fall, 30-41.

Holland, B. A. (1999). Factors and strategies that influence faculty involvement in public service. The Journal of Public Service and Outreach, 4: 37-43.

Holland, B. A. (2001). Exploring the challenge of documenting and measuring civic engagement endeavors of colleges and universities: purposes, issues, ideas. Retrieved June 18, 2008, from http://www.compact.org/advancedtoolkit/pdf/holland paper.pdf 
Holland, B. A. (2000). Institutional impacts and organizational issues related to service-learning. Michigan Journal of Community Service Learning, Special Issue, 52-60.

Holland, B. A. (1999). From murky to meaningful: the role of mission in institutional change. In R. Bringle, R. Games, and E. Malloy (Eds.), Colleges and Universities as Citizens. Boston, MA: Allyn and Bacon, 48-73.

Holland, B. A. (2005). Institutional difference in pursuing the public good. In Kezar et al. (Eds.), Higher education for the common good: Emerging voices form a national movement, San Francisco: Jossey-Bass, 235-261.

Jacoby, B. (1996). Service learning in higher education: Concepts and practices. San Francisco: Jossey-Bass.

John, O. P., \& Benet-Martinez, V. (2000). Measurement: Reliability, construct validity, and scale construction. In Judd, C. M., \& Reis, H. T. (Eds.), Handbook of research methods in social and personality psychology (339369). Cambridge: Cambridge University Press.

Johnson, R. B. (1997). Examining the validity structure in qualitative research. Education, 118, 282-293

Kecskes, K. (2004). Engaging the Department: Community-Based Approaches to Support Academic Unit Coherence. The Department Chair, 15(1), 7-9.

Kecskes, K. (2006). Behind the rhetoric: Applying a cultural theory lens to community-campus partnership development. Michigan Journal of Community Service Learning, 5-14.

Kecskes, K. (2006). Engaging departments: Moving faculty culture from private to public, individual to collective focus for the common good. Boston, MA: Anker Publishers.

Kecskes, K. (2008). Engagement in the disciplines. The Department Chair, 18(3), 1618.

Kecskes, K., Gelmon, S. B., \& Spring A. (2006). Creating engaged departments: a program for organizational and faculty development. To Improve the Academy, $24,147-165$.

Kecskes, K. \& Muyllaert, J. (1997). Continuums of Service Benchmark Worksheet. Western Region Campus Compact Consortium Request for Proposals. 
Retrieved on October 7, 2008 from http://www.wacampuscompact.org/documents/COSBenchmarkTool1997.pdf

Kennedy, D. (1995). Another century's end, another revolution for higher education. Change, November/December, 8-15.

Kerr, C. (1963). The uses of the university. Cambridge: Harvard University Press.

Kezar, A. J., Chambers, T. C., Burkhardt, J. C. \& Associates. (2005). Higher education for the common good: Emerging voices form a national movement, San Francisco: Jossey-Bass.

Leslie, D. W. \& Fretwell, E. K., Jr. (1996). Wise moves in hard times: Creating and managing resilient colleges and universities. San Francisco: Jossey-Bass.

Lynton, E. (1995). Making the case for faculty professional service. Washington, DC: American Association for Higher Education.

Marshall, C. (1989). Designing qualitative research. Newbury Park, Calif.: Sage Publications.

Miles, M. S., \& Huberman, A. M. (1993). Qualitative data analysis: A sourcebook of new methods ( $2^{\text {nd }}$ edition). Newbury Park, CA: Sage.

Mezirow, J. (2000). Learning as transformation. San Francisco: Jossey-Bass .

Morgan, D. (2001). The moral purpose of higher education: The role of civic education in liberal and professional education. Unpublished article prepared for the Civic Capacity Initiative Grant funded by the Fund for the Improvement of Post-Secondary Education.

Morreale, S. and Applegate, J. (2006). Engaged disciplines: How national disciplinary societies support the scholarship of engagement. In K. Kecskes (Ed.), Engaging departments: Moving faculty culture from private to public, individual to collective focus for the common good (pp. 264-277). Boston: Anker Publishing Company, Inc.

National Service-Learning Clearinghouse. (2008). History of Service-Learning in Higher Education. Retrieved August 16, 2008, from http://www.servicelearning.org/what_is_servicelearning/history hesl/index.php.

Newman, F. (1985). Higher education and the American resurgence. Princeton, NJ: Carnegie Foundation for the Advancement of Teaching. 
Newman, F., Couturier, L., \& Scurry, J. (2004). The future of higher education: Rhetoric, reality, and the risks of the market. San Francisco: Jossey-Bass, Publishers, Inc.

Perrow, C. (1986). Complex organizations: A critical essay ( $3^{\text {rd }}$ ed.). New York: Random House.

Perry, J. L., \& Jones, S. G. (Eds.). (2006). Quick hits for educating citizens. Bloomington, IN: Indiana University Press.

Plater, W. (2004). Civic engagement, service-learning, and intentional leadership. In M. Langseth and W. Plater (Eds.) Public work and the academy. Bolton, MA: Anker

Plater, W. (1999). Habits of living: Engaging the campus as citizen one scholar at a time. In R. Bringle et al. (Eds.), Colleges and Universities as Citizens. Needham Heights, MA: Allyn and Bacon.

Putnam, R. D., \& Feldstein, L. (2003). Better together: Restoring the American community. New York: Simon and Schuster.

Ramaley, J. A. (2005). Scholarship for the public good: Living in Pasteur's quadrant. In Kezar, et al. (Eds.) Higher education for the common good: Emerging voices form a national movement, San Francisco: Jossey-Bass, 166-182.

Ramaley, J. A. (2006). Civic engagement: A national context for the relationship between universities and community organizations. Winona, MN: Winona State University.

Rice, R. E. \& Richlin, L. (1993). Broadening the conception of scholarship in the professions. In 1. Curry, J. Wergin, \& Associates (Eds.), Educating Professionals. San Francisco, CA: Jossey-Bass Inc.

Rice, R. E. (2006). Foreword. In K. Kecskes (Ed.), Engaging departments: Moving faculty culture from private to public, Individual to collective focus for the common good. (pp. xiii-xv). San Francisco: Jossey-Bass.

Robinson, W.S. (1950). Ecological Correlations and the Behavior of Individuals. American Sociological Review 15: 351-357.

Roper, C. \& Hirth, M.A. (2005). A history of change in the third mission of higher education: The evolution of one-way service to interactive engagement. Journal of Higher Education Outreach and Engagement 10(3), 3-21 
Saltmarsh, J. \& Gelmon, S. B. (2006). Characteristics of an engaged department: Design and assessment. In K. Kecskes (Ed.), Engaging departments: Moving faculty culture from private to public, individual to collective focus for the common good (pp. 27-44). Boston: Anker Publishing Company, Inc.

Schmiede, A. and Ortolano, L. (2005). Public Service Education at Stanford: The Haas center's first twenty years. Stanford, CA: Stanford Univerity

Schön, D. (1995). The new scholarship requires a new epistemology. Change, 27(6), 27-34.

Schutt, R. K. (1999). Investigating the social world: The process and practice of research $\left(2^{\text {nd }} E d\right.$.). Thousand Oaks, CA: Sage Publications, Inc.

Scott, W. R. (1987). Organizations: Rational, natural, and open systems (2nd ed.). Englewood Cliffs: Prentice-Hall.

Selznick, P. (1948). Foundations of a theory of organization. American Sociological Review 13: 25-35.

Selznick, P. (1992). The moral commonwealth: Social theory and the promise of community. Berkeley: University of California Press.

Shinn, C. W. (1996). Taking stock of institutional thought: Institutions, institutionalization, and institutional effects. Administrative Theory \& Praxis, $18(2)$.

Smelser, N. J. and Baltes, P. B. (2001). International encyclopedia of the social \& behavioral sciences (Volume 1). Amsterdam: Elsevier

Sternberg, R. J., Forsythe, G.B., Hedlund, J., Horvath, J.A., Wagner, R.K., Williams, W.M., Snook, and S.A., Grigorenko, E.L. (2000). Practical Intelligence in Everyday Life Cambridge, U.K.: Cambridge University Press.

Strauss, A. (1987). Qualitative analysis for social scientists. Cambridge, England: Cambridge University Press.

Strauss, A., \& Corbin, J. (1998). Basics of qualitative research: Techniques and procedures for developing grounded theory. Thousand Oaks, CA: Sage.

Sullivan, W. M. (1995). Work and integrity: The crisis and promise of professionalism in America. New York: Harper Business. 
Wagner, R. K., and Sternberg, R. J. (1985). Practical intelligence in real-world pursuits: The role of tacit knowledge. Journal of Personality and Social Psychology. 49, (2) p. 436-458)

Wergin, J. (1994). The collaborative department. Washington DC: American Association of Higher Education.

Wergin, J. (2003). Departments that work: building and sustaining cultures of excellence in academic programs. Bolton, MA: Anker Publishing.

Westheimer \& Kahn. (2003). What Kind of Citizen? Political Choices and Educational Goals. Retrieved on June 18, 2008, from http://www.compact.org/reader/archives/Winter 2003.pdf.

Zlotkowski, E. (2000). Service-Learning research in the disciplines. Michigan Journal of Community Service Learning, 61-67.

Zlotkowski, E. (2005). The disciplines and the public good. In Kezar et al. (Eds.), Higher education for the common good: Emerging voices form a national movement, San Francisco: Jossey-Bass, 146-165.

Zlotkowski, E. \& Saltmarsh, J. (2006). The engaged department in the context of academic change. In K. Kecskes (Ed.), Engaging departments: Moving faculty culture from private to public, individual to collective focus for the common good (pp. 278-289). Boston: Anker.

Zlotkowski, E., Longo, N., \& Williams, J. (Eds.). (2006). Students as colleagues. Providence: Campus Compact.

Zuiches, J. (2008) Attaining Carnegie's community engagement classification. Change, January/February, 42-45. 


\section{APPENDICES}

A. Holland, B. (1997) Levels of Commitment to Service, Characterized by Key Organizational Factors Evidencing Relevance to Institutional Mission

B. Furco, A. (2003) Self-Assessment Rubric for the Institutionalization of ServiceLearning in Higher Education

C. Gelmon, S., Seifer, S. et al. (2005) Building Capacity for Community Engagement: Institutional Self-Assessment

D. Kecskes, K. (2006) Characteristics of Engaged Departments Matrix

E. Kecskes, K. (2008) Creating community-engaged departments: SelfAssessment Rubric for the Institutionalization of Community Engagement in Academic Departments 


\section{APPENDiX A}

Holland, B. (1997) Levels of Commitment to Service, Characterized by Key Organizational Factors Evidencing Relevance to Institutional Mission 
Holland, 1995).

nterviews with $35-40$ 2nts, provosts, deans, staff), and students h campus. Multiple recruitment materistrategic plans, pubeers, etc.) were also it included observa:nts on and off camsearch included the gy for assessing the onal mission, and a ng the defining fealistinctive academic $x$ described in this in outcome of this

categorize the difnterpreting the role o the organization. most significant in ence of a commitictivity. Recently, a tunity to refine the zes of a much larg.

cvaluation of 19 from The Pew ation for Nationa led to support the of service-leamsed on a compre igned at Portland inctive impacts of culty, institution, and, Gelmon, \& licators that opercarm goals were sup, and reflected in the matrix as

is evaluation proof size, mission, and history, and to test the proof settings. Two for conducting Interviews and mic administray partners, and rice-learning to upact variables. ewed, and each written report
Much of the existing research on institutiona engagement in service-leaming is limited because it is based on the experience of one or a few institutions. This matrix is derived from research that involved an unusual opportunity to explore the experiences of a large group of institutions Analysis of interviews and documents from the first research project resulted in the identification of four potential levels of commitment and seven oranizational factors that characterize institutiona) choices and behaviors regarding service. These constitute the proposed matrix that was then refined through application to the multiple subjects of the second research project.

These case studies were, among other things, a test of popularly-held but poorly-researched belief structures regarding the scholarship of service as a component of institutional missions and academic priorities. The matrix is meant to be a useful diagnostic tool to describe and interpret the dimensions, approaches, and levels of institutional commitmen to community service and service-learning and therefore, to facilitate institutional planning decision-making and evaluation. As framed by the dis-

FTGURE 1:

Levels of Commitment to Service, Characterized by Key Organizational

Factors Evidencing Relevance to Institutional Mission

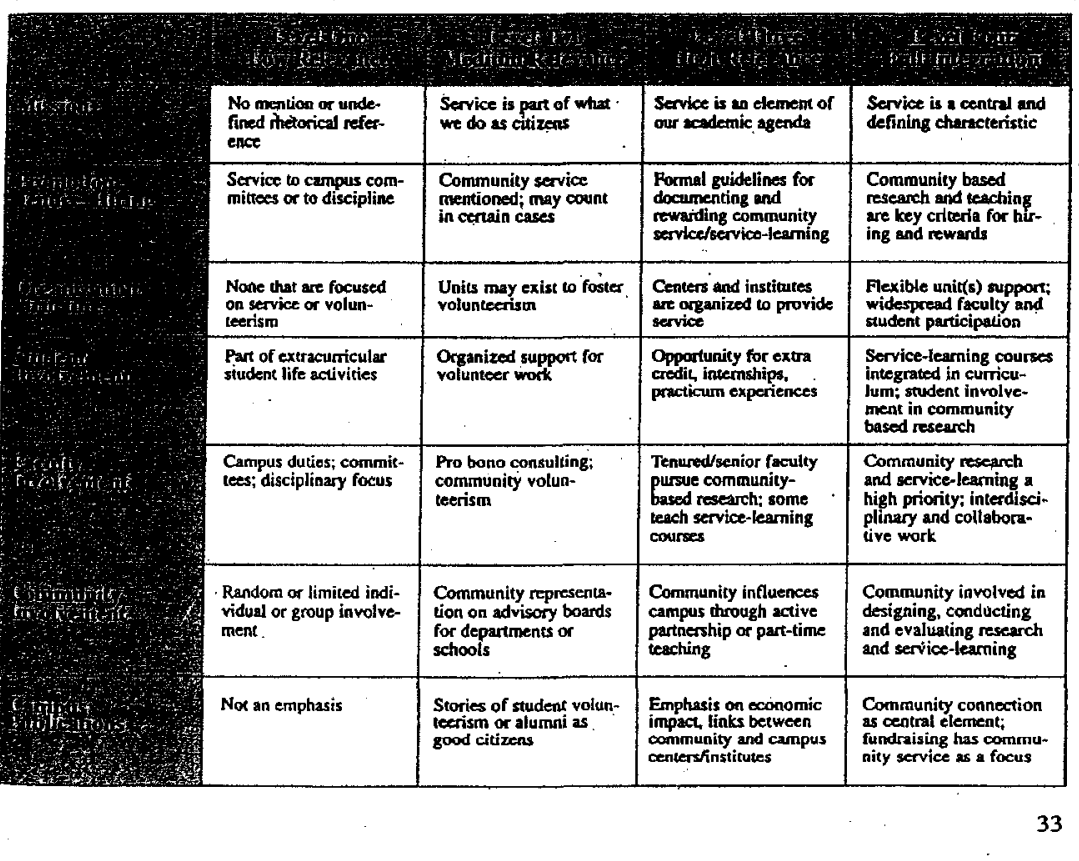

cussion of the literature in the introduction above, if we are to achieve a creative tension between vision and reality regarding the implementation of each institution's vision of the role of service, then there is a need for a method to guide and monitor institutional efforts and choices so as to foster institutionalization.

\section{A Proposed Matrix of Institutional}

\section{Commitment to Service}

From case studies and the literature, especially Crosson (1983), the proposed matrix was developed to explain the internelationship of levels of commitment to service with key organizational factors that illustrate and characterize each level. The matrix is shown in Figure 1.

The four levels of institutional commitment to service represent different institutional expressions of seven organizational factors most often cited as definitive components that frame an institution's service-related activities. The organizational factors represent important aspects of organizational infrastructure, policy, communication, and partici- 


\section{APPENDIX B}

Furco, A. (2003) Self-Assessment Rubric for the Institutionalization of ServiceLearning in Higher Education 


\section{SELF-ASSESSMENT RUBRIC FOR THE INSTITUTIONALIZATION OF SERVICE-LEARNING IN HIGHER EDUCATION (revised 2003)

\author{
ANDREW FURCO \\ Campus Compact Engaged Scholar \\ Service-Learning Research \& Development Center \\ University of California, Berkeley
}

\section{BACKGROUND}

The Self-Assessment Rubric for the Institutionalization of Service-Learning in Higher Education is designed to assist members of the higher education community in gauging the progress of their campus's service-learning institutionalization efforts.

The rubric is structured by five dimensions, which are considered by most service-learning experts to be key factors for higher education service-learning institutionalization. Each dimension is comprised. of several components that characterize the dimension. For each component, a three-stage continuum of development has been established. Progression from Stage One: Critical Mass Building to Stage Three: Sustained Institutionalization suggests that a campus is moving closer to the full institutionalization of service-learning.

The conceptual framework for the rubric is based largely on a benchmark worksheet that was developed by Kevin Kecskes and Julie Muyllaert of the Western Region Campus Compact Consortium's Continuums of Service program. The three-stage developmental continuum and most of the self-assessment rubric's institutionalization dimensions were derived from the Kecskes/Muyllaert Continuums of Service benchmark worksheet. ${ }^{1}$ The other dimensions of the rubric were derived from various literature sources that discuss the critical elements for institutionalizing service-learning in higher education. In particular, the work of the following individuals provided important foundational information for the development of the rubric: Edward Zlotkowski of Bentley College and the American Association for Higher Education: Rob Serow, Diane C. Calleson, and Lani Parker of North Carolina State University; Leigh Morgan or the North Carolina Commission on National and Community Service; Amy Driscoll of California State University, Monterey Bay; Donna Dengel and : Roger Yerke of Portland, Oregon; and Gail Robinson of the American Association of Community Colleges. $^{2}$

1 The author expresses gratitude to Mr. Kevin Kecskes, Western Region Campus Compact Consortium Program Director and Ms. Julie Muyllaert, State Network Director for their permission to use and adapt the Continuums of Service Benchmark Worksheet to develop this self-assessment rubric.

${ }^{2}$ The author wishes to acknowledge Dr. Tanya Renner of Kapi'olani Community College and Ms. Nicole Konstantinakos Farrar of the California Campus Compact for their assistance in reviewing and refining the components of the self-assessment rubric. 


\section{REVISIONS TO THE RUBRIC}

The rubric presented here is based on an original version that was first published in 1998. The original version of the rubric was piloted on eight campuses and was subsequently revised in 1999. The 1999 version of the rubric became part of a series of regional Service-Learning Institutionalization Institutes, which were offered by Campus Compact. Since that time, more than 80 institutions have utilized the 1999 version of the rubric. In 2000 , an accompanying planning guide was developed to provide a step by step process for campuses' use of the rubric. Feedback regarding the strengths and weaknesses of the rubric and planning guide was and continued to be collected. This feedback has been incorporated into this new version of the rubric.

Overall, the 2003 version maintains the rubric's original five-dimension structure. This new version includes a new "departmental support" component. This component was added to the rubric to reflect new insights regarding the important tole departments play in the advancement of service-learning in higher education (Holland, 2000). The others revisions were primarily slight changes in wording to more fully clarify the meaning and intention of various components.

\section{COMPONENTS OF THE RUBRIC}

The self-assessment rubric contains five dimensions, each which includes a set of components that characterize the dimension. The five dimensions of the rubric and their respective components are listed below:

\begin{tabular}{|l|l|}
\hline \multicolumn{1}{|c|}{ DIMENSION } & \multicolumn{1}{c|}{ COMPONENTS } \\
\hline $\begin{array}{l}\text { I. Philosophy and Mission of Service- } \\
\text { Learning }\end{array}$ & $\begin{array}{l}\text {-Definition of Service-Learning } \\
\text {-Strategic Planning } \\
\text {-Alignment with Institutional Mission } \\
\text {-Alignment with Educational Reform Efforts }\end{array}$ \\
\hline $\begin{array}{l}\text { II. Faculty Support for and Involvement in } \\
\text { Service-Learning }\end{array}$ & $\begin{array}{l}\text {-Faculty Awareness } \\
\text {-Faculty Involvement and Support } \\
\text {-Faculty Leadership } \\
\text {-Faculty Incentives and Rewards }\end{array}$ \\
$\begin{array}{l}\text { III. Student Support for and Involvement in } \\
\text { Service-Learning }\end{array}$ & $\begin{array}{l}\text {-Student Awareness } \\
\text {-Student Opportunities } \\
\text {-Student Leadership } \\
\text {-Student Incentives and Rewards }\end{array}$ \\
\hline $\begin{array}{l}\text { IV. Community Participation and } \\
\text { Partnerships }\end{array}$ & $\begin{array}{l}\text {-Community Partner Awareness } \\
\text {-Mutual Understanding } \\
\text {-Community Agency Leadership and Voice }\end{array}$ \\
\hline
\end{tabular}

2003, University of California, Berkeley 


\begin{tabular}{|c|c|}
\hline V. Institutional Support for Service-Learning & $\begin{array}{l}\text {-Coordinating Entity } \\
\text {-Policy-making Entity } \\
\text {-Staffing } \\
\text {-Funding } \\
\text {-Administrative Support } \\
\text {-Departmental Support } \\
\text {-Evaluation and Assessment }\end{array}$ \\
\hline
\end{tabular}

For each component, three stages of development are identified. Stage One is the Critical Mass Building stage. It is at this stage the campuses are beginning to recognize service-leaming and are building a campus-wide constituency for the effort. Stage Two is the Quality Building stage. It is at this stage that campuses are focused on ensuring the development of "quality" service-learning activities; the quality of service-leaming activities begins to supercede the quantity of service-learning activities. Stage Three is the Sustained Institutionalization stage. It is at this stage that a campus has fully institutionalized service-learning into the fabric of the institution.

It should be noted that some components might take many years to develop. According to Edward Zlotkowski institutionalizing service-learning (or any other reform effort) in higher education takes time, commitment, and persistence (Zlotkowski, 1999). It is only through the sustained commitment of the campus over time that true a sustained institutionalization of service-learning can be realized.

\section{USING THE RUBRIC}

As a tool to measure development of service-learning institutionalization, the rubric is designed to establish a set of criteria upon which the progress of service-learning institutionalization can be measured. Thus, the rubric is designed to measure the status of a campus' level of institutionalization at a particular point in time: The results of this status assessment can provide useful information for the development of an action plan to advance service-learning on the campus. It can help identify which institutionalization components or dimensions are progressing well and which need some additional attention. In addition, by using the tool at another point in time to reassess the status of service-learning institutionalization on a campus, the actual growth of each component and dimension over time can be measured.

"As a self-assessment tool, the rubric is designed to facilitate discussion among colleagues regarding the state of service-leaming institutionalization on a campus. Therefore, there is no one right way to use the rubric. Since a campus' unique culture and character will determine which of the rubric's dimensions are focused on most intensively, the dimensions and components of the rubric should be adapted to meet the needs of the campus. What is most important is the overall status of the campus' institutionalization progress rather than the progress of individual components. In some cases, individual components of the rubric may not be applicable to certain campus situations. In other cases, the rubric may not include some components that may be key to a campus' institutionalization efforts; campuses may wish to add components or dimensions to the rubric. 
Some institutions may wish to have key individuals on a campus use the rubric individually to conduct a self-assessment of the campus' service-learning institutionalization efforts. The individual assessments are then compared with one another; discussions regarding the similarities and differences between individual members' impressions may be discussed. Other institutions may wish to discuss the dimension or component in detail and then come to a consensus regarding which development stage best characterizes the campus' development for each component of the rubric. While some institutions will give an overall score for each "dimension," other institutions will look at each component individually. What is most important is that the results of the self-assessment are used to guide the development of a strategic action plan for institutionalizing service-learning on the campus.

Generally, it is not recommended that partial stage scores be given. In other words, a campus group should not state that for a particular component (or dimension), the campus is "between" stage one and stage two. If the campus has not fully reached stage two, then the campus, is not at stage two. Each dimension includes a "Notes" column, which allows for the inclusion of any statements, questions, or conclusions that might explain the particular assessment decisions that have been made or might suggest that further information be gathered before a final stage score is assigned.

Finally, this rubric should be viewed as only one assessment tool for determining the status of serviceleaming institutionalization on a campus. Other indicators should also be observed and documented to ensure that an institution's effort to advance service-learning on campus is conducted systematically and comprehensively. 


\section{BIBLIOGRAPHY}

Bell, R., Furco, A., Ammon, M.S., Muller, P., and Sorgen, V. (2000). Institutionalizing ServiceLearning in Higher Education: Findings from a Study of the Western Region Campus Compact Consortium. Westem Region Campus Compact Consortium. Bellingham WA: Western Washington University.

Calleson, D.C., Serow, R.C., and Parker, L.G. (1998). Institutional perspectives on integrating service and leaming. Journal of Research and Development in Education, 31(3), 147-154.

Dengel, D., Driscoll, A., and Yerke, R. (1999). Responding to problems and challenges, changing roles and direction: Service-learning in the context of long term partnerships. In Pascua, A. and Kecskes, K., Eds., Institutionalizing Service-Learning in Higher Education: Emerging Vision and Strategies. First Annual Continuums of Service Western Regional Conference: Selected Proceedings, 15-17.

Furco, A., Muller, P., and Ammon, M.S. (1998). Institutionalizing Service-Learning in Higher Education: Findings from a Study of the Western Region Campus Compact Consortium. University of California, Berkeley.

Gray, M.J., Ondaatje, E.H., Fricker, R., Geschwind, S., Goldman, C.A., Kaganoff, T., Robyn, A., Sundt, M., Vogelgesang, L., and Klein, S.P. (1999). Combining Service and Learning in Higher Education: Evaluation of the Learn and Serve America, Higher Education Program. Santa Monica: RAND.

Holland, B.A. (Fall, 2000). Institutional impacts and organizational issues related to servicelearning. Michigan Journal of Community Service Learning, Special Issue, 52-60.

Jacoby, B. (1996). Service-Learning in Higher Education. San Francisco: Jossey-Bass.

Kecskes, K. and Muyllaert, J. (1997). Continuums of Service Benchmark Worksheet. Western Region Campus Compact Consortium Request for Proposals.

Levine, A. (1980). Why Innovation Fails. Albany: State University of New York Press.

Pascua, A. and Kecskes, K., Eds. (1999). Institutionalizing Service-Learning in Higher Education: Emerging Vision and Strategies. First Annual Continuums of Service Western Regional Conference: Selected Proceedings.

Serow, R.C., Calleson, D.C., Parker, L., and Morgan, L. (1996). Institutional support for servicelearning. Journal of Research and Development in Education, 29(4), 220-225.

Zlotkowski, E. (1999). Beyond individual success: Issues in service-leaming implementation. In Pascua, A and Kecskes, K., Eds., Institutionalizing Service-Learning in Higher Education: Emerging Vision and Strategies. First Annual Continuums of Service Western Regional Conference: Selected Proceedings, 3-7.

Zlotkowski, E. ( $\mathrm{Jan} / \mathrm{Feb}$. 1996). A new voice at the table? Linking service-leaming and the academy. Change, 21-27. 


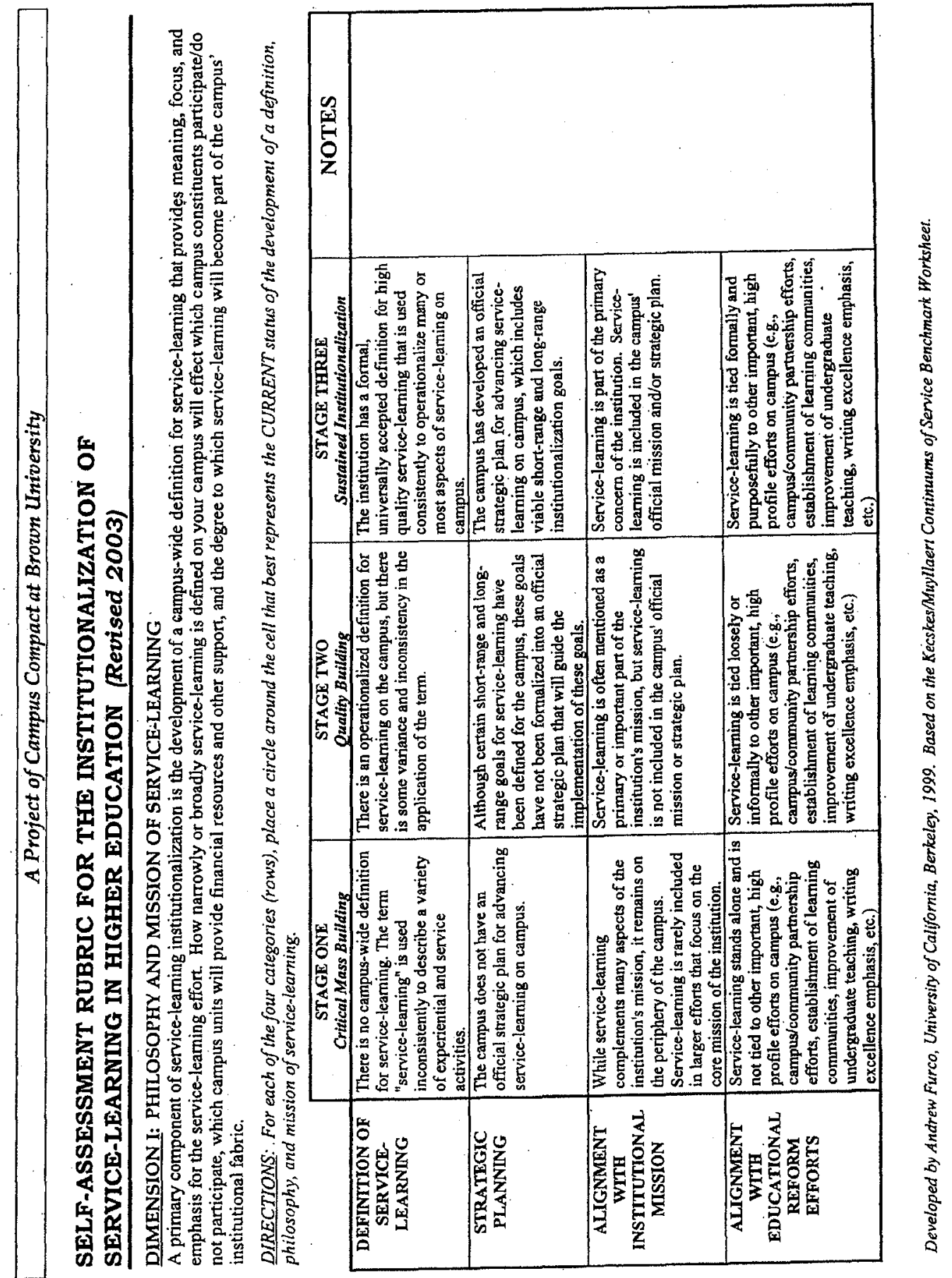




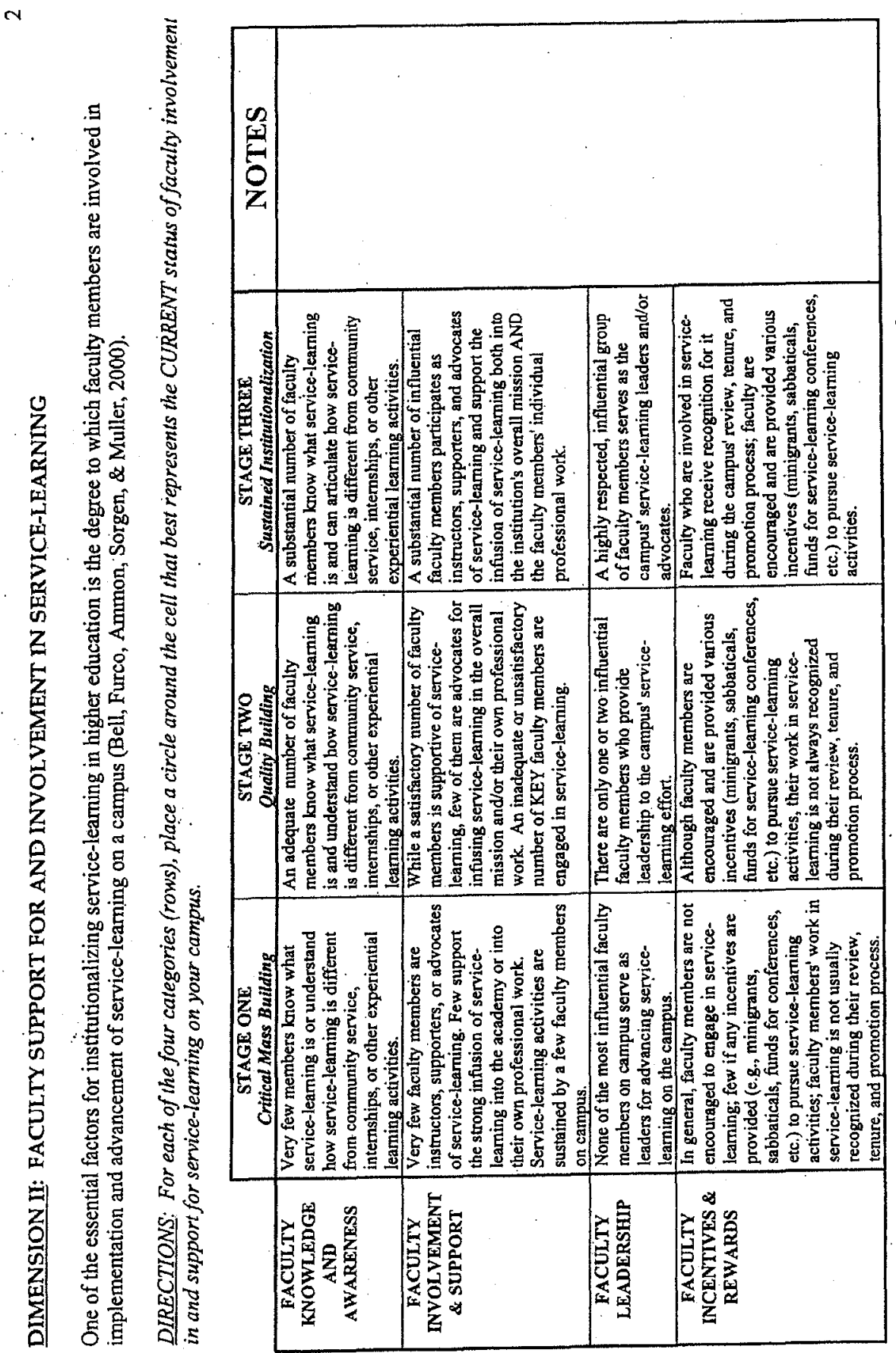




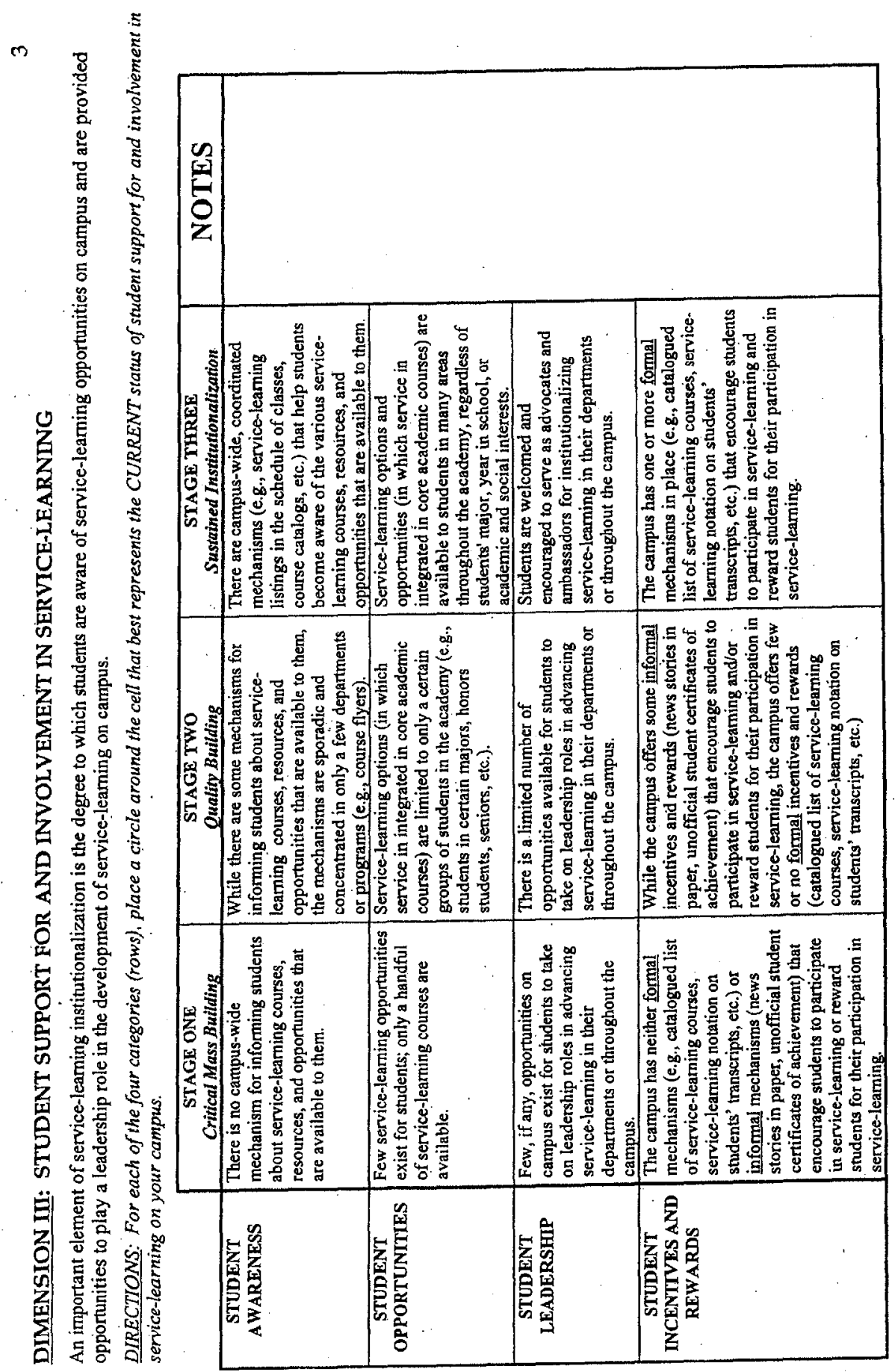




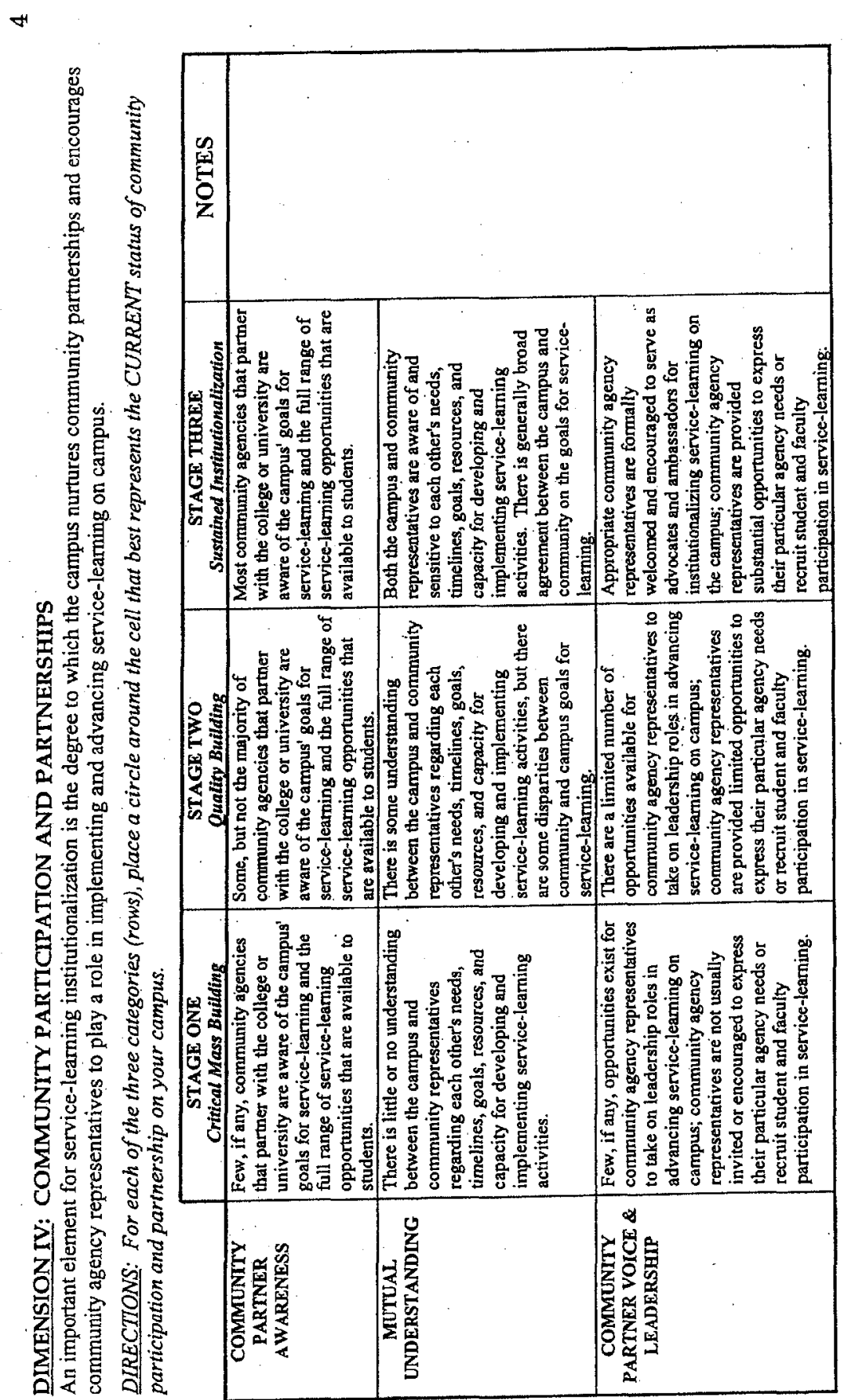




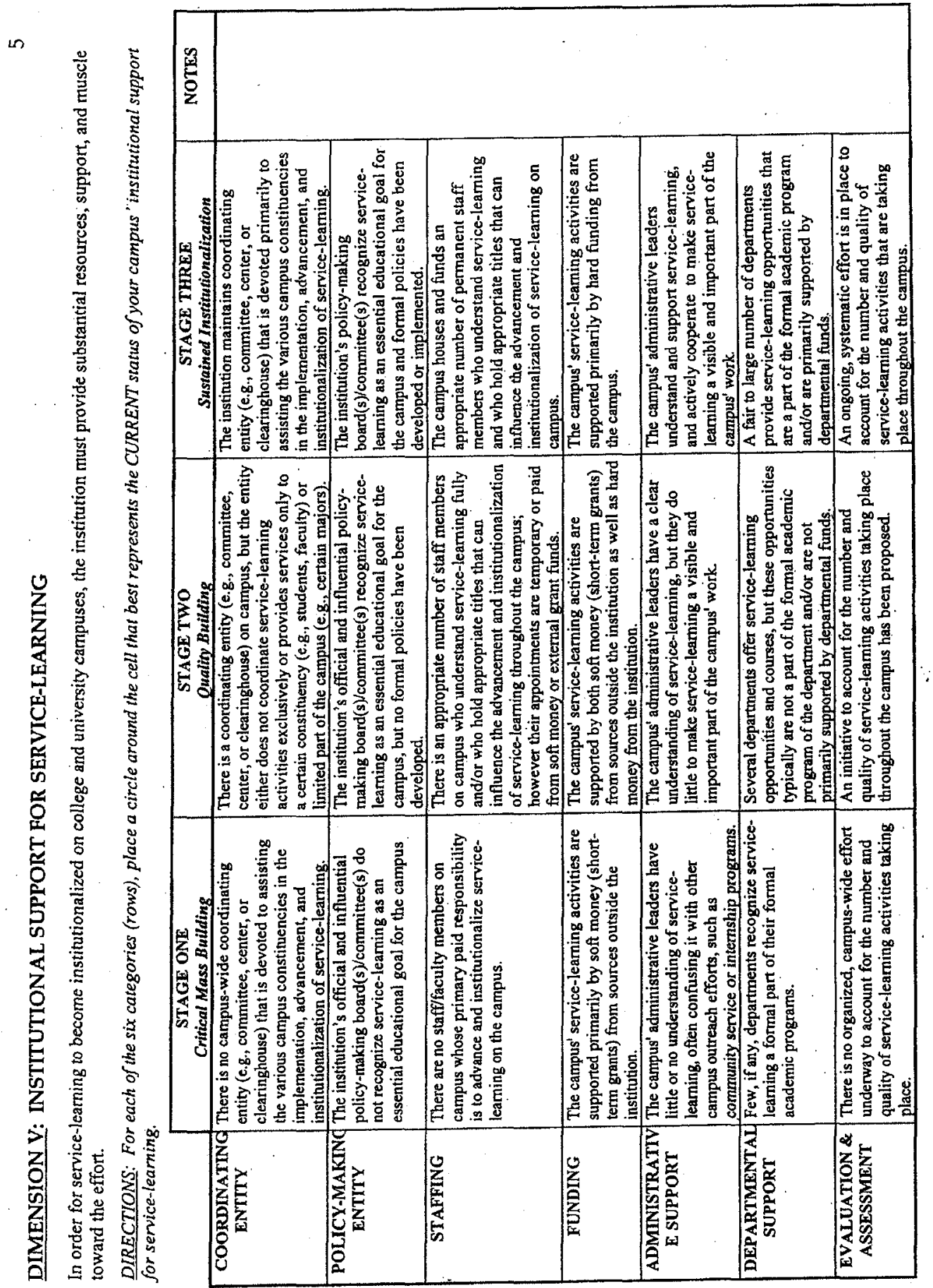




\section{APPENDiX C}

Gelmon, S., Siefer, S. et al. (2005) Building Capacity for Community Engagement: Institutional Self-Assessment 
Gelmon SB, Seifer SD, Kauper-Brown J and Mikkelsen M. (2005) Building Capacity for Community Engagement: Institutional Self-Assessment. Seattle, WA: Community-Campus Partnerships for Health. www.ccinh.info

\section{Building Capacity for Community Engagement:} Institutional Self-Assessment

Background: This tool is designed to assess the capacity of a given higher educational institution (or unit therein) for community engagement and community-engaged scholarship, and to identify opportunities for action. This assessment builds upon existing and validated prior work. ' It is intended to serve as a baseline for follow-up assessments, enabling institutions to track their progress and focus their work, while simultaneously enabling them to develop a longitudinal profile of their developing capacity for community engagement and communityengaged scholarship over time.

The Self-Assessment: The self-assessment is constructed around six dimensions:

I: Definition and Vision of Community Engagement (8 elements)

II: Faculty Support For and Involvement in Community Engagement ( 6 elements)

III: Student Support For and Involvement in Community Engagement ( 3 elements)

IV: Community Support For and Involvement in Community Engagement ( 6 elements)

V: Institutional Leadership and Support For Community Engagement ( 9 elements)

VI: Community-Engaged Scholarship (12 elements)

For each element of each dimension, four "levels" are articulated which represent a summairy of the literature and knowledge on institutional best practices with respect to commitment to community engagement and community-engaged scholarship. It is not expected that a given institution would necessarily align on the same level throughout the entire self-assessment. Rather, the results of the assesşment can be used to offer a profile of where the institution is at presently, and where opportunities for change might be identified.

Definitions: Three terms used in this self-assessment are particularly important to define:

By "community engagement" we mean applying institutional resources (e.g., knowledge and expertise of students, faculty and staff, political position, buildings and land) to address and solve challenges facing communities through collaboration with these communities. The methods for community engagement of academic institutions include community service, service-learning, community-based participatory research, training and technical assistance, capacity-building and economic development. Community engagement is not necessarily scholarship. For example, if a faculty member devotes time to developing a community-based program, it may be important work and it may advance the service mission of the institution, but it may not be "scholarly" unless it includes the other components which define scholarship (see below).

By "community-engaged scholarship" we mean "teaching, discovery, integration, application and engagement that involves the faculty member in a mutually beneficial partnership with the community and has the following characteristics: clear goals, adequate preparation, appropriate methods, significant results, effective presentation, reflective critique, rigor and peer-review."

Complete references are provided on the next page.

${ }^{2}$ Linking Scholarship and Communities. Report of the Commission on Community-Engaged Scholarship

in the Health Professions. (2005) Seattle, WA: Community-Campus Partnerships for Health. 
Gelmon SB, Seifer SD, Kauper-Brown J and Mikkelsen M. (2005) Building Capacity for Community Engagement: Institutional Self-Assessment. Seattle, WA: Community-Campus Partnerships for Health. www conh.info

The word "institution" is used as a generic term for the level of the organization on which the self-assessment is focused (e.g., a department, college, school, university).

Instructions for Completion: This self-assessment was designed to be completed by a team that reflects diverse institutional constituencies. This ideally is done as a two-phase process. First, team members review the assessment independently and complete it in a draft format. Then, team members come together and the actual assessment is completed through team conversation and discussion. This provides an opportunity to think through issues about community engagement as a team, and ideally will help to build team knowledge about school and institutional contexts and practices.

An answer should be provided for every element; if you do not have an answer, mark "Unable to assess." Please do not leave any elements blank. A "Notes" box is provided for you to record any comments.

References

1. Campus Compact. (2003). The Indicators of Engagement. Available at www.compact.org.

2. Community-Campus Partnerships for Health. (2001). Tool for Service-Leaming Sustainability. San Francisco, CA: Community-Campus Partnerships for Health.

3. Furco, A. (Forthcoming, 2005). Institutionalizing Service-Leaming in Higher Education. Bolton, MA: Anker Publishing.

4. Gelmon SB, Holland BA, Driscoll A, Spring A and Kerrigan S. (2001). Assessing Service-Learning and Civic Engagement: Principles and Techniques. Providence, RI Campus Compact.

5. Holland, B. (1997). "Analyzing Institutional Commitment to Service: A Model of Key Organizational Factors." Michigan Joumal of Community Service-learning, Fall, p.30-41.

6. Shinnamon AF, Gelmon SB and Holland BA. (1999). Methods and Strategies for Assessing Service Leaming in the Health Professions. San Francisco: Community Campus Partnerships for Health.

7. Gelmon SB, Seifer SD, Kauper-Brown J and Mikkelsen M. (2005) Community-Engaged Scholarship for Health Collaborative: Institutional Self-Assessment. Seattle, WA: Community-Campus Partnerships for Health.

Acknowledgement

The development of this instrument was supported in part by the Fund for the Improvement of Postsecondary Education in the U.S. Department of Education and the WK Kellogg Foundation. 


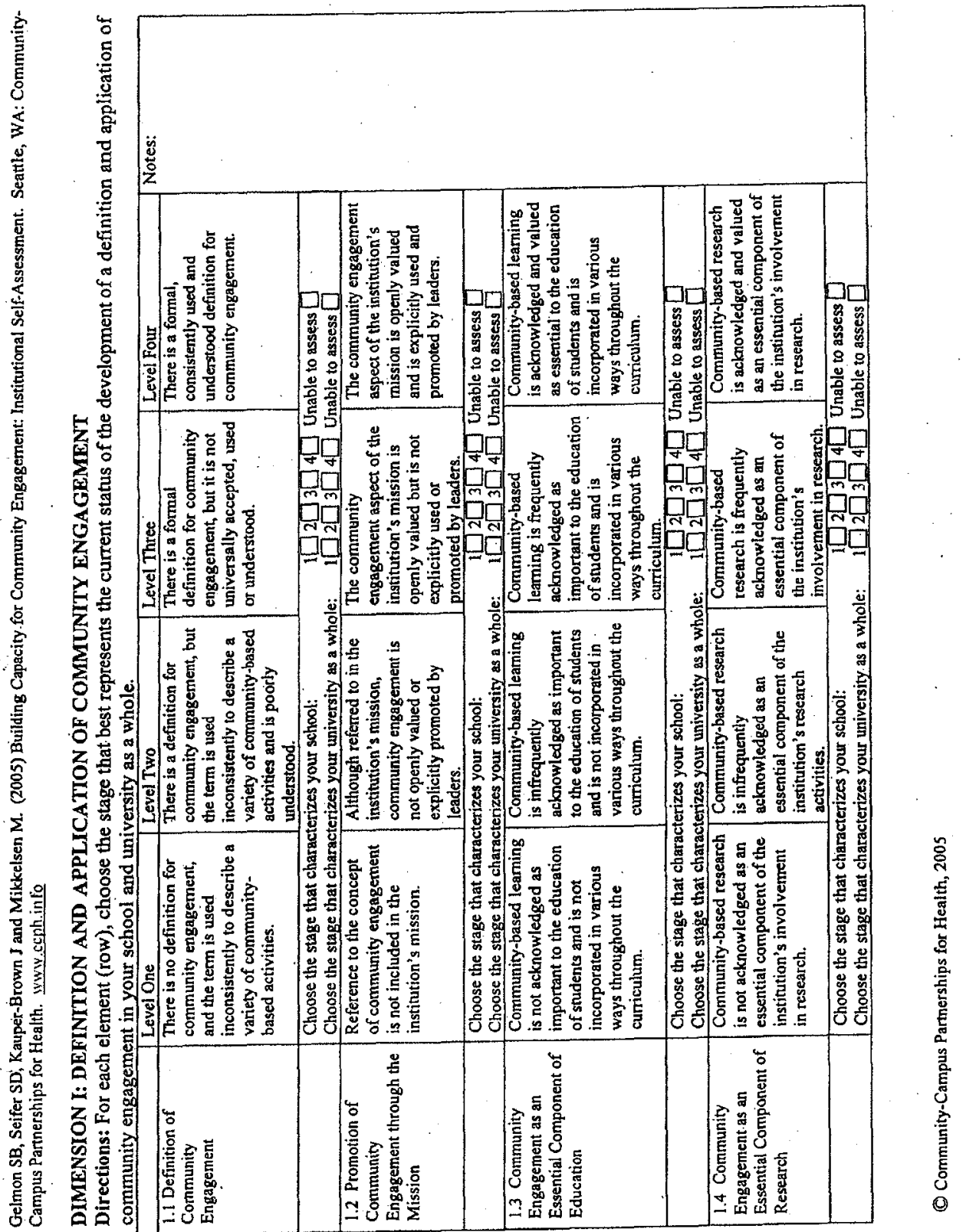




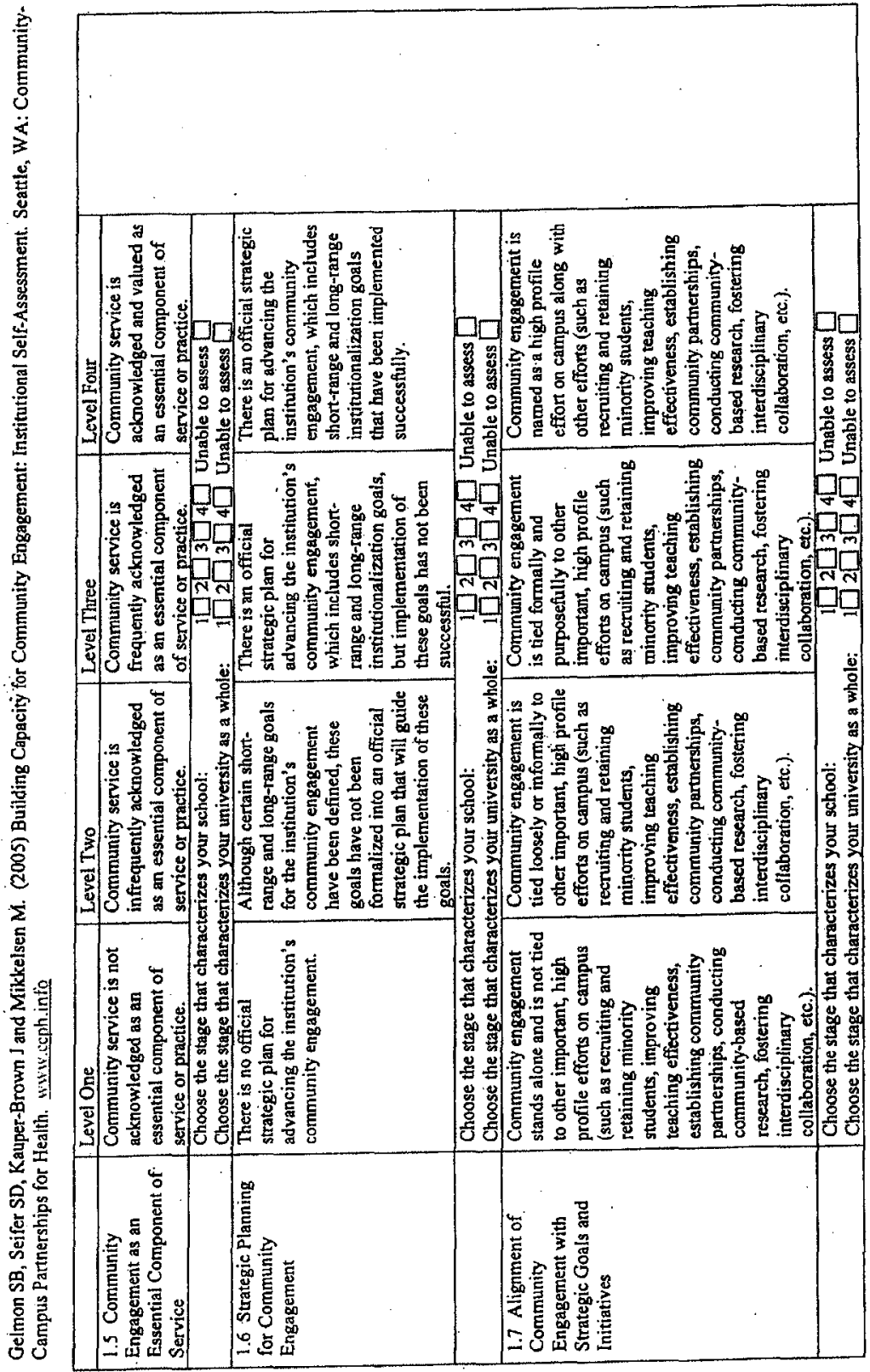

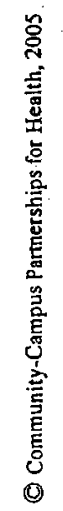




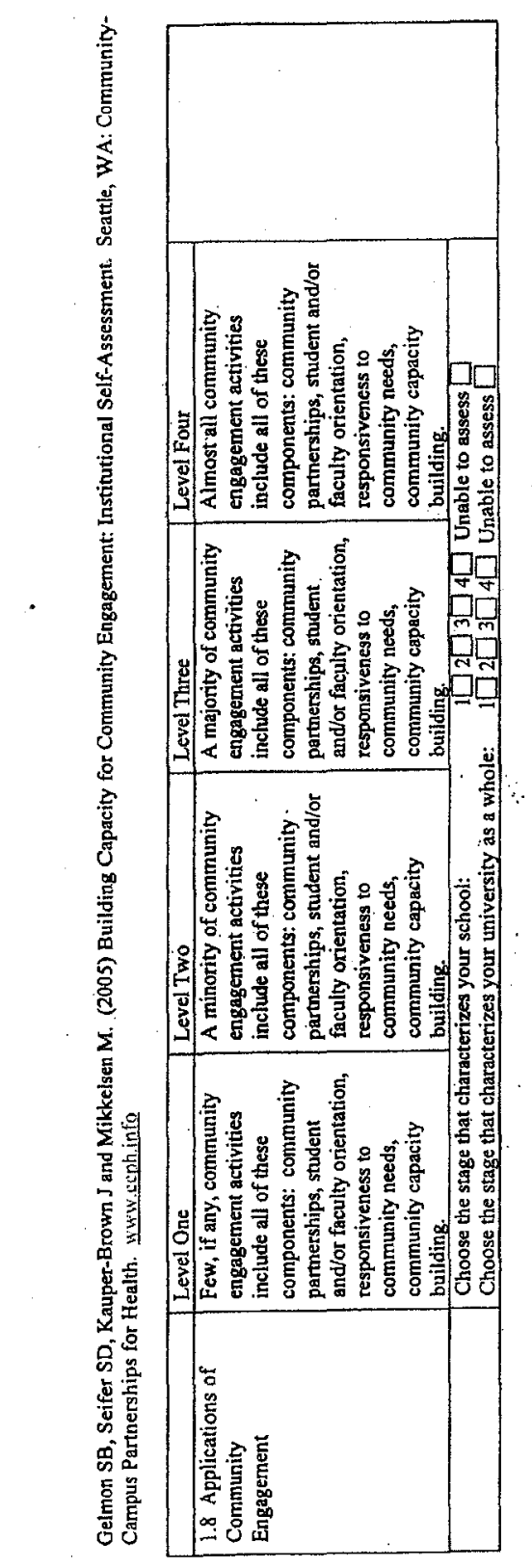

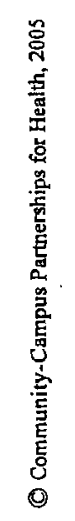




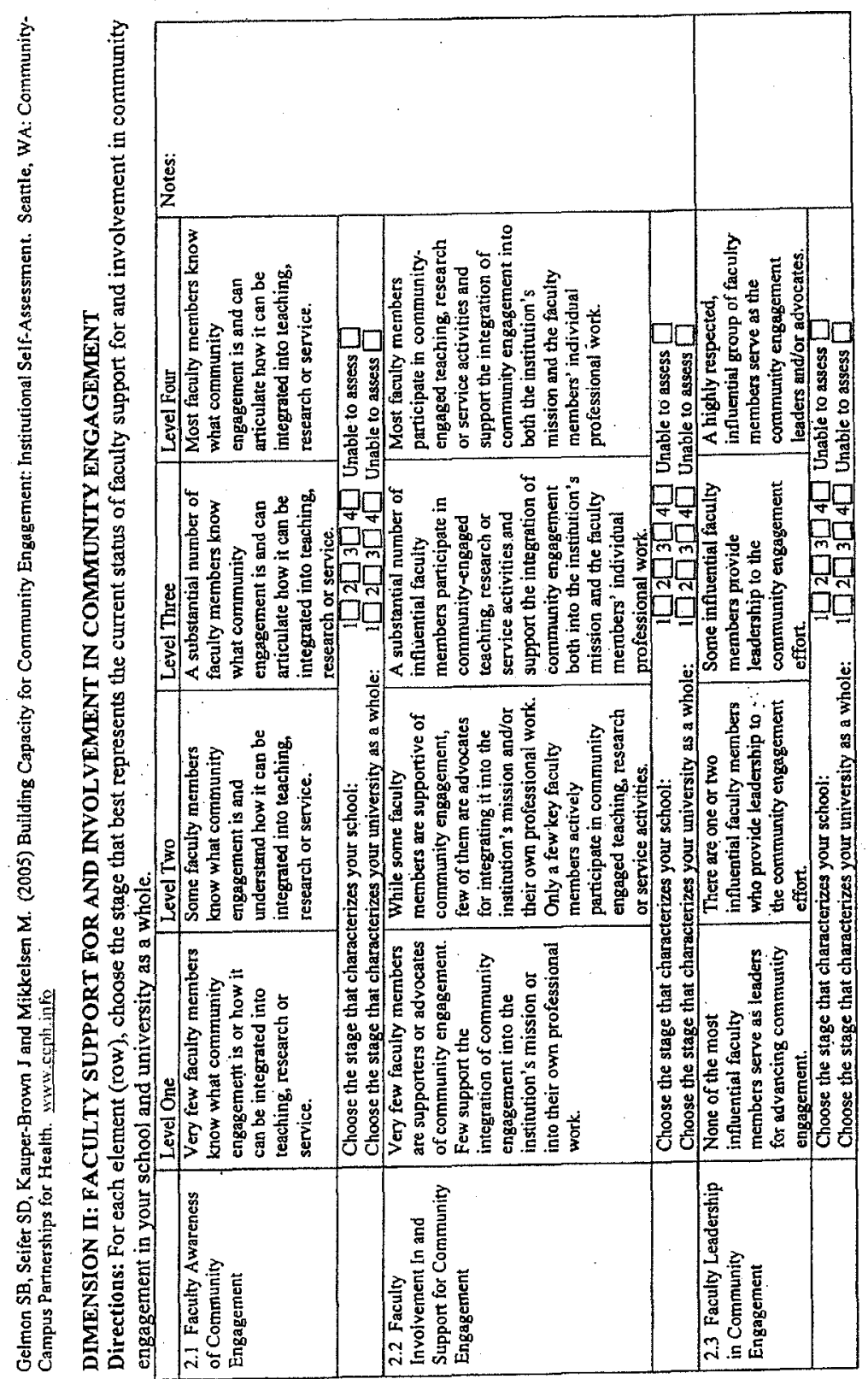

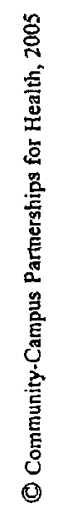




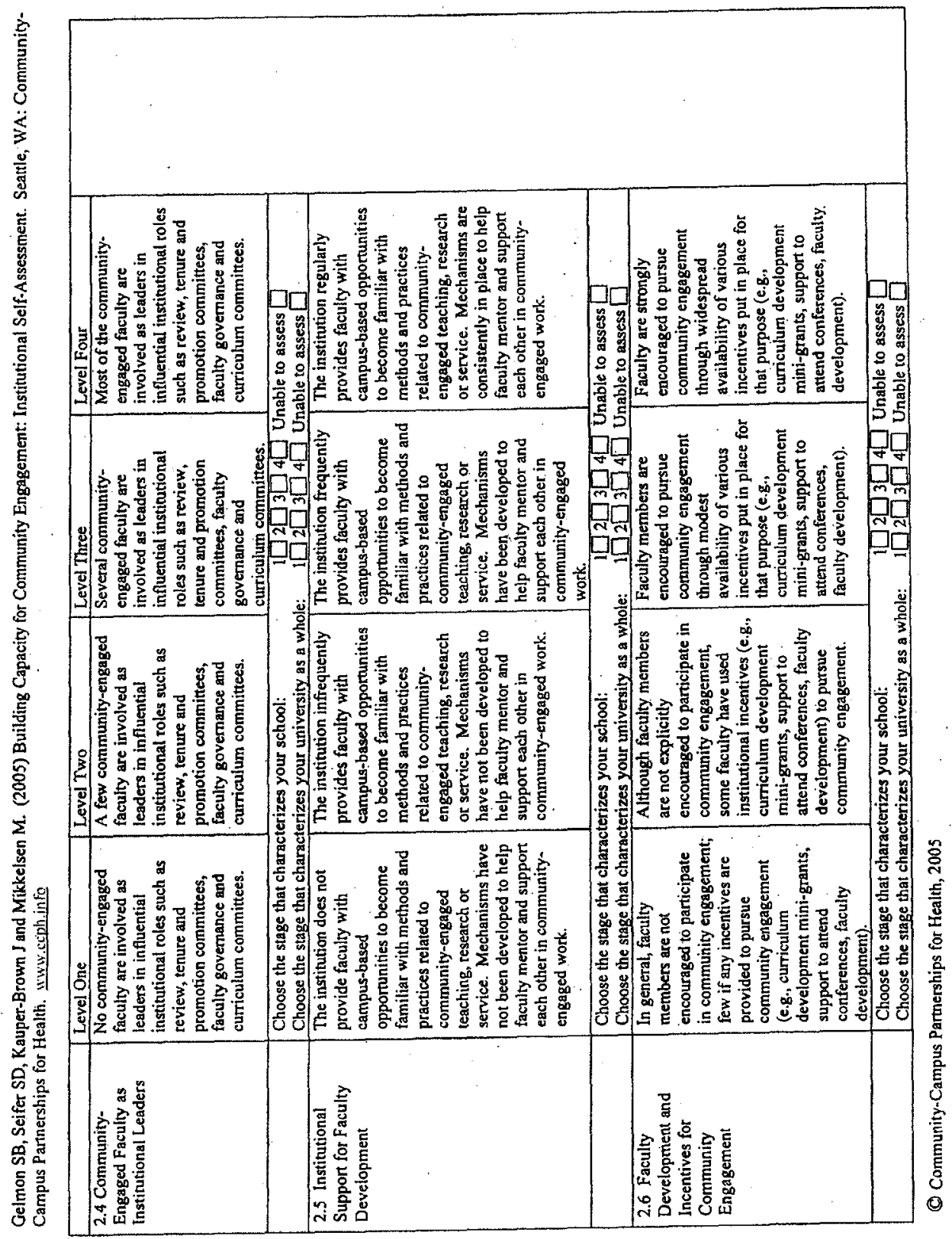




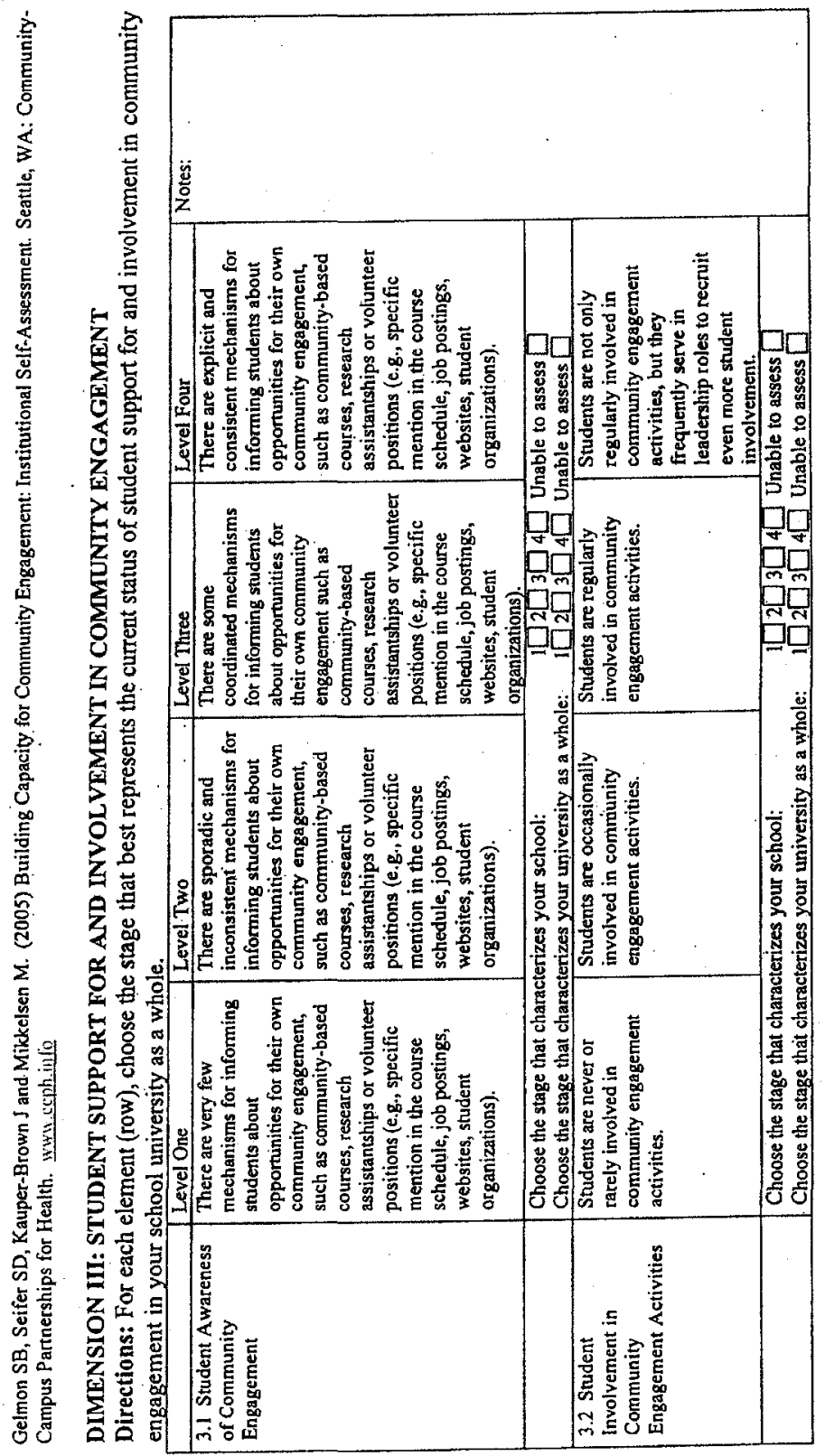

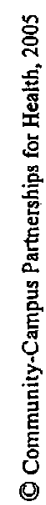




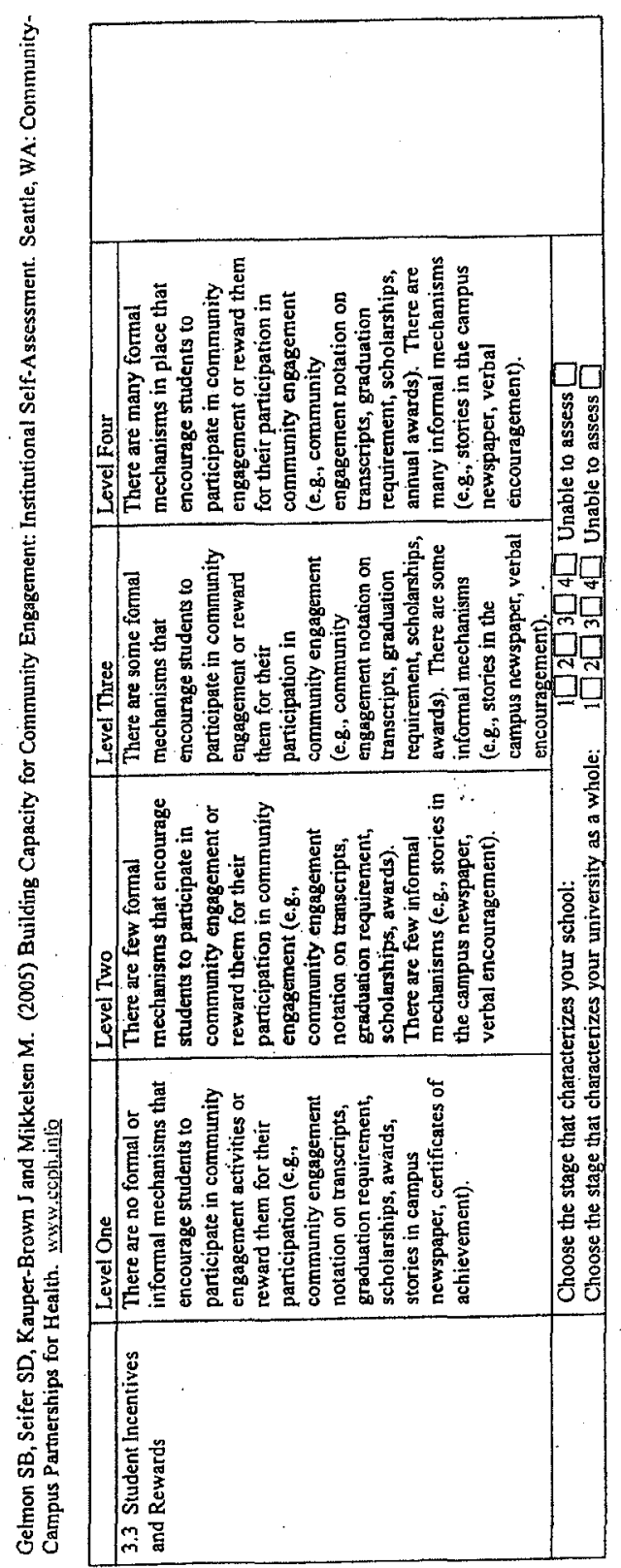

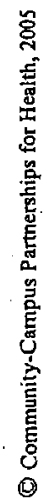




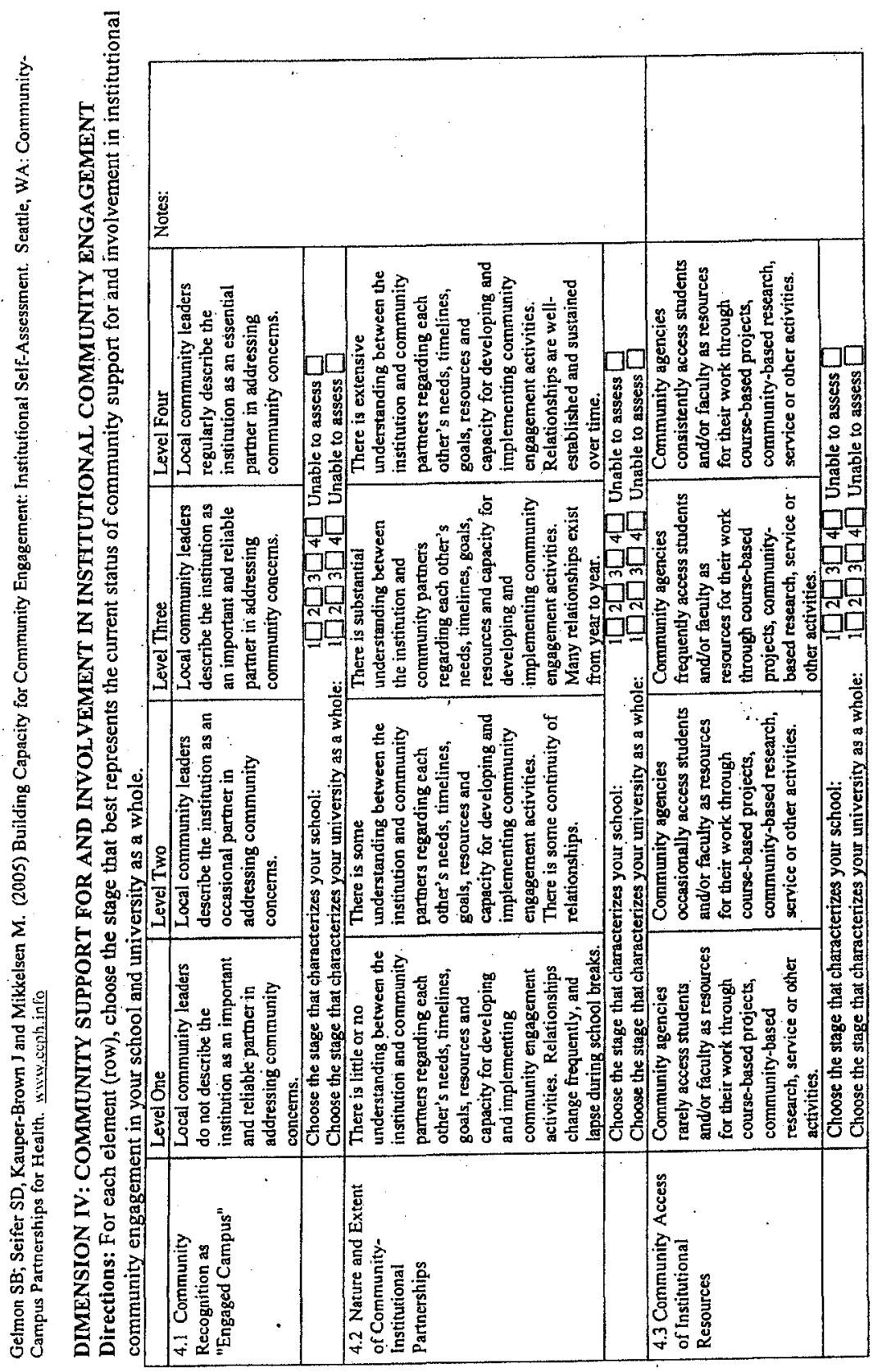

을

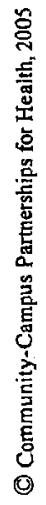




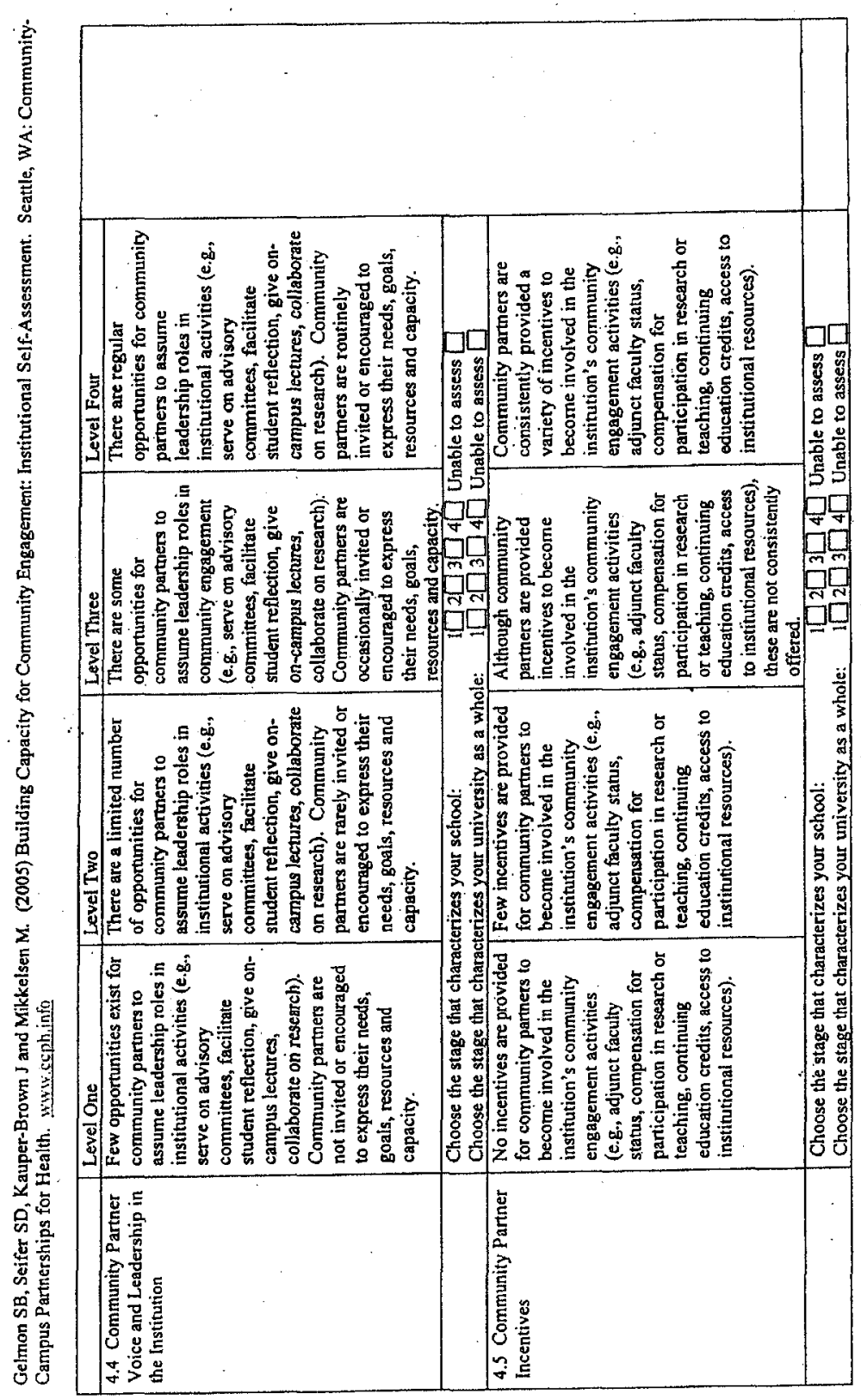

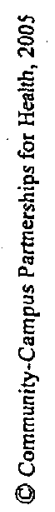




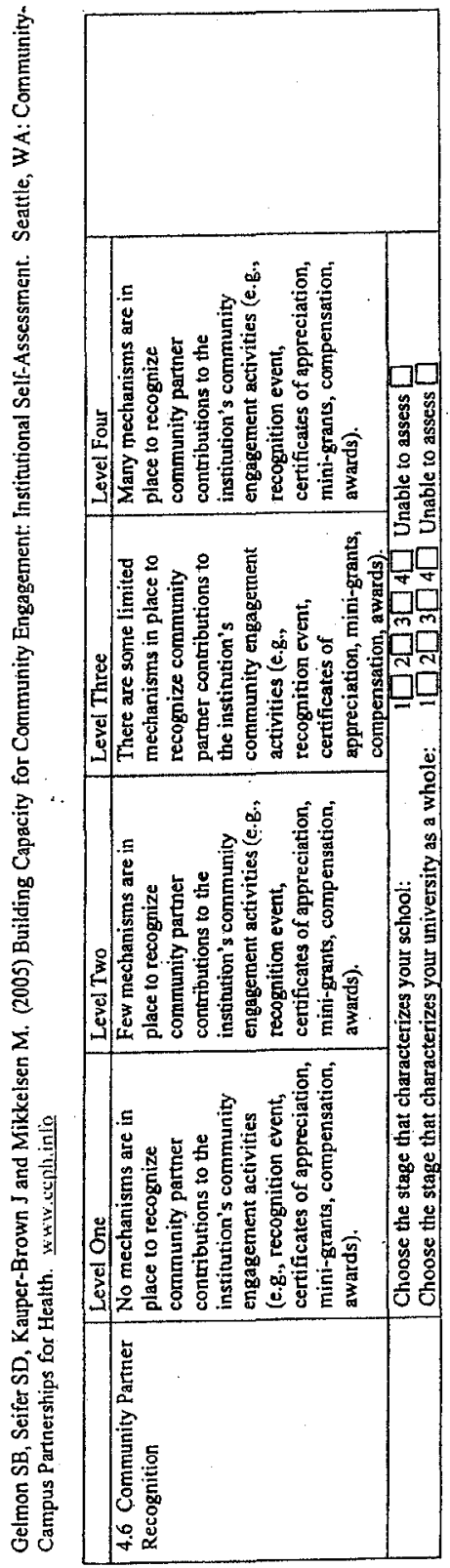




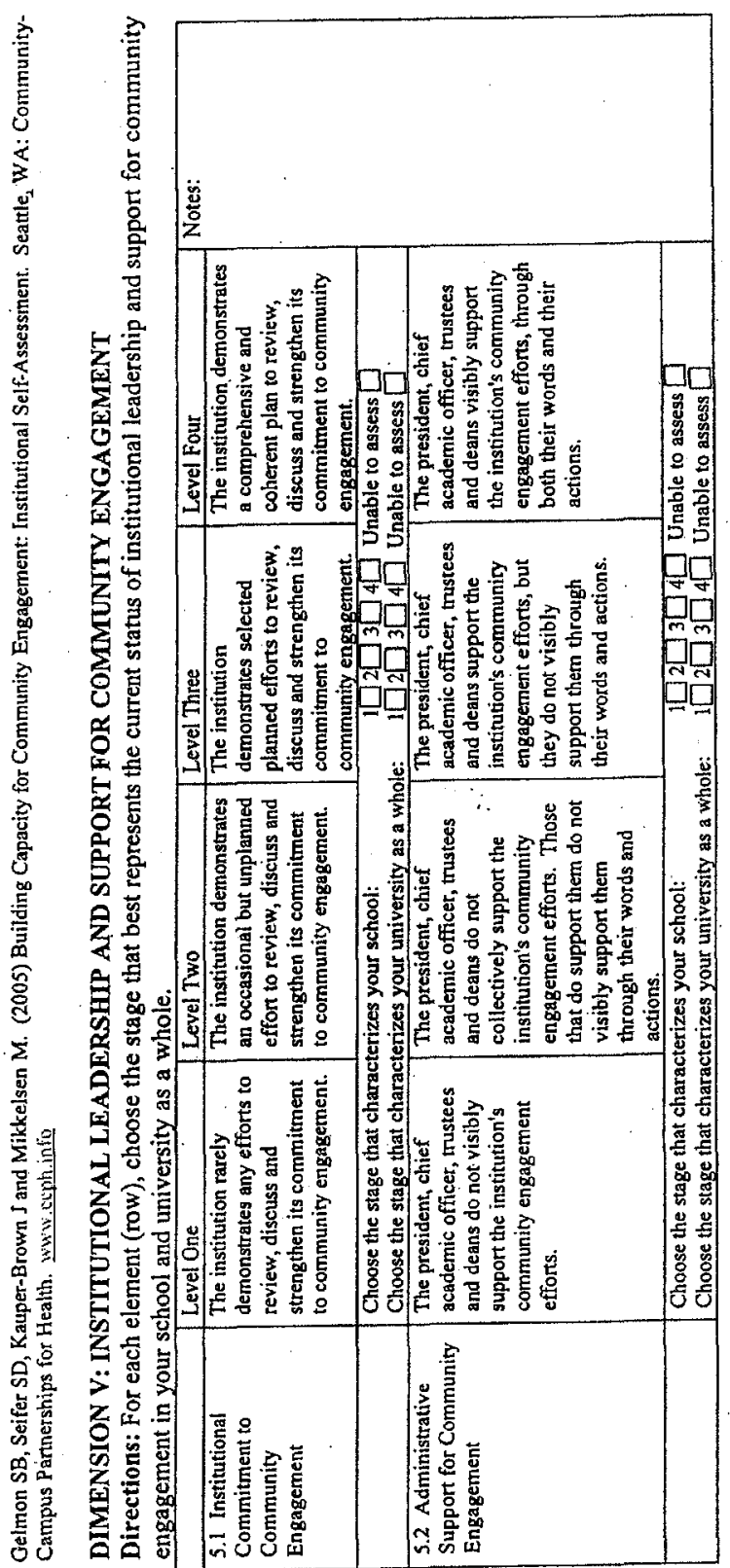

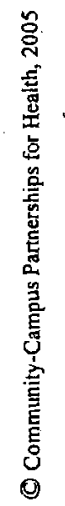




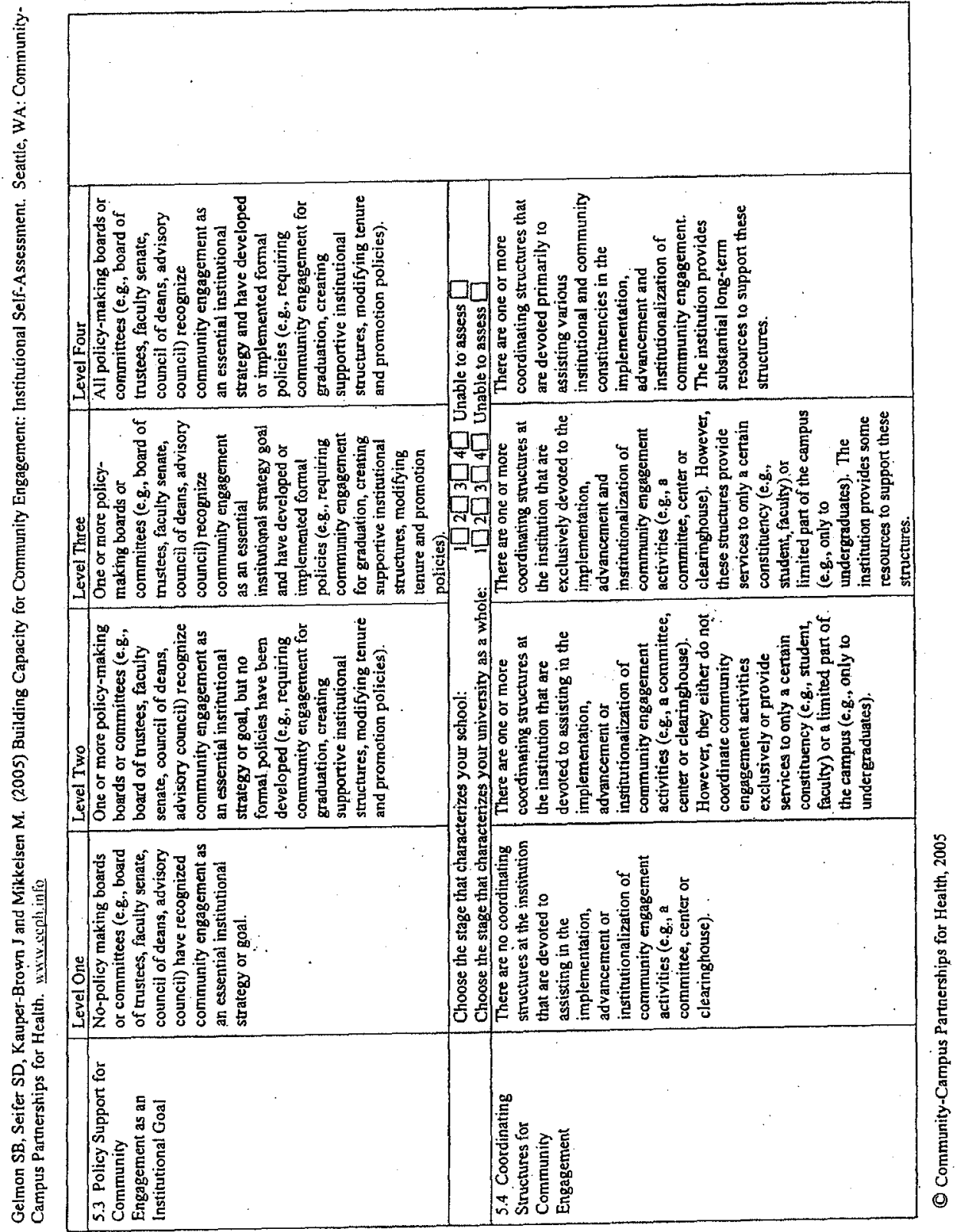




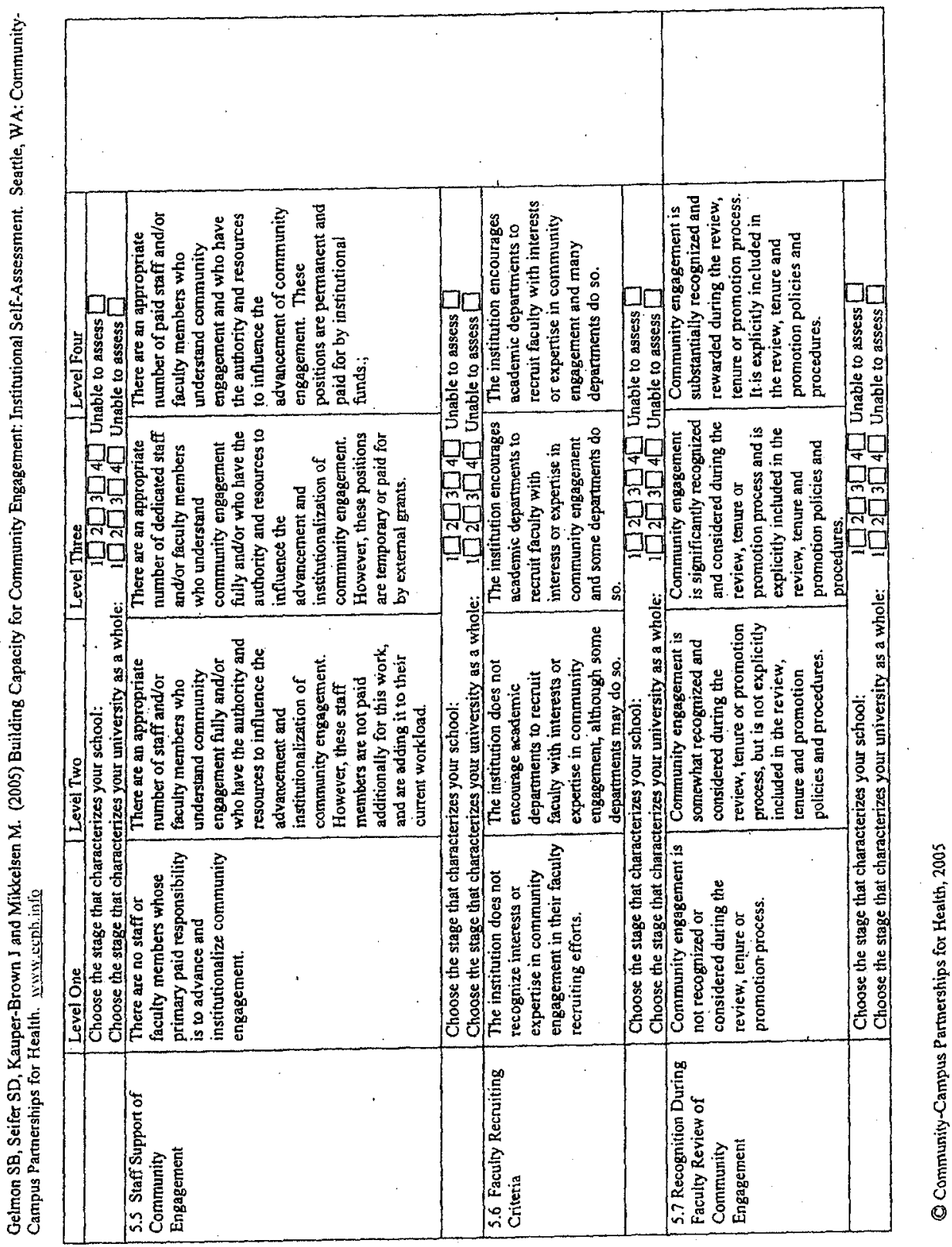




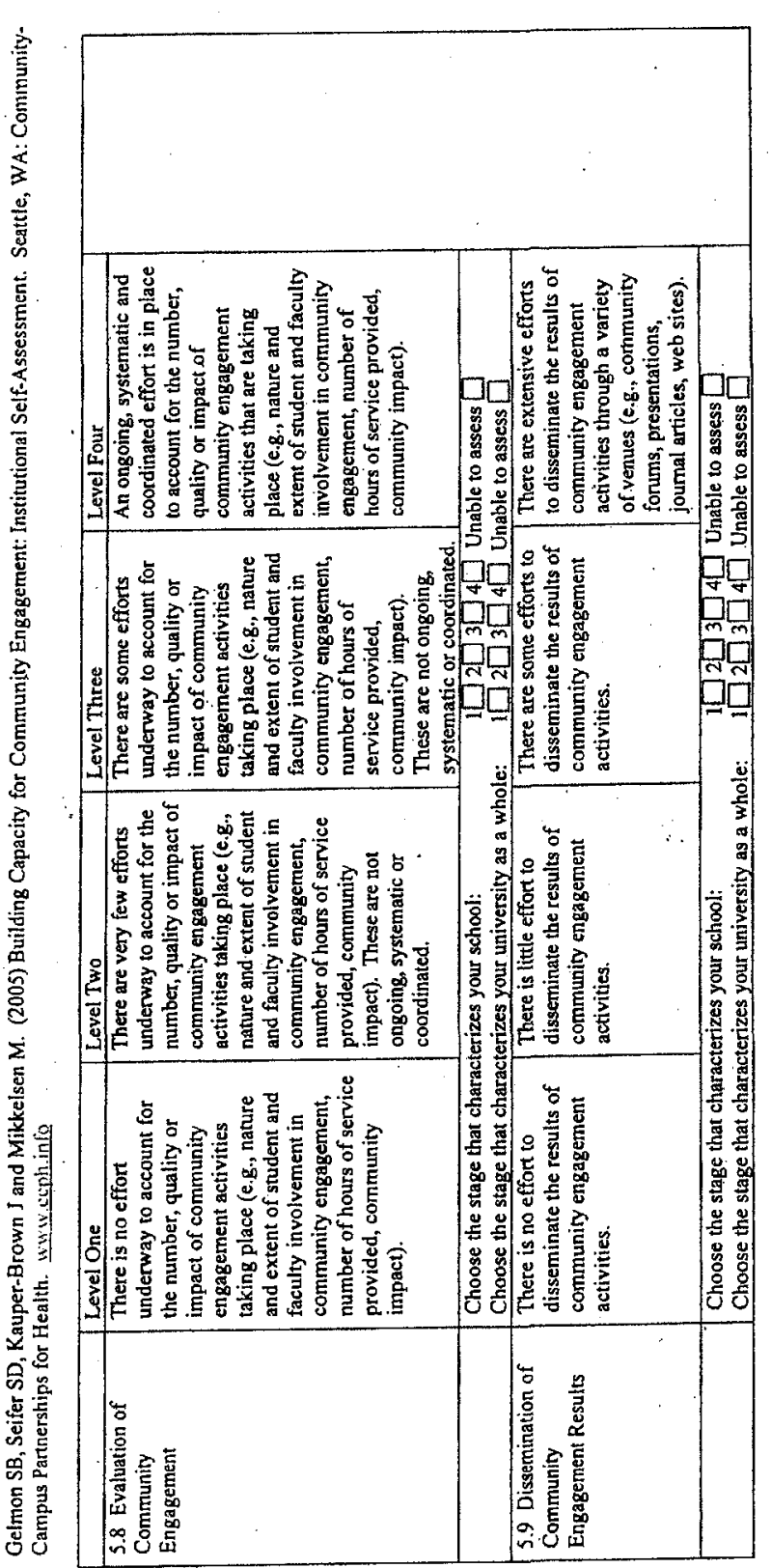

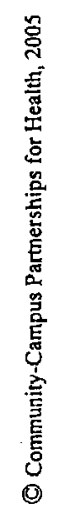




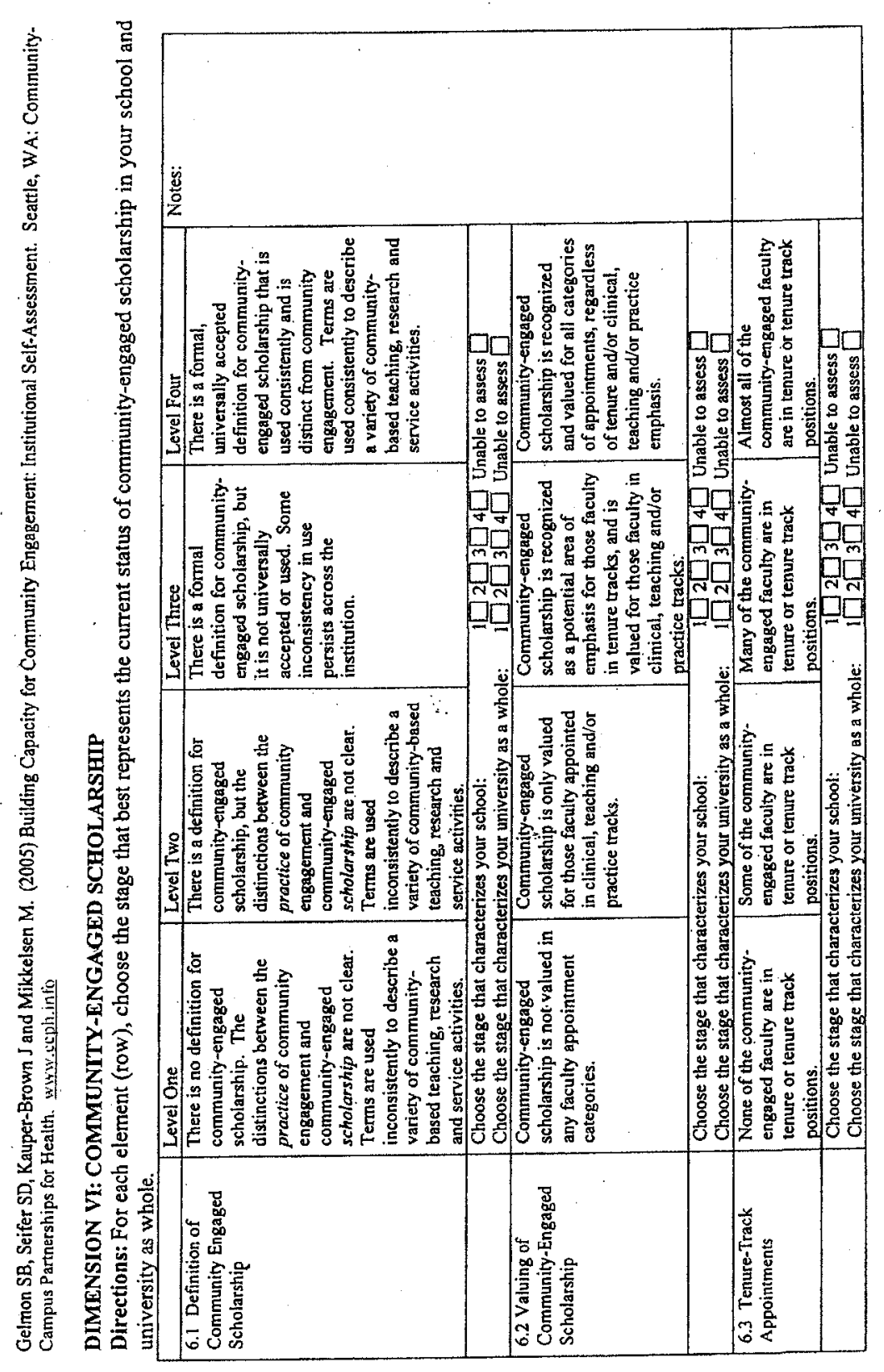

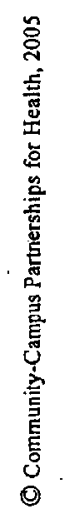




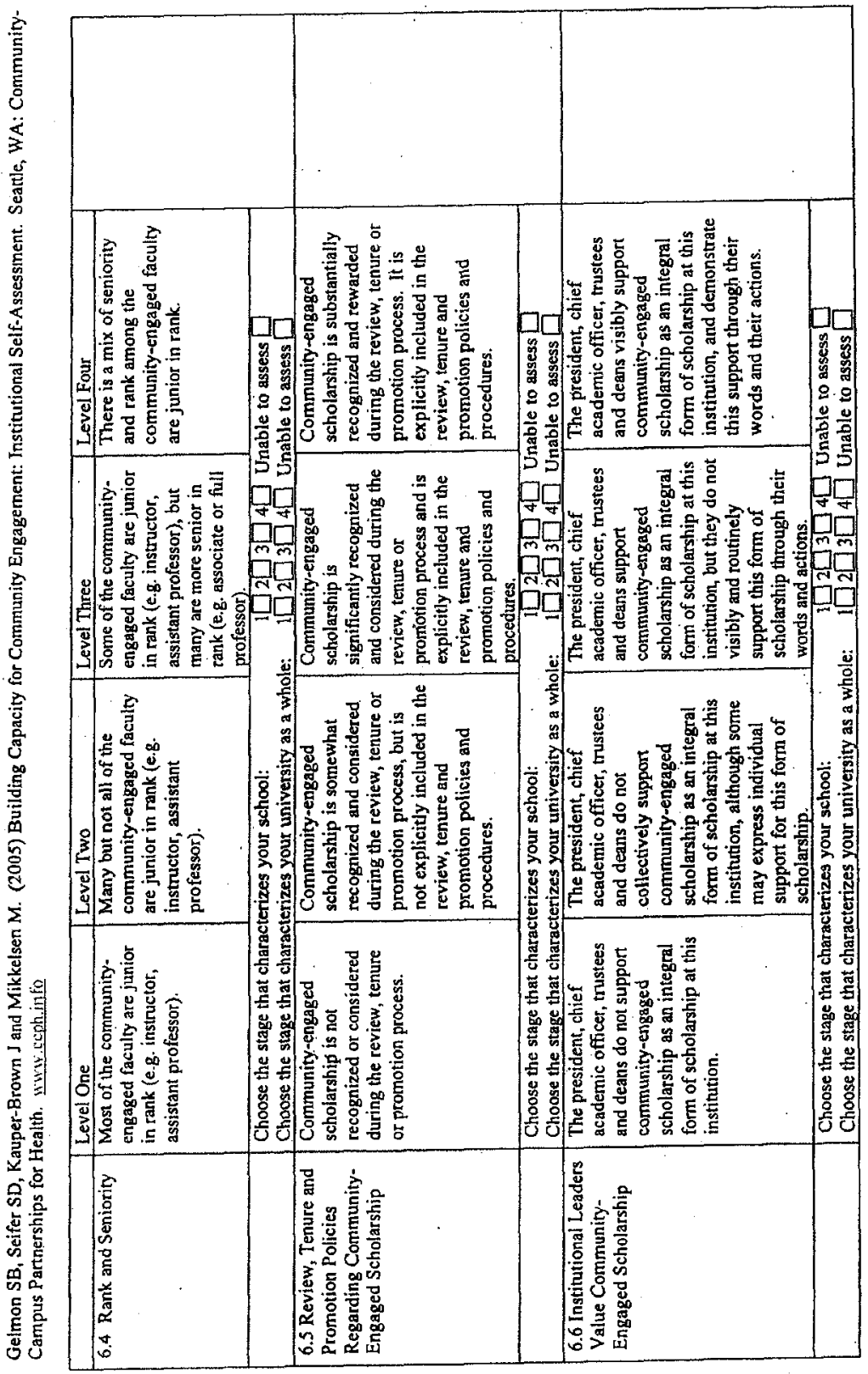

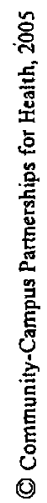




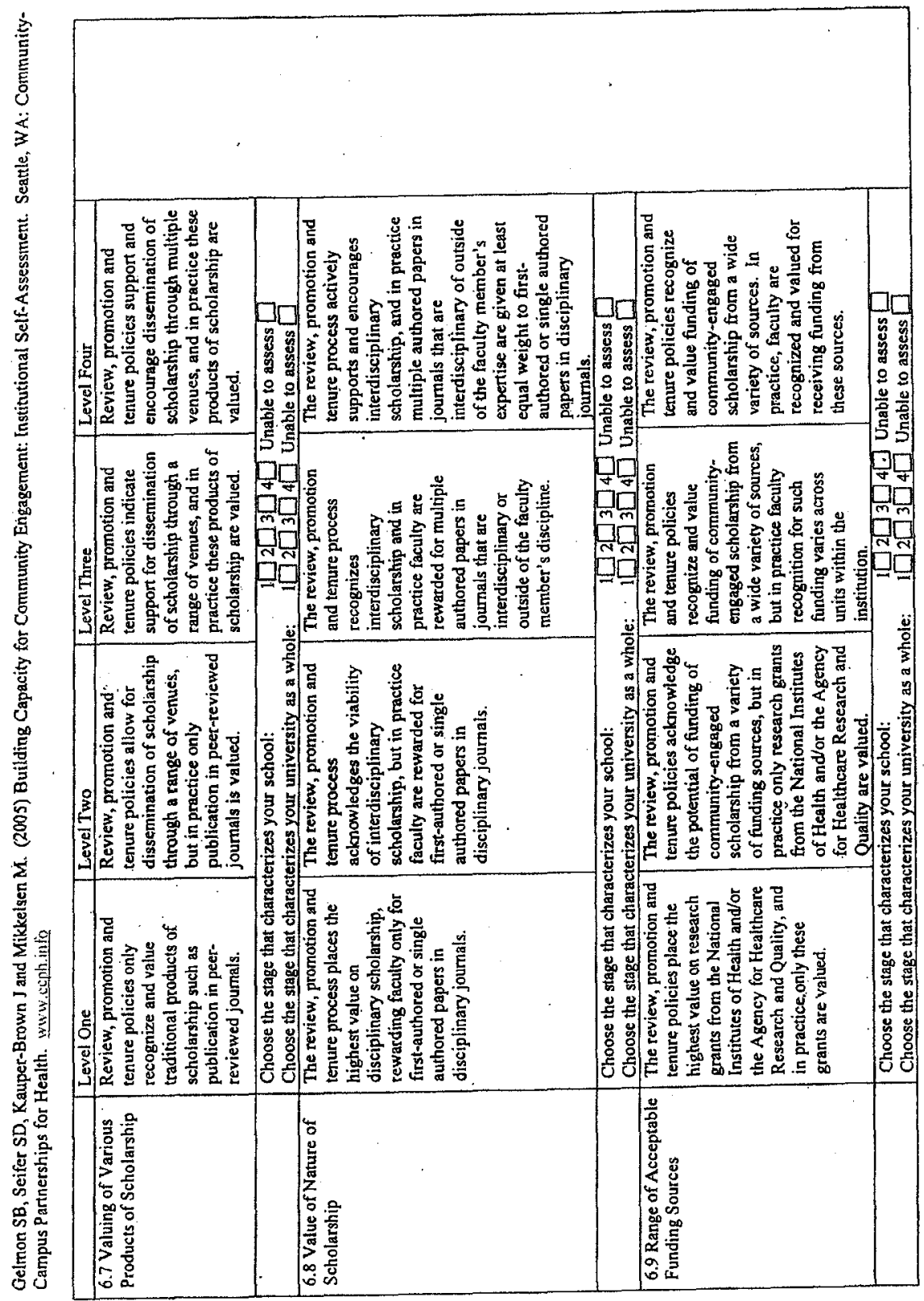

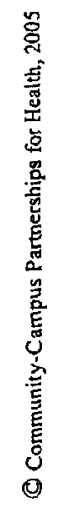




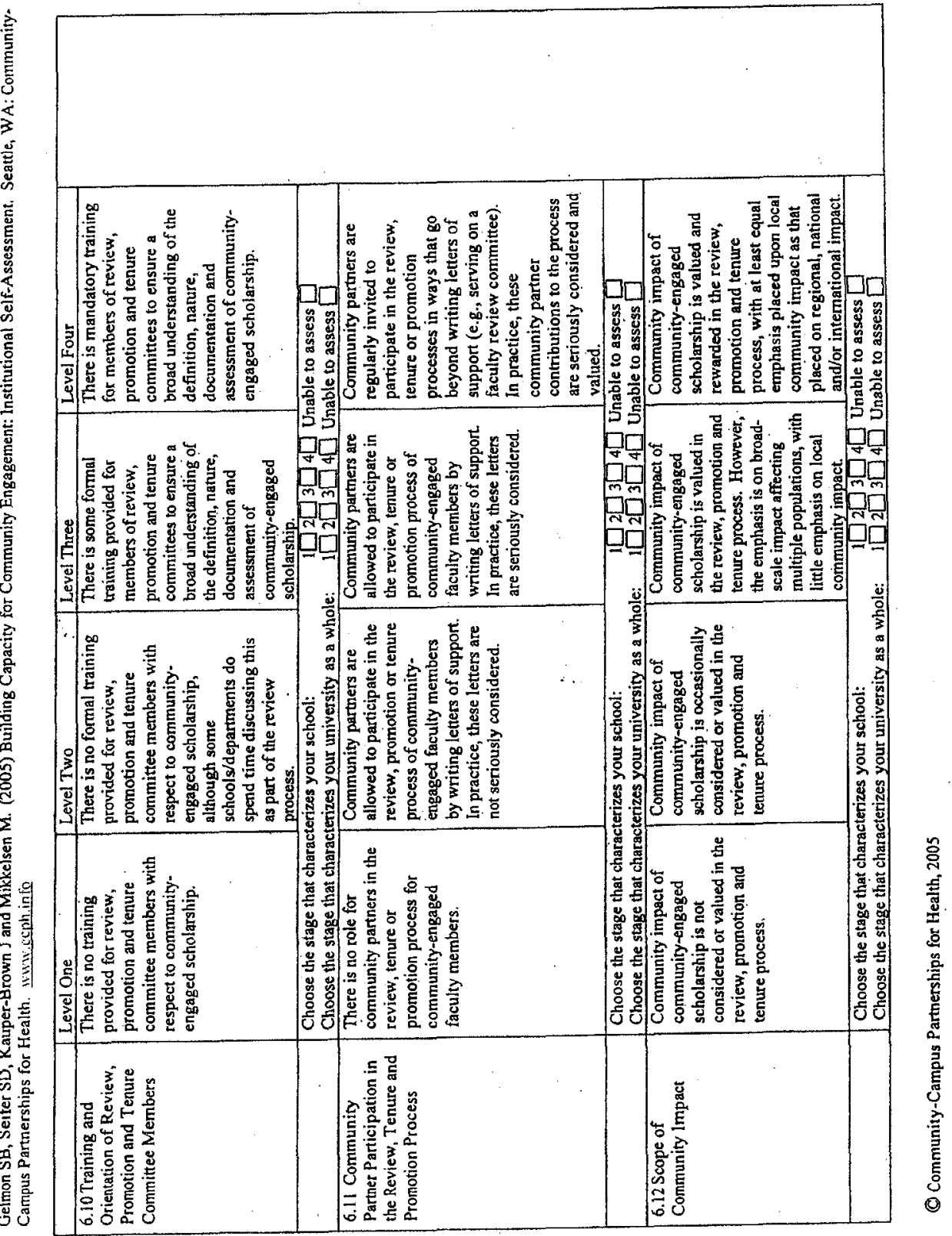




\section{APPENDIX D}

Kecskes, K. (2006) Characteristics of Engaged Departments Matrix 
Figure 1.1. Characteristics of Engaged Departments: Four Perspectives

Mission: The academic unit has a mission statement that includes civic engagement as a goal.

Leadership: The chair or other faculty leaders in the unit provide advocacy and support for engagement activities.

Visibility: The department publicly displays the collective commitment to civic engagement (on web sites, in promotional brochures, etc.).

Collaboration: The unit plans collectively and shares best practices.

Resource development: The unit pursues external resources to fulfill collectively determined, community-based, or civic engagement goals.

Inventory: The unit maintains an inventory of faculty members' community-based research and service-learning teaching activities.

Assessment: The unit tracks students' civic learning outcomes.

Common understanding: Faculty in the unit individually and collectively understand why the department is involved in community-based activities.

Rewards: Faculty in the unit are rewarded for their civic engagement efforts.

Research: Faculty in the unit are encouraged to pursue research initiatives that are applied or that have a clearly defined application in a community setting.

Articulation to student/community partners: Faculty in the unit regularly articulate to students (in courses, catalogues, and during advising) and to community partners why the department is involved in community-based activities.

Excellence at Portland State University implemented an Engaged Department Program in 2001. Based on insights gained from the reflective experience of working with 20 PSU departments on collaborative engagement initiatives within their units (in addition to those learned from the literature and the 11 exemplars showcased in this rolume), we have outlined an initial list of key
Figure 1.1. Continued

Common understanding: Studen ulty/unit is involved in comm activities.

Clarity of purpose: Students in involved in community-based ment activities.

Inclusion: Students in the majk opportunities for providing inf ulty/staff hiring curricular cha Leadership: Students in the ma opportunities (e.g. service-ler research) to develop civic leade

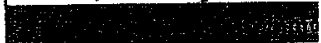

Common urderstanding: Comm ulty/unit is involved in commx

Clear expectations: Community tion to this academic unit.

Interaction: Community part classes, serving as adjunct facul Connection: Community partn. Collaborative planning and actic ing service-learning courses an designed with cornmunity part Note Adapted from Battistoni . 2006; Wergin, 2003.

characteristics of an engage. resented in this book or at $F$ demonstrates all of these . shown in Figure $1.1 \mathrm{can}$ in provide discussion prompts faculty, student, and comm 
lepartments:

\begin{tabular}{l} 
tement that includes civic \\
s in the unit provide advo- \\
the collective commitment \\
tional brochures, etc.). \\
\hline I shares best practices. \\
nal resources to fulfil col- \\
civic engagement goals. \\
of faculty members' com- \\
teaching activities. \\
arning outcomes. \\
idividually and collectively \\
ved in community-based \\
or their civic engagement \\
to pursue research initia- \\
r defined application in a \\
aculty in the unit regularly \\
and during advising) and \\
at is involved in commu- \\
\hline
\end{tabular}

mplemented an Engaged insights gained from the 0 PSU departments on hin their units (in addi$e$ and the 11 exemplars ined an initial list of key

Figure 1.1. Continued

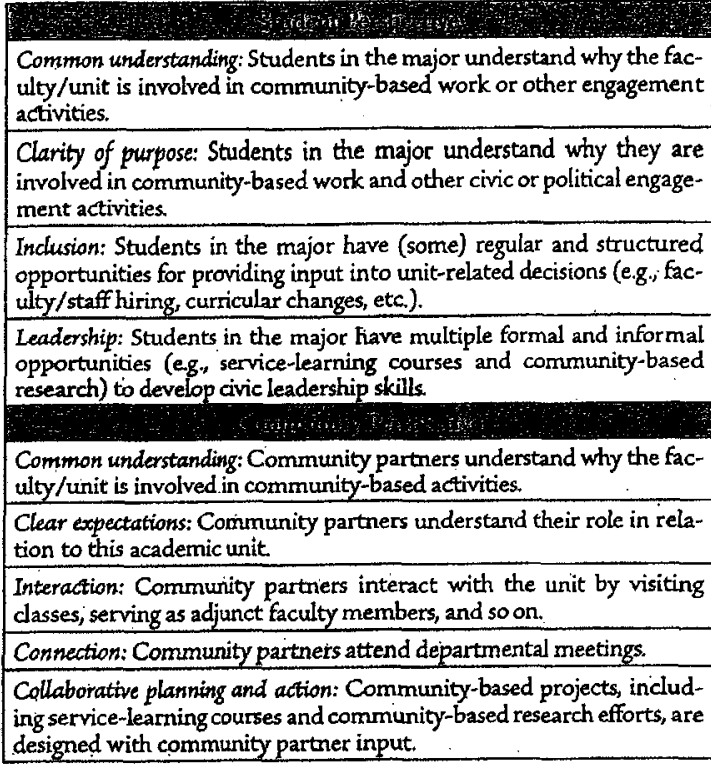

Note. Adapted from Battistoni et al., 2003; Kecskes, Gelmon, \&c Spring 2006; Wergin, 2003.

characteristics of an engaged department. No department represented in this book or at PSUU consistently and simultaneously demonstrates all of these characteristics; however, the rubric shown in Figure 1.1 can inform dialogue at the unit level and provide discussion prompts from four main perspectives: unit faculty, student, and community partner. If departments peri- 


\section{APPENDIX E}

Kecskes, K. (2008) Creating community-engaged departments: Self-Assessment

Rubric for the Institutionalization of Community Engagement in Academic Departments 


\title{
CREATING COMMUNITY-ENGAGED DEPARTMENTS: SELF-ASSESSMENT RUBRIC FOR THE INSTITUTIONALIZATION OF COMMUNITY ENGAGEMENT IN ACADEMIC DEPARTMENTS
}

\author{
KEVIN KeCSKES \\ PH.D. Candidate, PUblic Administration and Policy Doctoral Program \\ MARK O. HATFIELD SCHOOL OF GOVERNMENT \\ COLLEGE OF URBAN AND PUBLIC AFFAIRS \\ PORTLAND STATE UNIVERSITY
}

\author{
DIRECTOR, COMMUNITY-UNIVERSITY PARTNERSHIPS \\ CO-DIRECTOR, CENTER FOR ACADEMIC EXCELLENCE \\ PORTLAND STATE UNIVERSTTY
}

\section{INTRODUCTION}

Creating Community-Engaged Departments (hereafter referred to as the Rubric) is designed to assess the capacity of a higher education academic department for community engagement and to help its members identify various opportunities for engagement. This self-assessment builds upon existing and/or validated prior work (Furco, 2000, 2003; Gelmon \& Seifer et al., 2005; Kecskes \& Muyllaert, 1997; Kecskes, 2006). ${ }^{1}$ While many of these instruments have been developed primarily for institution-wide application, and some have been applied to academic units including colleges, schools, departments and programs, this Rubric has been developed solely for use in academic departments. This approach is based on advice from key informant interviews and the recognition of the importance of the role of academic departments in the overall institutionalization of community engagement in higher education (Battistoni et al., 2003; Furco, 2002; Holland, 2000; Morreale \& Applegate, 2006; Saltmarsh \& Gelmon, 2006; Zlotkowski \& Saltmarsh, 2006).

The Rubric is structured along six dimensions, which are considered by most community engagement experts to be key factors for the institutionalization of community engagement in higher education academic departments (Battistoni et al., 2003; Gelmon \& Seifer et al., 2005; Holland, 1997; Wergin, 1994, 2003; Zlotkowski, 2005).

Each dimension is composed of several components that characterize the dimension. For each component, a four-stage continuum of development has been established. Progression from Stage One: Awareness Building toward Stage Four: Institutionalization suggests that a department is moving closer to the full institutionalization of community engagement within the academic unit (Furco, 2000, 2003; Kecskes \& Muyllaert, 1997).

The conceptual framework for the Rubric is based largely on three knowledge sources: 1) the prior self-assessment rubric, matrix and benchmark instruments cited above; 2) various literature sources that discuss the critical elements for institutionalizing community engagement in higher

1 The author expresses gratitude to Andrew Furco; Sherril Gelmon, Sarena Seifer and Community-Campus Partnerships for Health (CCPH); and Julie Muyllaert and Washington Campus Compact for their permission to use and adapt their rubric, self-assessment, or benchmark instrument to assist the development of this departmental self-assessment rubric. 
education; and 3) key informant interviews that provided foundational information for the development and enhancement of this Rubric. In particular, the author wishes to express gratitude to the key informants and to the organizations that hold copyright on the source instruments. ${ }^{2}$

\section{DIMENSIONS AND COMPONENTS OF THE RUBRIC}

The self-assessment Rubric contains six dimensions; each includes a set of components that characterize the dimension. The six dimensions of the Rubric and their respective components are listed below:

\begin{tabular}{|c|c|}
\hline DIMENSIONS & COMPONENTS \\
\hline $\begin{array}{l}\text { I. Mission and Culture Supporting } \\
\text { Community Engagement }\end{array}$ & $\begin{array}{l}\text { - Mefinition of Community Engaged Teaching } \\
\text { - Definition of Community Engaged Research } \\
\text { - } \text { Definition of Community Engaged Service } \\
\text { - Collective Self-Awareness }\end{array}$ \\
\hline $\begin{array}{l}\text { II. Faculty Support and Community } \\
\text { Engagement }\end{array}$ & $\begin{array}{ll}\text { - Faculty Knowledge and Awareness } \\
\text { - } & \text { Faculty Involvement and Support } \\
\text { Engicular Integration of Community } \\
\text { - Faculty Incentives } \\
\text { - Review, Promotion, and Tenure Process } \\
\text { Integration } \\
\end{array}$ \\
\hline $\begin{array}{l}\text { III. Community Partner and Partnership } \\
\text { Support and Community Engagement }\end{array}$ & $\begin{array}{l}\text { - } \text { Placement and Partnership Awareness } \\
\text { - Commal Understanding and Commitment } \\
\text { - Community Partner Voice } \\
\text { - Community Partner Leadership } \\
\text { - Community Partner Incentives and Recognition } \\
\end{array}$ \\
\hline $\begin{array}{l}\text { IV. Student Support and Community } \\
\text { Engagement }\end{array}$ & $\begin{array}{ll} & \text { Student Opportunities } \\
\text { Student Awareness } \\
\text { Student Incentives and Recognition } \\
\text { Student Voice, Leadership \& Departmental } \\
\text { Governance }\end{array}$ \\
\hline $\begin{array}{l}\text { V. Organizational Support for Community } \\
\text { Engagement }\end{array}$ & $\begin{array}{l}\text { Administrative Support } \\
\text { Facilitating Entity } \\
\text { - Dvaluation and Assessment } \\
\text { - Faculty Recruitment and Orientation }\end{array}$ \\
\hline
\end{tabular}

2 Richard Battistoni, Providence College; Amy Driscoll, consulting scholar, Carnegie Foundation for the Advancement of Teaching; Andrew Furco, University of Minnesota; Sherril Gelmon, Portland State University; Barbara Holland, National Service-Learning Clearinghouse; Steve Jones, Indiana University-Purdue University Indianapolis; John Saltmarsh, University of Massachusetts, Boston; Sarena Seifer, Campus-Community Partnerships for Health; Jon Wergin, Antioch University; and Edward Zlotkowski, Bentley College. 


\begin{tabular}{|c|c|}
\hline & $\begin{array}{l}\text { Marketing } \\
\text { Dissemination of Community Engagement } \\
\text { Results } \\
\text { Budgetary Allocation } \\
\end{array}$ \\
\hline $\begin{array}{l}\text { VI. Leadership Support for Community } \\
\text { Engagement }\end{array}$ & $\begin{array}{l}\text { Department Level Leadership } \\
\text { - Campus Level Leadership from Departmental } \\
\text { Faculty } \\
\text { National Level Leadership from Departmental } \\
\text { Faculty }\end{array}$ \\
\hline
\end{tabular}

Each dimension has been divided into four phases of development. The first is an "awareness building" phase; the second is a "critical mass building" phase; the third is a "quality building" phase; and finally, the fourth is an "institutionalization" phase. The four "phases" are based on the scholarly literature on best practices with respect to commitment to community engagement (Furco 2000, 2003; Gelmon \& Seifer et al., 2005; Holland, 1997; Kecskes \& Muyllaert, 1997).

Departments may be in different phases of development for each of the six dimensions of the Rubric. The results of the self-assessment can be used to offer a profile of current departmental engagement and identify opportunities for change. The Rubric may also be used repeatedly to track progress and establish a longitudinal profile of the academic department's developing capacity for community engagement over time.

\section{DEFINITIONS}

Three terms used in this self-assessment are particularly important to define:

1) Community Engagement: Community Engagement describes the collaboration between institutions of higher education and their larger communities (local, regional/state, national, global) for the mutually beneficial exchange of knowledge and resources in a context of partnership and reciprocity (Carnegie Foundation Elective Classification: Community Engagement, 2007). This engagement may be described in the following various ways: community service, service-learning, community-based learning, community-based participatory research, training and technical assistance, capacity-building and economic development, among others. Community engagement is not necessarily scholarship. For example, if a faculty member devotes time to developing a community-based program, it may be important work and it may advance the service mission of the department, but it may not be "scholarly" unless it includes dimensions that are characteristic of scholarship (Commission on Community Engaged Scholarship in the Health Professions, 2005; Gelmon \& Seifer et al., 2005).

2) Community-engaged scholarship: Teaching, discovery, integration, application and engagement that involves the faculty member in a mutually beneficial partnership with the community and has the following characteristics: clear goals, adequate preparation, appropriate methods, new knowledge creation, effective presentation, reflective critique, rigor and peerreview (Commission on Community Engaged Scholarship in the Health Professions, 2005; Gelmon \& Seifer et al., 2005; Lynton, 1995).

3) Academic department describes a formal cohort of individuals organized around a common academic subject matter, theme or discipline in higher education. In the Rubric, the term academic department is used interchangeably with "academic unit," "department," and "unit." In 
some European-influenced higher education systems, the term academic department may equate with the term "college." In some Asia-Pacific higher education systems, the term academic department may equate with the term "faculty" or "faculties" (Personal communication with Wayne Delaforce, 2/29/08).

\section{USING THE RUBRIC}

The Rubric is intended to be used as a tool to measure development of community engagement by academic departments. The results of this self-assessment can provide useful information and help identify those components or dimensions of community engagement that are progressing well and those which may need some additional attention. By using the tool at different points in time, departments can measure the progress they are making.

The Rubric provides departments with a wide and flexible range of opportunities to increase their community engagement activities. The Rubric recognizes that community engagement is largely a function of a campus' and a department's unique character and cultures. For that reason, in some cases, individual components of the Rubric may not be applicable in certain departmental settings. In other cases, the Rubric may not include some components that may be key to a department's institutionalization efforts in which case a department may wish to add components or dimensions to the Rubric. What is most important is the overall status of the department's institutionalization progress rather than the progress of individual components.

General Instructions for Completion of the Self-Assessment Rubric: While there is value in the Rubric's being completed by an individual familiar with the academic department, the selfassessment is most effective when completed by a departmental team. Furthermore, the selfassessment is ideally completed as a two-phase process. First, individual team members review the assessment independently and complete it in a draft format. Then, team members come together and the final summary self-assessment is completed through team conversation and discussion. This provides an opportunity to think through issues about community engagement as a team, which" . ideally will help to build departmental knowledge about contexts and practices. A response should be provided for every component. Generally, it is not recommended that partial stage scores be given. In other words, a department should not state that for a particular component, the department is "between" stage one and stage two. If the department has not fully reached stage two ("quality building"), then the department is not presently at stage two, and should thus be designated at stage one ("awareness building") in the self-assessment for that particular component. What is most important is that the results of the self-assessment are used by departmental faculty and staff to build awareness for community engagement efforts at the unit level and to decide whether and how to move forward. Finally, the Rubric should be viewed as only one assessment tool for determining the degree and kind of integration of community engagement into the activities of the department. Other indicators should also be observed and documented to ensure that a department's effort to advance community engagement is conducted systematically and comprehensively (Furco, 2000, 2003: Gelmon \& Seifer et al., 2005; Kecskes \& Muyllaert, 1997)

\section{ACKNOWLEDGEMENT}

The author wishes to acknowledge the following individuals for their assistance in reviewing and refining the components of the self-assessment rubric: Douglas Morgan, Portland State University; Peter Collier, Portland State University; Sherwin Davidson, Portland State 
University; Barbara Holland, National Service-Learning Clearinghouse; Marcus Ingle, Portland State University; Craig Shinn, Portland State University.

\section{BIBLIOGRAPHY}

Agre-Kippenhan, S. and Charman, E. (2006). Engagement in the arts: Commitment to an urban experience. In K. Kecskes (Ed.), Engaging departments: Moving faculty culture from private to public, individual to collective focus for the common good (pp. 89-107). Boston: Anker Publishing Company, Inc.

Applegate, J., and Morreale, S. (2001). Creating engaged disciplines. The AAHE Bulletin, 16, pp. $7-9$.

Bell, R., Furco, A., Ammon, M.S., Muller, P., and Sorgen, V. (2000). Institutionalizing ServiceLearning in Higher Education: Findings from a Study of the Western Region Campus Compact Consortium. Westem Region Campus Compact Consortium. Bellingham WA: Western Washington University.

Battistoni, R. M., Gelmon, S. B., Saltmarsh, J. A., Wergin, J. F., and Zlotkowski, E. (2003). The engaged department toolkit. Providence, RI: Campus Compact.

Campus Compact. (2003). The Indicators of Engagement. Retrieved March 2, 2008 from http://www. compact.org/indicators/detail.php?id=14

Carnegie Foundation Elective Classification: Community Engagement, 2007. Retrieved March 2, 2008 from http://www.carnegiefoundation.org/dynamic/downloads/file 1 614.pdf

Commission on Community Engaged Scholarship in the Health Professions, 2005. Retrieved March 2, 2008 from http://depts.washington.edu/ccph/pdf files/Commission\%20Report\%20FINAL.pdf

Edwards, R. (1999). The Academic Department: How Does it fit into the University Reform Agenda? Change, September/October, 17-27.

Furco, A. (2000, 2003 rev.). Self-assessment rubric for the institutionalization of servicelearning in higher education. Providence, RI: Campus Compact.

Furco, A. (2002). Institutionalizing service-learning in higher education. Journal of Public Affairs, 6, 39-67.

Furco, A., Muller, P., and Ammon, M.S. (1998). Institutionalizing Service-Learning in Higher Education: Findings from a Study of the Western Region Campus Compact Consortium. University of California, Berkeley.

Furco, A. and Shumer, R. (2000). Developing a self-assessment instrument for higher education. In Kecskes, $K$ (Ed.), $4^{\text {th }}$ Annual "Continuums of Service" Conference Proceedings, retrieved June 30, 2006 from http://www.acadweb.wwu.edu/campcomp/pdf/4thCOSAnnualProceedings.pdf 
Gelmon, S.B., Seifer, S.D., Kauper-Brown, J., and Mikkelsen, M. (2005) Community-Engaged Scholarship for Health Collaborative: Institutional Self-Assessment. Seattle, WA: Community-Campus Partnerships for Health.

Gelmon, S.B., Holland, B.A., Driscoll, A., Spring, A., and Kerrigan, S. (2001). Assessing Service-Learning and Civic Engagement: Principles and Techniques. Providence, RI: Campus Compact.

Holland, B.A. (1997). "Analyzing Institutional Commitment to Service: A Model of Key Organizational Factors." Michigan Journal of Community Service-learning, Fall, p.3041 .

Holland, B.A. (Fall, 2000). Institutional impacts and organizational issues related to servicelearning. Michigan Journal of Community Service Learning, Special Issue, 52-60.

Jacoby, B. (1996). Service learning in higher education: Concepts and practices. San Francisco: Jossey-Bass.

Kecskes, K. (2004). Engaging the Department: Community-Based Approaches to Support Academic Unit Coherence. The Department Chair, 15(1), 7-9.

Kecskes, K. (2008). Engagement in the disciplines. The Department Chair, 18(3), 16-18.

Kecskes, K., Gelmon, S.B., and Spring, A. (2006). Creating engaged departments: a program for organizational and faculty development. To Improve the Academy, 24, 147-165.

Kecskes, K., Ed. (2006). Engaging departments: Moving faculty culture from private to public, individual to collective focus for the common good. Boston, MA: Anker Publishers.

Kecskes, K. and Muyllaert, J. (1997). Continuums of Service Benchmark Worksheet. Westem Region Campus Compact Consortium Request for Proposals. Retrieved May 19, 2008 from http://www.wacampuscompact.org/documents/COSBenchmarkTool1997.pdf

Lynton, E. A. (1995). Making the case for professional service. Washington, DC: American Association for Higher Education.

Morreale, S. and Applegate, J. (2006). Engaged disciplines: How national disciplinary societies support the scholarship of engagement. In K. Kecskes (Ed.), Engaging departments: Moving faculty culture from private to public, individual to collective focus for the common good (pp. 264-277). Boston: Anker Publishing Company, Inc.

Ramaley, J. A. (2005). Scholarship for the public good: Living in Pasteur's quadrant. In Kezar et al. (Eds.) Higher education for the common good: Emerging voices form a national movement, San Francisco:Jossey-Bass, 166-182.

Rice, R. E. and Richlin, L. (1993). Broadening the conception of scholarship in the professions. In Curry, L., Wergin, J., \& Associates (Eds.), Educating Professionals. San Francisco, CA: Jossey-Bass Inc. 
Saltmarsh, J. and Gelmon, S.B. (2006). Characteristics of an engaged department: Design and assessment. In K. Kecskes (Ed.), Engaging departments: Moving faculty culture from private to public, individual to collective focus for the common good (pp. 27-44). Boston: Anker Publishing Company, Inc.

Wergin, J. (1994). The collaborative department. Washington DC: American Association of Higher Education.

Wergin, J. (2003). Departments that work: building and sustaining cultures of excellence in academic programs. Bolton, MA: Anker Publishing.

Zlotkowski, E. (2000). Service-Leaming research in the disciplines. Michigan Journal of Community Service Learning, Fall 2000, 61-67.

Zlotkowski, E. (2005). The disciplines and the public good. In Kezar et al. (Eds.) Higher education for the common good: Emerging voices form a national movement, San Francisco:Jossey-Bass, 146-165.

Zlotkowski, E. and Saltmarsh, J. (2006). The engaged department in the context of academic change. In K. Kecskes (Ed.), Engaging departments: Moving faculty culture from private to public, individual to collective focus for the common good (pp. 278-289). Boston: Anker Publishing Company, Inc.

Zlotkowski, E., Longo, N., and Williams, J. (Eds.). (2006). Students as colleagues. Providence: Campus Compact. 


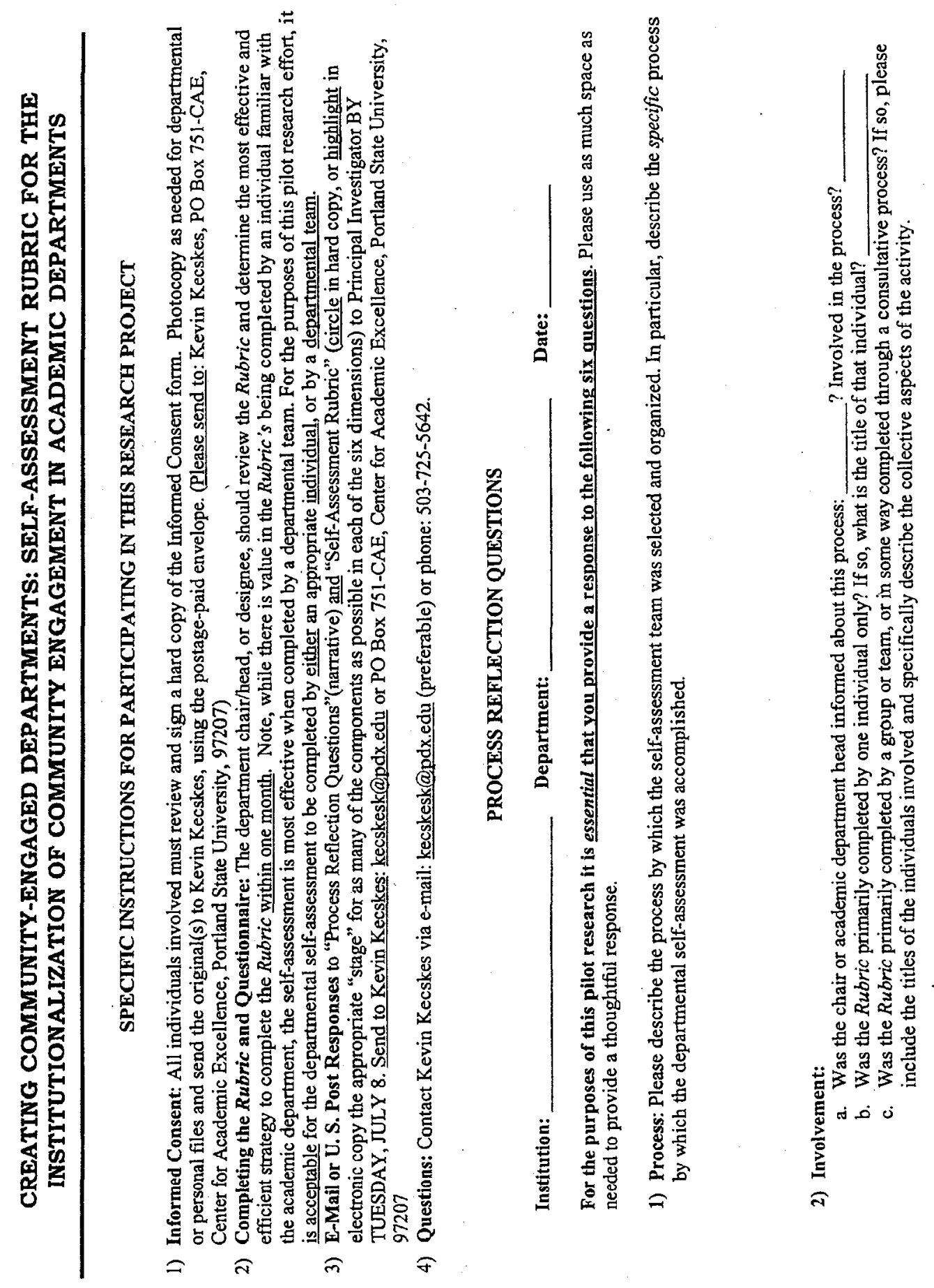




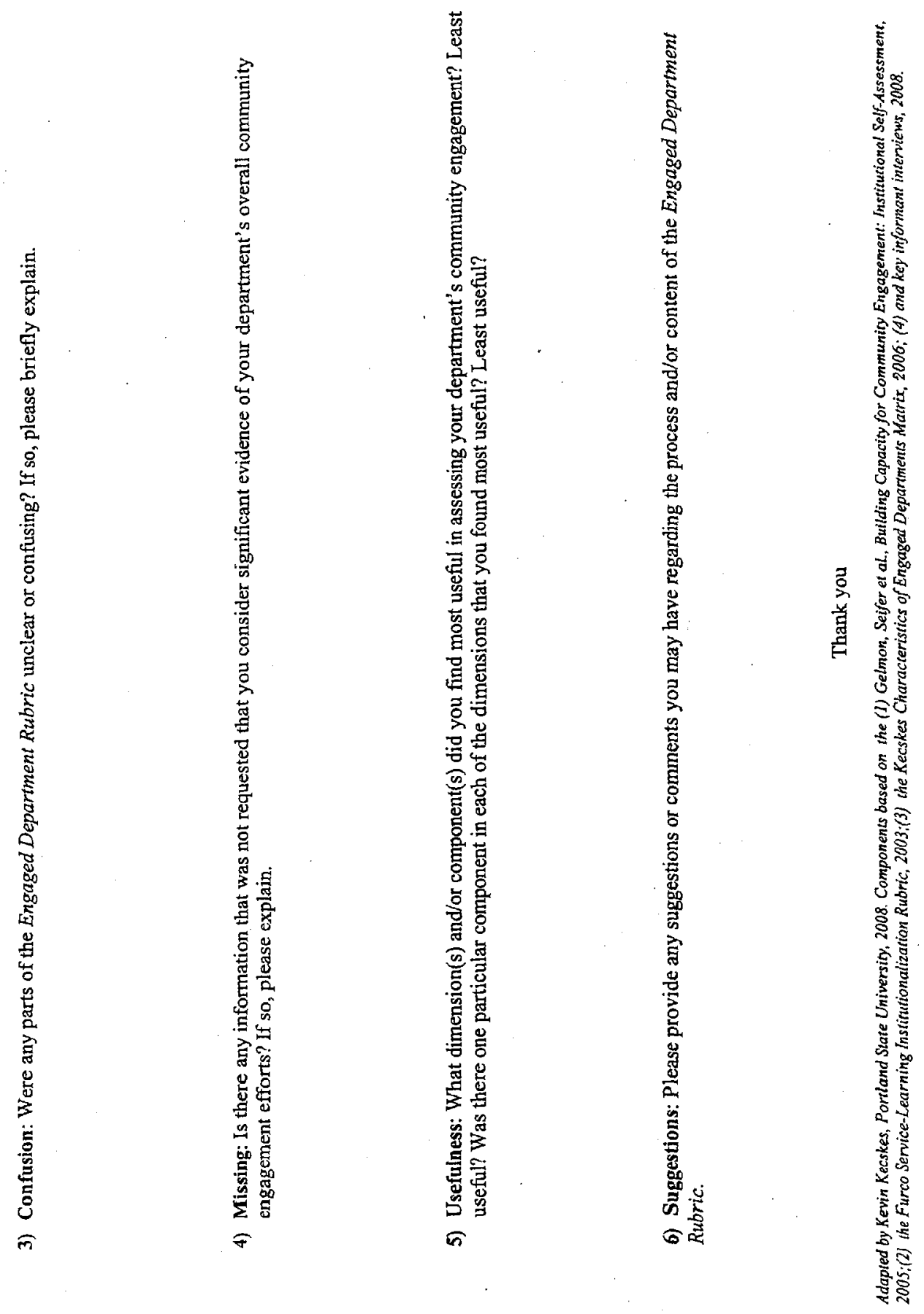




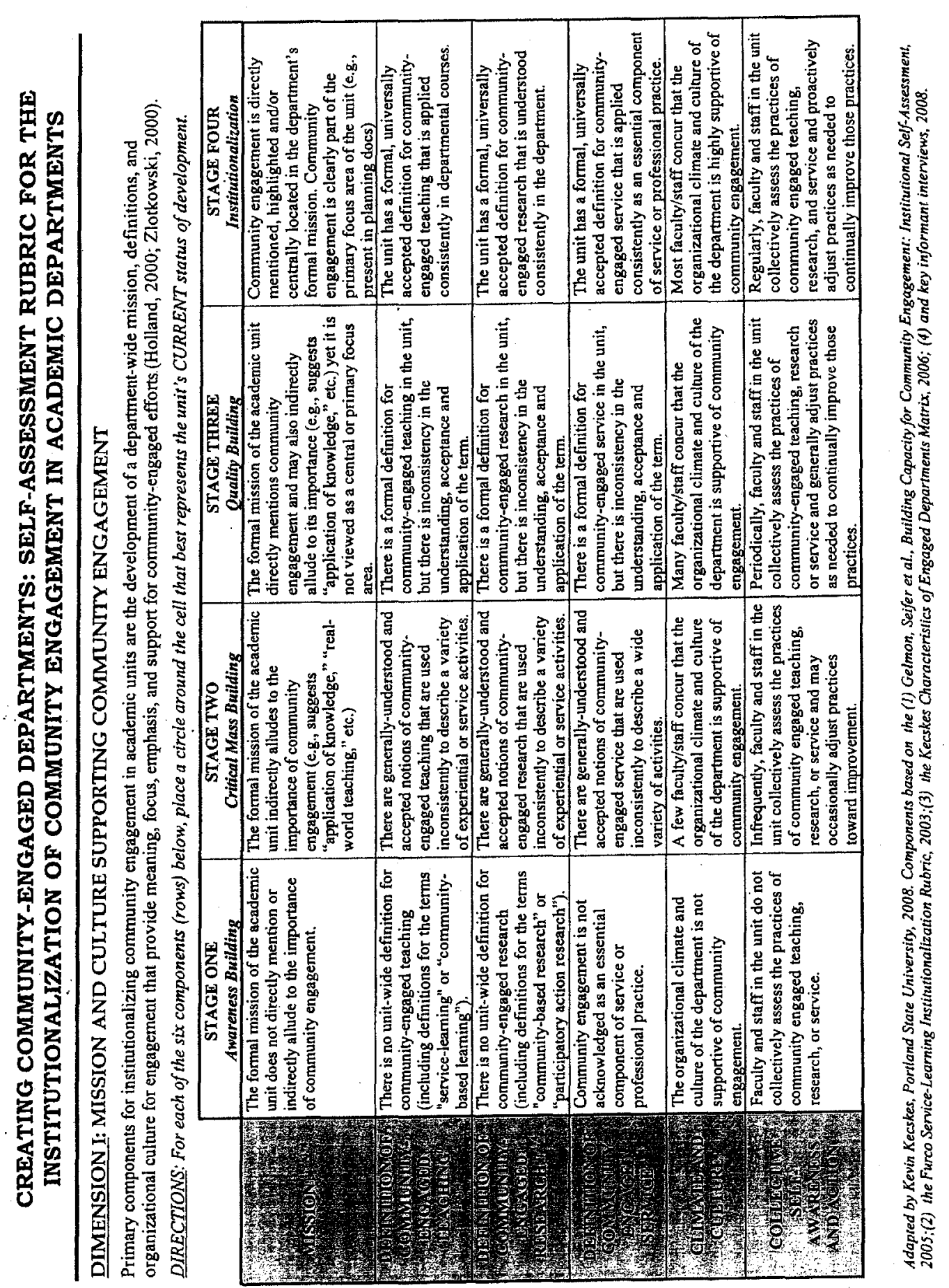




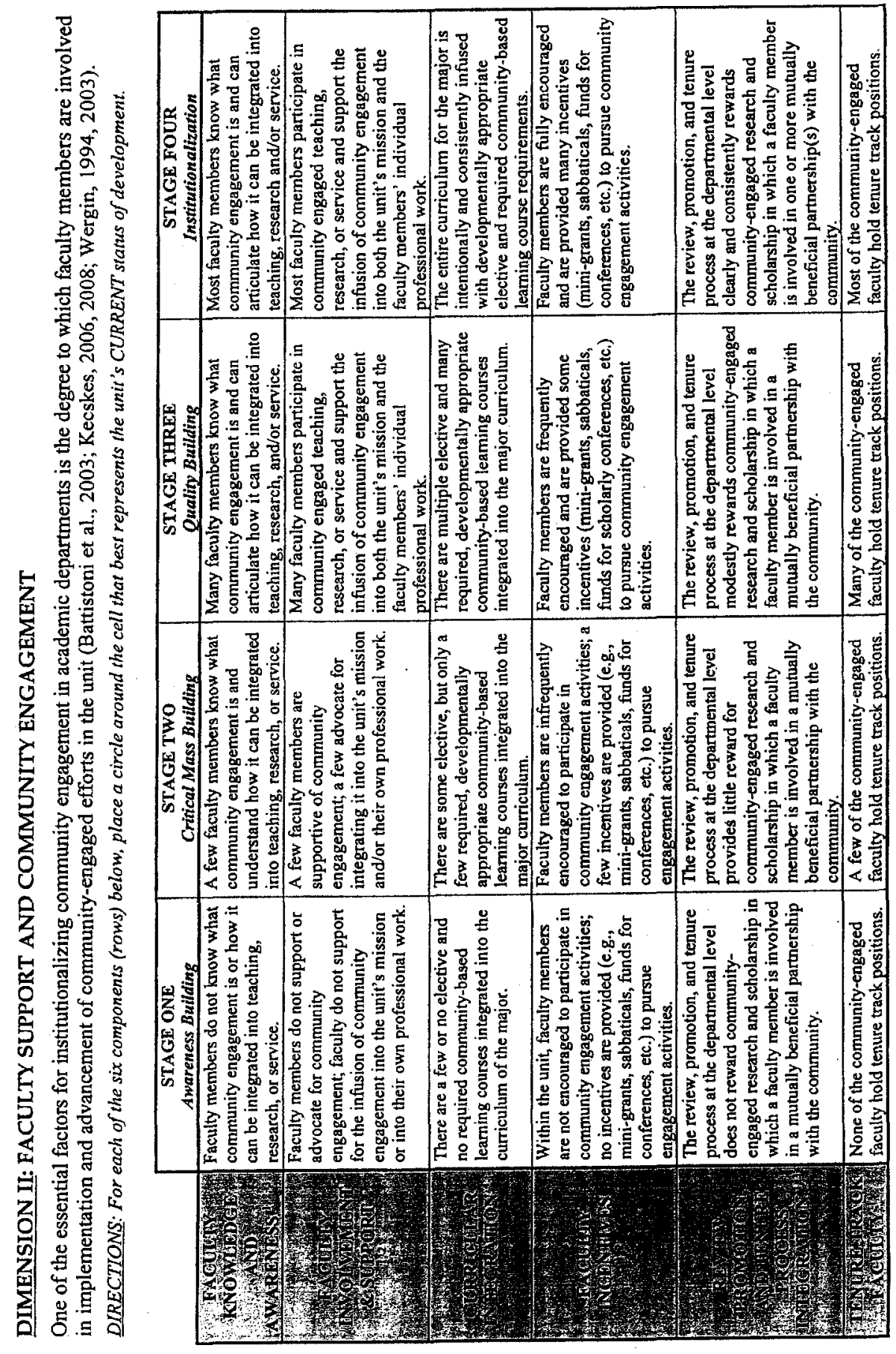

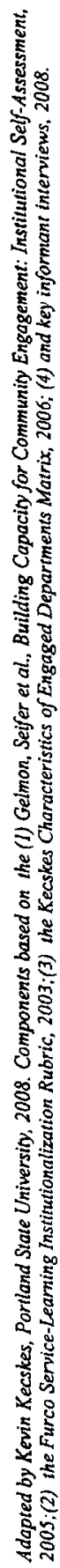




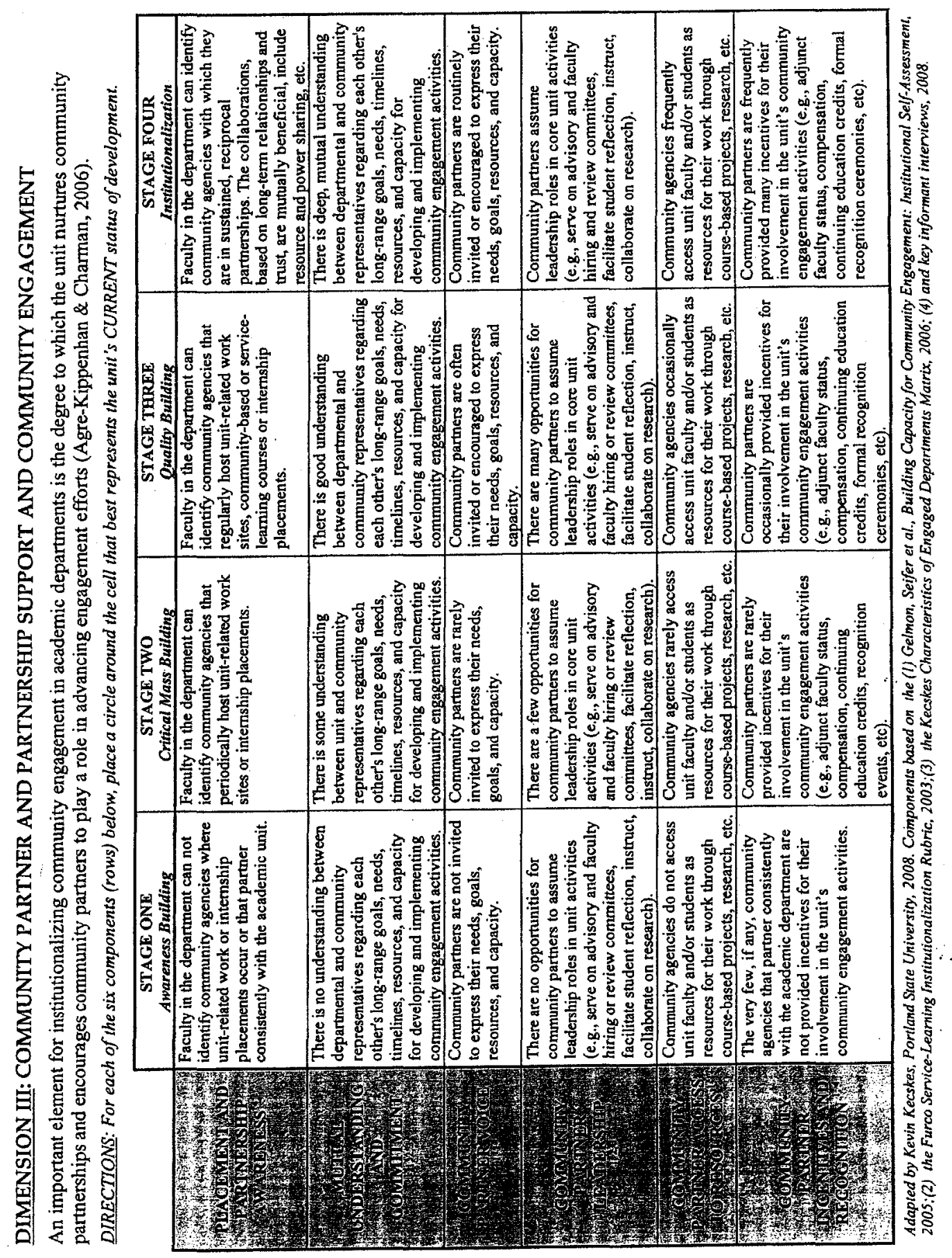




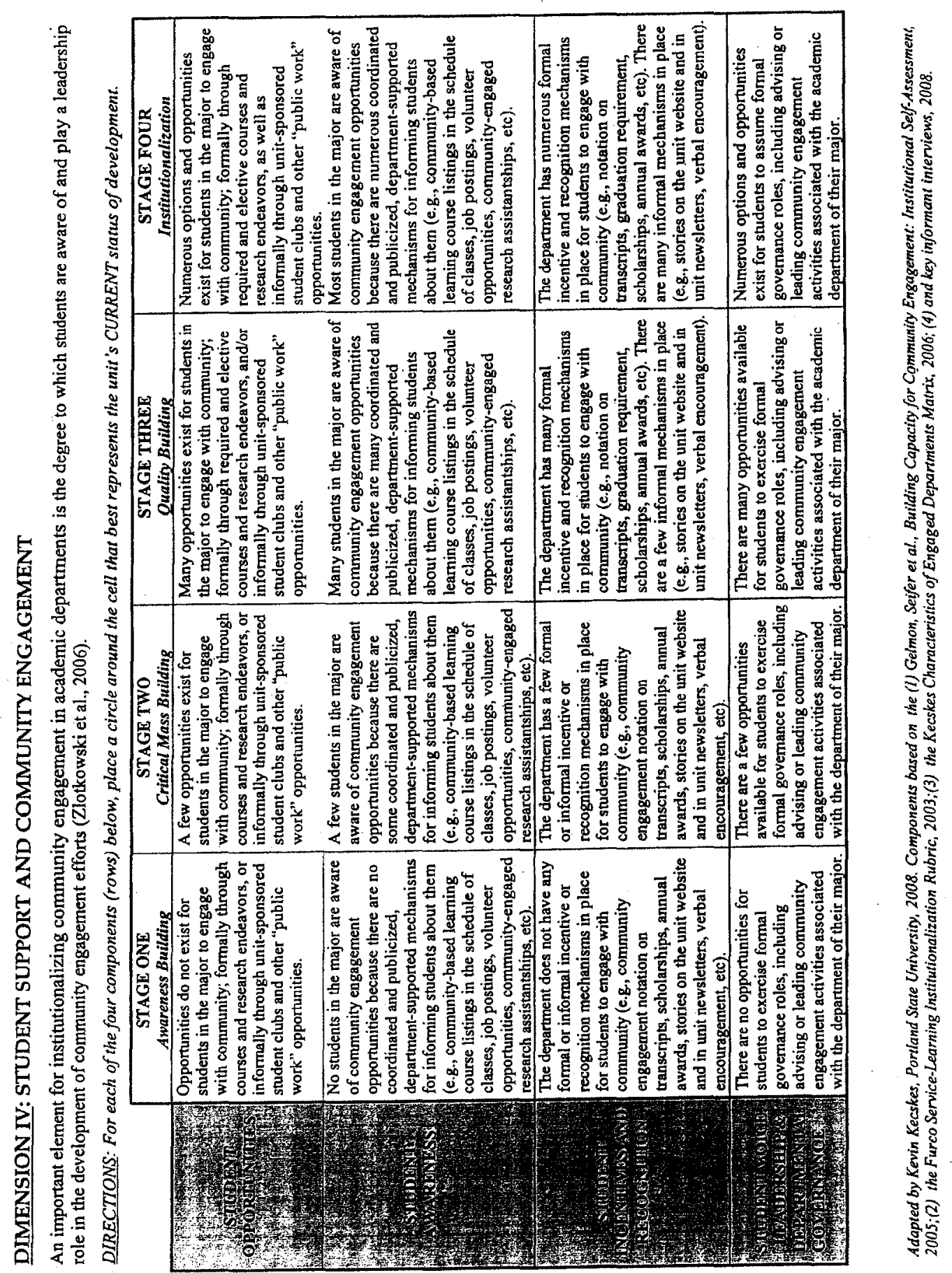




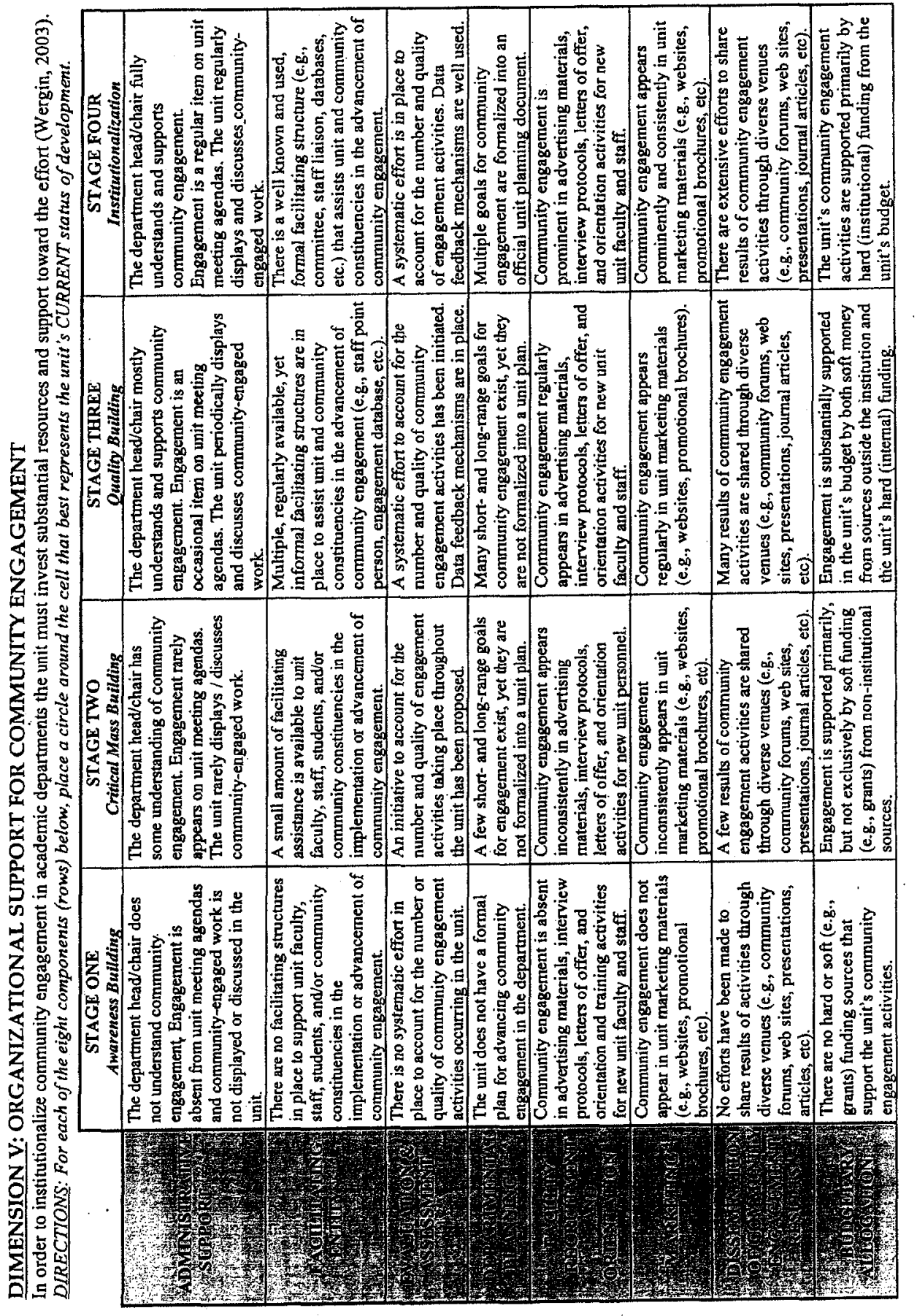

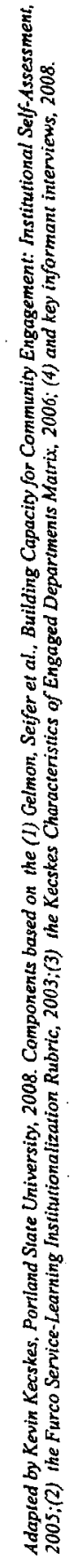




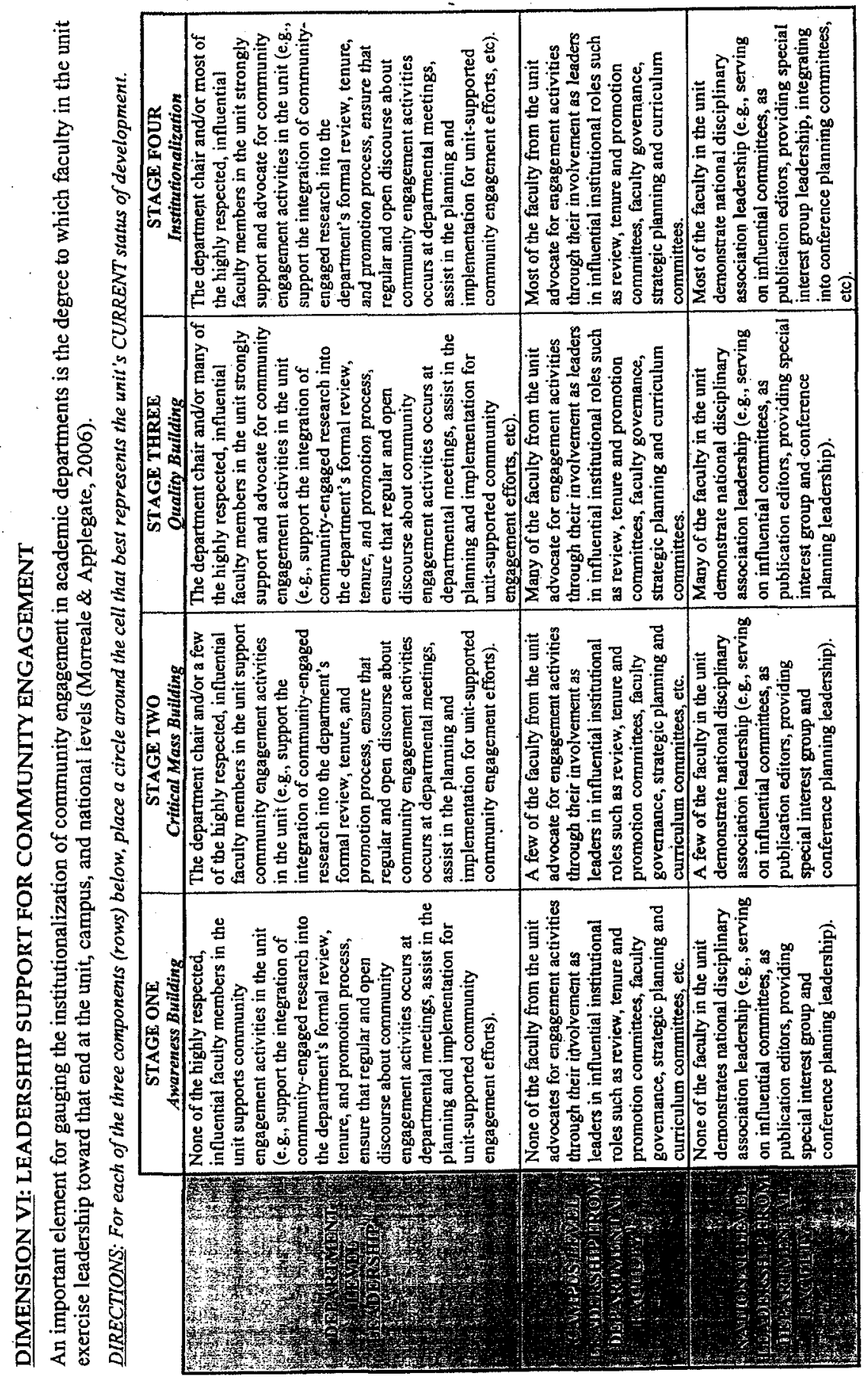

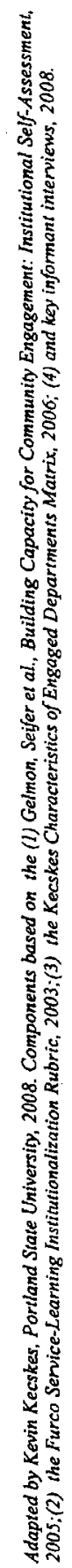




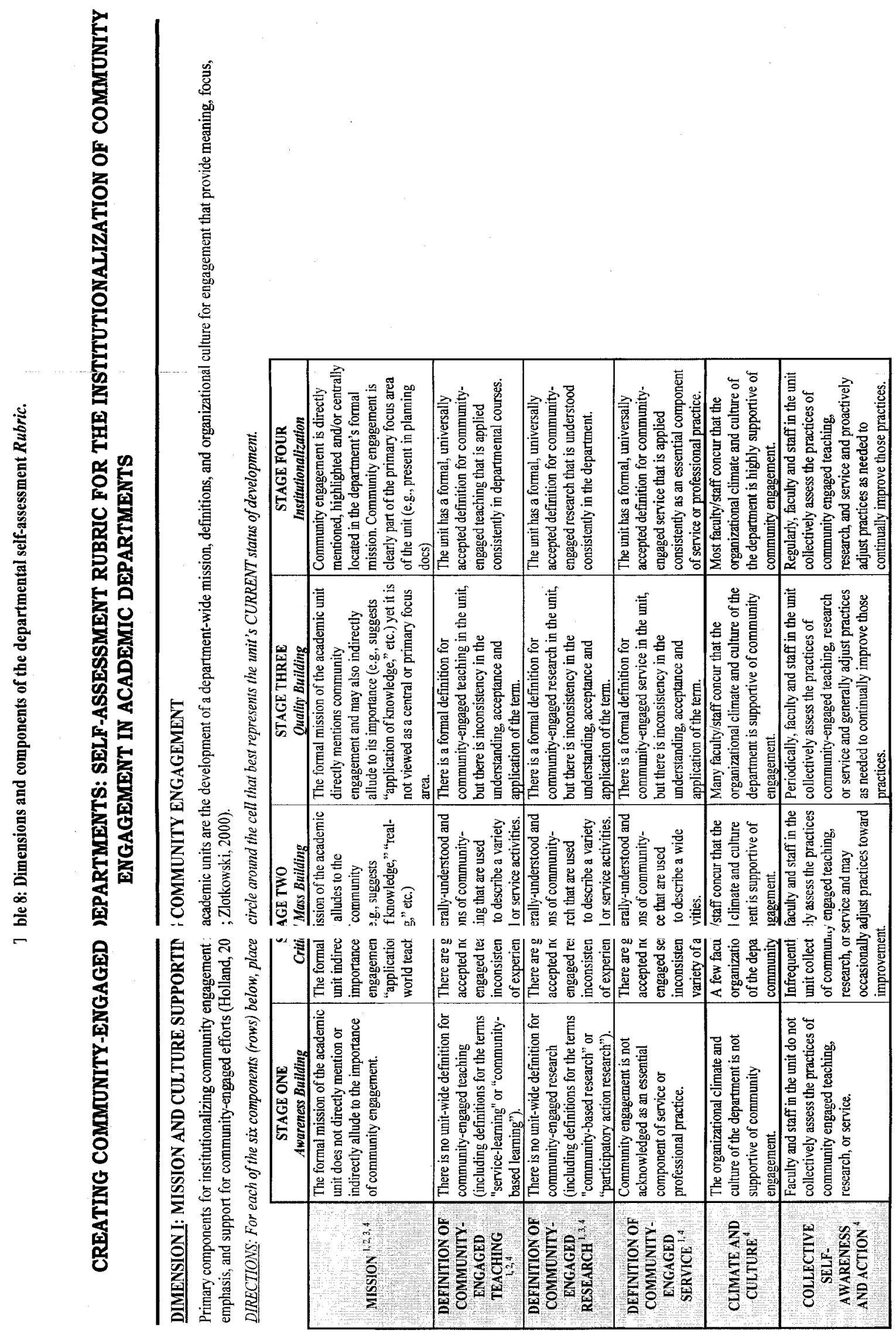




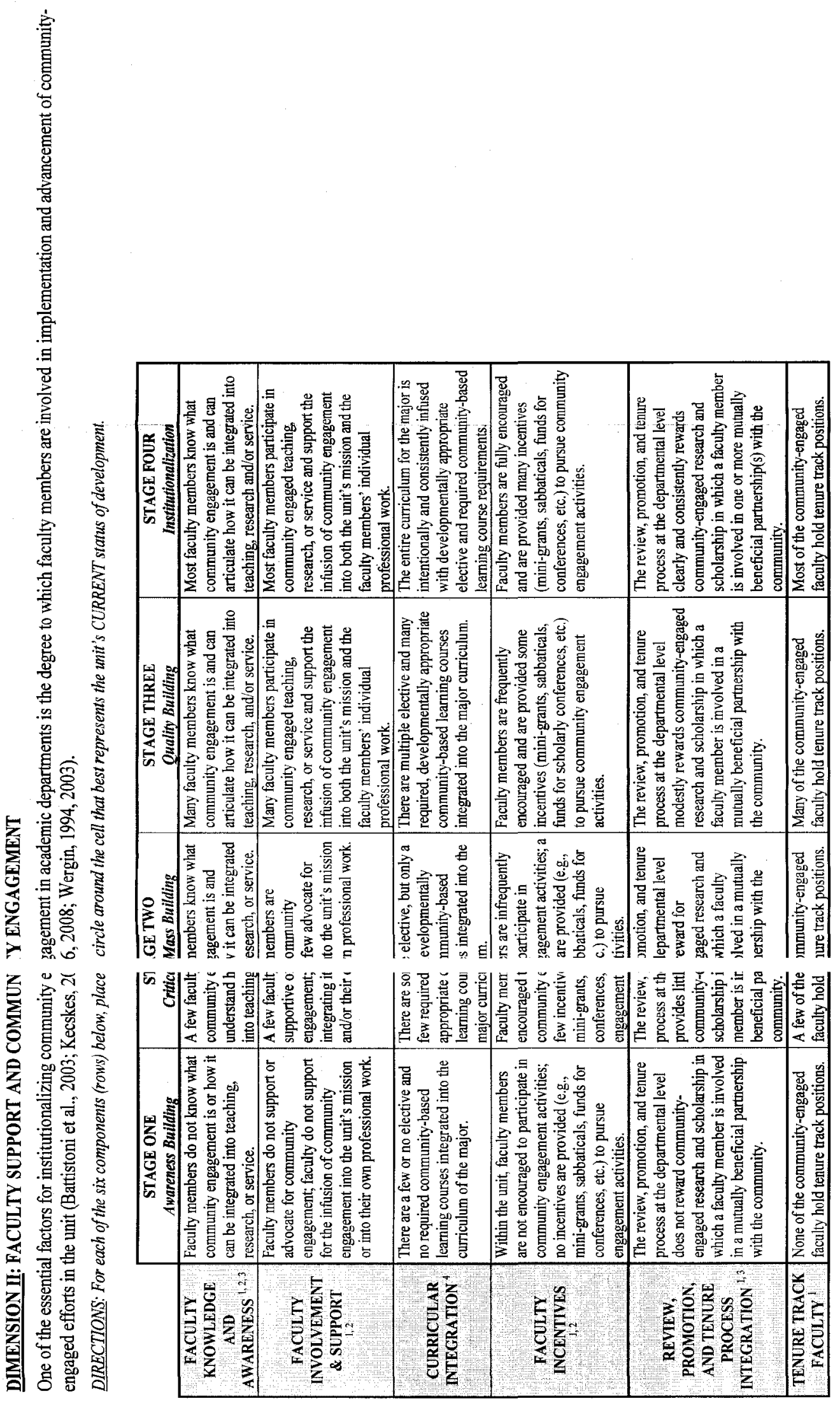




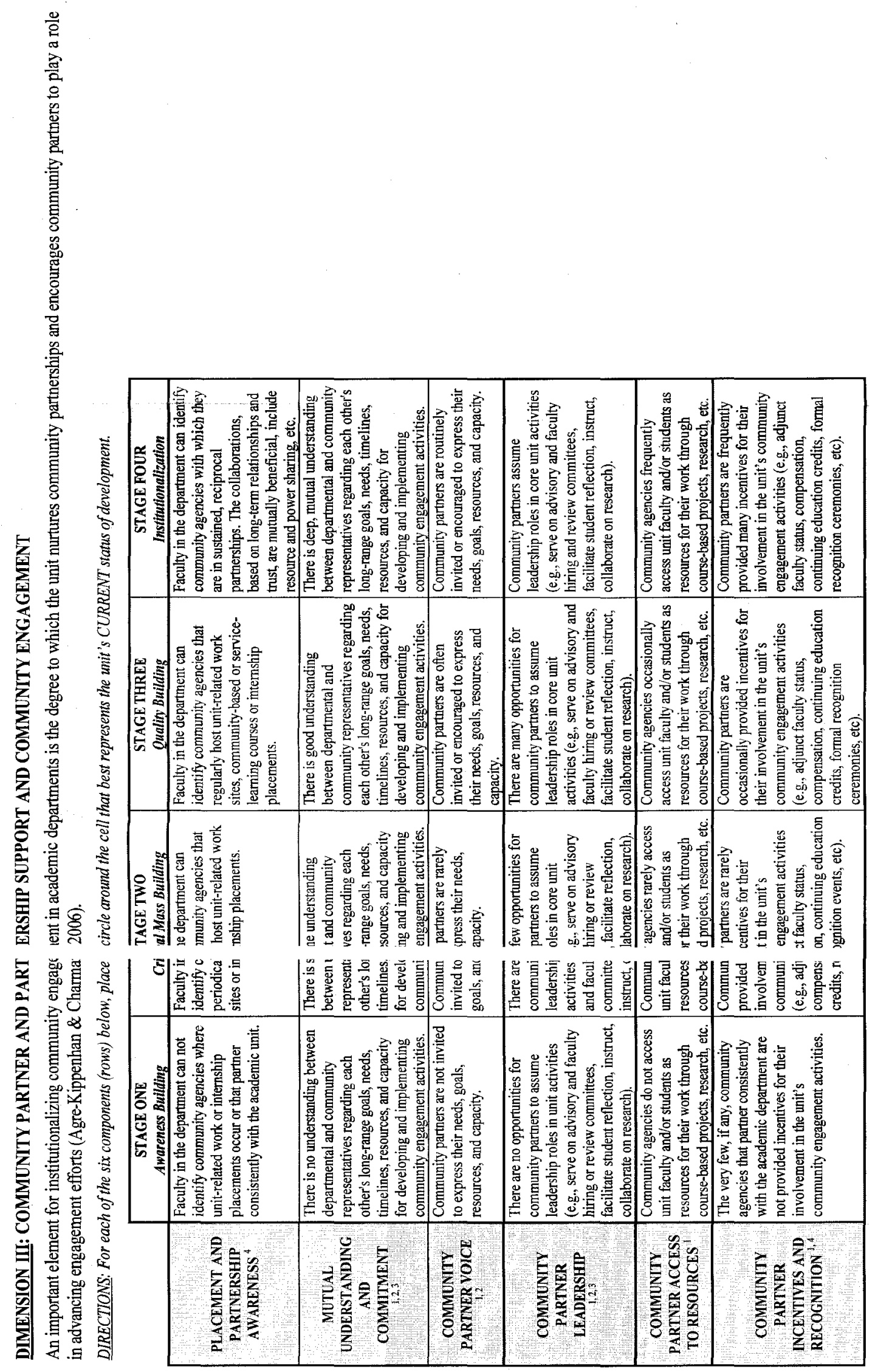




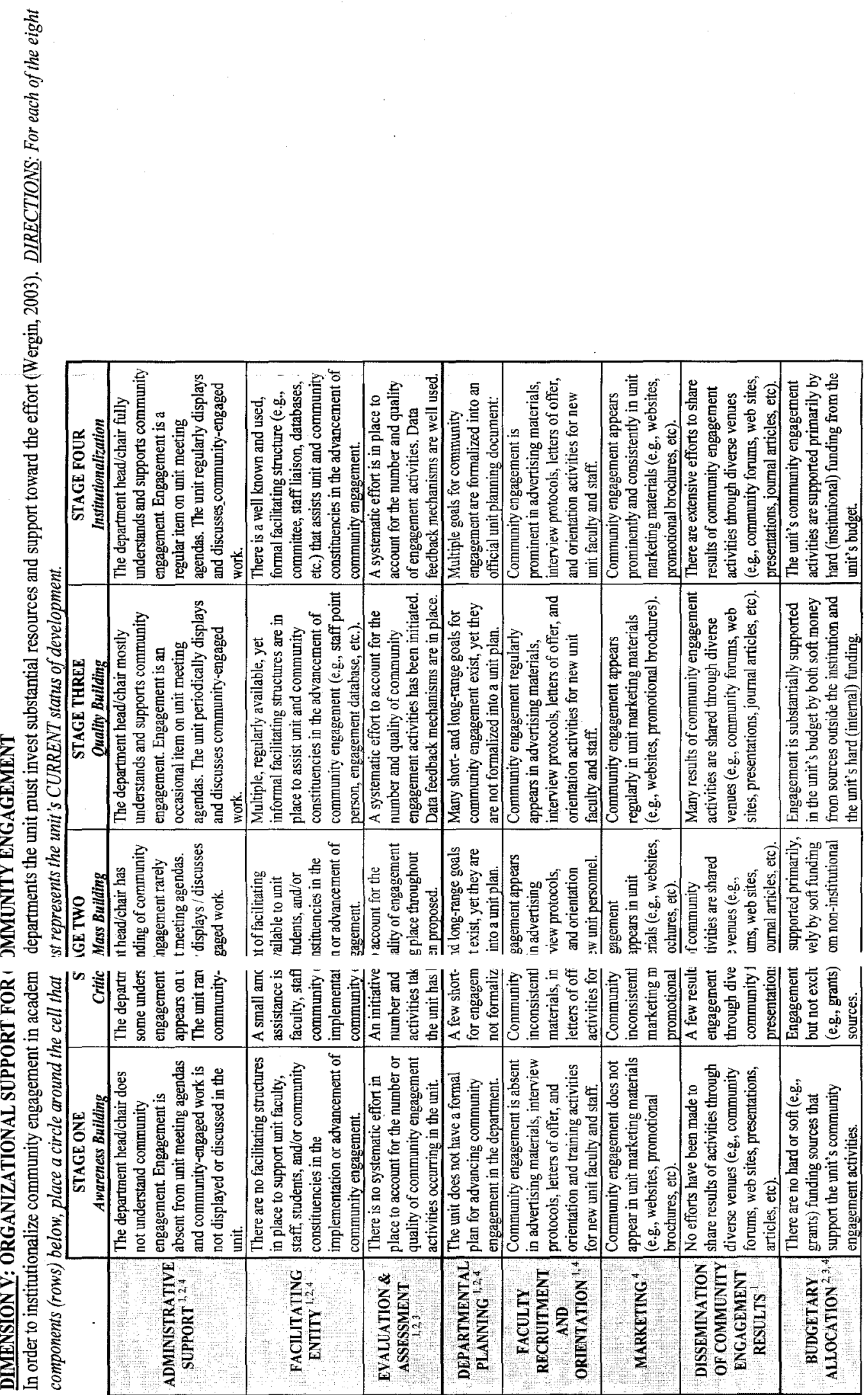




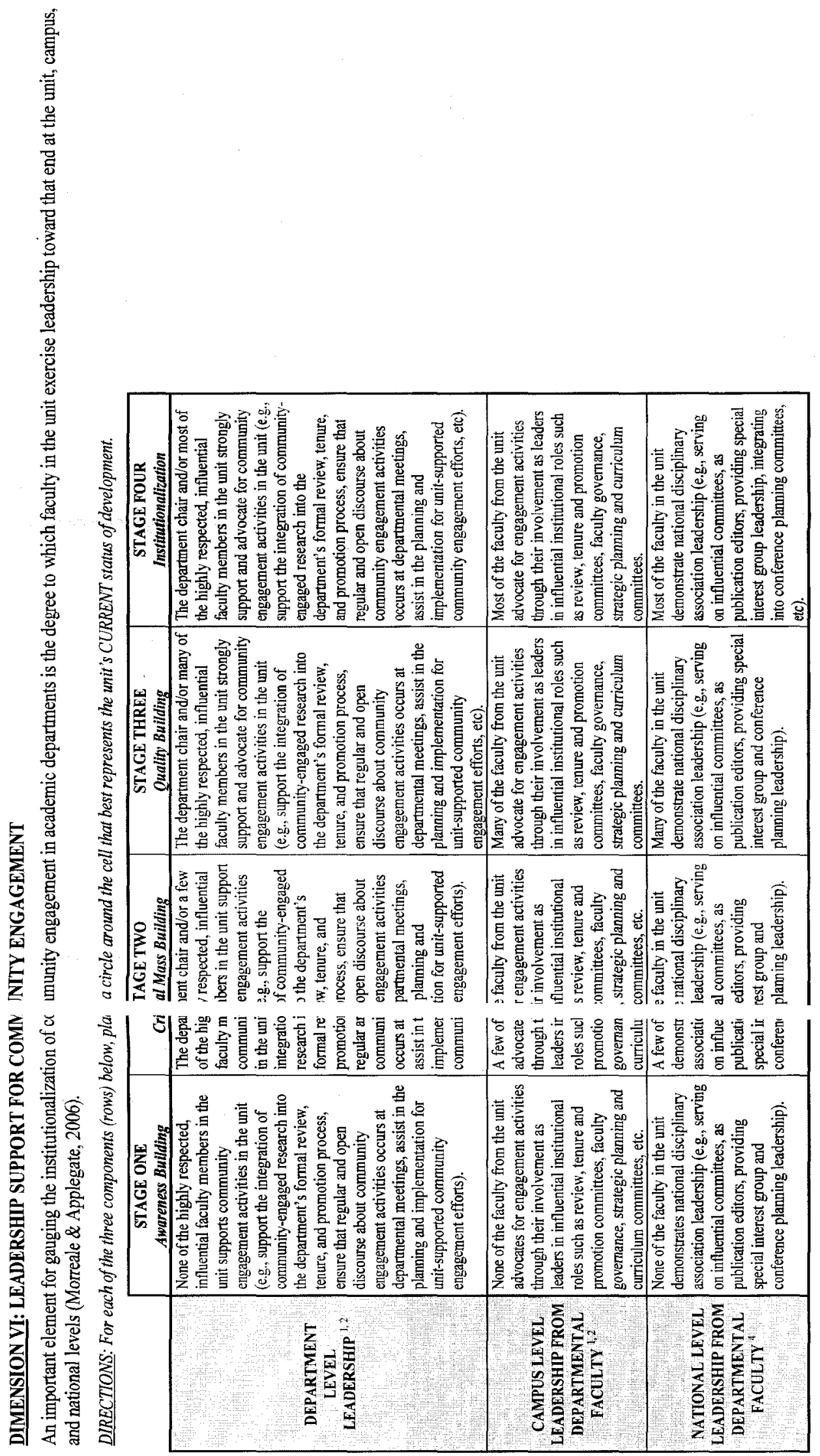

